\title{
Crowdsourcing the Cadastre:
}

The Applicability of Crowdsourced Geospatial Information to the New Zealand Cadastre

By

\section{Andrew David Clouston}

\author{
A thesis \\ submitted to the Victoria University of Wellington \\ in fulfillment of the requirements \\ for the degree of
}

Master of Geographic Information Science

Victoria University of Wellington

2015

Supervised by: Dr Mairead de Róiste

Dr Femke Reitsma 


\section{Abstract}

Crowdsourcing has transformed how geographic information is collected, stored, disseminated, analysed, visualised and used (Sui et al., 2013b). Yet, crowdsourcing has had little impact on core government geospatial data. This 'authoritative data' is often tightly controlled with a focus on data quality and security for protection from unauthorised change (Rice et al., 2012). Opportunities for consumers, users and existing data producers to contribute their skills and information to enhance authoritative government geospatial data has been limited. The adoption, or use, of crowdsourcing by Government has been slow (Haklay et al., 2014).

The New Zealand Cadastre, managed by Land Information New Zealand (LINZ) is an example of a core government geospatial system that has collated and managed data for over a century. Despite data meeting the contemporary acceptance standards when it was integrated into the cadastre, data quality is often questioned by users as inaccuracies or discrepancies are identified (Opus, 2013). Web 2.0 technologies and easy to use mobile devices enabled geospatial capability and a user skill base to an increased acceptance of crowdsourcing as a means to build and maintain geospatial datasets (Kostanski, 2012, McLaren, 2011, Rice et al., 2012). Accordingly, if cadastral data is to be maintained and enhanced to meet modern expectations for multiple use (LINZ, 2013a, Cadastre Ltd, 2003), one option is the use of crowdsourcing (Grant et al., 2014, LINZ, 2013a).

This thesis examines the potential applicability of Volunteered Geographic Information (VGI) as a specific form of crowdsourcing within an authoritative database - the New Zealand Cadastre. Using a two phase quantitative and qualitative methodology, the perspectives of users, data providers and administrators are explored to ascertain the applicability of VGI to the New Zealand Cadastre.

This thesis finds that crowdsourcing concepts could enable users to contribute data or information, reconceptualise the role of the existing data providers (predominately licensed cadastral surveyors) and enable the reuse of cadastral related work. Cadastral VGI can provide advances in data collection and maintenance processes; if users, data producers and administrators change their perception of what crowdsourcing is, and what it can provide. However, the importance of user perception in the quality of the dataset will need to be strongly considered in any integration of VGI into the cadastre or other authoritative datasets.

\section{Keywords}

Cadastre, Crowdsourcing, Integration, Motivation, Volunteered Geographic Information 


\section{Acknowledgements}

When I started this thesis, little did I comprehend that level of support that I would need. These acknowledgements are more than just words, they tell the back story to the roles and sacrifices of others on my behalf and I'm extremely grateful to everyone mentioned.

Firstly to Land Information New Zealand (LINZ), my employer and sponsor. The time provided to attend lectures and undertake this research was invaluable. Without LINZ support this study would not have occurred. In addition, there are numerous staff who actively supported me, but special thanks to my immediate manager Ron Munro who took an interest in what I was doing and enabled significant flexibility so that I could juggle work, family and study commitments. My team are due thanks for similar efforts. In addition a special mention to my two fellow students at LINZ who commenced study with me in 2010; being able to share a common purpose, trials and tribulations has made it easier. Finally to other colleagues across LINZ; who participated in my research, sent me information, and encouraged me in what was often seen as a 'wacky' idea, thank you. Although not a LINZ employee, special thanks to Dr Felicity Powell of Opus Research who provided valuable feedback and advice.

Secondly, to my supervisors, Dr Mairead de Róiste and Dr Femke Reitsma. I really had no idea what the role of a supervisor was. Mairead, your role as primary supervisor was the hardest. You had to be willing to debate, tell me 'as it is' while simultaneously provide encouragement. You have provided the sanity to get this thesis 'over the line' and have been referee, coach, opposition and teammate rolled into one. Through you, l've developed a respect for academic writing and I can only hope that this thesis does justice to your perseverance in getting me to write in a more acceptable style. Femke, knowing that you were available for additional comment and support provided much peace of mind. But most importantly it was comments and discussion from 2011 that set me on this thesis topic. Without your feedback and push, this thesis may never have come about.

Thirdly to my family. My aim in undertaking post graduate study was to set a good example to Sam and Aimee on the value of education. However, it was their insistence on games of Uno, a bike ride, back yard cricket or just a video in front of the fire that I cherish as providing the necessary breaks and reminding me what is really important. To my wife, Catherine, l'm even more grateful. When I felt it was all too much - who encouraged me. When I needed some transcription - who came to my aid. Not to mention taking on the role of chief grammar advisor and sounding board. But mostly for the daily support, including regular release from many things domestic (as pulling my weight around the house disappeared). In this sense, this thesis is a shared effort, and I think that maybe I got the easy part.

To everyone, I can only hope that the completion of this thesis is a down payment on the debt of gratitude that I owe you all. 


\section{Table of Contents}

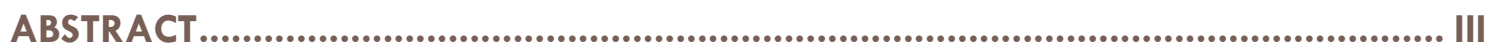

ACKNOWLEDGEMENTS $\ldots \ldots \ldots \ldots \ldots \ldots \ldots \ldots \ldots \ldots \ldots \ldots \ldots \ldots \ldots \ldots \ldots \ldots \ldots \ldots \ldots \ldots \ldots \ldots \ldots \ldots \ldots \ldots \ldots \ldots \ldots \ldots \ldots \ldots . \ldots . \ldots \ldots$

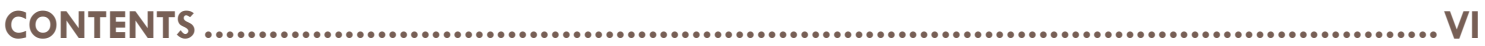

LIST OF FIGURES $\ldots \ldots \ldots \ldots \ldots \ldots \ldots \ldots \ldots \ldots \ldots \ldots \ldots \ldots \ldots \ldots \ldots \ldots \ldots \ldots \ldots \ldots \ldots \ldots \ldots \ldots \ldots \ldots \ldots \ldots \ldots \ldots \ldots \ldots \ldots \ldots \ldots \ldots \ldots \ldots \ldots . . \ldots \ldots$

LIST OF TABLES $\ldots \ldots \ldots \ldots \ldots \ldots \ldots \ldots \ldots \ldots \ldots \ldots \ldots \ldots \ldots \ldots \ldots \ldots \ldots \ldots \ldots \ldots \ldots \ldots \ldots \ldots \ldots \ldots \ldots \ldots \ldots \ldots \ldots \ldots \ldots \ldots \ldots \ldots \ldots \ldots \ldots$. $\ldots \ldots \ldots$

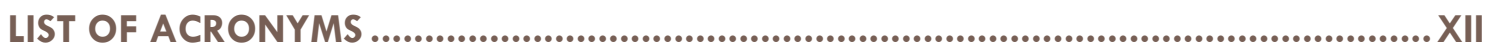

1. INTRODUCTION $\ldots \ldots \ldots \ldots \ldots \ldots \ldots \ldots \ldots \ldots \ldots \ldots \ldots \ldots \ldots \ldots \ldots \ldots \ldots \ldots \ldots \ldots \ldots \ldots \ldots \ldots \ldots \ldots \ldots \ldots \ldots \ldots \ldots \ldots \ldots \ldots \ldots \ldots \ldots \ldots \ldots \ldots, \ldots \ldots$

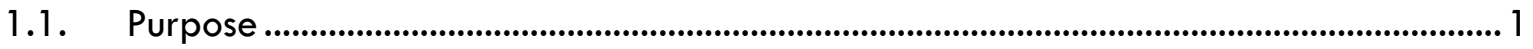

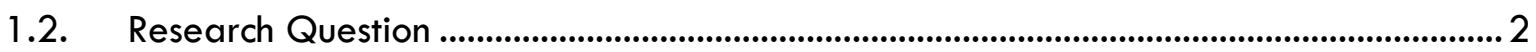

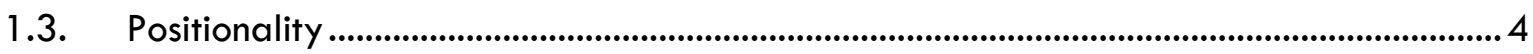

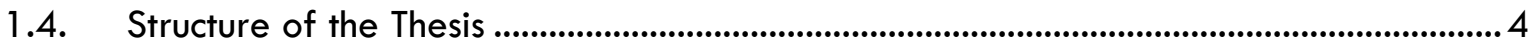

2. REVIEW OF THE LITERATURE ...................................................................................6 6

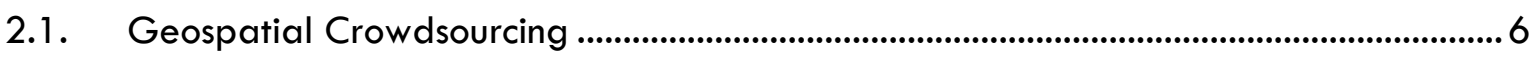

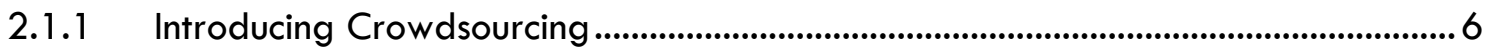

2.1.2 Introducing Volunteered Geographic Information (VGI) ........................................8

2.1.3 The Emergence of Geospatial Crowdsourcing ...........................................................8 8

2.1.4 User Motivations to Contribute ............................................................................1 10

2.1.5 The Role of Users in Geospatial Crowdsourcing..................................................11

2.1.6 Administrative and Volunteer Interaction ...............................................................13

2.2. Crowdsourcing Considerations for Authoritative Data ..................................................... 14

2.2.1 Maintenance and Data Acquisition..........................................................................1 14

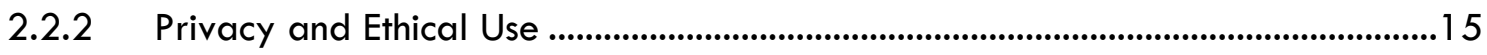

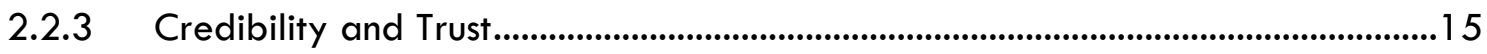

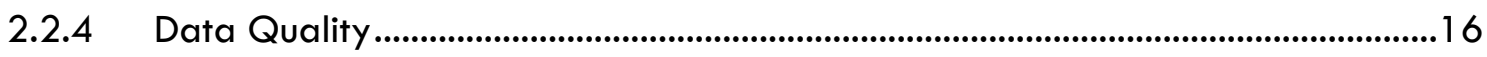

2.3. The Cadastre as an Authoritative System ......................................................................17

2.3.1 Understanding and Defining a Cadastre ...........................................................17

2.3.2 Modernising Cadastres and the Multipurpose cadastre ........................................1 18

2.3.3 Accuracy Issues with Cadastral Mapping..................................................................21

2.4. The New Zealand Context of the Research ......................................................................23

2.4.1 Defining the New Zealand Cadastre.....................................................................23

2.4.2 The Current Operational System .................................................................................24

2.4.3 New Zealand Cadastral Strategy and Legislation .................................................26

2.5. Summary of Literature Review ...................................................................................28 


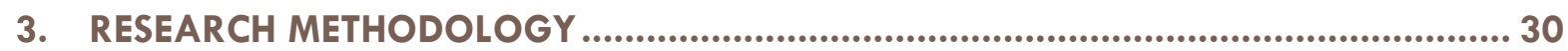

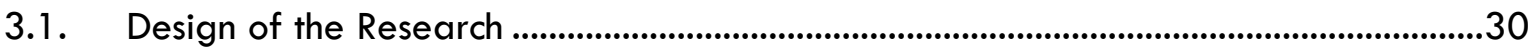

3.1.1 Characterising Potential Participants ...................................................................................30

3.1.2 Managing Bias .................................................................................................................... 31

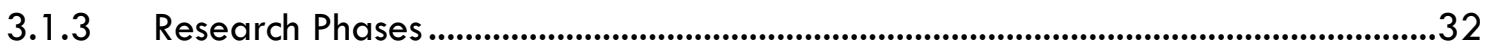

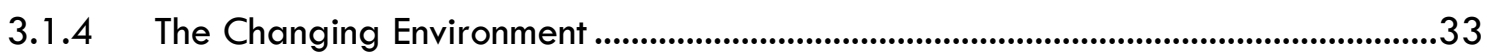

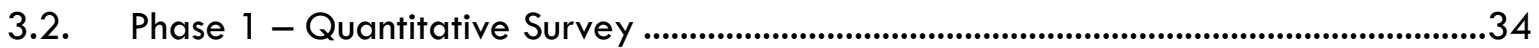

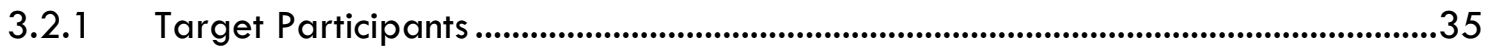

3.2.2 Data Collection Methods ................................................................................................35

3.2.3 Engagement with the Target Participants ......................................................................36

3.2.4 Survey Design and Response .........................................................................................

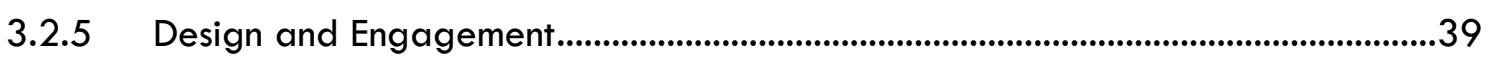

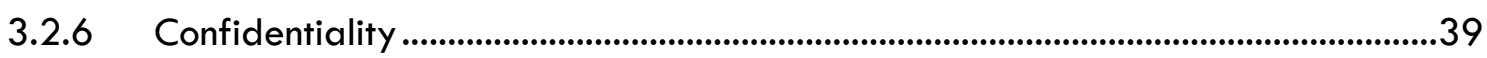

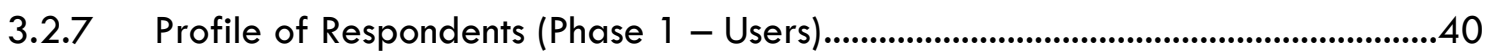

3.3. Phase 2 - The Qualitative Interviews and Online Survey .................................................42

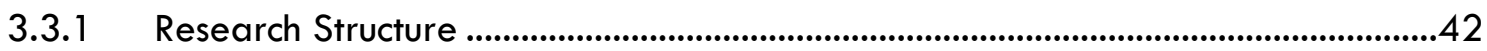

3.3.2 Research Engagement - Officials (Phase 2a) .......................................................44

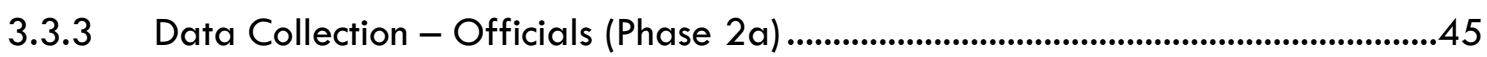

3.3.4 (Re)Engagement of Users and Data Collection (Phase 2b)....................................46

3.4. Analysis Methods for the Research......................................................................................47

3.4.1 Classification of Research Participants .......................................................................47

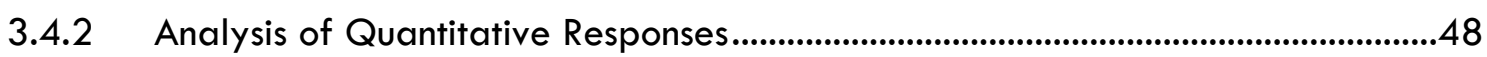

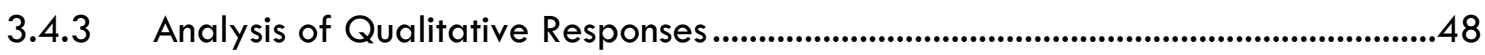

4. RESULTS AND PRELIMINARY ANALYSIS ............................................ 50

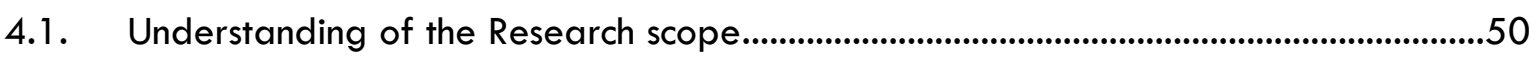

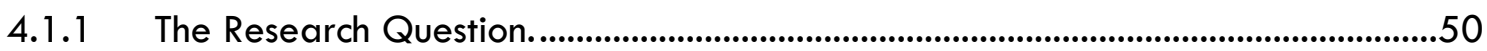

4.1.2 Participant Understanding of Crowdsourcing .........................................................5

4.1.3 Participant Understanding of the Cadastre..........................................................52

4.1.4 Participant Understanding of Authoritativeness...........................................................55

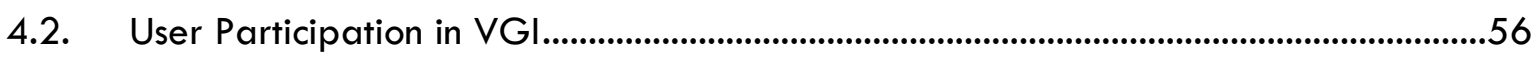

4.2.1 Produsers' Capability to Contribute ...................................................................56

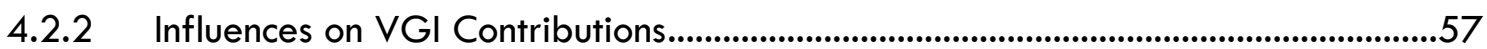

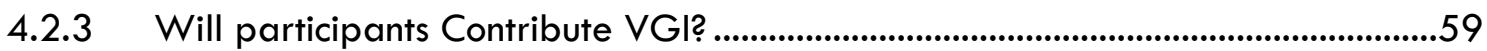

4.2.4 User Acceptance of Crowdsourced Information........................................................60

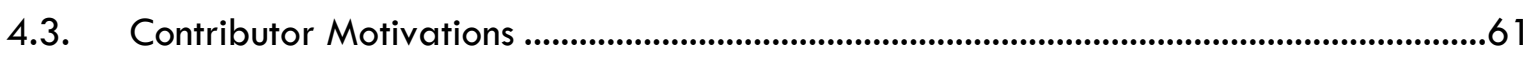

4.3.1 Altruism Through to Egoism..........................................................................................61

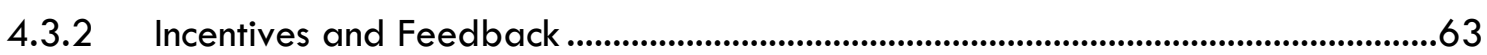




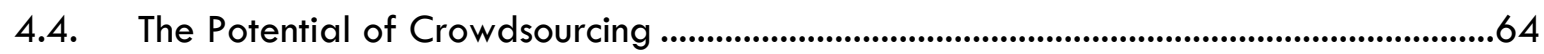

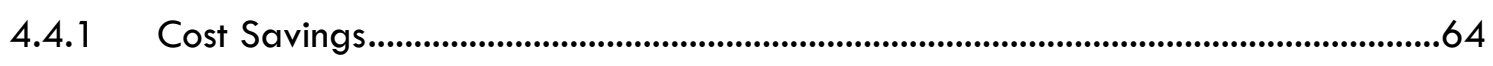

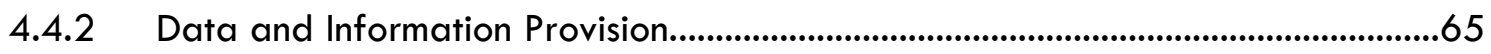

4.4.3 Data Reuse and Extending the Scope of the Cadastre.........................................68

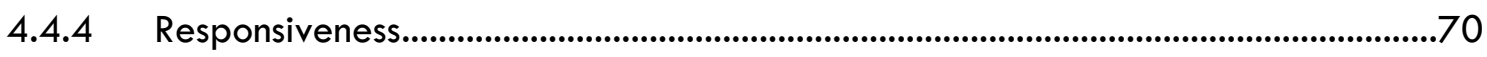

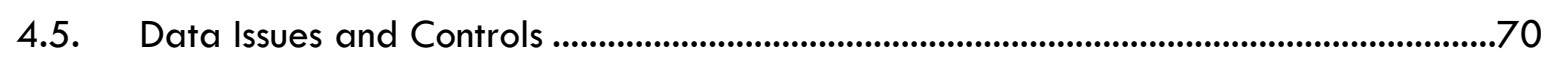

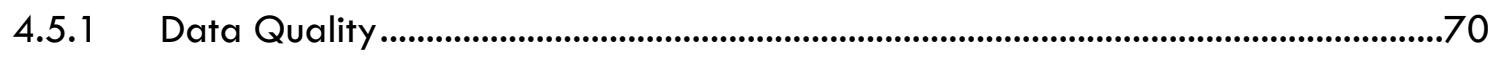

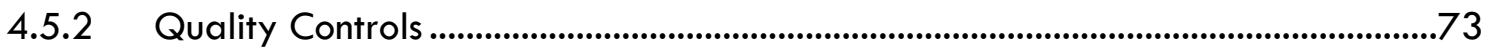

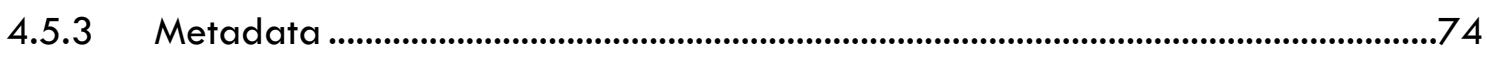

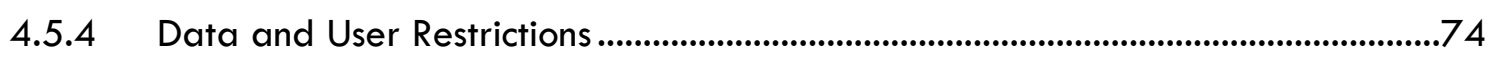

4.6. Effects of Accepting Crowdsourced Cadastral Information............................................75

4.6.1 Impacts on End Users and Public Effects........................................................................75

4.6.2 Impacts on Existing Data Contributors ................................................................76

4.6.3 Impacts on the Cadastral System and Data Management .....................................78

4.7. Challenges and Requirements .............................................................................................79

4.7.1 Data Integration Challenges.......................................................................................... 80

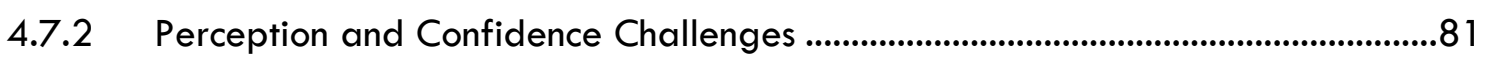

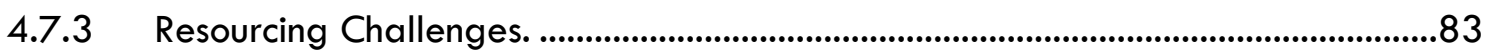

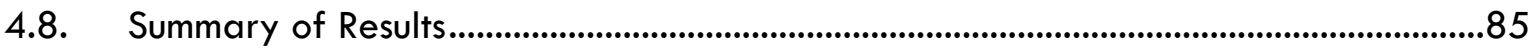

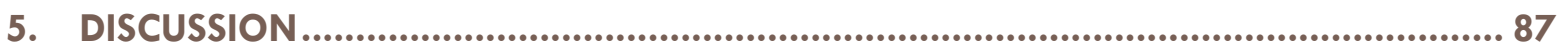

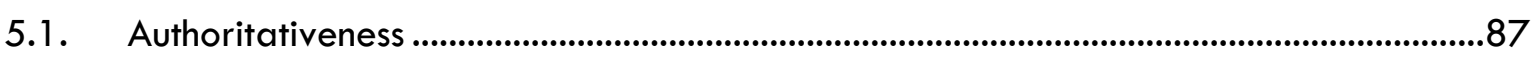

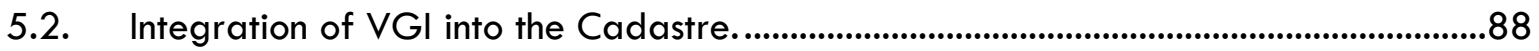

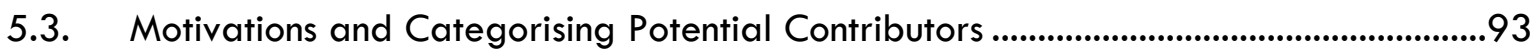

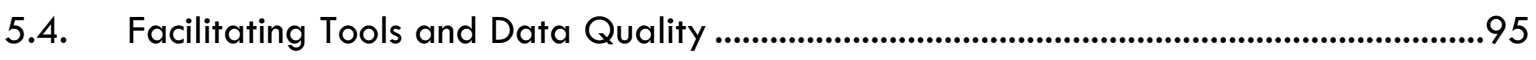

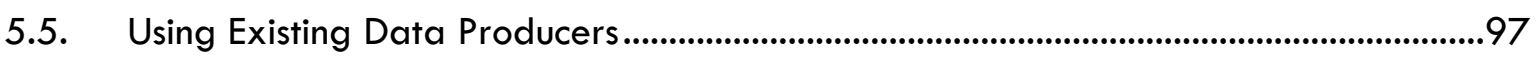

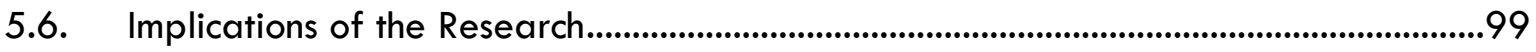

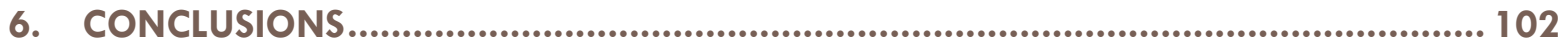

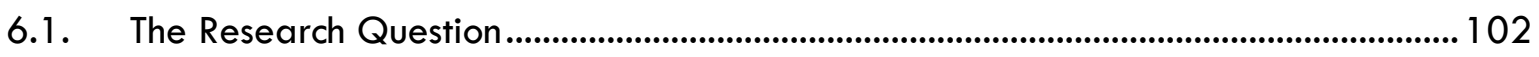

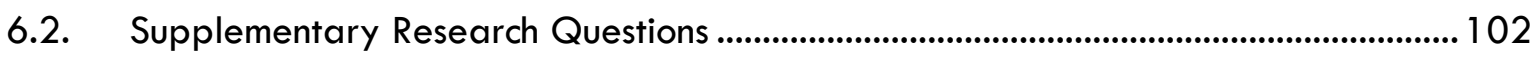

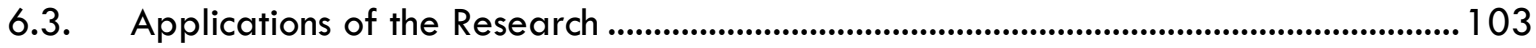

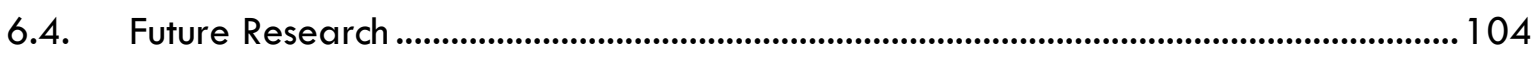

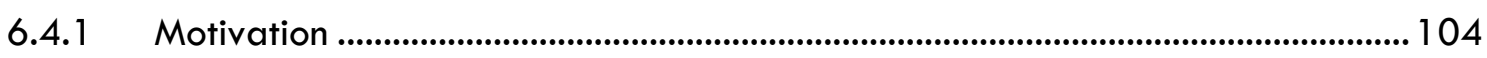

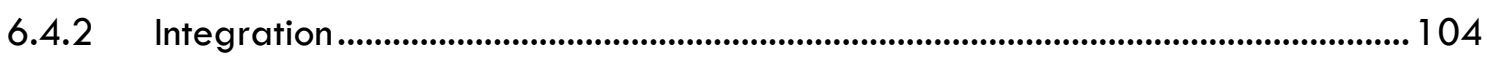

6.4.3 Interventions to Mitigate Data Issues.......................................................................... 105

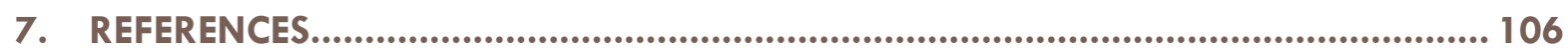

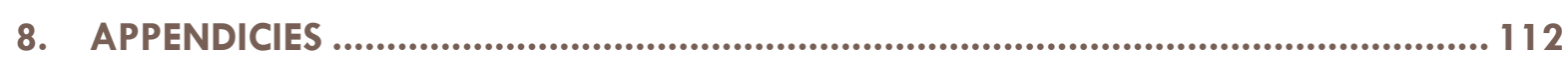

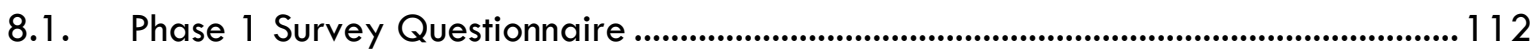

8.2. Phase 2 Interview Structure - Opening Questions and Discussion Prompts ............... 124

8.3. Qualitative Analysis with Survey Training Separation ............................................... 127 


\section{List of Figures}

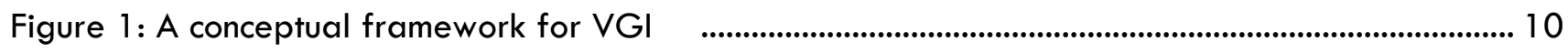

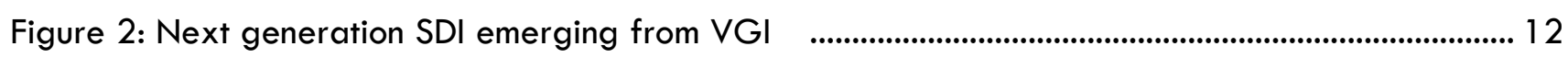

Figure 3: Approaches to Differentiating between Different Types of Contributors $\quad$........................ 12

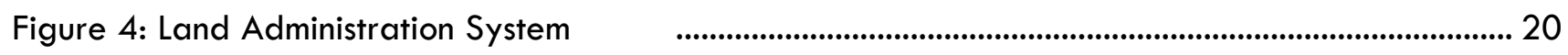

Figure 5: NZ Land Administration Users and Stakeholders.................................................................. 27

Figure 6: The user perspective of data functions in the Cadastre

Figure 7: Structure of the research engagement with participants ............................................................ 33

Figure 8: Age profile of phase 1 survey participants ........................................................................................ 41

Figure 9: Employment profile of phase 1 survey participants ........................................................................ 41

Figure 10: Produsers self-assessment as to whether they know what VGI means .......................................50

Figure 1 1: Have phase 1 participants used or encountered VGI............................................................51

Figure 12: Have phase 1 participants contributed VGI ........................................................................52

Figure 13: How well do produsers think they know what the NZ cadastre is?......................................... 52

Figure 14: How well do produsers think they understand the scope of cadastral data use? .................. 53

Figure 15: Produser perceptions of how important elements of the cadastre are.................................... 53

Figure 16: Important elements of the cadastre - survey qualified participants ......................................... 54

Figure 17: Important elements of the cadastre - non-survey qualified participants...................................5 54

Figure 18: Survey qualified participants' self-assessed capability to contribute data or services ........ 56

Figure 19: Non-survey qualified participants' self-assessed capability to contribute data or services 56

Figure 20: The influential factors for considering contributing VGl...............................................................5 57

Figure 21: The factors that limit produsers' provision of VGI................................................................5

Figure 22: Services or data that produsers might consider contributing as VGI .................................... 59

Figure 23: How concerned are produsers for the reliability and trustworthiness of the cadastre.......... 60

Figure 24: Issues encountered with the cadastre .......................................................................................... 66

Figure 25: How do survey qualified users perceive the potential impact of VGI contributions ............. 71

Figure 26: How do non-survey qualified users perceive the potential impact VGI contributions. .......... 72

Figure 27: How well do users think that they understand how cadastral data is created ........................ 81

Figure 28: Approaches to mitigating issues associated with geospatial crowdsourcing $\quad$..................... 89

Figure 29: Integration of VGI contributions into, or with the cadastre

Figure 30: Contributor motivation framework. ....................................................................................................... 94 


\section{List of Tables}

Table 1: Elements and characteristics of crowdsourcing

Table 2: Motivations of users to contribute information (based on Coleman et al. 2009).................. 11

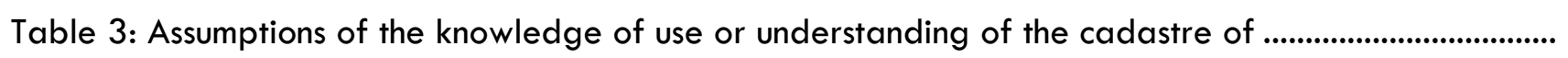

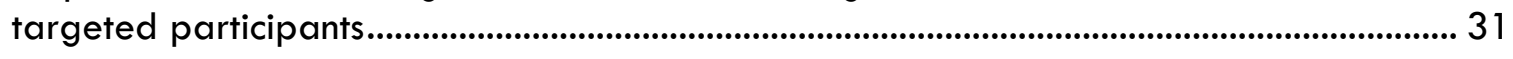

Table 4: Cross tabulation of the gender profile of phase 1 survey participants...................................... 40

Table 5: Cross tabulation of the location profile of phase 1 survey participants..................................... 40

Table 6: Survey and non-survey qualified produsers' self-assessed capability to contribute data

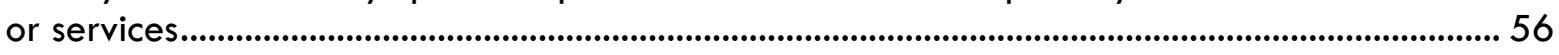

Table 7: Produsers' assessment of their likelihood of contributing VGI.....................................................59

Table 8: Extent of accuracy, completeness and currency issues................................................................. 66

Table 9: Demonstration level of cadastral integration based on dependent variables $\quad$...................... 91

Table 10: Potential examples cadastral geospatial crowdsourcing based on behaviour/motivation continua 


\section{Abbreviations and Acronyms}

Abbreviations and acronyms used are presented in full on first use and are thereafter abbreviated.

\begin{tabular}{|l|l|}
\hline Abbreviation & Description \\
\hline CSD & Cadastral Survey Dataset \\
\hline CGD & Crowdsourced Geographic Data \\
\hline CSLB & Cadastral Surveyors Licensing Board \\
\hline DCDB & Digital Cadastral Database \\
\hline DPI & Digital Parcel Improvement \\
\hline F-VGI & Facilitated Volunteered Geographic Information \\
\hline FIG & $\begin{array}{l}\text { Fédération Internationale des Géomètres } \\
\text { (International Federation of Surveyors) }\end{array}$ \\
\hline GIS & Geographic Information Science \\
\hline LINZ & Land Information New Zealand \\
\hline LoL & Landonline \\
\hline NZ & New Zealand \\
\hline NZIS & New Zealand Institute of Surveyors \\
\hline QA/QC & Quality Assurance/Quality Checking \\
\hline SDI & Spatial Data Infrastructure \\
\hline VGI & Volunteered Geographic Information \\
\hline
\end{tabular}




\section{INTRODUCTION}

\subsection{PURPOSE}

Core government geospatial data collection has generally focused on centralized production and distribution processes from an authorising agent - such as a government department (Rice et al., 2012). Accordingly, the systems and processes managing the authoritative data are generally highly controlled with a focus on data quality and security in order to protect the data from unauthorised change (Rice et al., 2012, Grant et al., 2014, Goodchild, 2009). Users of authoritative systems and other citizens need to rely on authoritative data, that it is fit for purpose (Allingham, 2014, Grira et al., 2010). By being set within a very risk averse environment, maintenance and development of the datasets are reliant on traditional data sources such as those provided by the highly skilled and/or regulated practitioners (e.g. surveyors), government agency staff and more recently via outsourced or partnership agreements with the private sector (McLaren, 2011). Opportunities for consumers and users and existing data producers to contribute their skills and information to enhance authoritative government geospatial data has been limited with adoption or use of crowdsourcing by Governments slow to eventuate (Haklay et al., 2014).

Involving the user in improving the system in the past has not been readily possible. The acquisition of geospatial information has largely been out of the reach of consumers and users due to the costs associated in data capture, equipment (Rice et al., 2012, Elwood et al., 2012) or reference data such as imagery (Hudson-Smith et al., 2009). In addition, there is a general reluctance from officials or administrators to accept user contributions due to data quality concerns (Rice et al., 2012, Flanagin and Metzger, 2008). However, the emergence of Web 2.0 technologies and easy to use mobile devices have enabled the developing geospatial capability and skill base within user groups to a point where there is an increased acceptance of crowdsourcing as a means to build and maintain geospatial datasets (Kostanski, 2012, McLaren, 2011, Rice et al., 2012). Rice et al., (2012) refers to this as "crowdsourced geospatial data' (CGD).

CGD is "derived from non-authoritative sources consisting primarily of end-users" (Rice et.al, 2012 p3) and "is a lightly controlled process with few constraints, specifications or quality assurance process" (Rice et.al, 2012, pl). The adoption of crowdsourced data is more prevalent in user developed (non-governmental) spatial datasets (such as OpenStreetMap), or where public/government spatial systems are inadequate or non-existent (McLaren, 2011 ).

In user developed datasets the rapid growth attained through crowdsourcing has outweighed known data quality issues, lack of authoritativeness and user perceptions around reliability (Rice et al., 2012). Often with little funding available, these crowdsourced spatial datasets 
have needed to obtain most of their resourcing from volunteers. Accordingly, research into crowdsourcing for spatial datasets has developed a bias towards non-authoritative datasets and issues associated with voluntarism - such as trust, accuracy and reliability. In other words there is a focus on the word "Volunteered" within the concept of Volunteered Geographic Information" (VGI) (Touya and Girres, 2010, Mooney and Corcoran, 2012, Heipke, 2010).

Research that encompasses and broadens the field beyond voluntarism, focusses on the concepts of CGD/VGI, and yet targets authoritative or core government geospatial datasets is required. Administrators of authoritative systems, such as the cadastre, are increasingly under pressure to adapt to changing user demands. These demands relate to factors such as accuracy, timeliness, completeness and consistency (Allingham, 2014, Grant et al., 2014, McLaren, 2011, Opus, 2013), and a need to provide greater transparency (Grant et al., 2014, McLaren, 2011); while also being faced with constrained budgets and resources (LINZ, 2013a, Haklay, 2010, Elwood et al., 2012). Researchers and administrators are now recognising that the users may be able to contribute to government geospatial systems or datasets in addition to the user derived ones (Basiouka and Potsiou, 2012, Johnson and Sieber, 2013, Keenja et al., 2012, Nedovic-Budic et al., 2008), but study into the opinions of users, existing data providers and administrators on the applicability of CGD/VGI prior to accepting contributions is still lacking.

This thesis, using the New Zealand (NZ) cadastre as an example, contributes to the elimination of the missing research link between an authoritative dataset and the opinions of users in conjunction with existing data providers and officials/administrators.

\subsection{RESEARCH QUESTION}

The potential benefits of crowdsourced information are only now becoming well understood in non-authoritative datasets. These benefits address factors such as cost, accuracy, timeliness, completeness and consistency (Allingham, 2014, Grant et al., 2014, McLaren, 2011, Opus, 2013). Yet it is only recently that research into how applicable crowdsourcing techniques are to government geospatial functions, associated authoritative systems, data or processes has been undertaken (Haklay et al., 2014, Johnson and Sieber, 2013, Keenja et al., 2012, Kostanski, 2012, McLaren, 2011 , Rice et al., 2012).

Research that links the opinions and attitudes of users, existing data producers and administrators (officials) is missing. An understanding of these opinions and attitudes are crucial to enable informed decisions to be made as to whether crowdsourced information should be allowed into authoritative systems. If crowdsourcing is permitted, how and to what extent it is acceptable is also not well understood, and are there significant differences between the three groups (users, existing data producers and officials) most closely associated with the system or data. 
Fundamentally, this thesis looks at the applicability of geospatial crowdsourcing in enhancing the New Zealand Cadastre. The knowledge gained from understanding the potential role, impact and influence that crowdsourced information may have, on this example of an authoritative database, will set the foundation in determining whether there is a role for nontraditional data sources in authoritative government data-sets. Accordingly this thesis addresses the following research question:

\section{How applicable is Geospatial Crowdsourcing to enhancing the New Zealand Cadastre?}

In the New Zealand context, Licensed Cadastral Surveyors are the only group of people allowed to define cadastral boundaries due to the legislative and regulatory controls from the Cadastral Survey Act 2002 and the Rules for Cadastral Survey 2010. Surveyors are therefore the primary contributors of cadastral information, and are a logical source of volunteered cadastral information or are potentially in a position to provide VGI support to other contributors. This study, by investigating the above research question examines the views and opinions of users, data providers and officials regarding the provision, support and integration of crowdsourced information into the cadastre.

However, crowdsourcing as a concept is extremely broad (Estellés-Arolas and GonzálezLadrón-de-Guevara, 2012) and this term may therefore not be appropriate in itself for this study. Existing terms that refine the scope to the geosciences domain namely; crowdsourced geographic data (CGD) (Rice et al., 2012) or volunteered geographic information (VGI) (Goodchild, 2007) are not adequately etymologically descriptive of research into authoritative information and systems. However, one established term is required for consistency in working with users, even though the concepts of both are generally interchangeable and both are a subset of crowdsourcing.

Based on the sheer volume of papers, books and reports relating to geographic information that use the term VGI at the time of commencing the research, it appeared that VGI was the preferred terminology for the geographic information sciences and was most likely to be recognised by users. In addition, Rice et al. (2012) highlight that Goodchild's (2007) introduction of $\mathrm{VGI}$ remains the highest cited paper in the field. Accordingly, VGI has been adopted in relation to work with research participants during the data collection stages of the research but the research title and question refer to geospatial crowdsourcing. The use of this term is discussed in section 2.1.3.

In addition to the research question, this thesis also addresses two further sub-questions:

- Should geospatial crowdsourced information be allowed into the NZ cadastre and if so to what extent?

- Are surveyors willing to provide geospatial crowdsourced information beyond their professional capacity? 


\subsection{POSITIONALITY}

The author qualified as a licensed cadastral surveyor, then practiced as a GIS consultant, before current employment with Land Information New Zealand (LINZ) in a range of roles including survey advisor to Landonline ${ }^{1}$ and the geospatial team leader. The author has personal experience as both a contributor, user and staff member associated with the NZ Cadastre. In addition to being employed by LINZ, the author has been supported in this research by LINZ via a financial scholarship comprising payment of university fees, associated expenses and study leave. The author is also a full member of the Institute of Surveyors (NZIS).

Although LINZ had no input or influence on the choice of research topic, subsequent to initiating the research, the author was tasked with preparing a business case for Digital Parcel Improvement (DPI) within the NZ cadastre. This project investigated the issue of the accuracy of parcel mapping, its impacts on cadastral data users and identified the high-level options for resolving the problem, one of which was the potential use of crowdsourcing (LINZ, 2013a).

The combined knowledge and experience of the author covering both cadastral data issues relevant to the geospatial sector, cadastral system administration and the cadastral surveying sector has been used to shape the research, especially in developing the questionnaires and in interviewing officials. However, it equally means that a significant perspective is missing from the research as the author's own views and influence on the future of the NZ cadastre are largely excluded except through inadvertent and unavoidable influences on others. Questioning of interviewees is also influenced through the intrinsic knowledge that comes from working within the sector or with interviewees. The analysis of the data acquired through the research has however endeavored to be as independent as possible. Chapter 4 focuses entirely on the categorisation and collation of the opinions and statements obtained from users or officials so is expected to be reasonably free from author bias. It is however, impossible to fully separate the author's prior understanding and knowledge from the analysis of the information acquired, so the discussion on the results (Chapter 5) may have an author bias as will the conclusions in chapter 6.

\subsection{STRUCTURE OF THE THESIS}

This thesis is structured into 6 chapters as outlined below.

\section{Chapter 1: Introduction}

This chapter provides an introduction to the purpose of the research, the background to why the research is important and where the scientific value lies. The research question is stated and the chapter incudes a positionality subsection on the relationship of the author to the subject matter and highlights necessary disclosures.

\footnotetext{
${ }^{1}$ Landonline, implemented in 2001, is New Zealand's computerised survey and title system.
} 


\section{Chapter 2 Literature Review and the Research Context.}

The chapter reviews relevant literature. The concept of geospatial crowdsourcing is developed from its roots in the broader concept of crowdsourcing before exploring the variations and considerations needed for its use in an authoritative data set. The development and role of the cadastre as an authoritative system is then outlined along with accuracy issues. The chapter concludes by providing NZ specific information about the local context.

\section{Chapter 3 Research Methodology.}

Opening with the overall design and methodological processes undertaken for this mixed methods research, the chapter then proceeds to outline how participants were identified and targeted along with the structure of the research. The multiple user groups and data collections stages comprising the research, the individual phases and how each subgroup of participants were targeted, engaged, surveyed and analysed are then outlined.

\section{Chapter 4 Results and Preliminary Discussion.}

The survey results of the three data collection stages are brought together by the preliminary discussion on related questions and responses from across the research. The chapter concludes with a summary of results.

\section{Chapters 5 Discussion.}

This discussion chapter explores the major issues, findings and opportunities identified in the research. It includes additional pertinent information from other discussion or correspondence with surveyors subsequent to the research data collection stage. The chapter discusses the concept and understanding of authoritativeness, data integration as it relates to the authoritative system, facilitating data acquisition, user motivations and the use of the existing data producers (licensed cadastral surveyors) to volunteer data and consider them a 'crowd' in their own right.

\section{Chapter 6 Conclusions.}

The main conclusions of this research are detailed in this chapter. The chapter then concludes with an outline of potential areas for further study that are revealed by this research. 


\section{REVIEW OF THE LITERATURE}

This chapter explores the literature underpinning the research into crowdsourcing and cadastre. The origins of geospatial crowdsourcing, its relationship to authoritative datasets and contemporary issues are covered first. Then similarly for the cadastre and land administration where cadastral origins, development, and accuracy issues are covered. The chapter concludes with a context section on the NZ cadastre to underpin the qualitative and quantitative research.

\subsection{GEOSPATIAL CROWDSOURCING}

The use of web technologies has enabled virtual communities and subsequently for users to generate their own content (Elwood et al., 2012, Goodchild, 2007, Heipke, 2010, Rice et al., 2012). Terms describing the concepts relating to user generated content are not discussed as they range well beyond the scope of this research, but key amongst concepts relating to user generated content are VGI and crowdsourcing. This chapter provides a background to two of the most common terms, VGI and crowdsourcing. It discusses their inter-relationship and level of interchangeability.

\subsubsection{INTRODUCING CROWDSOURCING}

Since Howe (2006) informally introduced the term 'crowdsourcing', by merging 'outsourcing' with 'crowd', the understanding of what geospatial information is has expanded rapidly and radically. Crowdsourcing has transformed how geographic information is collected, stored disseminated, analysed, visualised and used (Sui et al., 2013b). This transformation has especially been driven through the use and influence of web technologies, loosely called Web2.0, (Sui et al., 2013b, Heipke, 2010) and the increased pervasiveness of cheap satellite positioning technologies, such as that associated with smartphones (McLaren, 2011 ).

Crowdsourcing is common in public usage with variations such as 'crowdfunding'. This drives common user perceptions of participants or observers of the many crowdsourcing initiatives that exist. Wikipedia and OpenStreetMap are two examples of the most well-known crowdsourcing initiatives (See Wikipedia (2014) for an extensive list). A crowdsourcing definition contained with the animated video "Crowdsourcing and Crowdfunding Explained" provides a straightforward explanation for contextual purposes: 
"Crowdsourcing is the process of connecting with large groups of people via the internet who are tapped for their knowledge, expertise, time and resources. There are four different ways that crowdsourcing works:

1. through accessing a large online labour force

2. by enabling solutions to problems to be found by asking the crowd

3. by using the crowd to find and organize existing knowledge

4. by acquiring ideas, opinions and feedback from the crowd

(crowdsourcing.org, 2012)

Estellés-Arolas and González-Ladrón-de-Guevara (2012) however located forty distinct definitions of crowdsourcing between 2006 and 2011 . These arise from the wide ranging uses and applications, studied in a variety of disciplines (i.e. not just restricted to the geosciences). Their analysis shows that crowdsourcing can be categorised into three elements and eight characteristics as shown in Table 1.

\section{About the crowd: About the initiator About the process.}
(a) who forms it;
(d) who it is,
(f) the type of process it is
(b) what it has to do,
(e) what it gets in return for
(g) the type of call used
(c) what it gets in return the work of the crowd.
(h) the medium used

Table 1: Elements and characteristics of crowdsourcing

(based on Estellés-Arolas and González-Ladrón-de-Guevara, 2012)

Estellés-Arolas and González-Ladrón-de-Guevara (2012) also created an integrated definition of crowdsourcing. This definition attempts to enable researches to move beyond the discriminatory etymological meaning that is based on 'crowd' and 'outsourcing'. It is accordingly the most complete (and complex) definition found and is as follows:

Crowdsourcing is a type of participative online activity in which an individual, an institution, a non-profit organization, or company proposes to a group of individuals of varying knowledge, heterogeneity, and number, via a flexible open call, the voluntary undertaking of a task. The undertaking of the task, of variable complexity and modularity, and in which the crowd should participate bringing their work, money, knowledge and/or experience, always entails mutual benefit. The user will receive the satisfaction of a given type of need, be it economic, social recognition, self-esteem, or the development of individual skills, while the crowd sourcer will obtain and utilize to their advantage what the user has brought to the venture, whose form will depend on the type of activity undertaken.

(Estellés-Arolas and González-Ladrón-de-Guevara, 2012) 


\title{
2.1.2 INTROdUCING VolunteEREd GeOGRAPHIC INFORMATION (VGI)
}

Shortly after Howe (2006) coined crowdsourcing, Goodchild (2007) introduced the concept of VGI in the paper 'Citizens as sensors: the world of volunteered geography' where VGI was seen as a special case of the more general Web phenomenon of 'user-generated content.

Goodchild (2007, p2) explained Volunteered Geographic Information as being:

\begin{abstract}
"The widespread engagement of large numbers of private citizens, often with little in the way of formal qualifications, in the creation of geographic information, a function that for centuries has been reserved to official agencies. They are largely untrained and their actions are almost always voluntary, and the results may or may not be accurate"
\end{abstract}

Since becoming widely accepted in the geospatial literature, VGI appears however to have developed a plain English interpretation. That is, an individual focus on the words of 'Volunteered', 'Geographic' and 'Information'. Goodchild's original description has a lower emphasis on voluntarism as the creation of geographic information is "... almost always voluntary" (author's emphasis added). Semantically, contributed geographic information is not necessarily voluntary, and voluntary does not necessarily mean 'free'. It is also increasingly important to distinguish between whether information was volunteered via an 'opt in' process as opposed to contributed via an 'opt out' process, where the contributor may not be aware that their information is being harvested (Harvey, 2013). So although research into VGI has developed and matured, it appears voluntarism is now a requirement of VGI rather than a simple recognition that most contributions will be offered free of charge. Volunteered data should be without coercion and with the full knowledge and awareness of the contributor that they are providing information (Harvey, 2013, Rambaldi et al., 2006).

\subsubsection{The Emergence of Geospatial Crowdsourcing}

VGI and crowdsourcing have developed on near parallel paths where there are similarities in the use of 'non-traditional' data providers and by being facilitated through web2.0 technology and mobile phones (McLaren, 2011). Crowdsourcing though is considered too broad a concept for this thesis because its application extends well beyond the geosciences, yet the common etymological based understanding of 'volunteered' in VGI creates doubt as to what is intended.

Goodchild's (2007) original VGI description (refer to section 2.1.2) fits easily within the crowdsourcing definition of Estellés Arolas and González-Ladrón-de-Guevara on VGI (see section 2.1.1). Logically VGI is therefore a subset of crowdsourcing rather than a standalone 
topic. Viewing $\mathrm{VGI}$ as a subset is backed by the developing trend that uses crowdsourcing as a key term for VGI concepts in the geosciences with various papers, reports and books now referring to crowdsourcing in a geospatial sense (Haklay et al., 2014, Heipke, 2010, Keenja et al., 2012, Kostanski, 2012, McLaren, 201 1, Rice et al., 2012, Sui et al., 2013a, van Exel et al., 2010). Rice et al., (2012) acknowledges this move by preferring to use crowdsourced geographic data (CGD) instead of VGI. Using CGD, instead of VGl, provides increased refinement towards spatial matters than simply the term crowdsourcing. At issue however is the shift from 'information' to 'data' that although often used synonymously, may also limit its understanding and scope by users with respect to authoritative systems. This is not an issue for researchers as Rice et al. (2012) notes that:

"CGD can be primarily geospatial in nature, or could simply be an associated geospatial characteristic of non spatial information. CGD can be asserted by the end users, or could be the product of active harvesting and synthesis."

(Rice et al. 2012, pg 3)

The concept of crowdsourcing has developed its own niche within the geosciences fields. The development of crowdsourcing has been driven from an increased market and appetite from both individuals and organisations to contribute and consume crowdsourced geospatial information. Accordingly crowdsourcing has developed a role within government where citizen engagement is required such as public participatory projects GIS (Haklay et al., 2014, Ganapati, 2011, Kostanski, 2012, McLaren, 2011). Historically, the availability of VGI was dictated by what individuals wished to capture, by where they were, who they collaborated with (Mooney and Corcoran, 2012), and with what tools and time they had at their disposal (Mummidi and Krumm, 2008, van Exel et al., 2010). However, even greater growth and data volumes have come from the consumerisation of geographic information through the likes of the smartphone which has incorporated autonomous positioning and photography with traditional communications (Trimi and Sheng, 2008, Sui et al., 2013b, McLaren, 2011) and is expected to generate very large data volumes; an exabyte (1018bytes) is being generated daily (Sui et al., 2013b). This increased capacity/capability is such that to assist in managing the anticipated upcoming stream of data through harvesting of information from consumer devices, it has been proposed to use sensor web enablement concepts (Goodchild, 2007). By applying sensor web enablement concepts and standards, people can be treated as if they are selfaware sensors (Goodchild, 2007, Gouveia and Fonseca, 2008, Schade et al., 2010). Thather (2013) takes this one step further with the concept of volunteered geographic services (VGS) where users and service providers who are those subscribed to a VGS service are able to make requests for service and based on geography or availability potential service providers can respond. 


\subsubsection{USER Motivations to CONTRIBUTE}

In examining why users contribute to crowdsourcing initiatives, VGI researchers, explore the motivations of users. This research draws on psychology research relating to motivation and volunteerism. Much of this literature is beyond the scope of this research, but two set of terms standout in aligning with this research; firstly, altruistic and egotistical behaviours and secondly intrinsic and extrinsic motivations. Both sets of descriptors can be viewed as continua.

Budhathoki (2010) in developing a VGI framework, shows that motivations to contribute comes firstly from the contest of participation (being personal, social, or technological) to form either intrinsic or extrinsic motivations. In addition to motivations, a mechanism to contribute is also required in order to achieve the outcome (Figure 1).

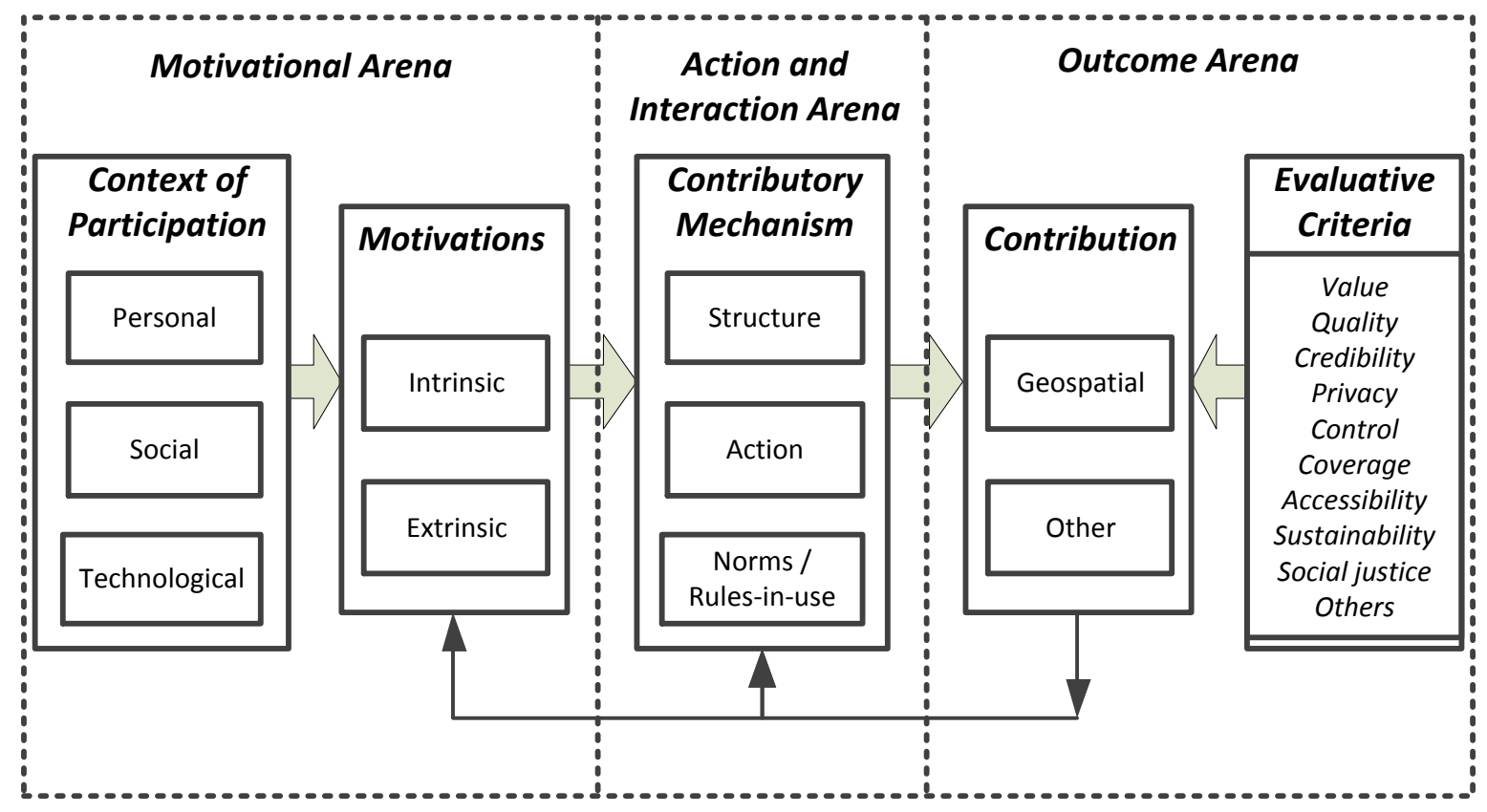

Figure 1: A conceptual framework for VGI

(Based on Budhathoki et al., 2010)

Johnson and Sieber (2013) identify the importance of understanding the contributors' motivations in assessing quality or determining whether the contributions are agenda-driven. Coleman et al. (2009) divides contributions into two primary motivations, those that are constructive (positive) and those that are not (negative) as shown in Table 2. 


\section{Constructive}

(1) Altruism;

(2) Professional or Personal Interest,

(3) Intellectual Stimulation

(4) Protection or enhancement of a personal investment

(5) Social Reward

(6) Enhanced Personal Reputation

(7) Provides an Outlet for creative \& independent self-expression

(8) Pride of Place

\section{Negative.}

(1) Mischief

(2) Agenda

(3) Malice and/or Criminal Intent

Table 2: Motivations of users to contribute information

(based on Coleman et al. 2009)

Recently in a study on the use of volunteers to create draft cadastral maps in Greece due to the absence of authoritative ones, Basiouka and Potsiou (2014) found that motivations were not the only factors leading to users contributing information. As Budhathoki (2010) suggests (Figure 1), Basiouka and Potsiou (2014) found that context is also important. For example, younger volunteers were more willing than older ones and participants who had already been involved in participatory mapping projects found the process less time consuming or confusing (Basiouka and Potsiou, 2014).

\subsubsection{The Role of Users in Geospatial Crowdsourcing}

Projects like 'OpenStreetMap' have developed master datasets through the use of VGI and 'user contributed content' and are now competing with those traditionally considered 'authoritative'. As large organisations and government agencies change their culture around ownership and security (Ackerman, 2008, Salkin, 2005), the original 'authoritative' datasets are increasingly being released under Spatial Data Infrastructure (SDI) initiatives that have a focus on supplying and sharing the data with users. Modern SDI use Web 2.0 technologies and standards (Alvarez et al., 2010, Nedovic-Budic et al., 2008). However current SDI users are passive recipients (Nedovic-Budic et al., 2008) and although they will identify errors and data gaps, are unable to rectify any shortcomings - despite many users potentially having the capability to produce the required information. A SDI development that better incorporates social aspects and user contributions is thereby proposed by a number of researchers to address this (Alvarez et al., 2010, Nedovic-Budic et al., 2008, Coleman et al., 2009). This concept of incorporating VGI with existing data is encapsulated by the term 'produser' (Bruns, 2008, Grinnell, 2009, Nedovic-Budic et al., 2008), which describes the "collaborative and continuous building and extending of existing content in pursuit of further improvement" (Bruns, 2008). 
Nedovic-Budic et al. (2008, p157) argue that "SDI and VGI are not separate, but complementary phenomena..." and "...can be brought within a single framework when the role of the user of SDI is reconceptualized to produser and VGI is included in the SDI-related processes" (Figure 2).

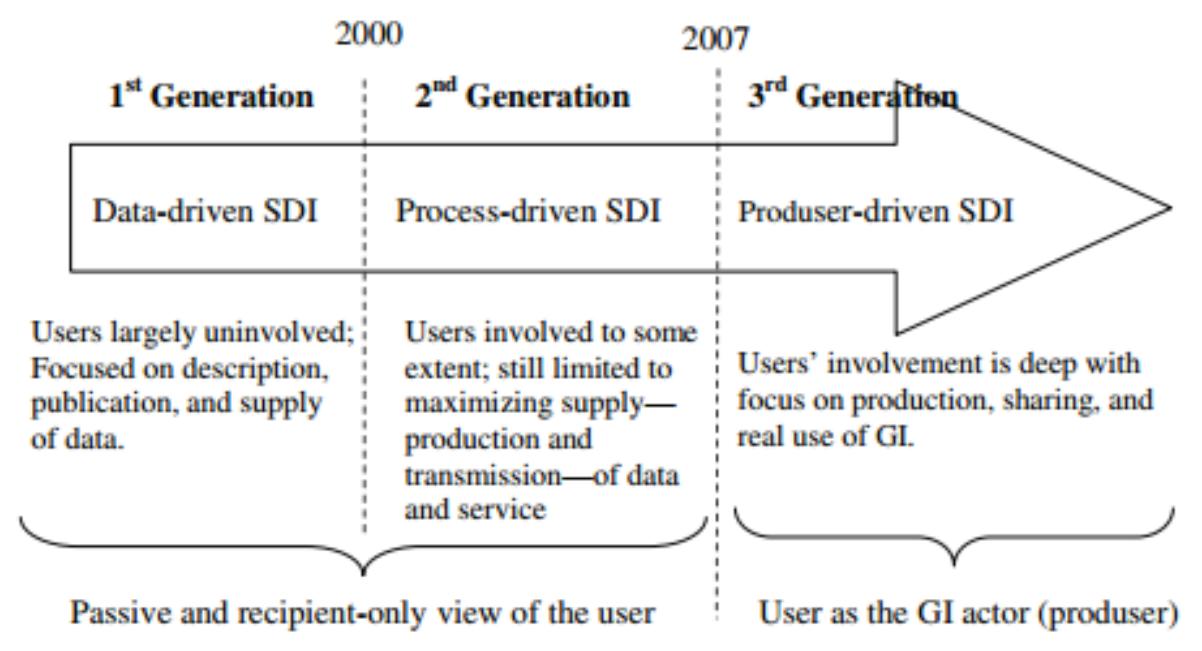

Figure 2: Next generation SDI emerging from VGI

(based on Nedovic-Budic et al., 2008)

If SDI's can expand their production base to incorporate 'produsers' then the use of voluntarism in governmental datasets "to change the balance between traditional values, practices and rules" (Coleman et al., 2009, p3) in government mapping moves beyond being just potential.

Coleman et al. (2009) identifies five categories of contributors that can be distinguished by either competence or accountability (refer Figure 3), but notes that this is more multidimensional as an individual may be in different categories for different contributions.
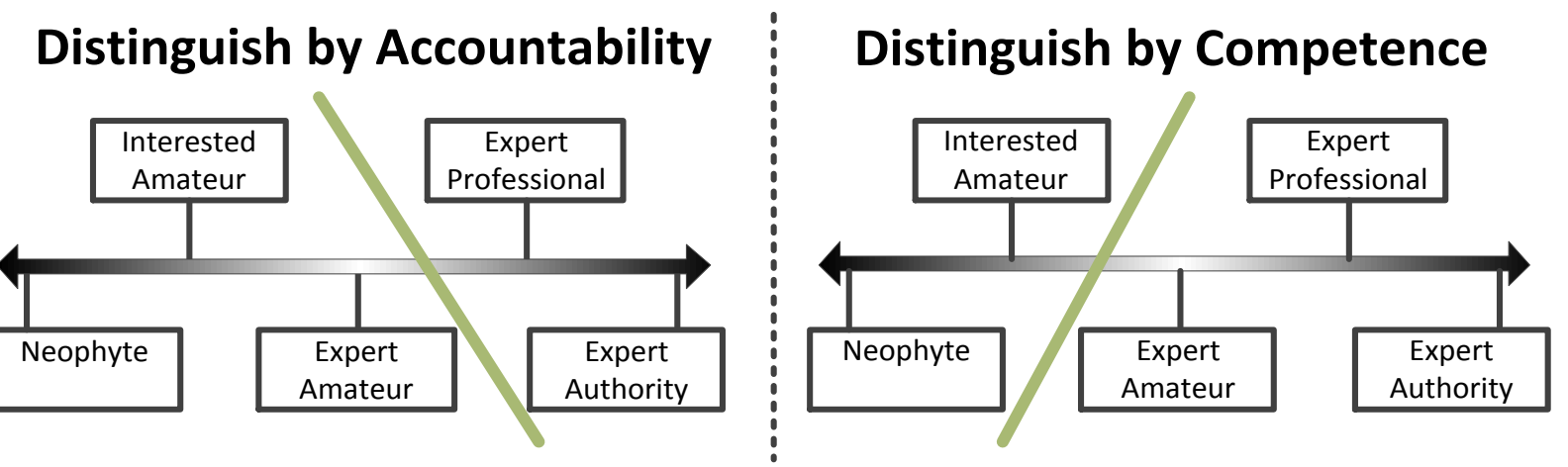

Figure 3: Approaches to Differentiating between Different Types of Contributors

(based on Coleman et al. 2009) 


\subsubsection{ADMINISTRATIVE AND VOLUNTEER INTERACTION}

Studies of participation between citizens and government prior to GIS are common and can be applied to this study. For example, Arnstein's ladder of participation. The ladder "juxtaposes powerless citizens with the powerful in order to highlight the fundamental divisions between them" (Arnstein, 1969). Comprising of eight rungs where citizen participation gradually increases from two rungs of non participation, to three middle rungs of varying degrees of tokenism through to the upper three rungs of varying degrees of citizen power, Arnstein shows that there are significant degrees of citizen participation. Subsequent work by authors such as (Tritter \& McCallum, 2006; Rees, 1999) highlight many flaws. Tritter and McCallum (2006) point to incongruencies, 'missing rungs'; adverse effects that can occur in applying Arnsteins ladder and that it focuses on single dimension of power. Whereas Rees (1999), identifies that a lack of hetrogeniety amongst volunteers does not fit the model.

Connor (1988) adapted Arnstein's ladder to provide a means to demonstrate the escalating building blocks towards preventing and resolving public controversy against government or private sector policies. Connor's ladder clearly segments into just two divisions separating the roles and appliction of the general public from that of the leaders. Facilitated-VGI (F-VGI) as proposed by Seeger (2008) follows a similar separation of public and leadership in that it takes VGI principles but allows for the volunteered information to be shepherded in by a facilitator as a part of a pre-established planning or design process. Under F-VGl, information might be contributed in response to a predefined set of criteria, such as an explicitly defined question, or limited to an established geographic extent.

Participatory and public forms of GIS (an extended form of VGI), are being used within government agencies and local government to leverage the expertise, knowledge and opinions of users - primarily for decision-making purposes (Elwood, 2008, Hansen and Reinau, 2006, Johnson and Sieber, 2013, Tulloch, 2008) and to inform the community (Aditya, 2010, Ganapati, 2011). While participatory forms of GIS are eliciting feedback and enabling reporting, can this information be used for governmental decision making? Johnson and Sieber (2013) discuss this issue, noting that due to the legal framework in which official decision making is made, defensible processes must be followed to balance the needs of society. Decision makers need to have confidence that the information their decisions are based on, is reliable and equivalent to other traditional ways of obtaining user opinions. Accordingly more controlling methods than other 'private' initiatives may be required to provide the level of surity and quality necessary for government decision makers. Johnson and Sieber (2013) also question whether decision makers would accept or reject information that has a VGI base and note that more research in this area is required. 


\subsection{CROWDSOURCING CONSIDERATIONS FOR AUTHORITATIVE DATA}

Government data provides the basis of many government services. These services are in turn used by businesses and the public for their own purposes and decision making. Government data is accordingly widely thought of as being authoritative. For crowdsourcing, to be incorporated in these 'authoritative' data sets there are a number of considerations that need to be taken into account.

\subsubsection{Maintenance AND Data Acquisition}

In the main, governmental datasets emerged from 'authoritative' mapping where it was predominately collected for security needs and national mapping functions (Ackerman, 2008, Salkin, 2005). These purposes required a very high standard of mapping and data. The costs associated in reaching this standard were high due to the need for specialised skills and sophisticated printing facilities, which is no longer the case as Web 2.0 technologies are increasingly used (Heipke, 2010). Web 2.0 is shifting the labour aspects and consequently the data capture, and maintenance processes are separating from mapping production (Coleman et al., 2009). This shift in production may also be able to be attributed to the decline in traditional mapping that occurred through the 1990's due to resourcing issues. Governmental outsourcing, although necessary, ran the risk that if too much was contracted out then in-house expertise would diminish. It is therefore important to retain some capability (Brown and Brudney, 1998). Ironically, facilitated-VGI, proposed by Seeger (2008), appears similar to traditional outsourcing in that it focuses on data collection for a specific purpose through the use of 'crowds'.

To acquire authoritative geospatial data from volunteers, the authority receiving the data must be "prepared to entertain some important procedural and cultural changes that build on the motivations and recognize the characteristics of the [produser] culture"(Coleman et al., 2009). According to Coleman et al. (2009), culture changes for the authority include; a move away from a culture of hierarchy to one of heterarchy, the respecting of the rules and values of the produser community, acceptance that the geo-information acquired will be "perpetually unfinished' and that new rules/legislation may be needed to balance the rights of all contributors and organisations. 


\subsubsection{Privacy and Ethical Use}

In 2000, Terranova in the social sciences, identified and explored the exploitation of labour in the digital economy (Terranova, 2000) and through subsequent work, including in the GIS field, researchers continue to influence our understanding of the social ramifications and the ethical use of volunteers and their information (Elwood, 2010, Pickles, 2006, Tulloch, 2008, van den Broek, 2010). To use third party information and to then take advantage of 'free' data or labour in the internet era also comes with often unspoken caveats relating to licensing, ownership and liability (Grinnell, 2009, Rambaldi et al., 2006).

Volunteers are independent and not just 'self-aware' sensors. Accordingly, there should not be any compulsion placed on potential contributors to provide information (Rambaldi et al., 2006). Harvey (2013) identifies that there is a difference between volunteered information and contributed information, where the distinguishing feature is whether information is obtained via an 'opt in' process (volunteered) or an 'opt out' process (contributed). Should information be taken without contributors' knowledge or consent, or used for purposes that they did not agree to, then issues such as privacy become important (Harvey, 2013, Rambaldi et al., 2006). Information cannot be considered to be volunteered where the contributor may not be aware that their information is being harvested, as may occur with 'opt out' processes (Harvey, 2013).

In addition the motivations of contributors to provide data also need to be taken into account if others wish to leverage their information. For example, if the data is provided to further a specific agenda of the contributor, or it will have negative effects on others, is it ethical or acceptable to use? (Rambaldi et al., 2006).

\subsubsection{Credibility ANd Trust}

Government agencies, especially, but often other large organizations, tend to pride themselves on data quality and rely heavily on credibility that has been built up over time through thorough processes and metadata and/or the fact that their ownership and responsibilities for maintenance are well known (Rice et al., 2012, Elwood et al., 2012). Consequently, these organisations are risk adverse and often reluctant to use VGI to change processes or introduce data that they do not control (Coleman et al., 2009, Rice et al., 2012). These organisations perceive that if quality diminishes or standards are no longer met, the 'value' of the data also diminishes rapidly as reliability is eroded (Lankes, 2008). With the plethora of data available, the traditional notion of authoritativeness of datasets is further evolving and is now more about trustworthiness and credibility (Coleman, 2013) than being a sole agent for that data source (Lankes, 2008). Credibility, according to Flanagin and Metzger (2008), is primarily based on social confirmation, for example, reputation, endorsement etc., or on contextual expectations, for example, appearance, professionalism etc. An approach 
proposed by Bishr and Mantelas (2008) when assessing credibility of VGl extends this somewhat in order to obtain some hard metrics, by not only assessing other users assessment, but including the proximity of the contributor and the frequency that a particular piece of information is supplied. A second approach is to simply focus on usability (Aditya, 2010, Haklay, 2010). A third, is to develop and apply robust specifications for VGI projects such as 'Open Street maps' (Touya and Girres, 2010)

\subsubsection{DATA QuALITY}

Section 2.1.3 showed that the extent of geospatial crowdsourcing is determined by factors of choice, location, skills and tools. This consequently means that, data or mapping gaps occur in some places, but in other areas the level of detail can be quite significant (Johnson and Sieber, 2013). Variability is further compounded because the same data is contributed differently by different people (Mummidi and Krumm, 2008, Haklay, 2010, Touya and Girres, 2010, van Exel et al., 2010). People however know their own local area better than non-resident 'experts' so some of this variability also reflects VGI contributors ability to rapidly respond to change in their areas of interest (Gouveia and Fonseca, 2008, Heipke, 2010, Tulloch, 2008). Unfortunately, these contributors commonly create geospatial data themselves without reference to the past methods and techniques and are 'reinventing the wheel' which is leading to a duplication of effort (Goodchild, 2008) and increased data variability. VGI variability also means the data is often considered to be a lower standard, especially as VGI participants commonly lack formal training (Heipke, 2010). Perceptions of low quality occurs irrespective of whether professionals or experts are involved (Goodchild, 2009). Developed from the five fundamental components required for a quality report as proposed by the National Committee for Digital Cartographic Data (NCDCDS and Moellering, 1987), the quality standards set by the International Organization for Standardization (ISO) use five categories to describe the quality of geo-information. These five categories are; positional accuracy, thematic accuracy, temporal accuracy, completeness and logical consistency (ISO, 2013; ISO, 2005). If VGI data is to be incorporated or used, then these data quality factors are important to users (Allingham, 2014). Allingham (2014) also highlight that the nature of VGI is a critical issue impacting on data quality and that additional research is required to "develop tools and services that can (semi-) automatically evaluate the quality of geo-data in the Internet." The context that the contributor is providing the data in (i.e. market-driven, social network, or civic/governmental) helps assess the quality of the data (Coleman et al., 2009). Van Exel et al. (2010) attempts to better define quality through examining the collective intelligence of crowds. Van Exel et al. (2010) takes a spatio-temporal context by looking at user qualityrelated aspects and feature quality related aspects. The combination of which, provides a measure of Crowd Quality. The user and feature quality aspects cannot however be considered independent of each other (van Exel et al., 2010, Severinsen and Reitsma, 2013). 


\subsection{THE CADASTRE AS AN AUTHORITATIVE SYSTEM}

The cadastre supports economic and social objectives for individual jurisdictions. However, society changes, and cadastres evolve over time. To identify the role that crowdsourcing can play in the cadastre understanding cadastral history, its future and current issues is required.

\subsubsection{Understanding and Defining a Cadastre}

Cadastres have been in existence as long as land has been able to be held or owned separately to the state or jurisdiction. The impetus for a cadastre in various jurisdictions has largely evolved from the need to record property for two primary purposes. Firstly, the fiscal based cadastres which enabled the state/jurisdiction to impose tax for revenue purposes and secondly the juridical cadastres that supported ownership and property rights (Bennett et al., 2010, Dowson, 1956, Williamson, 1985).

Williamson (1985) reworks the four characteristics of a cadastre identified by Dowson (1956 p48) to highlight that the:

"distinctive character of any cadastre is readily recognised and may be expressed as the marriage of:

1. a technical record of the parcellation of the land through any given territory, usually represented on plans of suitable scale; and

2. an authoritative documentary record, whether of a fiscal or proprietary nature or of the two combined, usually embodied in appropriate associated registers."

(Williamson, 1985 p 15)

Describing the characteristics of a cadastre however does not define a cadastre. According to Williamson (1985) a universal definition is impossible because no two cadastres are the same. Cadastres vary due to the historical development, jurisdictional differences in laws, customs and land registration processes. This additionally means that cadastral systems are continually evolving and changing to meet the needs of society. However, Commission 7 of the Fédération Internationale des Géomètres (FIG), in their statement on the Cadastre provide the following: 
"A Cadastre is normally a parcel based, and up-to-date land information system containing a record of interests in land (e.g. rights, restrictions and responsibilities). It usually includes a geometric description of land parcels linked to other records describing the nature of the interests, the ownership or control of those interests, and often the value of the parcel and its improvements. It may be established for fiscal purposes (e.g. valuation and equitable taxation), legal purposes (conveyancing), to assist in the management of land and land use (e.g. for planning and other administrative purposes), and enables sustainable development and environmental protection."

(FIG 1995, online)

\subsubsection{Modernising Cadastres and the Multipurpose Cadastre}

Land administration through the Bogar Declaration (UN-FIG, 1996) and then subsequently the Bathurst Declaration (UN-FIG, 1999) articulated the link between good land management and cadastre (Bennett et al., 2010). These declarations instilled a focus on sustainability of land development and the role and importance of the cadastre in all jurisdictions, irrespective of their level of maturity or how well developed the jurisdiction to which they support is. Central to the Bogor Declaration (UN-FIG, 1996) was a cadastral vision where the declaration also identified the need for cadastral reform so that cadastres are flexible enough to continue to meet the changing needs of society. In addition, cadastres must be parcel based and include all land and tenure systems in the jurisdiction. The Bogor declaration also highlighted that cadastres must move away from a focus on ownership and towards a focus on rights, responsibilities and obligations, and an increasing role for non-government organisations in operating or contributing to cadastres (UN-FIG, 1996).

The seminal piece of work with regard to cadastral vision for modernising cadastres was 'Cadastre 2014' (Kaufmann and Steudler, 1998). This vision envisaged cadastres having six characteristics, where they:

1. show the complete legal situation of land

2. merge maps and registers

3. contain models of cadastral objects including public rights and restrictions

4. are computerised

5. enable the private sector to work in greater partnership with government

6. recover costs for the system from the people transacting in land

(Kaufmann and Steudler, 1998). 
Although accepting the basic foundations in Cadastre 2014, van der Molen (2003) questions the suitability and applicability of the vision for the 140-160 countries without suitable land administration systems. van der Molen (2003) further notes that these countries will need to adopt new concepts and take an evolutionary approach to the implementation and development of land administration systems suitable for their needs. The use of crowdsourcing has been proposed as means to map the extents of human occupation and to enable the initial identification of property rights (McLaren, 2011, Basiouka and Potsiou, 2012, Basiouka and Potsiou, 2014). Bennett et al. (2012) however considers that that boundaries will become more organic. Accordingly, Bennett et al. (2012) look to ambient spatial intelligence and wireless sensor networks to continuously monitor and visualize these fuzzy/changeable boundaries, noting that a reliance on bearing/distances or coordinates may no longer be the best solution.

Enemark (2008) raises similar concerns about the use or development of modern cadastres in underdeveloped areas of the world and looks to the Social Tenure Domain Model to address the issues associated with informal settlements and customary tenure that cannot be accommodated in traditional cadastral systems. Bennett et al. (2010) also suggests cadastral science must continue to look to the future to remain relevant. Factors such as globalization, population urbanization, good governance, climate change response, environmental management, 3D visualization/analysis technologies, wireless sensor networks, standardization, and interoperability are driving developments in the cadastral domain. Based on these drivers Bennett et al. (2010) propose the following as potential characteristics of the future cadastre where they will be; survey accurate, object oriented, multi-dimensional (3d/4d), operate in real-time, global, and organic.

On the back of digital cadastres the concept of a multipurpose cadastre that meets a wide range of uses has emerged. According to Bennett et al. (2010 p4) the multipurpose cadastre has extended cadastres beyond the traditional fiscal/juridical purposes as they began to "underpin the important activities of land use planning, land development, environmental management and wider social organization". Williamson and Ting (2001) also include valuation within the view of a multipurpose cadastre and add more information on a wider range of property rights to the list. By their very nature, multipurpose cadastres have a wide range of users and stakeholders predominately in the Land Administration domain that is primarily concerned with economic, social and environmental sustainable development (Enemark, 2008). 
Cadastre 2014 and land administration concepts have widely impacted on the development of cadastral systems in many jurisdictions and significant progress has been made in modernising cadastres, including in NZ (Bevin, 1999, Hirst, 2010, Kaufmann et al., 2002, Manzoor et al., 2009, van der Molen, 2003). But the concept of the land object that was introduced by Cadastre 2014, has facilitated a conceptual shift in cadastral thinking from that focused on parcels to one that is objects oriented (Figure 4).

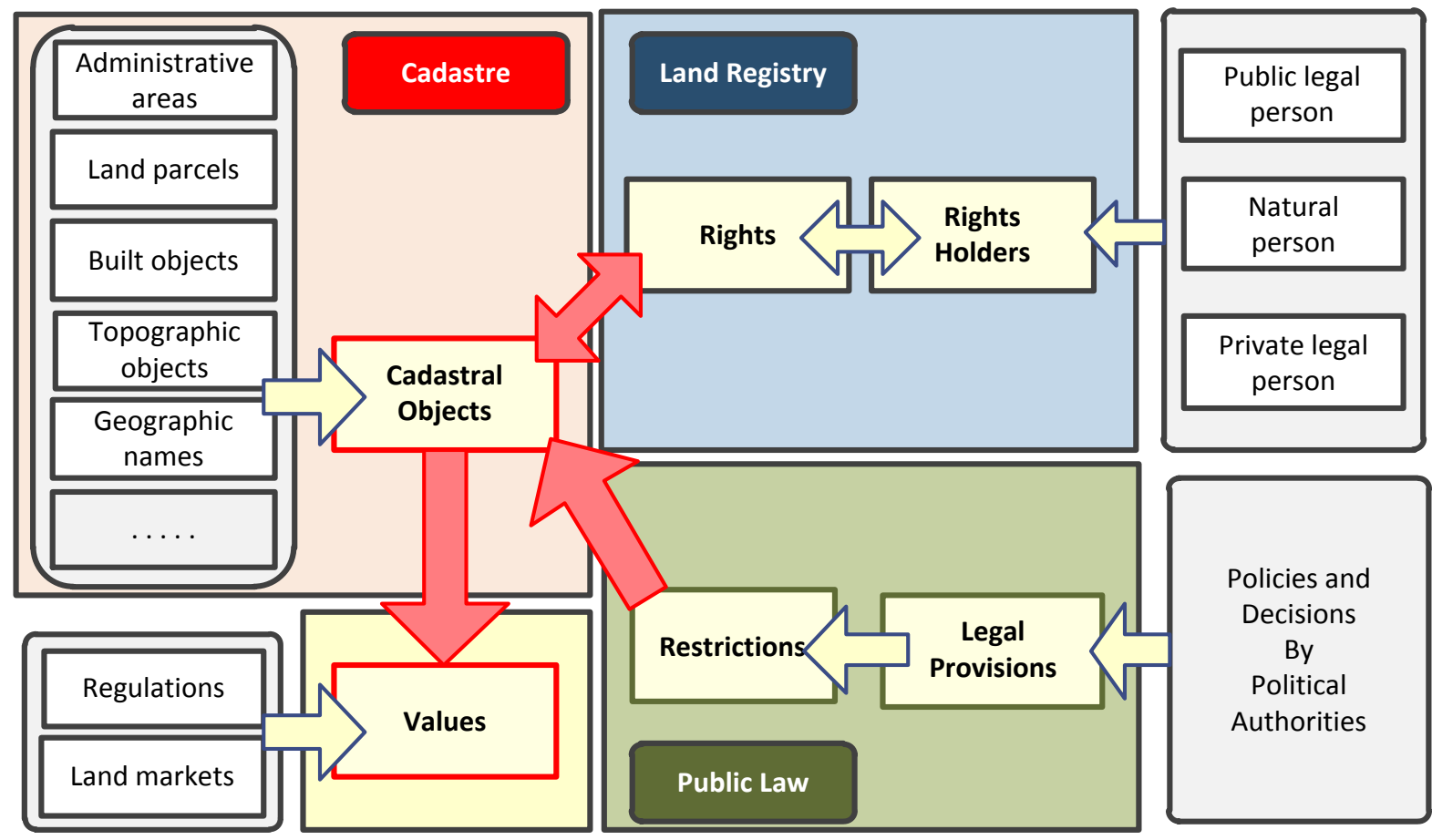

Figure 4: Land Administration System

(Horisberger, 2010 in Muggenhuber et al., 2011)

To support the changing needs of society, the modern cadastre must expand from a focus on ownership and property rights to better support and incorporate the public-law rights and interests in land (Grant et al., 2014, Grant et al., 2010, Kaufmann and Steudler, 1998). In general, these public law rights exhibit as public rights or as restrictions on private rights where activities are either permitted or forbidden. Public law rights are becoming increasingly important (Kaufmann and Steudler, 1998) and are now of almost equal importance as private rights to land (van der Molen, 2003). Examples include land use planning, environment protection, and licenses (such as mining), traditional rights, administrative units, zoning (for land protection or land use) and for resource management (Grant et al., 2014, Kaufmann and Steudler, 1998). Although public law rights impact on the property rights of the land owner (and may coincide with cadastral boundaries), they are often defined to much lower standards (Grant et al., 2014). This is because the definition and recording of these areas usually falls outside of the formal cadastre as part of the democratic processes (Kaufmann and Steudler, 1998). 
As concepts of cadastre extend and include public law, the needs of other stakeholders must be incorporated. This will drive the need for collaboration, and good governance (Grant et al., 2014, Hull and Whittal, 2013). Good cadastral governance according to Hull and Whittal (2013) is when the cadastre adheres to the following interdependant principles of being:

- efficient, effective and enduring

- transparent, accountable and follows the rule of law

- equitable and participatory

- secure and operating with integrity (Hull and Whittal, 2013).

The need for robust governance is linked to ideas that Bennett et al. (2013) propose about treating land administrations systems (and thereby the cadastre) as infrastructure. According to Bennett et al. (2013) by treating these systems as infrastructure, problems associated with funding and maintenance will be more easily resolved. In addition they note that flexible or adaptive management techniques are built into the lifecycle of infrastructure. This then ensures learning, rehabilitation, regeneration and decommissioning programs. Also according to Bennett et al. (2013), adaptive management helps to avoid stagnation and consequential failure; and protects these economic, social and environmental systems.

\subsubsection{Accuracy Issues With Cadastral MapPing}

The computerisation of cadastral mapping through the 1980's in developed countries converted authoritative paper indexes and maps of the cadastre to digital cadastral databases (DCDBs). This mapping conversion provided many benefits and efficiencies in locating cadastral records and visualizing the extent of property ownership for administrators and users of the cadastre (Cadastre Ltd, 2003). What DCDBs and integrated digital cadastres (such as that in NZ) have done is to effectively introduce:

- the practical application of a form of coordinated cadastre - where users increasingly rely on the calculated grid coordinates (as opposed to polar coordinates) of boundary corners and not the evidential physical boundary marking or monumentation (Goodwin and McKinnon, 2010);

- enabled the development of the multipurpose cadastre and contributed to a spatially enabled society (Steudler and Rajabifard, 2012). 
However, DCDBs in extending the use of cadastral information created new issues regarding boundaries and associated parcel information. These issues commonly occur because users do not realise that the mapping accuracy may differ from the surveyed accuracy (Effenberg and Williamson, 1997, Opus, 2013).

Bennett et al. (2012) shows that the understanding of what is 'survey accurate' is influenced by:

- differences in cadastral establishment processes of adjudication, demarcation, surveying and recording

- differences between the spatial component and textual components of legal boundary fabrics

- the inaccuracies that may occur in any measurement process including blunders, systematic errors and noise

In this regard, the spatial accuracy of boundaries in DCDBs are notoriously poor (i.e. the digital boundaries are not reflective of the surveyed accuracy of the actual boundary). This is because the source information was rarely based directly on the surveys that defined them, but rather relied on digitising existing larger scale cadastral index maps. As a consequence digital boundaries are representative of the graphical accuracy and the scale of the original maps (Effenberg and Williamson, 1997). This derivation of digital mapping from a range of paper plans introduces additional variability of spatial accuracy in different areas (Donnelly and Palmer, 2006, King, 2011 , LINZ, 2013a, Cadastre Ltd, 2003).

The inaccuracy of cadastral mapping generates confusion amongst users. This is especially the case when the mapping is overlaid with higher accurate aerial photography that clearly shows boundary mapping not spatially coincident with occupation, such as fences or buildings. (Department of Sustainability and Environment, 2011, Bennett et al., 2012, LINZ, 2013a, Opus, 2013). User concerns and confusion over misalignment then brings into doubt for the user, the validity and accuracy of the entire cadastre, not just the mapping representation of parcels or boundaries (Department of Sustainability and Environment, 2011, LINZ, 2013a). Accordingly, this can incur significant cost for the uninformed. The cadastral data is then often not fit for the variety of new purposes that cadastral mapping is being put to (LINZ, 2013a, Bennett et al., 2010, Opus, 2013). Unfortunately survey accuracy of cadastral mapping is still an aspiration yet to be realised (Bennett et al., 2010). 
The dynamic nature of the cadastre means that DCDB or cadastral mapping has to be continually updated. This is in addition to improving the mapping accuracy of the original data as entered into the DCDB. Jurisdictions apply a range of approaches to undertake improvement from simple 'rubber sheeting' processes to warp data so that it aligns with other reference points through to manual updates as surveys are submitted (Effenberg and Williamson, 1997). In the NZ case, where the cadastral surveys themselves now generate the mapping - survey data back capture projects (Rowe, 2003) and the computerised capture and management of digital survey information (Haanen et al., 2002) has also been undertaken. To move beyond just maintenance processes and improve survey accuracy across the entire cadastre is proving to be a large and expensive undertaking (Department of Sustainability and Environment, 2011, LINZ, 2013a, Cadastre Ltd, 2003). Increasingly researchers are proposing participatory GIS process and other forms of crowdsourcing as potential options for maintenance or data capture (Basiouka and Potsiou, 2012, Basiouka and Potsiou, 2014, Bennett et al., 2012, Keenja et al., 2012, McLaren, 2011, Navratil and Frank, 2013). This is especially the case where jurisdictions have very poor or non-existent cadastral mapping (Basiouka and Potsiou, 2014, Bennett et al., 2012, Navratil and Frank, 2013).

\subsection{THE NEW ZEALAND CONTEXT OF THE RESEARCH}

Every jurisdiction's cadastre is unique (refer section 2.3) and accordingly the specific context comprising of the NZ cadastre plays an important role in the research question of this thesis that examines the concept of geospatial crowdsourcing in authoritative systems. This section provides this context by introducing the recent developmental, legislative and strategic context of the NZ cadastre and how it aligns (or otherwise) with the wider cadastral literature.

\subsubsection{Defining the New Zealand Cadastre}

The NZ cadastre "supports various tenure systems including the land transfer system. Certainty of land ownership and other rights in land, coupled with the ability to locate the land on the ground..." (LINZ, 2009a). It has its roots in the English juridical cadastre, underpinned by English common law which came to NZ via colonisation and is governed by its own act of parliament, the Cadastral Survey Act 2002. 
The Cadastral Survey Act 2002 provides a simple straight forward definition for the NZ cadastre:

cadastre means all the cadastral survey data held by or for the Crown and Crown agencies.

However the Act also defines a number of key inter-related concepts and terms.

cadastral survey data-

(a) means information in or derived from cadastral surveys, and related information; and

(b) includes survey system information and tenure system information

survey-system information means information derived from, or relating to, survey observations in cadastral surveys

cadastral survey means the determination and description of the spatial extent (including boundaries) of interests under a tenure system

tenure system means a system that provides for the creation and transfer of interests in land

tenure means the kind of right or title by which land is held

As a result, definition of the cadastre becomes remarkably complex when the above additional terms and concepts are substituted into the original simple definition. Of note, the NZ cadastre does not include valuation of the parcel or its improvements (Grant et al., 2014) as is included in the FIG definition of cadastre (FIG, 1995).

\subsubsection{The Current Operational System}

The NZ cadastral system (like other cadastres in other jurisdictions) provides economic and social certainty through enabling the relationship of property rights to be confidently established and understood in the real world (Grant et al., 2014). Throughout the lifetime of the NZ cadastre, this has been achieved through a mix of regulation and by only allowing appropriately authorised or licensed people to submit data for inclusion into the cadastre.

The development of Landonline (circa 2000) was undertaken with the aim to better manage LINZ responsibilities for the NZ cadastre. Landonline was designed as an integrated cadastral and title (property rights) system to replace the paper based systems that were in place prior. 
Landonline also effectively upgraded the NZ DCDB to a multipurpose cadastre by combining digital cadastral mapping with the other traditional elements of the cadastre. The data from Landonline was made available to the geospatial community and data resellers via the bulk data supply process. This along with the massive reduction in bulk data fees to the cost of dissemination as directed by Cabinet (State Services Commission, 1997) enabled users to more readily access and use the data for purposes never originally intended. Examples include base-mapping for Local Government planning (zoning), context for as-built information of utilities (electricity, telephone, waste water etc.) (Opus, 2013) and the basis of statistical and administrative area definitions (meshblocks, territorial authorities, electoral boundaries etc).

Changes to the Landonline system and the risks associated with change, are balanced against other issues and drivers relating to formal third party data provider priorities (such as surveyors and solicitors) who provide the bulk of the funding through fees and charges (LINZ, 2011b, Cadastre Ltd, 2003). As new spatial information is acquired from the authorised data providers and integrated into Landonline, the spatial accuracy was expected to gradually improve (Haanen et al., 2002). However, over significant areas of NZ, the spatial accuracy of parcels represented in Landonline is not considered to be survey accurate (Donnelly and Palmer, 2006, Donnelly, 2009, King, 2011, LINZ, 2013a). This variability of survey accuracy in different regions occurred because only the metropolitan and major urban areas of New Zealand were upgraded through the conversion of survey observations to digital data when Landonline was built (Haanen et al., 2002, Rowe, 2003). Current LINZ processes and resources will not resolve this mapping issue in the near future, yet the national cost of not doing so is potentially significant (LINZ, 2013a).

The quality measures historically applied to the NZ cadastre are primarily applied at the beginning of the data life cycle and are focused on acceptance criteria. Incoming data is tested against a predefined standard (LINZ, 2012b) and where it does not meet the standard it is either rejected, or corrected before being accepted and integrated into the dataset (LINZ, 2009b). Once data has been accepted, it is rarely re-examined (Clouston, 2010). Standards and processes have generally become more stringent overtime as advancing survey technology has improved the accuracy and precision of survey measurements (LINZ, 2013a, LINZ, 2007). Accordingly, historic data issues are known to exist which are a mix of errors and the effects of lower standards (Manu, 2012). LINZ has a team who are charged with identifying and resolving these, in addition to improving attribute consistency and standardisation across what was once twelve largely independent survey land districts.

The challenge to improve data is all the greater as LINZ has predominately transitioned the data collection functions to the private sector via contract work or through licensed professionals (LINZ, 1996). This transfer of capability has likewise occurred in other 
jurisdictions (McLaren, 2011). The reduction in capability impacts on the ability to undertake extensive projects to enhance the maintenance of cadastral data (Manu, 2012). Unfortunately, this has occurred at a time when current, accurate and complete datasets are needed more than ever and there is a drive for increased spatial accuracy to enable different datasets to be used together by multiple users groups and stakeholders (Grant et al., 2010, Opus, 2013).

\subsubsection{New Zealand Cadastral Strategy and Legislation}

Research commissioned by LINZ in 2009 identified that approximately $\$ 480$ million worth of productivity gains per year could be obtained through improving NZ's geospatial resources (ACIL Tasman, 2009). The NZ Geospatial Office in implementing the 2011 geospatial strategy identified ten fundamental themes for geospatial data (LINZ, 2014). Subsequently work by the Geospatial Office has actively promoted SDI concepts (LINZ 2011c) and developed a framework for stewardship and custodianship of the fundamental data themes (LINZ, 2014). The framework for stewardship and custodianship focusses on enabling 5 key benefits which:

- address accountabilities and responsibilities for geospatial data

- supports administrators of geospatial data

- enables consistent data development and distribution using agreed standards

- promotes awareness of geospatial data for use or re-use

- improves sector coordination to reduce duplication

In additional, the framework for stewardship and custodianship has defined the following characteristics of a fundamental geospatial dataset, where it:

1. is geospatial; - the dataset is used in geospatial analysis or products, or is a foundational data set upon which other datasets are reliant

2. caters for the public good - the datasets is [sic] essential for public safety and wellbeing, critical for government functions, significantly contributes to economic, social cultural ore environment sustainability and enables innovation by many sectors (including government)

3. has a coverage that is appropriate for NZ land, waters or national responsibilities; or is a local/regional dataset that can be aggregated to a national dataset

4. is significant through enabling or supporting important functions, obligations or infrastructure; or derives its funding from a public source 
The NZ cadastre (along with property) is one of the ten identified fundamental data themes (LINZ, 2014). Accordingly it is a key geospatial resource however, to truly become a multipurpose cadastre new purposes and users need to be identified and embraced. For the NZ Cadastre these user groups and stakeholders are demonstrated in the following diagram (Figure 5) created from a 2009 joint working group between LINZ and the New Zealand Institute of Surveyors (NZIS) which examined the NZ survey strategic context.

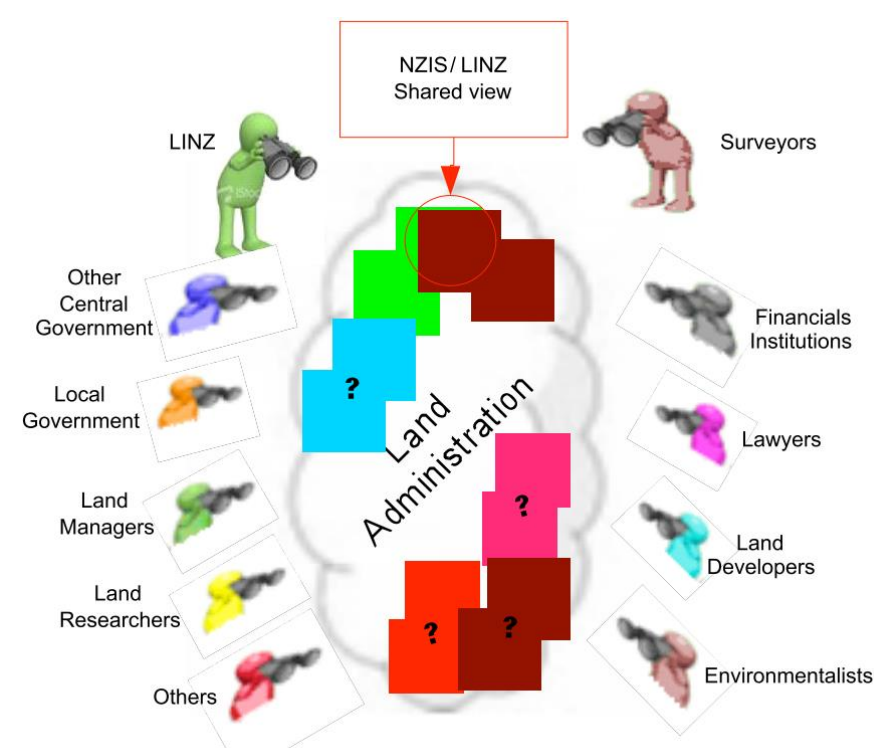

Figure 5: NZ Land Administration Users and Stakeholders (Grant et al., 2010)

With such a diverse group of stakeholders and users of cadastral information, the administrators of the NZ cadastre (LINZ) are under increased pressure to have a much greater regard for the needs of other users of the system and associated information. This is a formal requirement, amongst others, of the Surveyor General under section $7(2)$ of the Cadastral Survey Act section (2002) and is stated below:

In exercising his or her functions, the Surveyor-General must have regard to-

(a) the risks to the Crown and owners of interests in land of inaccuracies in cadastral surveys; and

(b) the efficiency and effectiveness of measures to manage risks to the accuracy of cadastral surveys; and

(c) the efficiency with which the costs and benefits of those measures will be allocated among the Crown, cadastral surveyors, current and future owners of land, and other parties; and

(d) the use of cadastral survey data for purposes other than cadastral surveys. 
To further the development of the NZ cadastral system, the Surveyor General has recently released a 10-20 year strategy - "Cadastre 2034" (Grant et al., 2014). This strategy is in line with the ideas discussed in section 2.3.2 on modernising cadastres. Key amongst the ideas is to formally acknowledge the need for inclusion of the public law rights, including the idea that their spatial accuracy may be to a lesser standard than the existing requirements for registered private rights. The distinction between these rights, responsibilities and restrictions are referred to by the terms "fundamental cadastre" and "broader cadastre" to describe the resultant components and concepts, which are defined as follows:

- the fundamental cadastre describes "the repository of cadastral survey datasets lodged with LINZ and integrated into its database, and which are regulated by the Cadastral Survey Act 2002 (CSA02)" and largely equate to the private registerable rights

- broader cadastre relates to rights responsibilities or restrictions that "are created and managed in terms of other legislation or rules of law and which are not clearly under the regulation of the CSAO2" which largely equate to the public law rights

(Grant et al., 2014)

The cadastral strategy further recognises and discusses the potential that crowdsourcing and VGI has to support and enhance the NZ cadastre, especially with regard to the broader cadastre.

\subsection{SUMMARY OF LITERATURE REVIEW}

Crowdsourcing concepts have evolved rapidly. In less than a decade, these concepts have been applied to a wide range of mainly non-authoritative geospatial datasets. As a consequence, spatial data infrastructures are evolving through increased user generated content and interaction with geospatial information. However, the same crowdsourcing concepts have not been as readily accepted for use within authoritative governmental datasets. This hesitancy is due to a reluctance to change processes, concerns about the data quality of user generated content, and the potential negative impact on the datasets credibility. The increased use and acquisition of crowdsourced information, predominately through the use and application of Web2.0 concepts, introduces new ways to develop and maintain geospatial data. Also shown is that as more users obtain geospatial tools, and as the capability of these tools evolves, that there will be a corresponding increase in the volume of 
geospatial information generated. The use of user contributed information has been identified as needing to be carefully managed to protect privacy and to ensure that information is being willingly and knowingly provided. Understanding the motivations of users to contribute information has been shown to be essential in assessing quality, potential use and the degree to which users will participate in crowdsourcing initiatives.

The cadastre, is in many jurisdictions, an established authoritative system. Where cadastres have been modernized through digitisation and the expansion of their supporting role to other systems, they have become suited to multiple purposes. Accordingly, the cadastre is increasingly a critical component in most spatial data infrastructures. Although crowdsourcing concepts have been applied to a limited extent to build missing spatial components of some cadastres, this has not been the case for the cadastres in the developed countries, where authoritative digital cadastres are already in place.

New Zealand has a robust regulatory and legislative framework for its cadastre. The NZ Cadastre in its development and management of its systems and cadastral data exhibits the necessary characteristics of a modern multipurpose cadastre. A modern multipurpose cadastre has been identified as one that better supports and incorporates public law rights in addition to the historical focus on ownership. However, NZ has only recently identified in its cadastral strategy that crowdsourcing could be a potential source of information to address a wide variety of data and maintenance issues. It is unknown how crowdsourcing could be applied or what is its potential impact on the cadastre or users? This is because very little research has been conducted on the application of crowdsourcing to modern, digital cadastres. 


\section{RESEARCH METHODOLOGY}

This chapter outlines the research design, methods and the phased data collection stages that are taken to obtain the perspectives of users, data providers and administrators. The chapter also outlines how the results were analysed.

\subsection{DESIGN OF THE RESEARCH}

To understand the potential applicability of volunteered geographic information in the NZ cadastre, this research gathered representative views of those using, producing or managing the data. Each of these three groups were expected to have slightly differing views, perspectives or perceptions as to the applicability of volunteered geographic information to the cadastre due their predominant relationship to, or use of, the cadastre.

This research followed, Dillman et al.'s (2009) approach to qualitative and quantitative surveys. Key elements considered on the basis of this preliminary research related to survey structure, managing bias, using balanced scalar questions and taking a participant perspective.

\subsubsection{Characterising Potential Participants}

Because the research focused on direct users, contributors and managers of the NZ cadastre, the dominant perspective will accordingly relate mainly to the creation, maintenance and management of data (a data lifecycle) (Figure 6).

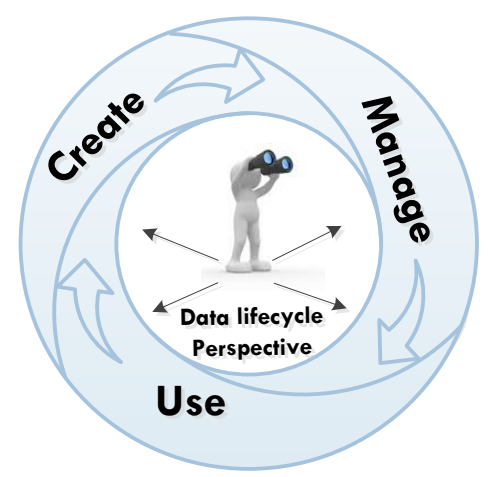

Figure 6: The user perspective of data functions in the Cadastre (Authors' own)

Focusing on users, data producers and officials consequently means that there will be very little input from the indirect users and beneficiaries of the cadastre as to how VGI or crowdsourcing could play a role in the cadastral system. The research will therefore not necessarily reflect the perspective of the wider public. The public view was not sought because it is assumed that citizens have a very limited understanding of the role of specific cadastral data elements and how they shape the ability of the cadastre to fulfill its function in underpinning property rights. 
Each of three target groups (users, administrators/officials, and producers) are comprised of more distinct subgroups based on roles or responsibilities, understanding of the data or their use of the data. Accordingly, the research design took into consideration the varying levels of knowledge and influence that the targeted participants have regarding cadastral information. Some individuals could be categorised into more than one group (Table 3).

These multi-category users were of particular interest in the design of the study as they could provide multiple perspectives (but at the risk of contributing the same opinions multiple times by being involved in several data collection stages - thereby introducing a bias if they contributed the same information more than once). Table 3 additionally demonstrates the assumptions made with regard to extent of knowledge or influence that different users groups in order to guide the choice of survey method and the level of detail in targeting participants.

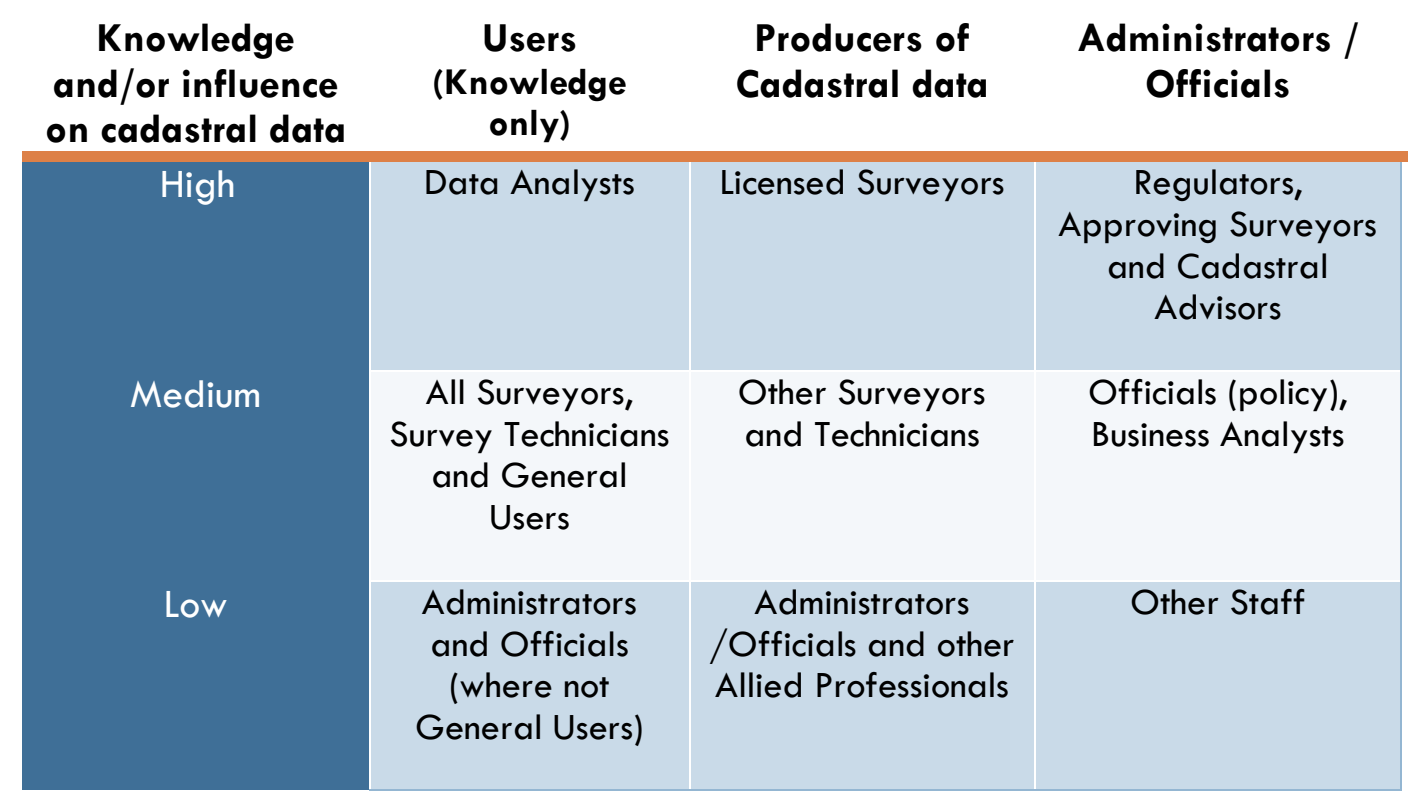

Table 3: Assumptions of the knowledge of use or understanding of the cadastre of targeted participants

\subsubsection{MANAGing Bias}

To obtain and understand participant views, perspectives or perceptions and to mitigate the bias risk of multiple response from the same individual, the research was undertaken in two phases with a mixed method approach.

A mixed methods approach provides triangulation of data where a combination of methodologies multiple views are provided to identify convergence and/or divergence of opinion. In this way, any variance reflects that of the trait and not of the method (Jick, 1979) although, this approach can create difficulties in analysing the range of data. Mixed methods 
provides increased coverage when a single mode cannot adequately cover the population of interest (Dillman et al., 2009).

Dillman et al. (2009, p 307) identifies four types of mixed mode surveys. Of these, two were applied in this research. The first method used was to apply different modes for different groups of respondents, and was used for the primary data collection phases to obtain a high coverage of the user base (quantitative survey) while seeking more detailed information from officials (qualitative interviews). Having a follow-up stage provided the second method. This collected new responses from the same group of users (surveyed in the first phase), by asking new specific questions to obtain greater detail. The information collected in this later stage (qualitative questions) could also be linked to the detailed information provided by the officials.

To reduce the risk of bias, the author's personal contacts were not directly requested to undertake the survey. Personal contacts may have however responded to one of the calls for participants and they may have independently decided to participate. The exception to this was in preliminary testing and where contacts were gatekeepers to key distribution networks, such as GIS lecturers. The author has a significant number of contacts in both the GIS and Survey industries and directly utilising these contacts may have shifted the profile of the participants more heavily towards views previously discussed or advocated by the author.

\subsubsection{Research Phases}

Users, data producers and the NZ cadastral administrators/officials (as sub categorised in Table 3) were contacted for this research. The research comprises of two phases, in three data collection stages:

- Phase 1 focused on the users and producers of cadastral Information and predominately took a quantitative approach. An anonymous online survey was chosen to elicit the information. This stage also included some open ended questions to enable participants to provide additional comments as appropriate.

- Phase 2 took a qualitative approach with two data collections stages, subsequently referred to as phases $2 a$ and $2 b$. Phase $2 a$ focused on the government officials or administrators who influence or manage the cadastre and phase $2 b$ focused on $a$ subset of those who took part in the quantitative phase of the research. Phase $2 a$ comprised structured interviews, with phase $2 b$ providing the questions from phase $2 a$ to users via an online survey tool (Qualtrics). 
Because some government officials will also be users or producers of cadastral information and may therefore also participate in the anonymous phase 1 research, significant effort was made to include a large number of users/producers in the first phase research so that any dual influence was minimised.

To inform the design of the semi-structured interviews with government officials or administrators, the findings and issues identified in the first phase were used. The high-level structure of these interviews was then provided via another online survey to the users who had indicated a willingness from the first data collection stage (phase 1) to participate in follow-up work (phase $2 b$ ). This enabled the data collection stages to be well linked by having officials consider and add their perspective to the same key issues that were identified in the first phase. From which the users could then provide greater input and consideration against the same points of interest. A check was made to ensure that none of the officials or administrators involved in the interviews (phase2a) were requested to participate in the follow up survey (phase 2b) as their opinions had already been collected. This thereby avoided any duplication of opinions, although the different data collection methods for users versus officials does raise the risk that the different groups may understand the questions subtly differently and provide varying amounts of information. A summary of the overall design of these linked phases is demonstrated in Figure 7.

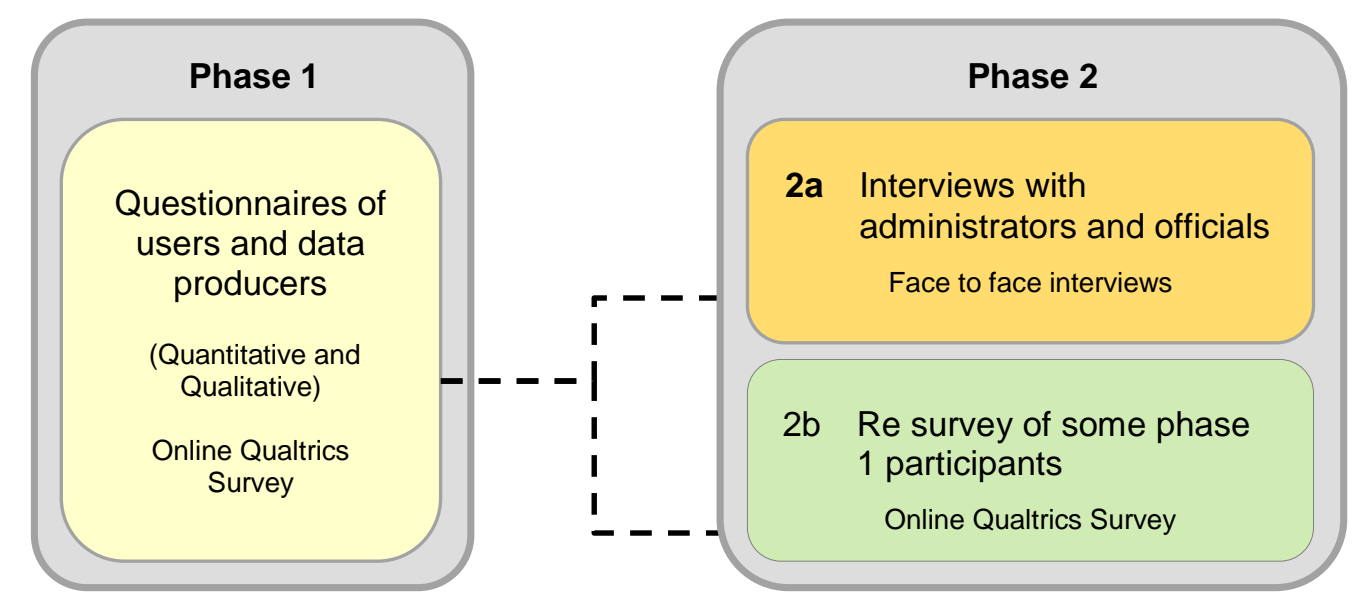

Figure 7: Structure of the research engagement with participants

\subsubsection{The Changing Environment}

Ethics approval for this research was obtained in March 2012 and in the two and a half years since, other research and public knowledge of crowdsourcing / VGI has advanced significantly and anecdotally perceptions have changed. This is reflected in personal observation of LINZ officials, work within LINZ to progress implementing the New Zealand Geospatial Strategy, responses to spatial data needs following the Canterbury earthquakes and strategy and planning work for many of its core spatial datasets such as the cadastre. 
The key environmental changes within LINZ over the last 2 years that has potentially impacted perceptions of users and especially officials with regard to the role of the cadastre and knowledge of crowdsourcing/VGI are:

- LINZ undertook formal consultation internally and externally to develop the new cadastral strategy which recognises that aspects of the cadastre could include crowdsourced information (Grant et al., 2014 p12).

- LINZ has developed an indicative business case for improving the mapping of digital parcels. This Business case included customer and economic research of users of the cadastral data and extensive discussion with several of the officials interviewed (LINZ, $2013 a)$.

- LINZ has developed a new 10 year strategy focused on the "power of where" which has reinforced to LINZ staff the value of location information and LINZ's role in building the location system (LINZ, 2013c).

- LINZ has begun to accept some VGI in its topographic data and is gaining practical experience in managing crowdsourced information (Kinzett, 2013)

- LINZ is releasing its core spatial data through the LINZ Data service, (https://data.linz.govt.nz). This is bringing LINZ closer to the end users that were previously serviced by data resellers. Accordingly there is a much greater understanding amongst LINZ staff of the issues in the data, the uses to which it is actually put and the evolving needs of users.

These environmental changes mean that many LINZ officials have been forced to face issues relating to crowdsourcing and changes to core spatial datasets. This may to some extent account for differences between them and users in relation to acceptance of crowdsourced information.

\subsection{PHASE 1 - QUANTITATIVE SURVEY}

Phase 1 aimed to understand the differences between different sub groups of users of the cadastre with respect to their knowledge of both VGI and cadastral data issues. Of particular interest was whether these differences were reflected in their opinions as to the applicability of VGI to the NZ cadastre their perceptions of cadastral data issues and the extent to which different groups may be able to contribute VGI. 


\subsubsection{TARget Participants}

This survey targeted cadastral data producers and data users of the New Zealand cadastre. The cadastral data producers are those whose work normally enters the cadastre as part of a cadastral survey dataset. Only licensed cadastral surveyors are permitted to submit cadastral survey data-sets. This set includes the licensed cadastral surveyors and those working under their directions such as other non-licensed surveyors, survey technicians or survey graduates. Undergraduate survey students and those with survey qualifications were also included in this target group, as many will in time become licensed surveyors and they often already have the skills and knowledge to effectively contribute data to the cadastre.

The secondary target group was significant users of cadastral data. Due to the spatial nature of cadastral data, the professional geographic information science (GIS) and spatial analysis community were of particular interest. This is because many individuals in this community work within central or local government and GIS consulting firms who commonly use cadastral data for base mapping purposes. Similarly to the cadastral surveying group, undergraduate students of geography or GIS were also prime candidates for inclusion in the research as they are likely to have been exposed to cadastral data and may be familiar with VGI and crowdsourcing methods and concepts.

\subsubsection{Data Collection Methods}

An online anonymous survey was chosen as the method to reach the diverse target audience. As the questionnaire was anonymous, individuals were able to contribute their personal views and understanding of the cadastre and VGI freely, without fear of being identified.

The questionnaire was made available via Qualtrics which is an internet based survey tool. Qualtrics provides for the collection of confidential responses and facilitates a range of question types, is customisable and can link multiple surveys. This linking ability was important as it enabled contact details of willing future stage participants to be recorded, whilst preserving their confidentiality with respect to their responses in the Qualtrics questionnaire. The survey was open and not restricted, so anyone was able to contribute - thus widening the survey base and enabling the questionnaire to be "forwarded" to others such as colleagues and friends. The decision to be both anonymous and open was taken in order to minimise barriers that limit participation. Barriers to participation were further lowered by advertising the link to the survey both digitally and in print targeted at the primarily audiences as detailed in section 3.2.3.

To avoid creating an unintended bias of those who took part in the survey, personal contacts were not targeted, except to assist in distributing links to the survey. 


\subsubsection{Engagement With the TARget Participants}

The New Zealand Institute of Surveyors (NZIS) was approached to assist in recruiting surveyor participants because they are the largest professional body for NZ Surveyors. NZIS published the link to the questionnaire in the June 2012 edition of their monthly newsletter. A direct posting on the private NZIS member's discussion forum then targeted the online NZIS members. At a regional level, all branch secretaries and chairs were also asked to distribute the questionnaire link to their local members. It is unknown how many of the 17 branches assisted in this way.

The professional GIS community in NZ is fragmented, with a range of vendor oriented user groups, a chapter of the Australian based Surveying and Spatial Sciences Institute (SSSI) and a diverse academic/research sector. The government sector also has a wide range of GIS users, who work in roles ranging from policy through to operational mapping and analysis. This fragmentation meant that several channels were required to obtain a cross-section of representation. To obtain participants for the survey existing mailing lists and public discussion groups were used to advertise the survey.

To reach the NZ academic sector a direct email was sent to the GIS or surveying lecturers at all NZ Universities asking them to distribute the link to other staff and students. In addition the Geospatial Office assisted by publishing a link to the questionnaire in their blog. This is expected to have assisted in reaching most GIS organisations, government agencies and territorial authorities, and will have drawn a wide range of participants especially those with an interest in geospatial policy.

LINZ is the steward and custodian of the NZ cadastre and has a number of staff involved in cadastral, policy, GIS or mapping roles. LINZ staff were requested to participate in the questionnaire via a published article about VGI that was published on the intranet and in the staff newsletter.

Unfortunately the survey was unable to be distributed to any of the newsletters or mailing lists of the SSSI through lack of response to an initial inquiry. Unfortunately the author was unaware of the online ESRI user group at the time of distributing the survey. To engage such the target audience in the absence of formal links, postings to GIS list groups and 'Linked-in' discussion groups were used to distribute the link to the survey. This focus on social media enabled a wider range of GIS users to be approached, and to also incorporate other groups with a focus on VGI. The posting to the SSSI discussion group also had the additional advantage of reaching both Australian surveyors and spatial scientists. The Australian GIS and surveying environments are very similar to NZ with GIS and survey professionals easily able to 
transfer their professional qualifications and experience between jurisdictions. Accordingly the Australian professional perspectives were expected to be of value. However due to the fragmentation of the industry GIS participation is likely to under-represent the full range of GIS users in NZ especially for potential participants who are not active on social media.

\subsubsection{SuRVey Design AND ReSPonse}

The methodology adopted for the questionnaire used a mix of quantitative and qualitative type questions as this enabled participants to further explain or qualify their answers to the quantitative type questions that provided overall statistics. The questionnaire was predominately quantitative as this:

- helped ensure that the survey did not take too long to complete

- enabled most responses to be statistically tested and compared to contrast different user/knowledge profiles

- enabled targeted questions to be directed to cadastral surveyors in relation to impacts or opportunities on their business

The majority of the questions were balanced scalar questions with four categories. The principle behind having 4 categories in most instances was that results would be able to be aggregated to two categories to show agreement/disagreement and so that participants could not 'sit on the fence' if they were unsure. A neutral category was used where participants were asked to assess the overall difference that a scenario would have to the cadastre, because not affecting the status quo was of interest. Special effort was taken to ensure that the categories, as suggested by Dillman (2009), were also conceptually equal distances apart with clear and unambiguous labels that described what was required. This meant that most questions had two categories on the negative side and two on the positive, however in other cases the category labels provided participants a means to differentiate 'steps' on an escalation scale.

The online questionnaire ran for three months from 4 July 2012 through to the 4 September 2012 . The survey comprised eight sections:

\section{Introduction}

This section outlined to the potential participants the background information to the survey and obtained their informed consent regarding their participation. 
2. Understanding Volunteered Geographical Information (VGI)

This section consisted of 8 questions. It sought to record the understanding and use of VGI along with the factors that influence or limit their potential to contribute VGI. If the participant did not know or were unsure of what VGI was, they were provided with a high-level definition. This information was provided so that they would be able to offer an opinion in later stages of the survey with regard to potential impacts of VGI.

\section{Understanding Cadastral Data}

These 8 questions focused on participants' knowledge and use of the cadastre and their views on the importance of various aspects and whether the participants had experienced issues relating to accuracy, completeness or data currency.

\section{Volunteered Cadastral Data}

The 10 questions in this section examined the potential of the participant to contribute VGI to the cadastre. It also sought information as to what the participants thought the impact of VGI would be on the cadastre if it was accepted.

\section{Profile Information}

To enable the separation of distinct groups within the participants, such as surveyors versus non surveyors, as well as identifying age profiles and geographic location (e.g. NZ resident versus overseas residents) the participants were asked 12 profiling questions .

\section{Cadastral Individual Profile Information}

To expand the general profile questions, surveying participants were asked a further 4 questions to identify the extent and expected trends associated with their personal use or generation of cadastral data.

\section{Cadastral Work Profile Information}

This section targeted those participants that owned or managed a surveying business. The section duplicated the questions from section 6 which were reframed in relation to the business. This section also included 5 additional questions as to whether the business would or could volunteer cadastral information and sought to determine what information may be available.

\section{Future stage consent}

To enable participants be approached for a future phase of research participants were asked for their consent to be re-approached. Where consent was given, the participants contact details were recorded into a separate survey specifically for this purpose. This separation of the primary survey and contact details ensured that participants phase 1 survey responses remained anonymous.

The survey is provided in Appendix 8.1: Phase 1 Survey Questionnaire 
The link to the survey was accessed 232 times. Forty two potential participants who followed the link did not proceed past the information and consent page by choosing to exit and not initiate the survey. Of the 190 survey participants, 61 did not complete the survey (i.e. approximately $1 / 3$ ) and two entries were the authors' final test responses. The results in this study are based on 127 completed responses. However only 117 unique participants responded to the questions on survey qualifications (Phase 1 questions 5.4-5.6). Accordingly 117 is the maximum response rate for analysis results that compare survey qualified participants to the non-survey qualified participants.

\subsubsection{Design AND Engagement}

The survey was carefully designed to ensure that anyone, irrespective of their knowledge or background, could effectively participate. Participants initially assessed their own knowledge of volunteered geographic information and the NZ cadastre. For participants with little professed knowledge of cadastral information, surveying, VGl or crowdsourcing, additional summary information was provided after the participant answered the initial questions. This meant that all participants were able to assess whether the implications of VGI were important and what impact VGI may have, having been supplied with information on what VGI was. To minimise the risk that a bias could be introduced where only some users have a shared understanding of the applicability of VGI to the cadastre, the additional information provided was very factual and no examples of how it could be applied to the cadastre were provided.

The strong focus on using social media as a means of recruiting participants also comes with a risk of bias. In general social media, tends to be more heavily adopted and used by younger individuals, equally $\mathrm{VGI}$ is also more easily contributed by this demographic (Basiouka \& Potsiou, 2014). The use of Linked-in discussion groups was chosen because this is more widely accepted as a 'professional networking' site unlike other sites such as Facebook which has a greater focus on friendships. It is also quite widely used in the GIS area with over 1,500 members in the SSSI members group that provided a clear target group for what is quite a fragmented industry.

\subsubsection{CONFIDENTIALITY}

To allow potential participants to make an informed choice as to whether they would participate, and to ensure transparency; the introductory section included full disclosure of the researcher's relevant personal affiliations (Appendix 8.1). In order to additionally protect the confidentiality of responses, the disclosures section therefore also emphasised that the results will not be made available in a raw format to LINZ or any other organisation such as NZIS. 
An unforeseen issue was that the Qualtrics software automatically recorded IP addresses of participants. This provides the potential to link the primary survey to the secondary survey (that collected contact details of those willing to participate in any potential future research). Accordingly, IP addresses were deleted from both surveys before any analysis was undertaken.

\subsubsection{Profile of Respondents (Phase 1 - Users)}

\section{Gender}

Over $80 \%$ of the participants were male (Table 4). A gendered analysis of the results was not undertaken as it did not fit with the research aim. The observed gender imbalance is driven by the high number of male survey qualified participants in comparison to a low number of females. This figure is in keeping with the NZIS 2014 membership salary survey where of 322 members responded, with $90.6 \%$ of them male (NZIS, 2014).

\begin{tabular}{|l|l|c|c|c|c|c|c|}
\hline \multicolumn{2}{|l|}{ What is your gender? } & $\begin{array}{c}\text { Survey } \\
\text { Qualified }\end{array}$ & $\begin{array}{c}\text { Not } \\
\text { Survey } \\
\text { Qualified }\end{array}$ & Combined & $\begin{array}{c}\text { Survey } \\
\text { Qualified }\end{array}$ & $\begin{array}{c}\text { Not } \\
\text { Survey } \\
\text { Qualified }\end{array}$ & Combined \\
\hline & Male & 65 & 25 & 90 & $59.1 \%$ & $22.7 \%$ & $81.8 \%$ \\
\cline { 2 - 9 } & Female & 10 & 10 & 20 & $9.1 \%$ & $9.1 \%$ & $18.2 \%$ \\
\cline { 2 - 9 } & Total & 75 & 35 & 110 & $68.2 \%$ & $31.8 \%$ & $100.0 \%$ \\
\hline
\end{tabular}

Table 4: Cross tabulation of the gender profile of phase 1 survey participants

\section{Location}

The regional profile showed that over $80 \%$ of respondents were New Zealand based. In addition approximately a little over two thirds are survey qualified. This means that the risk of a New Zealand based survey being overwhelmed by offshore based GIS professionals due to the difficulties in engaging NZ based professional did not eventuate (refer 3.2.3).

\begin{tabular}{|l|l|c|c|c|c|c|c|}
\hline \multicolumn{2}{|l|}{ Where do you live? } & $\begin{array}{c}\text { Survey } \\
\text { Qualified }\end{array}$ & $\begin{array}{c}\text { Not } \\
\text { Survey } \\
\text { Qualified }\end{array}$ & Combined & $\begin{array}{c}\text { Survey } \\
\text { Qualified } \\
(n=76)\end{array}$ & $\begin{array}{c}\text { Not } \\
\text { Survey } \\
\text { Qualified } \\
(n=35)\end{array}$ & $\begin{array}{c}\text { Combined } \\
(n=111)\end{array}$ \\
\hline & NZ & 64 & 29 & 93 & $57.7 \%$ & $26.1 \%$ & $83.8 \%$ \\
\cline { 2 - 9 } & Australia & 7 & 4 & 11 & $6.3 \%$ & $3.6 \%$ & $9.9 \%$ \\
\cline { 2 - 9 } & Other & 5 & 2 & 7 & $4.5 \%$ & $1.8 \%$ & $6.3 \%$ \\
\hline & Total & 76 & 35 & 111 & $68.5 \%$ & $31.5 \%$ & $100.0 \%$ \\
\hline
\end{tabular}

Table 5: Cross tabulation of the location profile of phase 1 survey participants 


\section{Age}

The survey reflected a good range of participants at various career stages. The profile of survey participants in this survey shows a similar weighting to the older age profile with the median age category for those with survey training being 35-50 years (Figure 8 ). The median age of those without survey training is non-survey qualified 18-35. Of this 'young professionals' category the survey trained participants were only $28 \%$ of their subgroup in contrast to the $51 \%$ of the non-survey qualified subgroup.

To gain an understanding of whether this reflects the cadastral surveyors as a wider group, results were compared against the 2014 NZIS members survey (NZIS, 2014). The age brackets were different making direct comparison impossible. To enable a comparison median age, the average of each age bracket, for both surveys was determined and then used to create an estimated age average. This research has an estimated average age of 41 years and the NZIS survey 47 years.

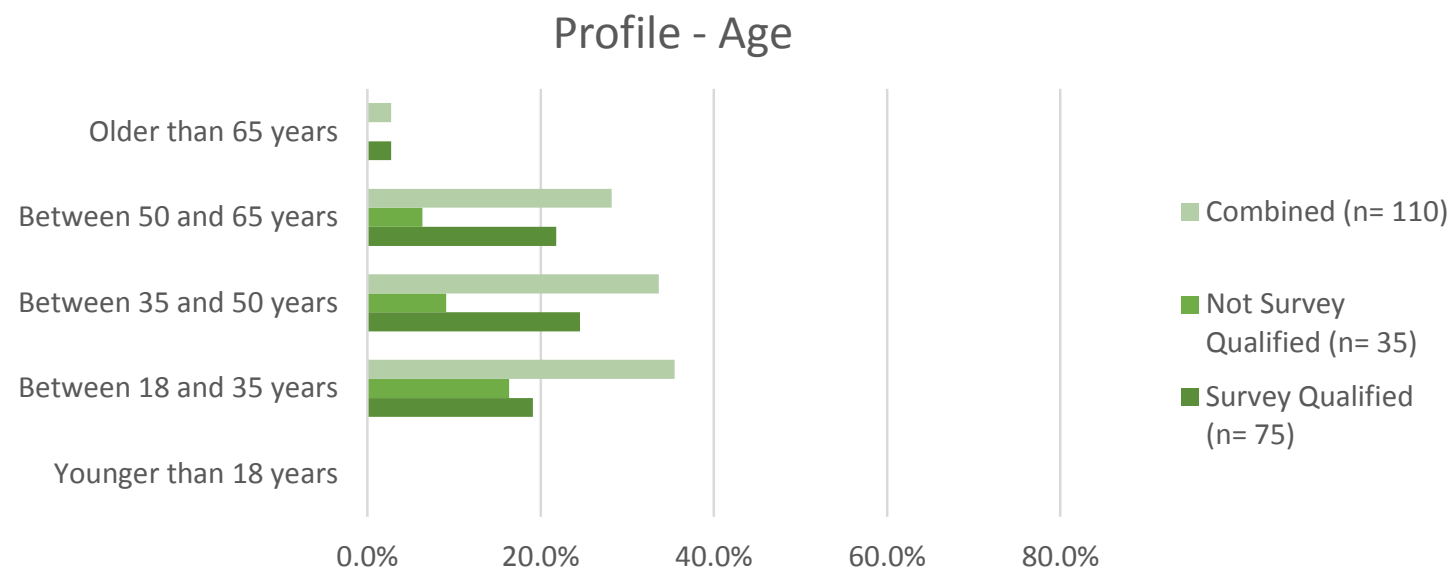

Figure 8: Age profile of phase 1 survey participants

\section{Employment Status}

The employment question indicates over $80 \%$ of participants are in the workforce (Figure 9). Given that only three participants were older than 65 (Figure 8 ), it is likely that the majority of the not-employed are students as they were specifically targeted for participation.

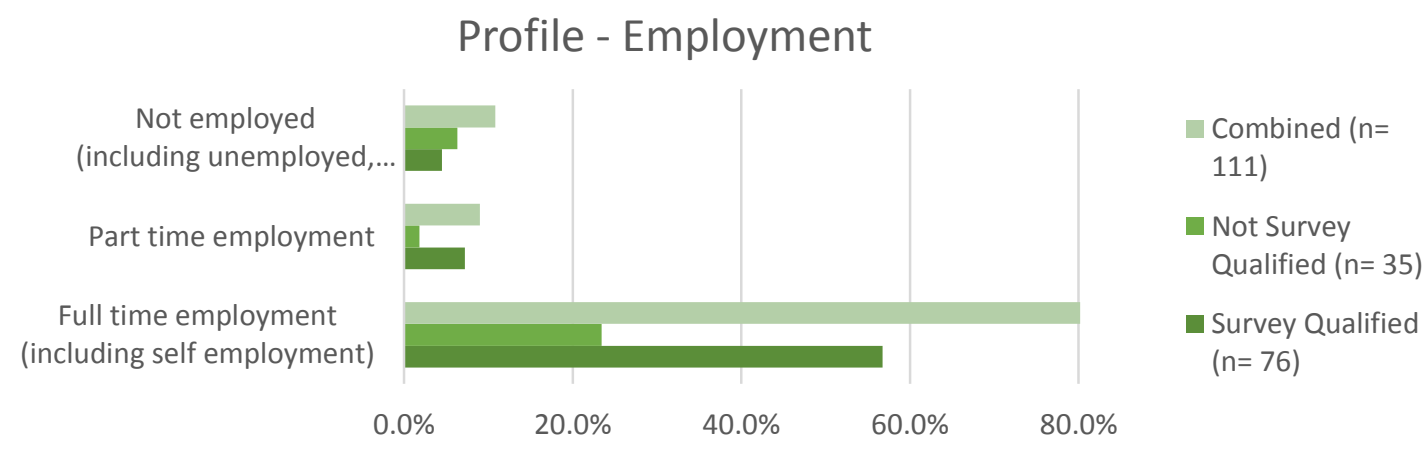

Figure 9: Employment profile of phase 1 survey participants 


\subsection{PHASE 2 - THE QUALITATIVE INTERVIEWS AND ONLINE SURVEY}

The second phase was designed to gauge the government and user perspective on the applicability of VGI to the cadastre by:

- Developing an understanding of what changes (and to what extent) are required to officials, users and existing producers' perceptions of VGI to enable the use of VG.

- Exploring how these perceptions and issues related to $\mathrm{VGI}$ can be mitigated so that VGI can be applied to government data collection and maintenance processes.

- Assessing whether the perceptions of VGI and assumed risks of incorporating VGI in authoritative datasets are valid.

This phase of the research as discussed in section 3.1.3 was undertaken in in two data collections stages. The research structure (an interview) for phase $2 a$ was then reused in phase $2 b$, but in an online survey form.

\subsubsection{Research Structure}

Interviews were semi-structured to enable flexibility to discuss related ideas with participants if they arose and to focus on the participant's views, knowledge and role within LINZ. Questions were tested with a single colleague for general feedback and to provide an estimate of time required for the formal interviews.

The questions were structured into groups that followed the phase 1 survey so that full coverage and compatibly were assured, which lowered the risk of not fully pre-testing the interview. The semi structured element was comprised of a series of open ended questions within these seven primary sections of the interview. Each section had a specific lead question that provided the overall structure and guided the direction of interview.

The seven sections of the interview were as follows:

1. Introduction and consent

The introductory section initiated the interview, ensured that the interviewee had read and understood the introductory information and had signed the consent form. Permission was also sought to record the interview. 
2. Understanding the participant

These questions focused on the participant's role in order to gain an understanding of their responsibilities and relationship to the cadastre. The questions also explored the relationship to other roles and functions with LINZ.

3. Understanding VGI

This section of the interview sought to understand the participant's knowledge of volunteered geographic information, how that had changed over time and whether they had heard of facilitated-VGI. Given their current understanding, the section sought to discover whether the participant supported the concept of VGI being incorporated into the cadastre. For this aspect, participants were expressly given the option to ensure that this opinion could remain confidential if they wished.

4. The potential of VGI for the cadastre

The primary purpose of this section was to gather the interviewees' opinions about how VGI could be used in the cadastre and what values VGI would provide. Further questions were set to have interviewees consider the long or short-term differences, and what would be the best use of VGI for the cadastre.

\section{Concerns about VGI with regard to the cadastre}

To balance the previous section, this section focused on whether there was a negative side to the use of VGI in the cadastre. The section focused concerns, limitations and risks along with any potential mitigations.

6. The impact of VGI on people

Assuming that $\mathrm{VGl}$ in some form was incorporated into the cadastre, this section focused on the potential changes to skills, and roles required to collect VGI and then manage that information.

7. Integrating $\mathrm{VGI}$ and managing the cadastre

To discover the extent to which VGI should be integrated (if at all) within the cadastre, this section sought to ascertain the impact that incorporating VGI would have on LINZ. Of particular interest was the management and continuing provision of the cadastral data to users. 


\subsubsection{Research Engagement - Officials (Phase 2A)}

As noted previously, the management of the cadastre is undertaken by LINZ and at the time of the interviews, this function was shared between the statutory regulator (the Surveyor General) and the customer services business group. The customer services business group is responsible for operating the computer system known as 'Landonline'; survey data approval and integration processes. Accordingly, managers, administrators and officials in LINZ that hold roles that have specific cadastral responsibilities or delegations were the primary target participants. A secondary group was those who held strategic or influencing roles such as policy and technical support. To simplify the language used, the term 'officials' refers to this entire group due to its common usage by users outside of government. Where officials are specifically referred to, their official role is stated to avoid confusion, for example, the Surveyor General, Deputy Surveyor General, or the Chief Executive. No distinction is made for staff that may be acting under delegation from the above officials.

Face to face interviews were deemed the most efficient and effective method to capture both the diverse range of roles and to facilitate the identification of unexpected avenues related to the research topic. Interviews were recorded and transcribed. The interviews covered two specialist areas, VGI and the cadastre. This semi-structured interview design enabled all interviews to cover the full scope of the survey, despite the variability of interviewees' knowledge, understanding and experience of the topic areas. To ensure that interviews were able to participate as fully as possible and provide considered responses to questions, a short crowdsourcing video clip (crowdsourcing.org, 2012) was distributed.

For research purposes, it was important that free and frank opinions from all staff could be obtained, yet the participants contributed as part of their role within LINZ and permission was obtained on the understanding that this information would be shared afterwards with LINZ. LINZ staff therefore had to balance the rights, duties and obligations that come with their roles against engaging in the research. To facilitate engagement and support from the target audience, the Chief Executive of LINZ was successfully approached for permission to interview staff. Following which a short list of roles and functions was prepared, and staff or officials approached directly to ascertain their willingness to participate in the research. Those that were willing to be involved were then sent copies of the information sheet and a participation approval form and a meeting was scheduled for the interview to take place. Because key roles and identities of officials requested to participate are well known, the design of this phase of the research had to consider the issue and management of attributing comments to individuals. Similarly to the first phase research a full set of disclosures was provided to interviewees to ensure that they understood that although LINZ had financially supported and approved their involvement in this research, the research was independent. 
To accommodate any conflicting needs, participants were advised in advance that the transcript of the interview would be available for LINZ and therefore comments made would not be confidential. However this transcript would only be available after they had approved the content. Participants could withdraw from the survey at any time up until their transcript was approved, and if they did so the audio and transcript would be destroyed. Research interviewees were given the opportunity to review and edit the transcript prior to approval of the transcript for use in the research. The intention was to lower the risk of official not approving their transcript because of something confidential, a misinterpreted of a question or an answer would be in conflict with expectations of their role, by allowing correction. This decision to enable edits did carry a risk that pertinent comments relating to the research would be unnecessarily removed. Loss of some comments was considered to outweigh the risk of losing all the comments from key individuals through lack of transcript approval. To mitigate loss of a few pertinent comments via this edit process, interviewees were additionally able to separate comments that would be treated confidentially, such as those that were separate to their role, or that they would not wish to be associated with their role. These confidential comments would then be moved to a separate aggregated/non-attributable transcript which would preserve their use and be included in phase $2 \mathrm{~b}$. The ability to edit, also had the potential for a positive effect of improving ambiguous statements and the addition of new and more considered responses.

\subsubsection{Data Collection - Officials (Phase 2a)}

The interviews took place between March 2013 and August 2013. Thirteen LINZ staff members were approached to participate. Representation was from across the LINZ including the Office of the Surveyor General, Policy, Landonline and Geospatial services, Survey and Title operations and the Geospatial office. Eleven interviews were conducted with only one interviewee not returning/approving their transcript. This interview was therefore excluded and accordingly not analysed.

LINZ officials and staff interviewed were

- Dr Don Grant - Surveyor General

- Anselm Haanen - Deputy Surveyor General

- Di Anorpong - Principal Policy Analyst - Geospatial

- Trent Gulliver - Auditing Surveyor

- Lyndon Telfer - Principal Cadastral Surveyor

- Scott Warman - Survey and Title Operations Business Support Manager

- Graeme Blick - Chief Geodesist and Manager of Topography

- Nic Donnelly - Cadastral Adjustment specialist

- Ron Munro - Manager Landonline and Geospatial Services

- Colleen Manu - Manager Data Quality (Landonline)

- Mike Judd - Fundamental data leader (New Zealand Geospatial Office) 
All interviews were fully transcribed, except for any conversational 'stuttering' where sentences were started and restarted. Sentence fillers such as "umms and ahhs" were also not transcribed. Care was taken to retain short affirmations or dissentions such as "yeah", and "yep" along with expressions of uncertainty such as "errr".

A copy of the raw transcript was provided to the interviewees to review and correct where they felt it was necessary. No official took up the opportunity to redact any of their comments. Of those that edited their transcripts, none deleted discussion points and all edits were focused on cleaning up grammar, syntax or adding additional comments and information for increased clarity.

Two transcriptions were quite hard to interpret due to very long sentences or multiple unfinished sentences. A "tracked changes version" was supplied (in addition to the original transcription) in these two instances in order to facilitate the interviewee editing phase. This additional version simplified the transcription to what the researcher understood the interviewee was trying to say. Interviewees were then able to accept the researchers edit, or choose to revert the text to what was originally said.

\subsection{4 (Re)Engagement of Users and Data Collection (Phase 2B)}

The second data collection stage in phase 2 of the research sought to better understand the views, perspectives and perceptions of the users or data producers and to ensure strong alignment with the interviews of the government staff and officials.

Qualtrics survey software was again used. This data collection stage followed a similar structure to the $1^{\text {st }}$ data collection stage (interviews of officials) but re-targeted users and producers of cadastral data. The 14 participants in phase $2 b$ were a subsection of participants to the survey undertaken in the first phase who had self-identified as being willing to engage in future research.

Phase $2 \mathrm{~b}$ provided these repeat participants of phase 1 (data users/producers) the ability to participate in the extended scope of the research provided by phase 2. By using the same questions posed to officials albeit by online survey capture, participant responses from both data collections stages (phase $2 a$ and $2 b$ ) were able to be analysed together and compared. 


\section{4. $\quad$ ANALYSIS METHODS FOR THE RESEARCH}

\subsubsection{Classification of Research Participants}

To enable sub groups within the participants to be differentiated and referenced for specific statements the following conventions and terminology is used:

- User:

An undefined user (or surveyor) of the cadastre that did not participate in this research.

- Licensed Cadastral Surveyors (LCS):

A person licensed, or deemed to be licensed, under part 3 of the Cadastral Survey Act (2002)

- Participant:

An individual who responded to any of the three data collection stages. This term is generic across all phases except where refined by the phase in which the information is gathered, or the type of user. For example survey qualified participant, phase 1 participant

- Survey qualified:

A phase 1 participant that indicated they had cadastral survey qualifications, cadastral training or had been/is an LCS

- Non-survey qualified:

A phase 1 participant that is not 'survey qualified'

- $\quad$ Produsers: (see 2.1.5)

Phase 1 or phase $2 \mathrm{~b}$ participants. This subgroup of participants are comprised of both the 'survey qualified' and the 'user' participants. In the case of phase $2 b$ participants the differentiation between being survey qualified or not, is unknown.

- Officials:

Participants from phase 2a. As noted in section 3.3.2, All LINZ staff who participated in the research are referred to as officials and no distinction is made from the legislated roles of Surveyor General, Deputy Surveyor General, and Chief Executive. 


\subsubsection{Analysis of QuANTITATIVE Responses}

The Qualtrics survey package has built in analysis functions and provides simple statistics on the responses including the minimum, maximum, and mean values as well as the variance, standard deviation and total number of responses. Qualtrics also has the ability to undertake filters, cross tabulations and associated statistical tests such $T$ and chi-square tests. The statistics, graphs and results produced by Qualtrics were used to identify and develop the key elements for the phase 2 questions.

Cross tabulations of the phase 1 quantitative data were used to see if there were clear differences between users who were survey qualified and those who were not. Similarly, whether respondents professed knowledge of VGI should be accounted for in analyzing specific questions. Graphs and charts associated with from phase 1 questions relate to the percentage of responses by participants. A percentage basis has been used because not all questions were mandatory, and therefore the number of participants varies slightly. Reducing the results to a percentage enables the results to be more easily compared with other questions.

Section 7, targeted participants identified as owning or managing a surveying business. This section is not reported on as very little additional information was added to that in section 6 on which the section was based.

\subsubsection{Analysis of Qualitative Responses}

Because the primary purpose of the research was to identify applicability for VGI to the cadastre, the most important information was contained within free form responses and the transcripts interview of officials. For the first data collection stage in phase $2 a$, some structure was imposed through set questions in the online surveys and through following a pre-defined interview template. Individuals though had wide ranging interests and experiences and consequently direct comparison of the free form responses between participants was not possible as responses to question often resulted in covering completely different topics to that of other participants.

A key reason for using a mixed methods approach is to enable similar information to be obtained, then compared and contrasted from different groups of research participants through a process known as data triangulation (Jick, 1979). This was expected to enable the convergence of opinion from different user groups to be identified. To aggregate and categorise all the textual information for this purpose, the Weft QDA qualitative analysis tool (Fenton, 2006) was used. Each transcript and all the freeform questions from the Qualtrics 
surveys (phases 1 and $2 b$ ) were imported into Weft QDA. Where responses held a point of interest, the response was highlighted and category made, if the category had not already been defined. Responses that contained more than one idea or concept were tagged against multiple categories. For example, a discussion on cost savings from quality assurance would be categorised as both "Cost Saving" and "QA". As the list of categories grew, the categories were rearranged so that sub categories could be formed and trends, commonalities or differences identified between responses and/or the response source. 


\section{RESULTS AND PRELIMINARY ANALYSIS}

This chapter presents the results from all three data collection stages. The headings structure of this chapter is based on the categories created from the aggregation of points of interest in analyzing phase 2 (the qualitative data collection) in conjunction with free form responses from phase 1. The exception to this is section 4.1 which focuses of phase 1 participants and their understanding $\mathrm{VGI}$ and Cadastre. The remainder of the quantitative results (phasel) is presented where it relates to results from the qualitative phases ( $2 a$ and $2 b$ ). Preliminary discussion is also presented in this chapter to connect the results from each of the phases. The chapter concludes with a summary of results.

\subsection{UNDERSTANDING OF THE RESEARCH SCOPE}

For officials (including others not participating in this research) and administrators to use crowdsourced geographic information to help maintain and develop the cadastre, greater understanding of the characteristics of different crowds and their capabilities is required. Knowledge of who might contribute crowdsourced information to the cadastre is important so that officials ensure that appropriate support is provided to contributors and that the material sourced from varying crowds is relevant and enhances the cadastre.

\subsubsection{The RESEARCh Question.}

To adequately answer the research question, participants' knowledge of what VGI is was important. With a strong understanding of VGI participants views on integrating or using VGI in the cadastre would be more meaningful. Figure 10 below shows that a clear majority of produsers, just over $60 \%$, indicated that they thought they knew the meaning of VGl; with just $10 \%$ of participants not knowing.

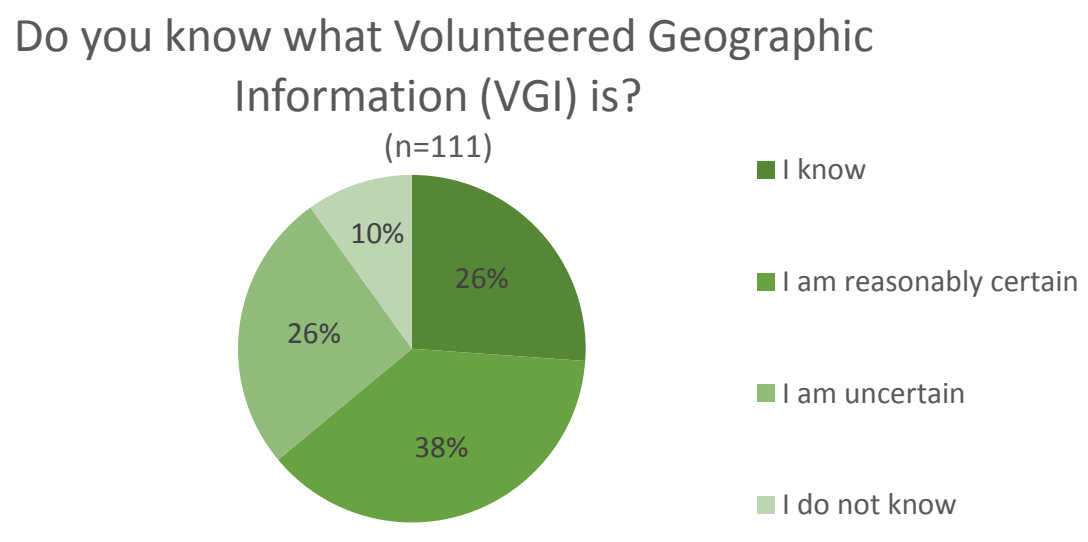

Figure 10: Produsers self-assessment as to whether they know what VGI means 
However given the wide range of comments regarding cadastral information in latter stages of the first research phase, it is clear that most produsers actually equate the use of low accuracy GPS units as being virtually synonymous with VGI. In analysing the open ended questions from all phases, most produsers did not differentiate between volunteered geographic information and more generic crowdsourced concepts. Consequently the analysis and categorisation of responses in this research also does not differentiate between VGI and crowdsourcing and the two terms are used synonymously in this research. Because crowdsourcing concepts are discussed, "crowdsourcing" terminology (or tense variations) are used in preference to that of VGI where appropriate. The exception, is in the original questions, participant response and any associated results, tables or figures where VGI is used.

\subsubsection{Participant Understanding OF CrowdSOURCING}

Phase 1 participants were asked whether they had used or encountered volunteered geographic information as shown in Figure 11. Forty five percent of all produsers had either used or encountered VGI in some form, with the remainder certain that they had not, or were unaware of having done so.

By splitting the information according to whether the produsers are survey qualified or not, survey qualified users actual awareness of VGI (or use of it), was much less than that of the non-survey qualified, i.e. only $37 \%$ of survey qualified users had used or encountered VGI in comparison to $67 \%$ of the non-survey qualified (a clear majority). This was surprising in that licensed cadastral surveyors are able to submit "survey information only datasets" for nonboundary marks and related vectors (LINZ, $2011 \mathrm{~b}$ ). This dataset is commonly used to submit additional information for the benefit of the cadastre. It would appear that surveyors do not normally equate this as being $V G I$.

Have users used or encountered VGI?

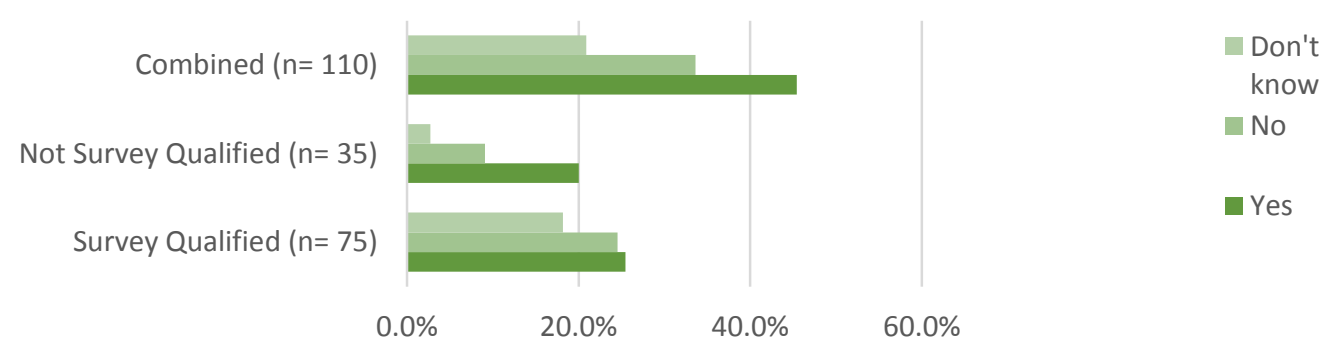

Figure 11: Have phase 1 participants used or encountered VGI 
As shown in Figure 12, only $22 \%$ of survey qualified users contributed VGI. This was approximately half of those that had used VGI (1 1 out of 22 non-survey qualified users and 13 of 26 survey qualified users). Eleven percent of contributors were unsure if they had contributed. The apparent confusion exhibited by the survey trained participants where five sixths of them (10/12) were 'unsure' if they had contributed VGI could potentially lie in their interpretation or understanding of VGI.

\section{Have users contributed VGI?}

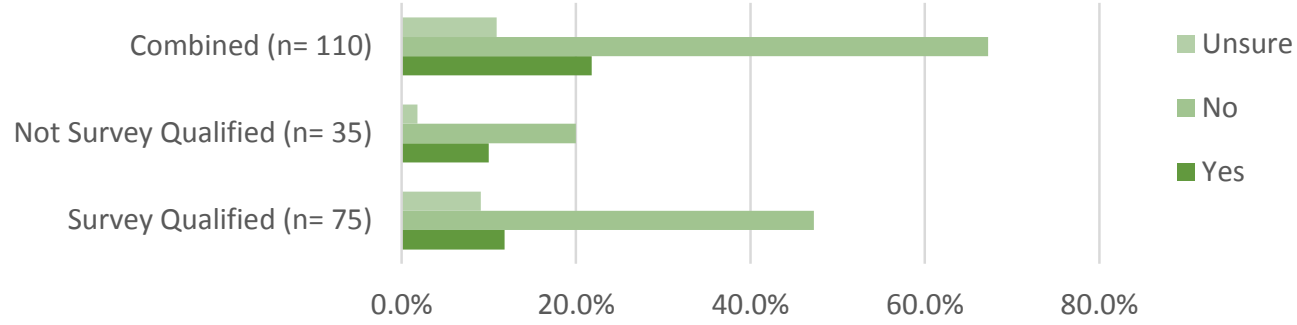

Figure 12: Have phase 1 participants contributed VGI

With just over $20 \%$ of all survey qualified users having already contributed VGI, there may be a potential base should a role for VGI be established in the NZ cadastre. Produsers have a conceptual idea of what volunteered geographic information is, but do not easily recognise where, or how it is being applied.

\subsubsection{Participant Understanding of the Cadastre}

There was very little difference between the survey and non-survey qualified produser groups with regard to whether they thought that they knew what the cadastre is (Figure 13).

\section{Do users know what the New Zealand cadastre is?}

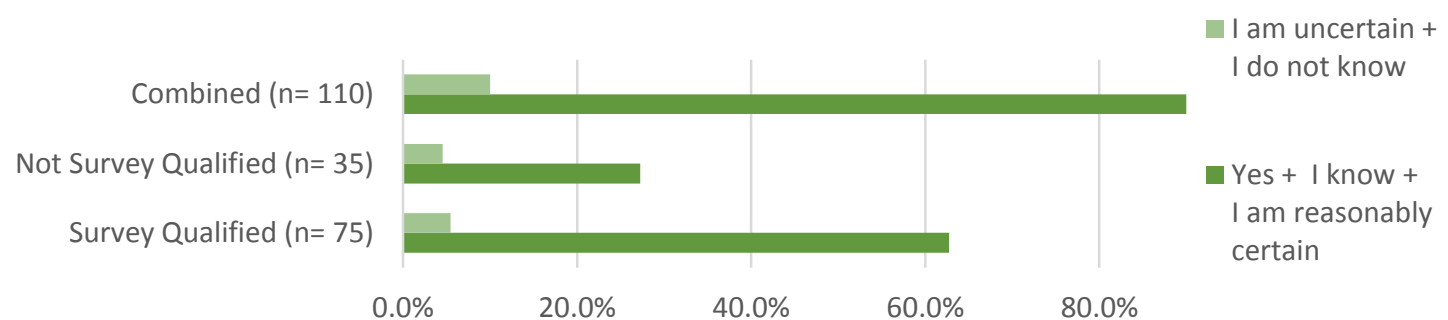

Figure 13: How well do produsers think they know what the NZ cadastre is? 
However, as shown in Figure 14, the non-survey users have less understanding of the scope of the cadastre than their survey qualified counterparts. Given that both produser subgroups use and/or contribute to, the cadastre for different purposes, such a marked difference is of note.

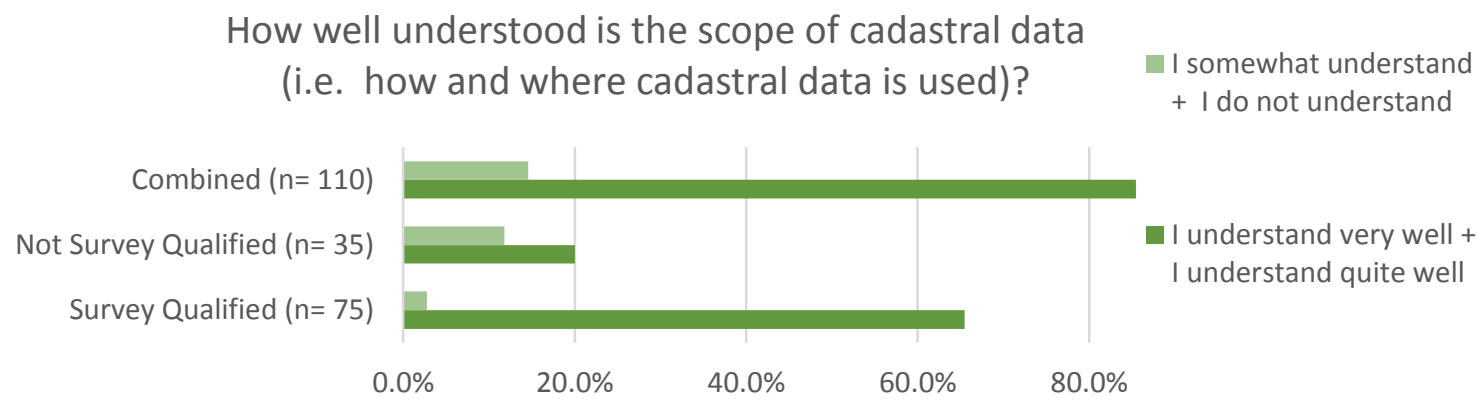

Figure 14: How well do produsers think they understand the scope of cadastral data use?

Phase 1 sought to understand the user perception of the importance of core components of the cadastre. The actual components of the cadastre are extremely diverse as reflected in the data model of Landonline bulk data extract (BDE) which groups data tables into seven distinct data sets. (LINZ, 2012a). The BDE data model (LINZ, 2012a), in conjunction with the 2010 rules for cadastral survey dictates the division of data on the cadastral survey dataset (CSD) and title plans (LINZ, 2012b). This survey/title division formed the basis for the separation and grouping of cadastral components for the questions asked of participants regarding the important aspects of the cadastre. The authoritativeness of the cadastre was added to this list. Authoritativeness was considered to be the most important (Figure 15).

\section{The Important elements of the Cadastre}

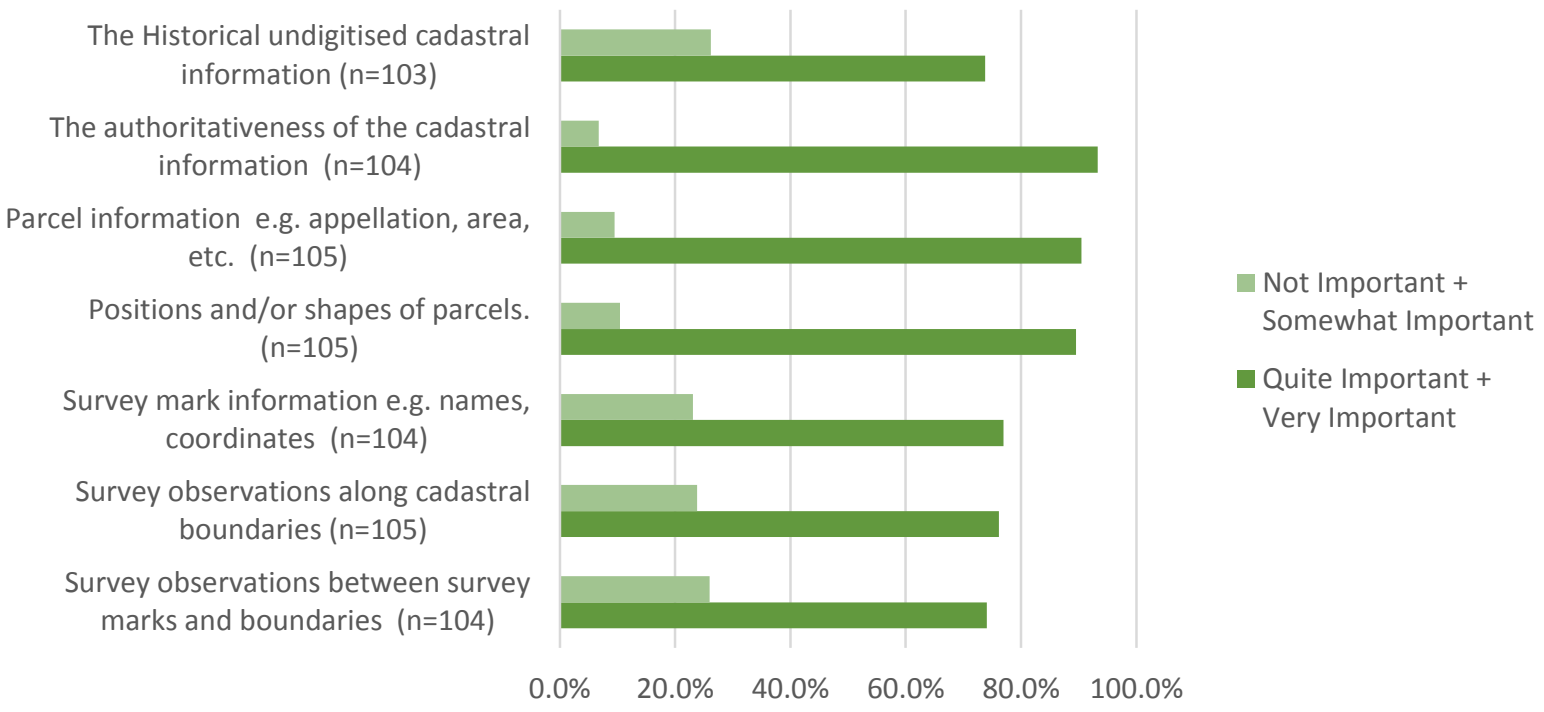

Figure 15: Produser perceptions of how important elements of the cadastre are. 
Produsers indicated that all of the cadastral elements listed were important. Because there is a very high proportion of survey qualified participants amongst the produsers, understanding whether the strong indication of importance was due to sample size, the data was analysed at a more detailed level by separating the survey qualified from the non-survey qualified. These results are shown in Figure 16 and Figure 17.

The survey qualified participants were unanimous in assigning importance to the authoritativeness of the cadastre. No survey qualified participants indicated that it was not important or only somewhat important (Figure 16). Existing information that has not yet been digitised was the least important data to those with survey qualifications. The status of this data may be because this is the only component that is not readily available outside of Landonline and not all participants will have access to it.

\section{Important elements of the cadastre Survey Qualified respondants}

$(n=73)$

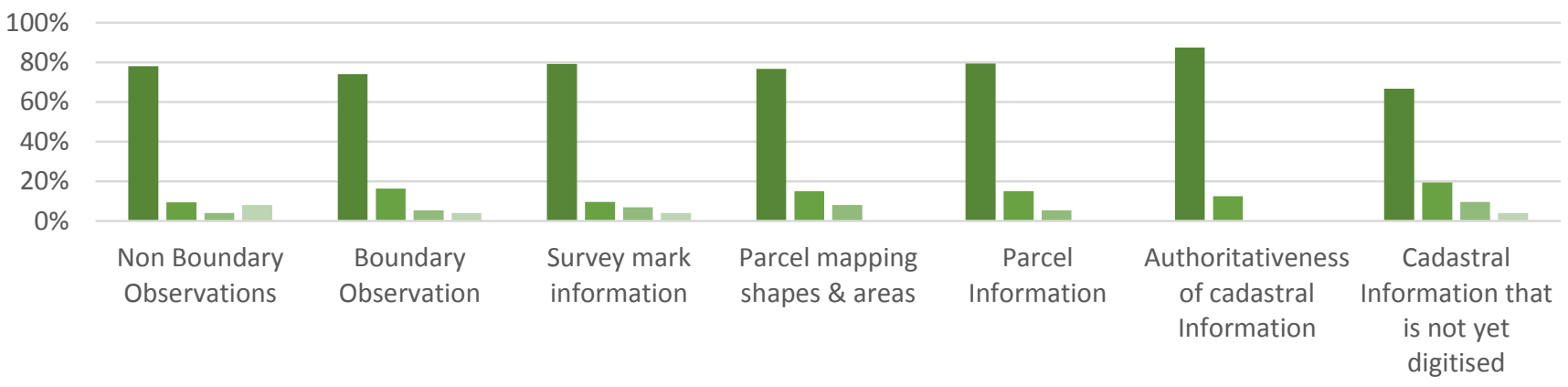

- Very Important $\quad$ Quite Important $\quad$ Somewhat Important $\quad$ Not Important

Figure 16: Important elements of the cadastre - survey qualified participants

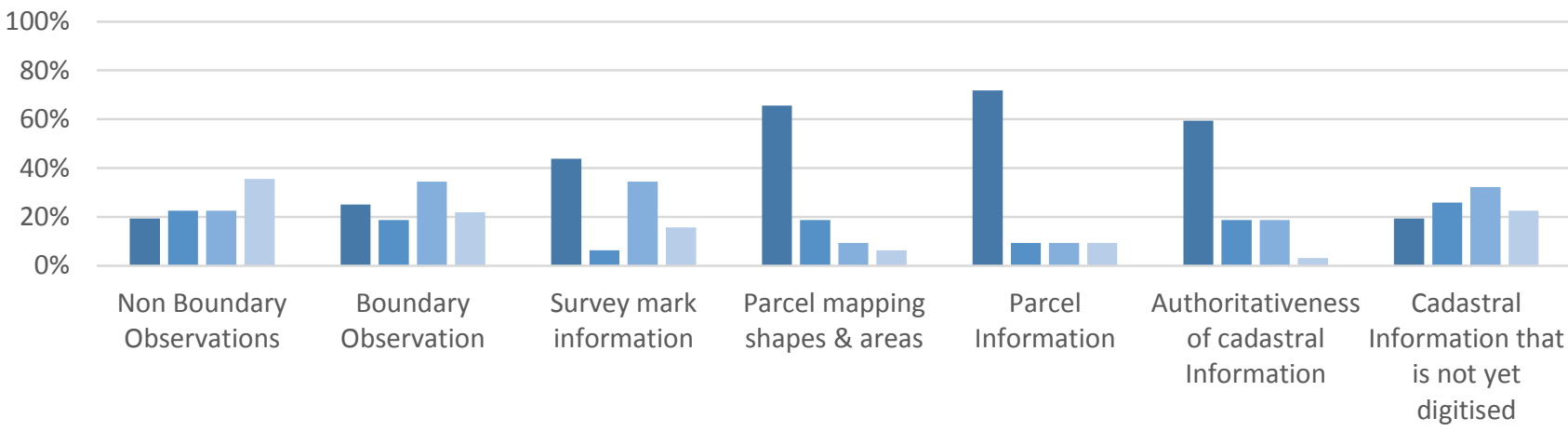

- Very Important $\quad$ Quite Important $\quad$ Somewhat Important $\quad$ Not Important

Figure 17: Important elements of the cadastre - non-survey qualified participants 
The non-survey qualified participants identified that aspects relating to parcels as the most important, with the positions or shapes of the cadastral parcel data being the most important, followed by the parcel information such as ID's and appellations. The importance of parcel information may be because these are key elements that analysts need to join parcel data to other authoritative databases, such as Rating and Valuation. Non-survey qualified participants also highly rated the authoritativeness of the cadastre. Overall however the produsers without survey qualifications are less in agreement as to the level of importance of cadastral data, especially the survey specific elements that create the information that they were more interested in (parcels). Accordingly it can be inferred that phase 1 participants who answered these questions mainly based on their data familiarity and use.

\subsubsection{Participant Understanding of Authoritativeness}

In addition to the high rating assigned to authoritativeness, throughout the free-form questions in the produser survey (phase 1) and then in the interviews with officials and administrators (phase 2a), issues and concerns raised by participants were regularly centered on the concept of authoritativeness. However, the context for 'authoritativeness' generally differed between those with a survey background or a strong understanding of cadastral systems, and other users or officials with a less sophisticated understanding of the breadth and scope of the cadastre (Figure 13 and Figure 14). Participants with survey qualifications, were largely concerned with the effect or impact that crowdsourced data would have any information forming part of an approved cadastral survey data set, or which influenced boundary definition. Non-survey qualified participants inferred that availability of the information (by LINZ) made it authoritative. Accordingly these produsers focused on the cadastre as visualised via mapping, with a particularly interest in inaccurately mapped digital parcels (Figure 16 and Figure 17), rather than how the data supports the definition and placement of individual cadastral marks. If crowdsourcing is introduced to the cadastre, non-survey qualified participants will be more interested in:

- differentiating the authoritative information from the new crowdsourced information (i.e. 'non-authoritative')

- contributing information that improves the positional mapping accuracy of digital parcels

Being able to see the extents of other rights (completeness of the parcel fabric) was also of interest. 


\subsection{USER PARTICIPATION IN VGI}

\subsubsection{Produsers' Capability to Contribute}

Produsers assessed their own capability to provide a range of survey information or services with respect to data acquisition. The profile and experience of the survey qualified and nonqualified subgroups was found to be very different (Figure 18 and Figure 19).

\section{Self assessed capability in providing data/services}

Survey Qualified respondants

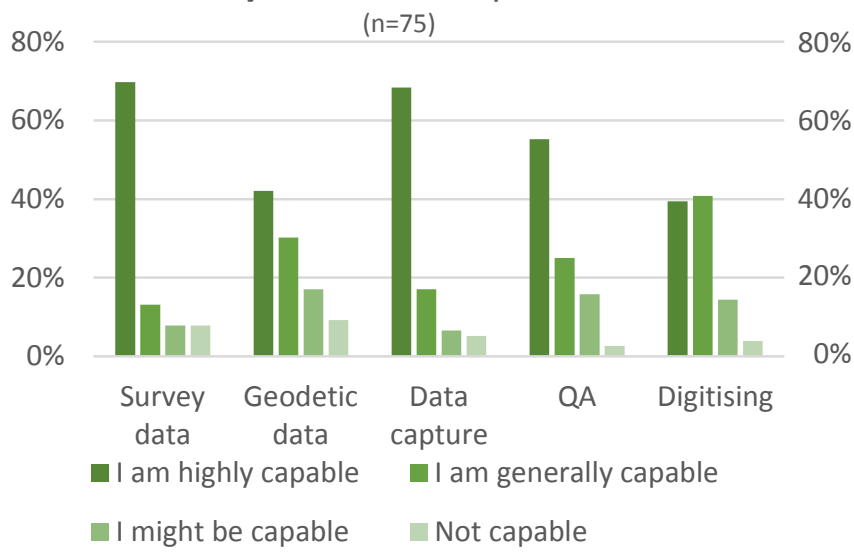

\section{Self assessed capability in providing data/services}

Not Survey Qualified respondants $(n=35)$

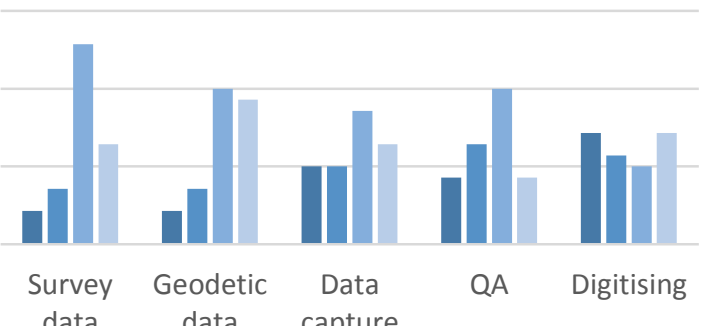

- I am highly capable I am generally capable

I might be capable $\quad$ Not capable
Figure 18: Survey qualified participants' self-assessed capability to contribute data or services
Figure 19: Non-survey qualified participants' selfassessed capability to contribute data or services

Survey qualified participants considered themselves highly capable in three of the five service options. By merging the four categories of capability to generate a capable/not capable perspective, the survey qualified participants also considered themselves to be capable in the remaining two service options. By contrast, participants without survey qualifications only considered themselves capable in the provision of digitising services category and even then only by a slim majority (51\%) (Table 6). Of note, is that section 4.5.1 shows that produsers consider that digitising information will harm the cadastre. With over $70 \%$ of all survey qualified participants considering themselves capable in all categories there is a clear difference in perceived capability of the two sub groups to provide cadastral data or services.

\begin{tabular}{|c|c|c|c|c|c|c|c|c|c|c|}
\hline \multirow{2}{*}{$\begin{array}{l}\text { How capable are you } \\
\text { to provide the } \\
\text { following data } \\
\text { services? }\end{array}$} & \multicolumn{2}{|c|}{$\begin{array}{l}\text { Providing new } \\
\text { survey data to } \\
\text { cadastral } \\
\text { standards }\end{array}$} & \multicolumn{2}{|c|}{$\begin{array}{l}\text { Providing new } \\
\text { survey data to } \\
\text { geodetic } \\
\text { standards }\end{array}$} & \multicolumn{2}{|c|}{$\begin{array}{l}\text { Capture of } \\
\text { historic/old } \\
\text { survey } \\
\text { observations }\end{array}$} & \multicolumn{2}{|c|}{$\begin{array}{l}\text { Providing } \\
\text { Quality } \\
\text { assurance } \\
\text { services }\end{array}$} & \multicolumn{2}{|c|}{$\begin{array}{l}\text { Providing } \\
\text { digitising } \\
\text { services }\end{array}$} \\
\hline & $\begin{array}{l}\text { Survey } \\
\text { Qualified } \\
(n=75)\end{array}$ & $\begin{array}{c}\text { Not } \\
\text { Survey } \\
\text { Qualified } \\
(n=35) \\
\end{array}$ & $\begin{array}{l}\text { Survey } \\
\text { Qualified } \\
(n=75)\end{array}$ & $\begin{array}{c}\text { Not } \\
\text { Survey } \\
\text { Qualified } \\
(n=35)\end{array}$ & $\begin{array}{l}\text { Survey } \\
\text { Qualified } \\
(\mathrm{n}=74)\end{array}$ & $\begin{array}{c}\text { Not } \\
\text { Survey } \\
\text { Qualified } \\
(n=35) \\
\end{array}$ & $\begin{array}{l}\text { Survey } \\
\text { Qualified } \\
(n=75)\end{array}$ & $\begin{array}{c}\text { Not } \\
\text { Survey } \\
\text { Qualified } \\
(n=35)\end{array}$ & $\begin{array}{l}\text { Survey } \\
\text { Qualified } \\
(n=75)\end{array}$ & $\begin{array}{c}\text { Not } \\
\text { Survey } \\
\text { Qualified } \\
(n=35) \\
\end{array}$ \\
\hline $\begin{array}{l}\text { am highly capable }+ \\
\text { am generally capable }\end{array}$ & $84.0 \%$ & $22.9 \%$ & $73.3 \%$ & $22.9 \%$ & $87.8 \%$ & $40.0 \%$ & $81.3 \%$ & $42.9 \%$ & $81.3 \%$ & $51.4 \%$ \\
\hline $\begin{array}{l}\text { I might be capable + } \\
\text { Not capable }\end{array}$ & $16.0 \%$ & $77.1 \%$ & $26.7 \%$ & $77.1 \%$ & $12.2 \%$ & $60.0 \%$ & $18.7 \%$ & $57.1 \%$ & $18.7 \%$ & $48.6 \%$ \\
\hline Total & $100.0 \%$ & $100.0 \%$ & $100.0 \%$ & $100.0 \%$ & $100.0 \%$ & $100.0 \%$ & $100.0 \%$ & $100.0 \%$ & $100.0 \%$ & $100.0 \%$ \\
\hline
\end{tabular}

Table 6: Survey and non-survey qualified produsers' self-assessed capability to contribute data or services 


\subsubsection{INFLUENCES ON VGI CONTRIBUTIONS}

Phase 1 sought to understand factors which influence whether produsers would contribute. Of the four potential influencing factors provided for consideration Figure 20, the most influential factor was where produsers felt that they would contribute a valuable or public service. All remaining suggestions considered were not strongly influential with less than $50 \%$ of participants ranking them as quite or very influential. Giving away data so as to be free of the responsibilities of managing that data was the least influential factor. This view is held by both the survey and non-survey qualified subgroups. Questions on accessing support and guidance, or being able to share a passion in a particular data set was relatively evenly split. However, with only $17 \%$ of survey qualified participants having contributed VGI, it was not surprising that they indicated that support was an influential factor.

To what extent are the following influences

on VGI contributions

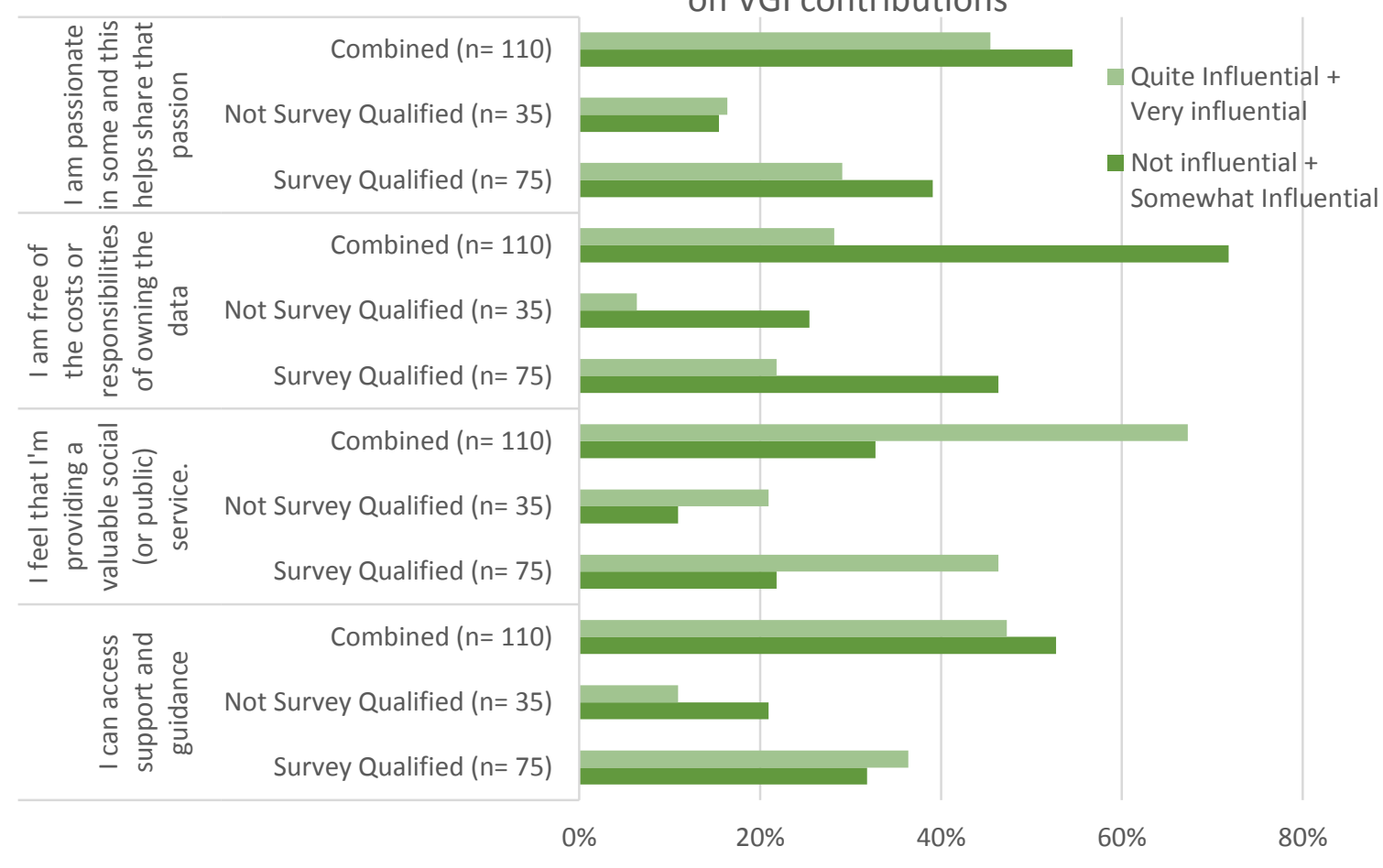

Figure 20: The influential factors for considering contributing VGI

Barriers to contribution were also assessed (Figure 21). Lack of time was the only identified limitation, with 'not knowing how to be involved' the next closest. Lack of skill and an unwillingness to give away data were not identified as being limitations. However, the skill question stands out as it is potentially contrary to the capability results regarding the participants without survey qualifications. The results in section 4.2.1 identified that non survey qualified participants had low capability across a broad range of categories with respect to providing cadastral data (Figure 18 and Figure 19), so it would have been expected that skills 
would have been a limiting factor. VGI can be contributed at a range of levels and this may just reflect that users recognise that they are only capable of contributing non specialised information.

\section{To what extent do the following factors limit the provision VGI contributions}

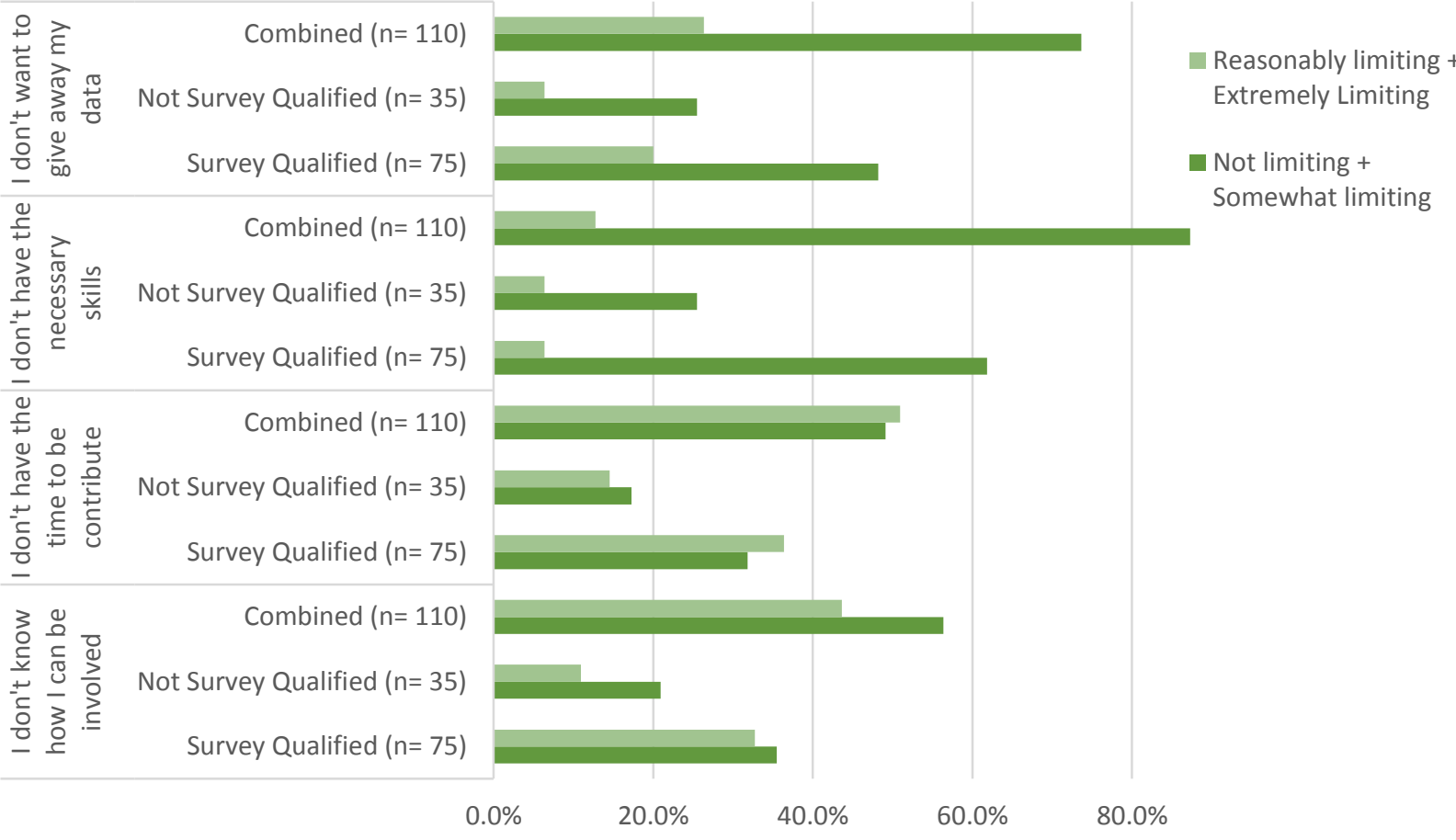

Figure 21: The factors that limit produsers' provision of VGI

Produsers primarily focused on responses to factors polled in the open ended questions. However, several responses identified that ownership of data was a factor. One survey qualified participant explained that potential contributions may be client data, and that accordingly release permission would be required. Privacy was also cited as a barrier, although no participant indicated specifically what this meant or provided an example. Other responses related to time constraints and costs.

Comments from phase 2 highlighted that potential contributors need to know that avenues to contribute information are available. Directly requesting information was seen as necessary to drum up support if there were specific projects. If the contributions are to feed into a specific project or initiative then officials believe that contributors also want to understand the aims and objectives of the project - this may require additional marketing. In general, responses regarding contributing information to the cadastre indicate that it must be easy - easy to understand, easy to contribute and easy to use. 


\subsubsection{WILL PARTICIPANTS CONTRIBUTE VGI?}

Produsers were asked what 'was the likelihood of them providing volunteered cadastral data'. The individual results for survey and non-survey qualified participants was close to even, although survey qualified participants indicated that they are more likely to contribute data or services than their non-qualified counterparts (Table 7). Despite non-survey qualified participants' low opinion of their capability (refer section 4.2.1) to provide cadastral data or services, $46 \%$ of this subgroup still thought that they were likely to contribute. One reason may be that this result is based on possible provision of digitising services.

\begin{tabular}{|c|c|c|c|c|c|c|}
\hline & & $\begin{array}{l}\text { Survey } \\
\text { Qualified }\end{array}$ & $\begin{array}{c}\text { Not } \\
\text { Survey } \\
\text { Qualified }\end{array}$ & $\begin{array}{l}\text { Survey } \\
\text { Qualified } \\
(n=74)\end{array}$ & $\begin{array}{l}\text { Not } \\
\text { Survey } \\
\text { Qualified } \\
(n=35)\end{array}$ & $\begin{array}{c}\text { Overall } \\
\text { result } \\
(n=109)\end{array}$ \\
\hline \multirow{3}{*}{$\begin{array}{l}\text { What is the likelihood of } \\
\text { you providing Volunteered } \\
\text { Cadastral Data, if the } \\
\text { mechanisms to do so are } \\
\text { available? }\end{array}$} & $\begin{array}{l}\text { Very likely + } \\
\text { Likely }\end{array}$ & 39 & 16 & $52.7 \%$ & $45.7 \%$ & $50.5 \%$ \\
\hline & $\begin{array}{l}\text { Don't Know + Unlikely + } \\
\text { Very unlikely }\end{array}$ & 35 & 19 & $47.3 \%$ & $54.3 \%$ & $49.5 \%$ \\
\hline & Total & 74 & 35 & $100.0 \%$ & $100.0 \%$ & $100.0 \%$ \\
\hline
\end{tabular}

Table 7: Produsers' assessment of their likelihood of contributing VGI

Produsers were then asked to assess their likelihood of contributing to five specific data or service categories (Figure 22)

What VGI services will users contribute to?

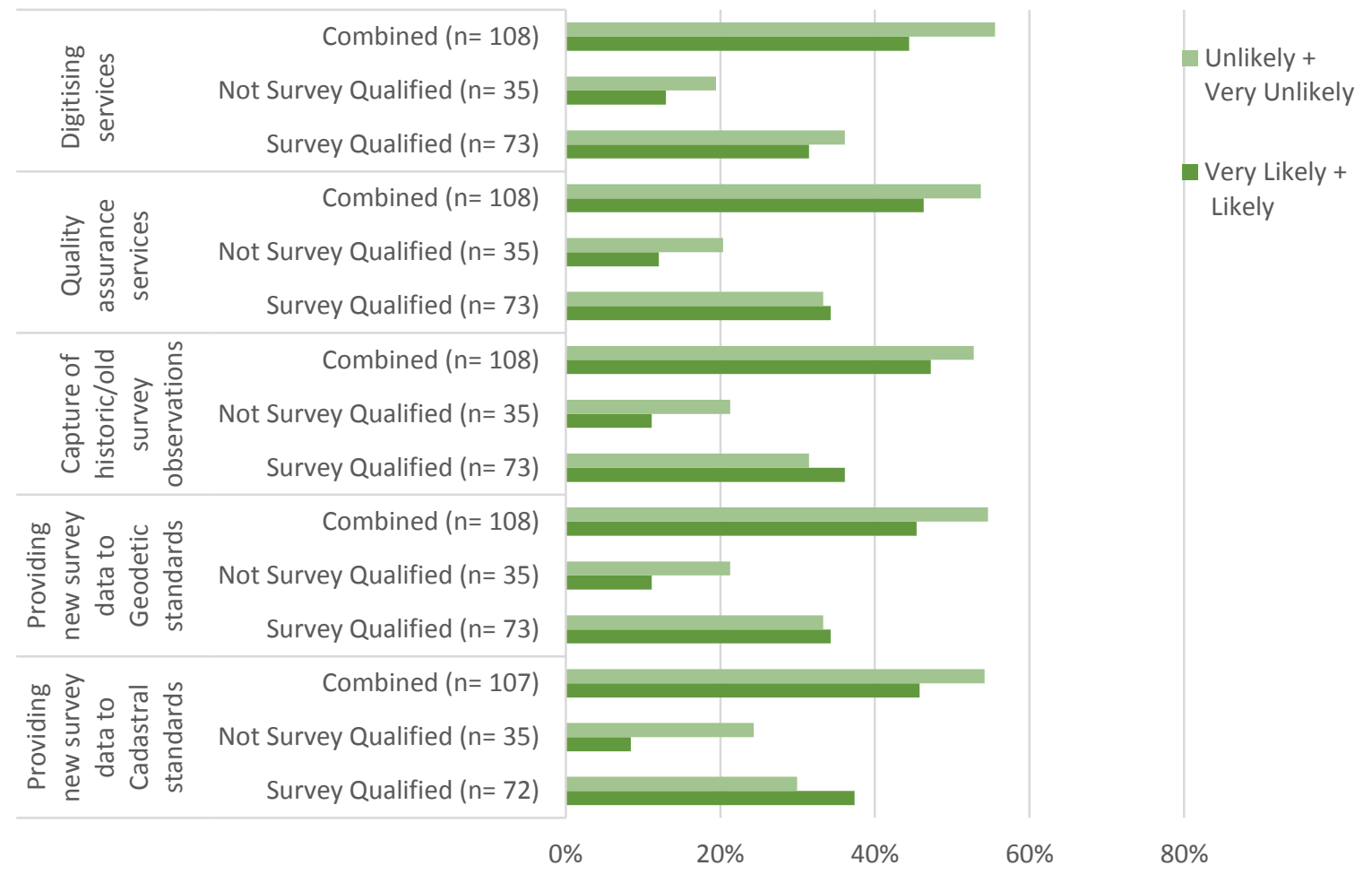

Figure 22: Services or data that produsers might consider contributing as VGI 
When faced with specific options, most produsers thought it unlikely they would contribute. The combined result across the specific options is $46 \%$. This is contradictory to the results in (Table 7) where $51 \%$ thought that they would contribute. Perhaps some of the potential contributions envisaged by produsers were not in the options provided in the question. Alternatively, some produsers may have realised that they actually had little interest in the specifics of cadastral data and changed their mind. Slightly more than half of the survey qualified participants responded positively to all categories (except providing digitising services) but this was not in sufficiently large enough numbers to counteract the number of user participants who thought it unlikely that they would provide cadastral information. These results appear to indicate that if $\mathrm{VGI}$ is crowdsourced, the primary contributors will be survey centric users, i.e. existing data providers. It is possible that survey qualified users are more likely to contribute because the work is better aligned to their current skills and data needs. Alternatively, roles for the non-survey qualified users will require greater support services.

\subsubsection{USER ACCEPTANCE OF CROWDSOURCED INFORMATION}

There was a high level of concern about allowing VGI to influence the NZ cadastre. Phase 1 participants (produsers) were asked if they were concerned for the reliability and trustworthiness of the cadastre if VGI was added (Figure 23). Over $60 \%$ of produsers were moderately or very concerned. As a percentage of their respective groups, survey qualified participants were more concerned than those without survey qualifications. However, in the qualitative comments from all phases, the concept was generally supported - especially by the officials. A very small minority of participants across the produser centric data collection stages (phases 1 and $2 a$ ) were strongly opposed to crowdsourced data influencing the cadastre. These produsers predominately identified themselves as being licensed cadastral surveyors. Of note was that the context of most of their commentary was associated with surveying boundaries. Few of these produsers appeared to consider that crowdsourcing other areas of the cadastre would add value, such as providing supporting or contextual information that did not alter boundary definition. This information would include for example the monitoring and recording rivers banks where they coincide with water boundaries and thus ensure information is available for a surveyor to assess in redefining these boundaries.

\section{Are users concerned for the reliability and trustworthiness}

\section{of the cadastre if VGI is added?}

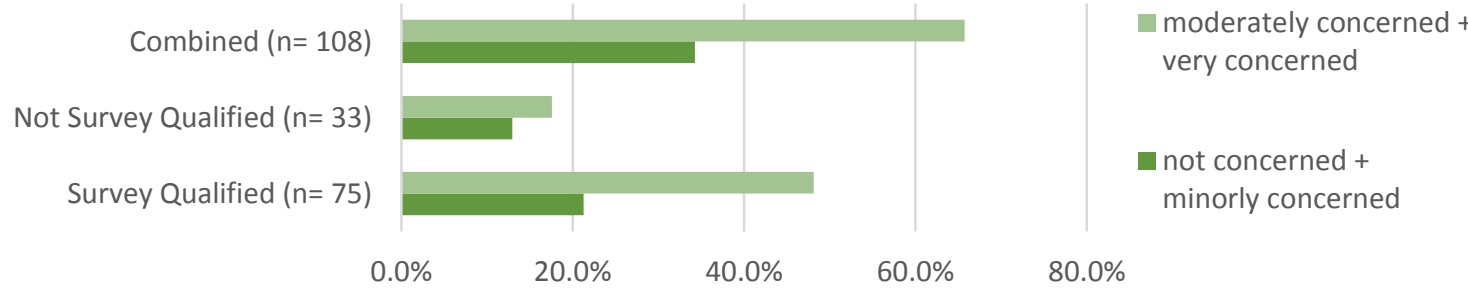

Figure 23: How concerned are produsers for the reliability and trustworthiness of the cadastre. 
The strongest crowdsourcing supporters indicated that crowdsourcing risks were overstated in comparison to potential benefits. However, in keeping with the views of the vast majority of those surveyed (who were more ambivalent), their support was tempered with the understanding that crowdsourcing has the potential to degrade data or impair perceptions of the cadastre through error, lack of knowledge, and even malicious acts. All supporters were aware that there was potential for improvement of the cadastre to meet new and emerging needs but only if the existing cadastre was protected from unmitigated risk. Supporters generally placed caveats on their support of crowdsourcing, such as not allowing users of the cadastre to define boundaries. Supporters also proposed a number of mitigations to minimise potential negative impacts to users, the cadastral system or the data. These caveats are further outlined in section 4.5 .

Section 4.2 .1 found that only $22 \%$ of produsers have previously contributed to VGI initiatives (Figure 12), however the results from the question examining what 'services that users might provide' (Figure 22) found that $46 \%$ of produsers would consider making cadastral contributions. By providing the opportunities to contribute, there is the potential to more than double the number of contributors of VGI from this type of user. This result when combined with the high numbers of produsers who had experienced issues with the cadastre (see section 4.4.2 and Figure 24), shows that not only is there room for cadastral improvement, but also that crowdsourcing may have a role through an increasingly likelihood of VGI participation by users. The extent of this role however depends on the potential impact of the challenges created by crowdsourcing information (discussed in section 4.7) and whether produsers concerns (as identified in section 4.5) could be mitigated.

\subsection{CONTRIBUTOR MOTIVATIONS}

The research phases explored reasons and underlying motivations as to why users might contribute VGI. The reasons and motivations identified covered the gamut of those that were highly altruistic, through to more egocentric reasons providing personal benefits to the contributor.

\subsubsection{Altruism Through to Egolsm}

Altruistic reasons to contribute recurred throughout answers to the different research phases. This reoccurrence may be due to the common perceptions that volunteering information meant giving it away with no expectation of return or direct benefit. Altruism however often only went so far. Drivers to collect the data for more personal reasons or mutual benefit, as well as of a consequence of feedback and incentives were also identified from participant responses 
(see section 4.2.2). Altruistic motivations were also evident in the limiting factors results which showed that giving data away was not a barrier (Figure 21) as long as they had the authority to do so. In addition, the most influential factor on the likelihood of produsers providing cadastral contributions (with $63 \%$ of participants as shown in Figure 20), was if the contribution provided a valuable social or public service.

During phase 2, both officials and users indicated that some participants were willing to provide the data even at a cost to themselves. For example some surveyors were quite willing to share historical work such as original project files simply because doing so would reduce the work required for other surveyors. Other participants noted that tapping into less obvious user groups with parallel interests could be sufficient to elicit contributions. Potentially aligned user groups may include historians and genealogists who have interest in the data and want data preserved and more easily searched. A produser also suggested using student 'assignments'. This response indicates the potential not only for data reuse, but that with some planning, training exercises could make valuable contributions. Another 'in kind use' recognised by some of the survey qualified participants was that by providing much of their survey information to the cadastre, their own needs to store and manage the data was reduced. Accordingly this may be a potential cost saving in the long term for the contributor and enable the data to be used by others. Interestingly, this question was part of a first phase question (Figure 20) where it was found to be the least influential option of the four options participants were asked to assess as considerations on whether to contribute VGI.

Some participants felt that cadastral improvement for parcel accuracy was too slow. They saw crowdsourcing as a potential way to speed up improvement. Participants highlighted that some users have to continually apply ad-hoc workaround methods or data corrections to their copies of cadastre information. These users may wish to make cadastral contributions directly into the cadastre to avoid the necessity of these repetitive ad-hoc solutions, thus making their work more efficient and enabling the solution to be shared with other users of the cadastre. Examples provided included large organisations such as Territorial Authorities maintaining spatial alignment with their data (such as planning zones) and utility companies maintaining or searching for underground infrastructure in relation to boundaries. Where participants had strong personal or self-interest drivers, interest in contribution appeared to be greater. A passion for the cadastre or particular cadastral issues or data was related to possible contributions. For example, it would be expected that property owners would be more interested in their property than land parcels elsewhere in NZ. It was suggested that landowners, tenants or interested parties may wish to contribute in order to inform future survey work so that their existing use and/or property rights are protected. 
The accuracy of the cadastre underpinned many issues identified relating to VGI and crowdsourcing. Whereas surveyors were predominantly concerned about the existing accuracy state of any boundary information, other cadastral users with few avenues to improve boundary accuracy (except engaging a surveyor), commonly identified that the ability to notify officials of errors and inaccuracies in the cadastre would be welcomed. A few participants, mainly surveyors, wanted to contribute so that they could correct errors themselves. Various users or officials noted that capturing and providing occupation indicators (such as the positions of fences, buildings and shelterbelts) would enable this. A frequently cited example related to the after effects of the Canterbury Earthquakes in 2010, where land moved and the occupation indicators have subsequently been removed and the extent of land use no longer obvious. A second example related to determining water boundaries. The definition of the water boundary (where the associated water feature has moved) relies on knowing the rate of change to assess whether the current or past position of the river determines the boundary location. Specific legal rules determine whether the boundary stays where it was, due to slow an imperceptible movement (accretion) or moves with the river due to rapid change (avulsion). Historical evidence of the features changing positions would be beneficial in this regard and it was suggested that some users may wish to provide this to support any claims they may make now or in the future. An alternative protective measure suggested was to enable non-cadastral information that relates to peoples' ad-hoc, informal or temporary agreements to be mapped or documented without the need to engage a solicitor/surveyor. The examples provided included documenting fencing/boundary discrepancies issues, temporary access and other neighbourly agreements.

\subsubsection{InCEntives ANd Feedback}

Many participants in all phases indicated that feedback and encouragement was an important incentive to contribute. Feedback and encouragement were fundamental to ensure that contributors did not feel that they were being 'taken advantage of', to show that the data was being used and to assist in building/retaining a 'feel good factor' associated with altruistic contributions.

"You'd be amazed at how people want to participate and get quite excited by simple things like pats on the back and their name up in lights" LINZ official.

Feedback and encouragement was also considered necessary to build and to retain contributor engagement by indicating appreciation.

If I noticed an anomally [sic], I would be prepared to 'alert' someone (particularly if it was easy to do so ... and I got some kind of feedback from doing so) 
Feedback was commonly cited with reference to data quality issues, primarily as a means of advising when the data information did not meet expectations. Some users and officials also noted that feedback was an important way of advising of a 'good job' and thereby encouraging more of the same as well as showing how much information individuals have contributed.

Disincentives relating to various forms of payment also occurred in participant responses to other questions throughout all phases and data collection stages. The perceived or assumed lack of potential for payment reimbursement of costs is the primary reason participants (especially surveyors) were against VGI or crowdsourcing. Participants highlighted that they should not carry additional costs to obtain, assemble, repackage or forward data - especially if it was being provided for the public good or where requested by government.

Participants were generally of the view that where the information was given freely, then it should subsequently be returned without charge if requested and/or made freely available for other users. There was some skepticism that this would actually occur amongst produsers, who implied a reluctance to contribute if reciprocity was not certain. One survey qualified participant went as far as suggesting that data sharing agreements may be necessary. Similarly one official extensively discussed data capture from existing survey plans and the need for a suitable tool. The implication within this interview was that for data capture to occur, the survey plans (that currently incur a charge) would need to be freely available.

\subsection{THE POTENTIAL OF CROWDSOURCING}

\subsubsection{Cost SAVIngs}

It is commonly understood that VGI is provided free of charge. Where there is a charge, it is often at cost. Not surprisingly almost all participants envisaged VGI would provide free data. This 'free' assumption meant some participants thought that even if requested, their efforts or costs to provide or data would not be able to be recouped. Some participants also indicated that obtaining and applying VGI to the cadastre was an underhand method of obtaining free data and the government's way to avoid paying for services. The majority of participants (especially officials) however did not portray such views. Commonly participants thought VGI would enable LINZ to improve the cadastre by acquiring data that may not otherwise be provided and in a cost effective manner. Some data providers and users considered that VGI would provide a low cost mechanism to provide data that they thought should be part of the cadastre - i.e. to avoid the necessity for a CSD and associated high compliance costs such as additional QA and fees. For one surveyor, this also included the personal liability associated with signing and submitting data via a CSD. 
Most officials saw this differently. Although they recognised that the information may be free or of low cost, they highlighted that LINZ might incur significant costs in system changes to allow and manage crowdsourced information and were unsure if aspects such as the increased integration costs would make crowdsourcing financially viable. Currently, changes to the system are funded through fees and charges from system usage and are therefore borne by third parties (surveyors, solicitors and their clients) (see section 2.3.3.) The officials who held roles associated with the management and maintenance of Landonline noted that enabling the inclusion of crowdsourced information would have to reprioritise LINZ's third party income. This would accordingly impact the maintenance and improvement of the core system, which may also impact on efficiency.

Most officials and some produsers were concerned about possible additional support that may be needed - assuming that many contributors would not have the skill levels of existing data contributors (predominately LCS's). Encouraging specific 'high value' contributions was suggested as a means to ensure that contributions did not incur costs beyond the value of the contribution. Some participants identified the concept of providing services, or information in kind such as exchanging access to survey information for data entry.

\subsubsection{Data AND Information Provision.}

Produsers experience currency, completeness and accuracy issues with the cadastre as shown below in Figure 24 and in Table 8 . Over $60 \%$ of all produsers have experience issues with all three quality indicators. For the survey qualified participants and as tabulated in Table 8 below, $94.5 \%$ of survey qualified participants had experienced issues with accuracy and $86.3 \%$ with incompleteness. Currency was less frequently cited. The higher percentages of survey qualified participants (than the non-survey qualified) who encountered cadastral data issues may be related to their greater first-hand experience of the data. Many survey qualified participants currently contribute to the survey record and accordingly have a better understanding of the cadastral data and its scope than the non-survey trained participants (Figure 13 and Figure 14.) 


\begin{tabular}{|l|c|c|c|c|}
\hline \multicolumn{2}{|c|}{$\begin{array}{c}\text { Have you experienced issues in relation to the } \\
\text { following attributes? }\end{array}$} & $\begin{array}{c}\text { Survey } \\
\text { Qualified }\end{array}$ & $\begin{array}{c}\text { Not } \\
\text { Survey } \\
\text { Qualified }\end{array}$ & Combined \\
\hline \multirow{3}{*}{$\begin{array}{l}\text { Part Question: Cadastral data that } \\
\text { is inaccurate }\end{array}$} & Yes & $\begin{array}{c}69 \\
(94.5 \%)\end{array}$ & $\begin{array}{c}16 \\
(59.3 \%)\end{array}$ & $\begin{array}{c}85 \\
(85.0 \%)\end{array}$ \\
\cline { 2 - 5 } & No & $\begin{array}{c}4 \\
(5.5 \%)\end{array}$ & $\begin{array}{c}11 \\
(40.7 \%)\end{array}$ & $\begin{array}{c}15 \\
(15.0 \%)\end{array}$ \\
\hline & Total & 73 & 27 & 100 \\
\hline \multirow{3}{*}{$\begin{array}{l}\text { Part Question: Cadastral data that } \\
\text { is incomplete }\end{array}$} & Yes & $\begin{array}{c}63 \\
(86.3 \%)\end{array}$ & $\begin{array}{c}15 \\
(57.7 \%)\end{array}$ & $\begin{array}{c}78 \\
\end{array}$ \\
\cline { 2 - 5 } & No & $\begin{array}{c}10 \\
(13.7 \%)\end{array}$ & $\begin{array}{c}11 \\
(42.3 \%)\end{array}$ & $\begin{array}{c}21 \\
(21.2 \%)\end{array}$ \\
\hline \multirow{3}{*}{$\begin{array}{l}\text { Part Question: Cadastral data that } \\
\text { is out-of-date }\end{array}$} & Total & 73 & 26 & 99 \\
\cline { 2 - 5 } & Yes & $\begin{array}{c}45 \\
(61.6 \%)\end{array}$ & $\begin{array}{c}13 \\
(59.1 \%)\end{array}$ & $\begin{array}{c}58 \\
(61.1 \%)\end{array}$ \\
\cline { 2 - 5 } & No & $\begin{array}{c}28 \\
(38.4 \%)\end{array}$ & $\begin{array}{c}9 \\
(40.9 \%)\end{array}$ & $\begin{array}{c}37 \\
(38.9 \%)\end{array}$ \\
\hline
\end{tabular}

Table 8: Extent of accuracy, completeness and currency issues

What aspects of the cadastre have users

have experienced issues.

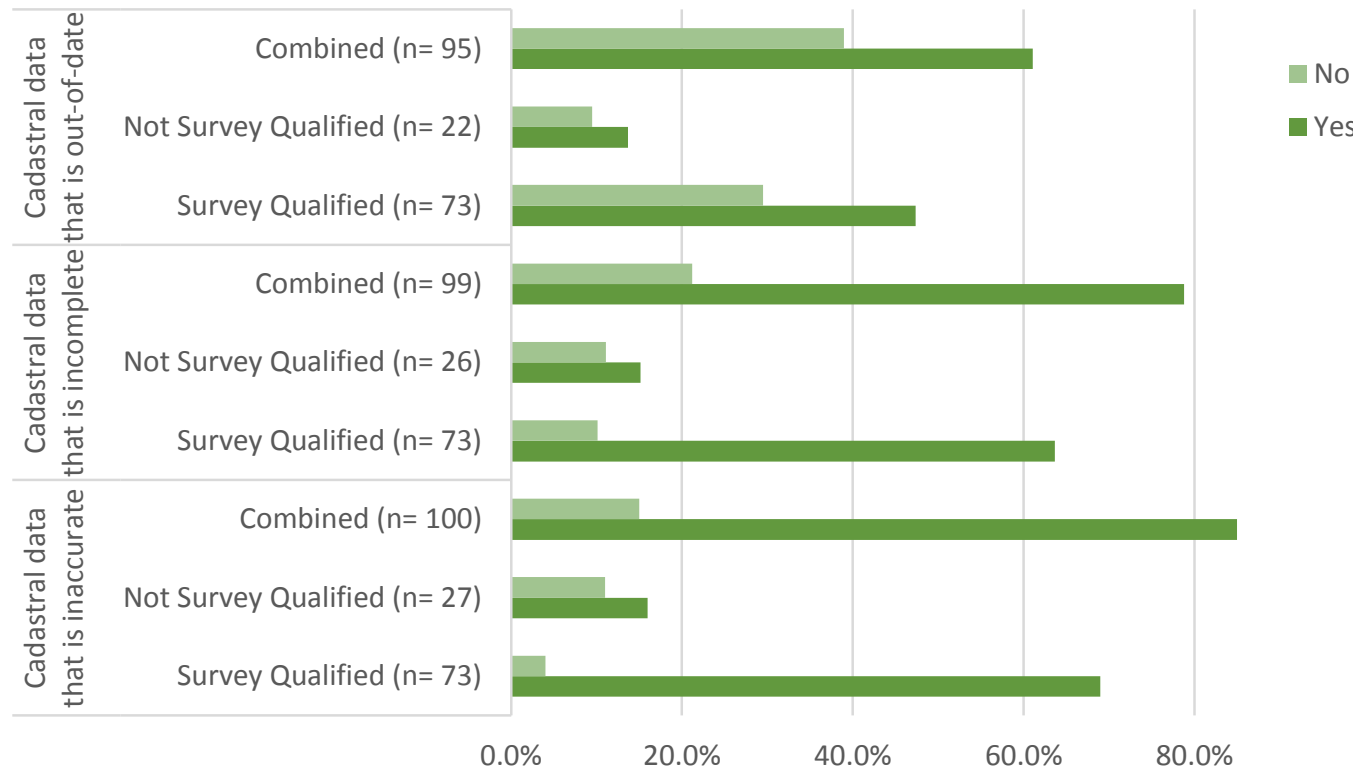

Figure 24: Issues encountered with the cadastre

Because the research participants predominantly managed, used or contributed data, their knowledge of visual data issues such as misalignment of parcels mapping was greater than their knowledge of other issues in the cadastre, such as missing information. This lack of knowledge and understanding of cadastral process was identified through comments provided by participants such as the desire to have the poor spatial alignment with imagery improved 
through the provision of measurements, coordinates or contextual information (e.g. fences). Other cadastral data issues such as or missing parcels (especially non primary and Maori partitions), additional/missing nodes in parcels or incorrect/missing data attributes (such as survey dates) were not mentioned despite $79 \%$ of all users in the first phase having experienced issues with cadastral incompleteness (Table 8). Participants had a greater focus on spatial data acquisition rather than provision or improvement of a-spatial (tabular) information. Consequently, there was little focus on the potential or benefits of crowdsourcing to improve existing a-spatial cadastral components and linkages to other inter-related systems, such as the titles system. Further, few participants identified opportunities or benefits in relation to providing supporting information (or metadata) either. However some officials thought that users could be encouraged to report aspects such as mark interference, destruction or where maintenance is required (e.g. missing covers or geodetic marks with a beacon (trigs) in disrepair). Some produsers also identified the opportunity to improve the cadastre through informing officials about the disturbance of survey marks or identifying areas where parcel accuracy did not meet accuracy expectations. It is possible, however, that the mention of mark disturbance and parcel accuracy was associated with the timing of the commencement of LINZ's use of the beforeUdig service (www.beforeUdig.co.nz) and the spatial parcel improvement project (www.linz.govt.nz/survey-titles/stats-projects-notices/spatial-parcel-improvement).

Across both phases, VGI was seen as a means to improve the cadastral dataset through identification or correction of data issues. Data improvement suggestions included ${ }^{2}$ :

- back capture of digital data where digital parcel boundaries are based on digitised data

- notification or correction of errors

- notification of mark disturbance, destruction or a need for maintenance

- provision of more accurate irregular boundaries

Few specific suggestions were made on how to enable the collection and integration of data. Of those suggested, the comments fell within the categories provided in the phase 1 (Figure 22).

Phase 1 and 2 participant comments (especially officials) about data capture tools indicated that users, producers and officials assume that LINZ would lead the process and provide appropriate tools or methods. Data capture (including new data) almost always focused on

\footnotetext{
2 The author is aware of many additional examples of where potential improvement to the cadastre can be made to examples such as parcel attributes through the identification and correction of appellations issues, matching between survey/title. LINZ maintains a database of these.
} 
boundary mapping improvement, or the provision of information that related to boundaries. This was especially the case where authoritative data was missing in a structured digital form (as opposed to examples such as scanned images of plans). Few research participants discussed what that data might be. Transcribing survey data from survey plans which had not been resurveyed or previously recaptured (transcribed into the cadastral database) was proposed by officials as an area most likely to be of direct benefit to the cadastre. This potential data source was considered most likely by participants as the focus of $\mathrm{VGl}$ (Figure 22.)

Many participants expressed concerns that most field based data capture from non-survey professionals is likely to be obtained via consumer grade devices (such as mobile phones) using the device's in-built positioning capability. Consequently coordinates rather than bearing and distances, as traditionally supplied by surveyors, would be provided. Some participants saw this as an opportunity, where the potential use of digital photography from consumer devices could be used to show information potentially relevant to boundaries and to map the indicators of occupations for surveyors to use when defining boundaries.

Some officials indicated that VGI could also aid cadastral maintenance. In addition to providing independent data or information, users could also provide some services i.e. contribute their time as directed by LINZ. Specifically identified were tasks that assisted with cadastral system management processes, such as quality assurance of data (either CSD's or user supplied data). Another option identified by an official was assisting with the integration of CSD's by setting up cadastral adjustments ready for authorisation. These ideas show that there is support for crowdsourced, service-based solutions that integrate with, or supplement, existing system and processes.

\subsubsection{Data Reuse and Extending the Scope of the Cadastre}

Cadastral information actively managed by LINZ is limited to the fundamental cadastre, despite the cadastre being quite broadly defined in the Cadastral Survey Act 2002 (Grant et al., 2014). Surveyors continually reuse information already in the cadastral system (from earlier surveys) and other work that they have undertaken in the area. However it was officials who saw opportunity for VGI in data re-use where data has been collected and held for other purposes, as exemplified by the following official.

"it seems silly to waste that work that someone's done already... ... it just
seems that we're reinventing, creating a whole [lot of] work for us when someone's
done it"
LINZ official 
Users identified a number of data sources as a result of other functions or uses not directly related to cadastral work. This information which is unlikely to have been collected or created by licensed cadastral surveyors is not permitted in cadastral survey data sets, irrespective of its quality. Several participants noted that various users capture survey data to obtain accurate parcels and areas and is currently lost. It was noted that if systems or processes were available the information could be reused, including even the identification of areas of poor cadastral (parcel mapping) accuracy. A phase $2 \mathrm{~b}$ participant suggested that just because some contributions may not be suitable for direct inclusion in the cadastre, it may be suitable for other datasets.

Data acquired by professionals in land development disciplines (such as planning, surveying, engineering) was seen as having greater potential for reuse. Often this data had been collected for purposes similar or related to the cadastre, e.g. drainage and utility as-built surveys, infrastructure design and resource consenting. Other data reuse identified related to information linked to public law or aspects that Grant et al. (2014) refers to as the broader cadastre, e.g. territorial authority planning and zoning boundaries. One official also suggested that the huge datasets provided by private entities (such as roads and laser scanning collected by Google) may also provide independent, unbiased value.

Two officials provided examples related to the Canterbury earthquake response to show that the reuse of data as a VGI contribution would be beneficial to the cadastre; firstly survey mapping work undertaken by students that provided evidence of ground movement for geological purposes could also be reused to provide the evidence of the impact on boundary occupation (fences) for future definition purposes; and secondly, engineering and monitoring surveys that re-surveyed cadastral reference marks which identified mark movement could also be reused. A third example from a survey qualified participant also related to the earthquake, in this case it was identified that data collected not needed for definition purposes for a cadastral survey, is often excluded from CSDs and therefore does not become part of the cadastral record. This is despite the likelihood that such data collection may provide useful information for other surveyors for a variety of purposes.

Users identified that there is currently no simple way to record any information (pertinent to boundaries) that related to their rights, responsibilities or restrictions without engaging a solicitor. The examples provided were provision of supporting information regarding fencing issues, temporary access and other neighbourly agreements. If there was such a mechanism to accept, and store user information about cadastral features then this would be a reason to contribute. 


\subsubsection{RESPONSIVENESS}

In some instances, phase 2 participants felt that cadastral improvement was too slow and that LINZ was not fulfilling its custodial or stewardship obligations to the cadastre or users.

LINZ has responsibility for the cadastre and needs to step up to actually bring it up to speed at a far higher rate than it is doing. User respondent

Other participants indicated that resolving issues relating to digital parcels as a specific element of the cadastral data set was also too slow and crowdsourcing could potentially speed this up.

Produsers strongly indicated that they had experienced issues with cadastral data (Figure 24). The cadastral issues surveyed covered inaccuracy, incompleteness and whether cadastral data was out of date. Although being out of date had the lowest percentage of phase 1 participants indicating that it was an issue, it still showed that over $60 \%$ of them had experienced 'out of date' data. Given that the cadastre is supposed to be current, this may also be indicative that participants consider responsiveness to change to be an issue. The other issues of inaccuracy and incompleteness may also be contributing to the perception of nonresponsiveness if users are not seeing data corrections or enhancements occurring to the cadastre within their undisclosed time expectations.

\subsection{DATA ISSUES AND CONTROLS}

Phase 2 participants were asked about possible issues with using VGI and then asked to discuss potential mitigations. The vast majority of those surveyed proposed mitigations and many had already placed caveats for the use of $\mathrm{VGl}$ earlier in the interview or questionnaire (depending on research collection phase). Suggested mitigations included developing user trust mechanisms (these were mainly focused on metadata such as who, when, and what equipment was used), authorising contributors, ensuring contributors provided supporting information and good governance.

\subsubsection{DATA QUALITY}

Public confidence is paramount in the success of a government system or process. It was not surprising that data quality issues were expressed by most participants. Participants were concerned not only with the quality of submitted data but also how poor quality data could affect the wider system, other data and whether data could be remedied if necessary. Many participants (predominantly those with survey qualification) were strongly against the inclusion 
of VGI for this reason alone. Specifically, the survey qualified participants highlighted the risk that it will change the cadastre in such a way that it would no longer met their, or other users' expectations through data quality issues relating to data integrity, authoritativeness, trustworthiness, efficiency and reliability. Why a distinct group of users held this view is unclear. However, by analyzing the responses of participants in phase 1 and $2 a$, a conceptual link with VGI and untrained users defining boundaries was identified as exemplified in the following quote.

\begin{abstract}
"The cadastre is a very important framework that NZ keeps functioning correctly and there are certain areas that require the skill and experience of the licensed surveyor - peg placement and boundary definition are key to the framework so this work needs to be done by the specially trained so I don't think we can open source this work outside their expertise." Survey Qualified Participant
\end{abstract}

In Phase 1 asked participants about the impact of integrating several different data sources. Both survey and non-survey qualified participants felt that survey data provided by nonsurveyors would harm the cadastre, especially if they were new observations. Participants were supportive of using qualified surveyors for data recapture, irrespective as to whether they were currently licensed as cadastral surveyors, but thought the same data provided by non-survey qualified people would harm the cadastre. Alternative forms of data such as that obtained from digitising was considered harmful by survey qualified participants the nonsurvey qualified participants indicated that digitising boundaries from old survey plans was beneficial. This may be because they recognise that these may be more accurate than the same boundaries as originally digitised from large scale record sheets, or are aware how large some of the mapping inaccuracies are.

\title{
Impact of different data sources \\ Survey Qualified respondants
}

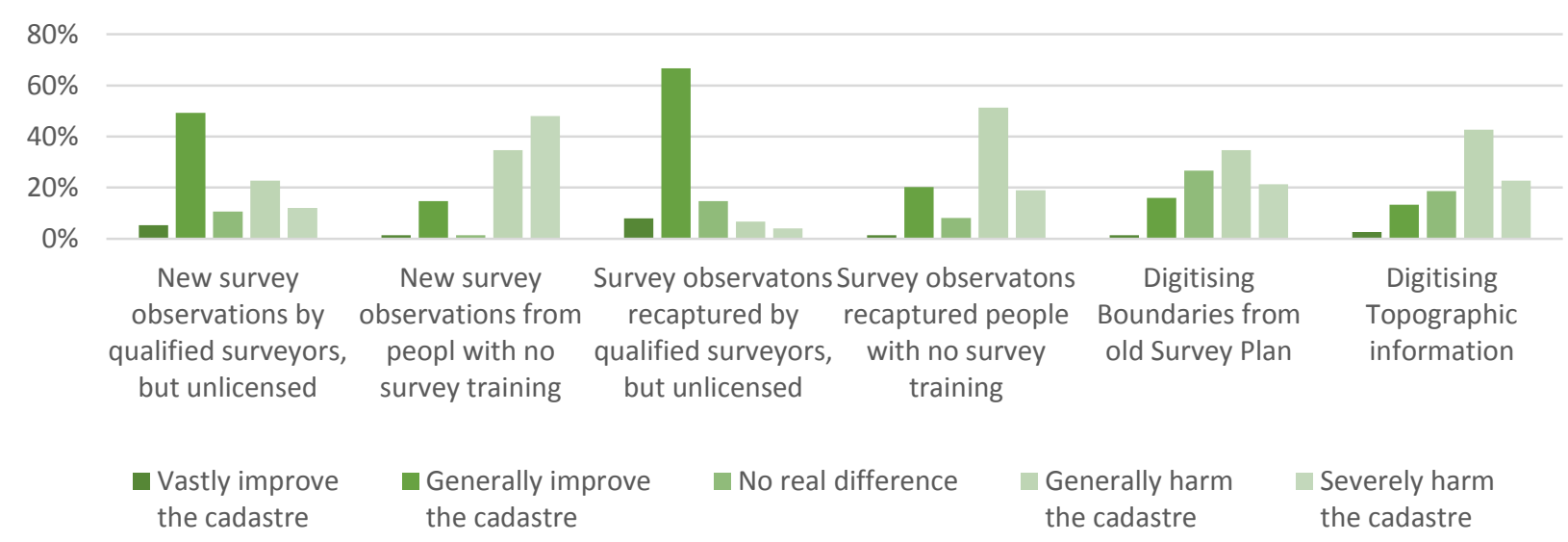

Figure 25: How do survey qualified users perceive the potential impact of VGI contributions 


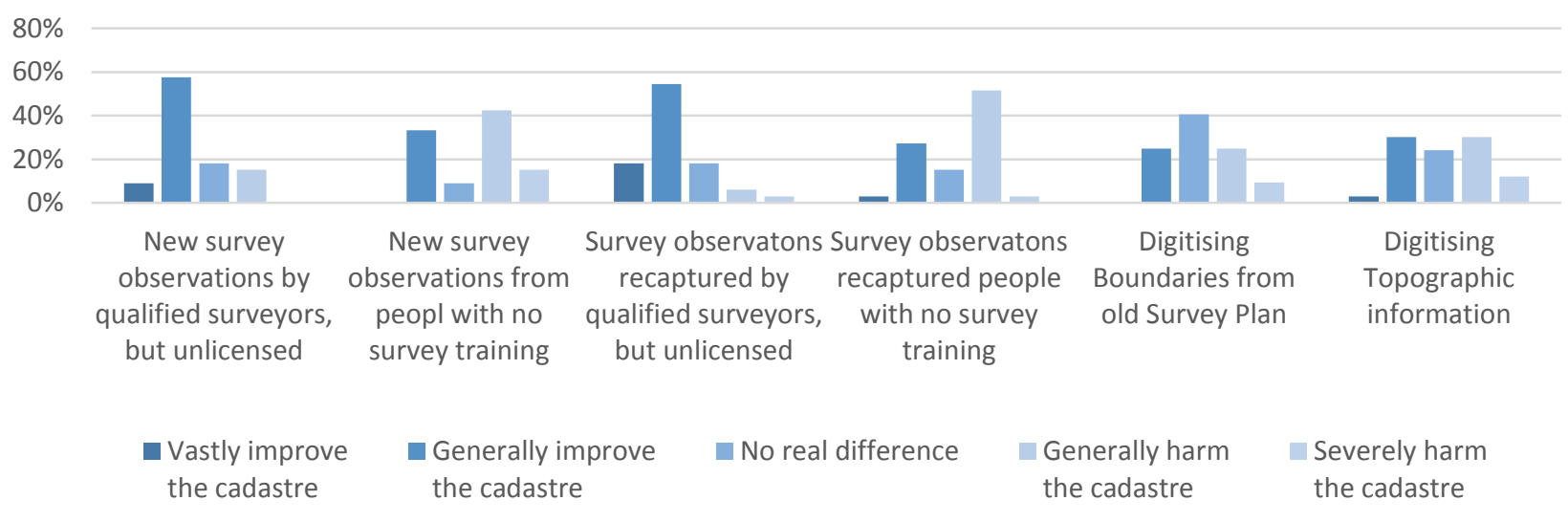

Figure 26: How do non-survey qualified users perceive the potential impact VGI contributions.

Phase 2 participants seemed to assume that if users contribute information it will be observational/measurement based and that contributors will provide information (such as fences) assuming that this would be sufficient for them to show where the boundary is and improve the mapping. A key aspect of cadastral data quality relates to accuracy of field measurements. Some officials and other participants thought that crowdsourced contributions would not meet accuracy standards that licensed cadastral surveyors have to meet because they are likely to have been collected using low accuracy or un-calibrated equipment (such as mobile phones). Consequently there was a fear that low accuracy information would lead to an overall degradation of the cadastre through the acceptance of low quality data. Accordingly survey qualified users and officials tended to object to volunteered occupation data or other measurements being used for definition purposes because presumably survey definition considerations were outside the knowledge base of non-surveyors. Some of these objectors were more comfortable with the use of volunteered data if it was assessed and used by a licensed cadastral surveyor who then takes responsibility for the data. Other participants however, were so concerned about the positional accuracy of data contributions that they were strongly opposed to VGI that contained field measurements.

Is LINZ serious? Why have licenced cadstral [sic] surveyors(LCS) if LINZ allows input from other sources to be incorporated into the cadastre? Once again LINZ does not appear to value LCS worth. I do not understand the rationale behind this proposal when everyday LCS are confronted with the requirement to provide very high quality information for incorporation into the cadastre. So high is the requirement that if the infomartion [sic] is of insufficient quality then the LCS could have his status to lodge datsets [sic] affected and be brought to face the CSLB in extreme circumsatnces!!!!! [sic] If LINZ accepts this proposal then they deserve the results that are likely to follow as consequence of such a move.

Survey qualified participant 


\subsubsection{QUALITY CONTROLS}

Quality control such as data checking, verification and other quality assurance processes were widely mentioned in all research phases usually in conjunction with data quality statements (refer section 4.5.1). Quality control discussions were focused on mitigation, as a caveat for accepting crowdsourced data or as a supporting mechanism to facilitate data acquisition or integration. Some produsers noted that malicious acts may occur but overall most users would have good intentions and poor data would be a consequence of errors, lack of experience or equipment of low capability. One produser summed up this sentiment by redefining $\mathrm{VGI}$ : "Very Good Intent" = "VGI". The common view was crowdsourced data will not be of the highest quality and most users' indicated that data verification was essential.

Although not explicitly expressed, a strong presumption existed that data checking or quality assurance (QA/QC) would be required and should be undertaken by submitters in the first instance. Supporters of VGI (including those who qualified their support) also presumed that data verification at acceptance would then be undertaken by LINZ. Contributor independent verification being undertaken by other surveyors and other trusted providers was suggested as a better use of the surveyor's higher expertise. Further some participants suggested that surveyors could assist by taking guiding and mentoring roles.

I do not think it is a question of being professional or un-licensed. Instead, the surveyors and those with knowledge need to assume the role of mentor/influencer to engage others. There is a need to shift professional surveyors to a higher plane, one where they do not fiddle with tools, but develop better policies, methods and approaches.

Survey qualified participant

In addition, surveyors could also assist validation and verification, including leveraging their existing quality assurance/checking ( $Q A / Q C)$ processes which may fall within their current professional work, or as a separate contribution in its own right.

VGI data must be reliable and trustworthy. Consider introducing it to an interim 'layer' in the cadastral database so it can be QA'd and accepted by Licensed Cadastral Surveyors at some later stage either voluntarily or in conjunction with a 'real' job.

Survey qualified participant 


\subsubsection{Metadata}

One surveyor implied that metadata was essential as "demanding that excellent metadata accompanies volunteered information, so that appropriate use/validation can occur", while another surveyor suggested information on contributor identity is necessary. Several officials noted the importance of suitable metadata but acknowledge metadata also comes with its own quality issues. Officials were open to 'fit for purpose' contributions so less accurate data may still be accepted, but without metadata all contributions would be considered to be of 'unknown accuracy' and therefore may not be suitable for the use that the contributor might have intended.

Metadata was also seen as a way to input large quantities of data with less controls as experts can then remove high-risk data according to the metadata.

Really a lot boils down to the appropriate provision of feature metadata. The user needs to know how the boundary was captured and it's [sic] spatial accuracy. This allows critical areas to be improved first (where underground infrastructure exists) then outlying areas corrected later. If title dimensions are stored and coordinates of supporting cadastral marks it's possible to run least squares adjustments to highlight erroneous entries for further investigation by experts. Leave the hard bits for them but let the semi-professional crowd get the bulk of the data in quickly.

User respondent

\subsubsection{DAta AND User REStrictions}

Many officials and those with survey training highlighted that licensed cadastral surveyors, are not only well trained, but to provide information to the cadastre they must first verify and prove their identity, and formally certify that data.

The cadastral survey act places requirements on cadastral surveyors to be responsible for the data they capture for their entire life regardless of who they work for. This is because capturing data incorrectly into the cadastre is seen as extremely risky. It would be wrong to allow unlicensed people to alter the cadastre because they are not in a position to accept the same responsibility. This is not an area where all care and no responsibility is acceptable.

Survey Qualified Participant

However, there was some recognition (predominantly by the survey qualified participants or officials) that the cadastre already includes information provided by non-licensed surveyors (although usually under the guidance of one). Also noted was that undertaking measurements does not require the same level of specialised training or equipment as in the past. 
Restrictions were proposed by users (most of whom supported VGI). These participants considered crowdsourcing should be limited to supporting the authoritative data already within the cadastre, specific components or alternatively only allow information that can be easily verified. An official suggested that all contributions come through an interface or tool which, in addition to limiting the data to a specific element, provides checking and ensures correct structure. There was a general consensus that some form of data management would be necessary (such as independent QA) if crowdsourced data was to merge with existing cadastral data. Whether contributor restrictions and user management was also necessary was not mentioned, other than in the context of providing metadata (see section 4.6.2). The alternative option was to not undertake any data controls or management and therefore accept that volunteer contributors must be kept separate from authoritative data.

The most restrictive option proposed was not to permit volunteer contributions:

Non surveyors should not have access to the database. Full stop.

Survey Qualified Participant

\subsection{EFFECTS OF ACCEPTING CROWDSOURCED CADASTRAL INFORMATION}

Users and officials clearly recognised significant benefits of VGI. However, these views were tempered by concerns about data use and impacts on cadastral use and management of the cadastre. These $\mathrm{VGI}$ concerns fell into three primary categories and are presented separately in this section.

\subsubsection{Impacts on End Users and Public Effects}

In general, the cadastre was perceived by most participants (including some officials) as being authoritative and therefore can be relied upon for its intended cadastral purpose. Simply allowing crowdsourced data into the cadastre could impact this perception. Its inclusion may cast doubt on its suitability to service the public need to define the 'where' in property rights restrictions and responsibilities. Although officials were generally supportive of $\mathrm{VGI}$, they were notably wary. Prime concern was that before decisions were made, an assessment of the risks of crowdsourcing data would be undertaken so that decisions were well thought through and consulted on. The impression from officials was that allowing crowdsourcing was akin to opening 'Pandora's box'. If crowdsourcing was a poor choice then closing it would not be easy and the cadastre could be irreparably broken. 
Survey qualified participants were also concerned about 'breaking the cadastre' or compromising its integrity through the inclusion of crowdsourced data (refer 4.5.1). The cadastral users' expectations are not known. All of the data quality comments reflect an expectation of stability and that the cadastre must retain its existing characteristics without significant compromise. Several officials took time to focus on the role the cadastre plays in supporting the property rights system, in underpinning the economy and providing security. They highlighted that the existing fundamental cadastre must be protected. One official noted that not all countries receive the same benefits from their cadastre and land registration systems - the implication being that NZ stands to lose substantially if it damages the cadastre or land registration systems through the use of crowdsourced data.

Cadastral surveyors are 'trusted professionals' (although paid by their clients) and as part of gaining their cadastral license are required to be neutral when assessing evidence to determine the positions of existing boundaries (Cadastral Surveyors Licensing Board, 2013). Of great concern expressed, by both survey qualified participants and officials alike, was that if information was accidentally or deliberately incorrect, it would alter people's rights to land. Given that VGI for the cadastre may be less regulated, some survey qualified participants and officials worried that some contributors might choose to supply their own data on order to manipulate the cadastre to their advantage. Malicious or accidentally incorrect data could lower trust in the system or leave users and land owners disadvantaged through loss of rights (either real or perceived). Incorrect data could lead to land owners making decisions that they would not have otherwise make. In addition, one official commented that such a reliance on crowdsourcing might leave the Crown open to claims for compensation.

\subsubsection{ImPACTS ON EXISTING Data CONTRIBUtORS}

A commonly expressed risk by survey qualified participants and officials was that crowdsourcing would generate large data volumes, much of it potentially irrelevant, damaging or unusable with regard to formal boundary definition. These survey qualified participants and officials recognised cadastral surveyors may have to undertake additional work or check to assess the impact and validity of crowdsourced data in the vicinity of a cadastral survey. This potential extra work raised fears that the efficiency of working in the cadastral systems would be lowered through increased timeframes and costs to undertake surveys and land registration processes for land subdivision. 
Participants identified a number of examples where increased costs or effort could occur:

- Licensed Cadastral Surveyors and their assistants may have to sift through vast amounts of information to find what is relevant and reliable.

- Additional requirements could be placed on Licensed Cadastral Surveyors and their assistants as they try to "undo" informally introduced errors.

- LINZ quality assurance and audit processes could be negatively affected through the need for additional validation.

It is important to note that some participants considered that large data volumes associated with crowdsourced data would be advantageous, because it would lead to repetition, and where people agreed there was a greater likelihood that provided data was correct or would 'self-correct'. One official acknowledged that the potential for 'data wars' to eventuate as specific features or attributes oscillate between two states as contributors battle to impose their view. Such data disagreements might need official moderation.

Participants strongly against crowdsourced data came solely from phase 1 participants. The majority of dissenting voices identified themselves as licensed cadastral surveyors. Although most survey qualified participants were either positive or ambivalent about the use of crowdsourced data, the anti-crowdsourcing users focused on the risks and dire consequences of poor data undermining or corrupting the cadastre. They expressed concerns about the lack of training, knowledge and understanding that potential contributors to the cadastre regarding cadastral surveying and the processes that are required to define cadastral boundaries. In some cases, licensed cadastral surveyors expressed concerns that through this research LINZ was attempting to undermine the position of the NZ licensed cadastral surveyor (despite clear instruction that this was not LINZ directed research). A number of licensed cadastral surveyors noted that they would not participate in volunteering data, because it would negatively impact on their ability to earn a living. This minority view was at odds with the rest of the surveyors who recognised crowdsourced information was not limited to submission of survey observations and could include other information such as notification of missing or destroyed marks. As mentioned earlier, one survey participant noted that surveyors already contribute information voluntarily through the use of a 'survey information only' dataset. 


\subsubsection{Impacts on the Cadastral System and Data Management}

Users and officials clearly recognised that there are significant benefits to be gained from crowd sourcing cadastral data but indicated that because of data quality issues, LINZ or licensed surveyors needed to retain the control of data entering the system. Participants indicated that an understanding of who the contributors are is important in order to build trust or apply vetting processes so only suitably trained or skilled people could contribute. This indicated that participants believed that there was variety of contributor knowledge, experience and data capture capability. Participants in the phase 1 confirmed this in the capability question that showed variable ability to provide different services and a significant difference in capability between the survey qualified and those without survey qualifications (Figure 18 and Figure 19). Participants also assumed that contributors would not have strong surveying skills, implying that participants did not see "surveyors" as a crowd in their own right.

As discussed in section 4.6.2 participants were concerned about anticipated high volumes of data acquired if contributors were given free rein to submit whatever they liked. Associated with this concern was the increased risk that much of it may in turn be of little use and would 'clog the system' or be unable to be integrated for use in a timely manner. Surveyors in particular were concerned that additional effort by officials to encourage, check and integrate crowdsourced data would have to be shared with the effort required to integrate authoritative data and that this would affect approval and integration timeframes for the cadastral survey datasets lodged by a LCS.

Whereas officials were more concerned about the necessary system changes required which could be challenging because the nature of the data and its submission is likely to be quite different to that currently supplied by licensed cadastral surveyors. Two distinct options were able to be distilled from participants which amounted to either:

1. data would need to be either managed in an unstructured way, and therefore not integrated (or very loosely integrated) with the existing cadastral data; or

2. contributors would need to be managed by ensuring that only specific data or information could be submitted that was correctly structured so that it could be integrated with the existing cadastral data.

Officials tasked with responsibilities to maintain the system displayed a preference for the second option as it could be tailored to support or enhance existing data for long term benefits. Other officials and users more concerned about maintaining the integrity of the cadastre and ensuring that 'wrong data' could be isolated and removed. These participants were also in favour of option two because data that is structured to comply with existing data 
models is more conducive to quality assurance processes and its use is easier to validate. However some users and officials were less concerned about strong integration with other data, seeing instead benefits in supporting contextual (or unstructured) data, which if available would enable surveyors to better make decisions. A repeated example (as previously mentioned) was movable boundaries (such as rivers/streams) where being able to understand the history of any movement helps to determine the location of the boundary.

Most participants considered that it was especially important to be able to distinguish between different users. Separating users or their contributions is important to manage situations where users cannot provide information to a high enough standard (or have deliberately provided false information). Commonly, officials were the group who indicated that appropriate controls should be put in place and that changes to the existing system are needed. These additional tools, processes will enable the limitations of the existing cadastral system (Landonline) to be overcome or worked around to enable the acquisition, integration and use of VGI. Those officials who are involved in system management queried the costs associated with altering the system in order to manage additional data (including associating appropriate metadata to identify the source of the data). They were also wary of adding new tools due to additional costs and workloads in their development and integration with existing systems.

The primary reason given for lack of support by participants was the risk of wasted effort by either users or officials. Potential system changes will need to include requirements for capture of appropriate metadata, tools and processes. Another potential "waste of effort" was associated with a 'lack of uptake'. Whether enough potential contributors could be found was questioned and therefore the sustainability of managing a crowdsourcing process in addition to the existing cadastral survey driven processes. Accordingly, unless the value of contributing was widely marketed and contributions from users acknowledged and acted upon in a timely manner, a risk was identified that contributions would diminish to unsustainable levels - thereby effectively wasting the investment to enable crowdsourcing.

\subsection{CHALLENGES AND REQUIREMENTS}

Reflecting the wide cross section of interested parties directly involved in the management, maintenance, and use of the cadastre (especially digital cadastral data), participants identified many challenges. These challenges related to:

- data integration challenges

- perception and confidence challenges

- capability challenges

- support and resourcing challenges 
Some of the challenges have (in part) been addressed or alluded to in earlier sections (see sections 4.5, and 4.6) due to their close association with the potential of crowdsourcing, data issues, concerns and the effects on users, producers and managers.

\subsubsection{Data InTEgration Challenges}

Assuming that $\mathrm{VGl}$ is accepted in some form, the main data challenge identified concerns how the data will be integrated into the cadastre. Qualitative questioning in phases 1 and $2 b$ focused on allowing crowdsourced information to influence the cadastre. The interviews and online survey did not cover examples of how to integrate data or informational contributions because these are well defined in LINZ standards and defined processes. The officials interviewed who work directly with cadastral data should be familiar with them (LINZ, 2009b, LINZ, 2013b). With a focus on 'should' contributions influence the cadastre, users or officials took an outcomes rather than a data perspective. The data perspective highlighted the nature of the linkages and dependencies between data elements and their influence or relationship to the cadastre that is important to users. The extent to which these linkages should be developed or maintained was highlighted as another complicating consideration. There was concern that if 'low value' data was strongly integrated then removal might not be possible if the data was found to be unnecessary. Officials were wary about the potential need to integrate data extensively as such efforts may be more costly than the value of the contribution. Section 4.5.1 showed that phase 1 participants considered that VGI from users with no survey qualifications would generally harm the cadastre. The exception was that the non-survey qualified participants thought that digitising boundaries from plans by those without survey qualifications would generally improve the cadastre, yet capturing the survey observations would not. An improvement to the cadastre was expected by both survey qualified and non-qualified if survey data recapture was undertaken by qualified but not licensed surveyors.

Comments from phase 1 participants and officials indicated that the riskier the source of the information (such as fears of the data coming from untrained people) the more likely it was that it should be not formally integrated. This meant that there was for example a preference for linking the data or relying on information within the contribution itself for use in conjunction with cadastral data. If the data was just for context (such as mapping of occupation) or information (e.g. advice of possible mark disturbance) then indicators were that it just be loosely integrated. The reverse situation for tight integration applied to high value data that cadastral users could rely on, examples include the coordinates and data relating to private continuous operating reference stations (CORS), and other volunteered survey information undertaken by professional surveyors. 
In the comments, phase 1 participants were slightly wary of relying on user trust mechanisms such as frequency of a contribution, the location of a contributor or even who the contributor is, due to the difficulties in identifying and holding accountable the actual contributors for any issues subsequently found. Most interviewees felt that the as the regulator of the data, LINZ should undertake data verification, including the use of mathematical checks and ensuring redundancy for observational data. A common assumption was that LINZ would provide appropriate data capture and verification tools to support and ensure only the data needed is provided. This presumption of a final verification step, rather than leaving 'errors or wrong data to be corrected by the crowd' is unusual for crowdsourced data sets, but normal for authoritative datasets. It may indicate that there may be higher expectations of the data, and of contributors, where crowdsourcing information is to be included in authoritative or nationally significant datasets such as those provided by Government. Many users expected that LINZ would provide both in-house expertise and education and training to contributors where necessary.

\subsubsection{Perception and Confidence Challenges}

As mentioned earlier incorporating crowdsourced information may change user perceptions of the cadastre was a perceived risk.

Survey qualified users almost exclusively assert that they understand how survey information is created (Figure 27)

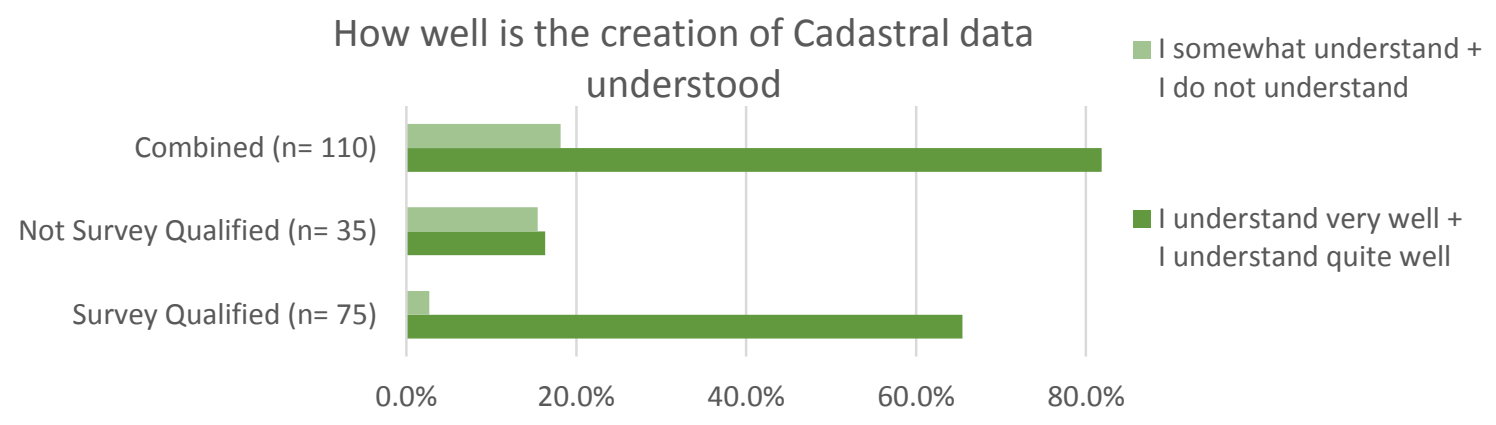

Figure 27: How well do users think that they understand how cadastral data is created

Most of the survey qualified users view non-survey qualified users as possibly providing data that will harm the cadastre (Figure 25 and Figure 26). In conjunction with the lack of support from the survey qualified participants, this negative view of other potential VGI providers may be influenced by a greater understanding of surveying complexities and the risks associated with poor data in defining boundaries. Whether this is the case would require further research. 
Officials and survey qualified participants were concerned that although all practical steps may be taken to ensure crowdsourced information was appropriately used, unrealistic negative perceptions may develop by cadastral users and faith or trust in the cadastre may be lost. Simply accepting VGI may cast doubt on the authoritativeness of the dataset irrespective of the quality of the contribution.

"..there is a reputational risk around people now perceive that LINZ accepts data from everyone, and with it not just coming from licensed surveyors and therefore particularly perhaps within the surveying and spatial professions, there may be a perception that LINZ doesn't care so much about the data any more, because we are accepting information from anyone. Now I don't believe that's a real risk, but it could be a risk to our reputation if we don't tell our story right. $\quad$ LINZ official

A large majority of participants expressed a view on user confidence on their perspective of authoritativeness, trust or data integrity. Participant views were about maintaining confidence (not necessarily building it). Ensuring data was suitable, correct and appropriately integrated was identified as fundamental. The confidence perception issues identified did not solely affect the public or end users. Confidence in crowdsourcing contributors is needed to ensure that the cadastre provides (and continue to provide) appropriate information.

"...there's a lot of information out there in the world which we would benefit from having. And it's a bit harder in the cadastre because the cadastre is about boundaries and boundaries have a great deal of value. So people need confidence that the information is coming from a neutral and trusted source if it's going to affect their boundaries. “

LINZ official

Participants indicated that ensuring individual contributions were dealt with in a timely manner along with the use of the data by the provider would ensure contributors felt valued and may be sufficient to keep them engaged. Critical in the views of some surveyors was the confidence of licensed cadastral surveyors. Licensed cadastral surveyors provide information that becomes authoritative and are stakeholders in the cadastre. Losing the confidence of surveyors to re-use information would be detrimental to the development of the cadastre.

"If there is some perception that it is not or cannot be relied on any more, then you may as well not do it".

LINZ official 
Participants highlighted that expected data issues with VGI will need to be planned for and mitigate against to preserve confidence and maintain quality. To integrate VGI the level of integration, the types of contributions that will be encouraged and allowed, and the extent to which data quality controls are implemented will need to be determined. Additional strong negative comments also indicates that LINZ will also have to address the perception that they are not freeloading but are investing and taking the maintenance and development of the cadastre seriously.

"LINZ has responsibility for the cadastre and needs to step up to actually bring it up to speed at a far higher rate than it is doing. This needs funding. Private organisations can contribute, but not for free! This is LINZ's core, absolute core, business. Total attention needs to be paced [sic] on this and a lot of 'sideline' activities which consume funds need to be stopped so that funds can be applied to cadastre maintenance" Survey qualified participant

Not all participants focused on negative perceptions with some (mainly LINZ officials) commenting that enabling users to contribute information reflects public expectations, that only receiving data from cadastral surveyors is a narrow perspective and that crowdsourcing will reduce the perception that the cadastre is just for expert users. In addition, the existing perception of some users is that the cadastre is not very accurate and is missing information or incomplete. For these users, information provided via crowdsourcing

"If handled correctly it has got to be better than what we've currently got"

User response

Given some phase 1 comments, an immediate challenge may be to convince a small but strongly opposed group of surveyors that crowdsourcing is safe, that it will enhance the cadastre, will not compromise its integrity or authoritativeness, and will not cost them their livelihood.

\subsubsection{Resourcing Challenges.}

There was a widespread view that applying crowdsourcing to the cadastre will not be possible without the support of LINZ. The consensus where an opinion was provided was the overall workload in managing the cadastre will increase and LINZ will need to ensure that existing systems and processes continue uninterrupted. 
Between the users and officials, a range of resourcing challenges were identified that will need to be addressed, as follows:

- Additional funding to enable resourcing and technical changes (listed below).

- Additional trained and knowledgeable staff to provide contributor support.

- Neutral Quality Assurance especially for data that will influence authoritative information.

- Education and training to support and encourage uptake.

- Changes to the systems and processes that enable the information to be accepted, integrated and re-used.

The extent to which the above support and resourcing is required will depend upon what contributions will be accepted, and the level to which they will be integrated into the cadastre. Participant opinions regarding the provision of facilitating tools postulated that increasing support or restrictions in one area simply changes the support or resourcing in another.

"It's where you put your costs. You could build a very simple tool with no costs (low cost) that would trawl a whole bunch of information. But then you'd have a cost of the backend to analyse and interpret that. Whereas, if you built an expensive tool with rules and business processes and people go "it's too hard" and you don't get any information."

LINZ official

Further, to provide information that some users thought could be volunteered would require much more of the information already in the cadastre to be made freely available than currently, for example additional fee based information includes the images of existing survey plans (CSD's), traverse sheets and field notes, was also considered necessary. This same information was also noted as being required for the potential of a LINZ facilitated crowdsourcing led data back capture project of the survey information originally recorded on these old CSD's. When considering the potential crowdsourcing areas, users and officials had noted that increased access to LINZ knowledge and expertise would mitigate risks associated with poor data. 


\subsection{SUMMARY OF RESULTS}

Amongst participants, there is general consensus about the importance of the cadastre and that the data within it is authoritative. The implied concept of incorporating "non-authoritative" data in the form of volunteered contributions generated significant concern amongst participants, primarily due to their perception and understanding of what VGI is and its scope.

This leads to several key points:

- The perceptions of VGI contributions are almost as important as the contribution itself. Participants felt that simply accepting VGI as contributed could cast doubt on the authoritativeness of the dataset - irrespective of the quality of those contributions.

- There is a strong perception that VGI and crowdsourcing relates to 'amateurs' and therefore the crowdsourcing implications of information that is already volunteered to the cadastre was overlooked by research participants. This perception may have driven the few very strong 'anti VGl' reactions encountered in this research.

Officials supported crowdsourcing more than either the survey or non-survey qualified participants but placed caveats on this support as the decision to accept crowdsourced data from users may be irreversible. In addition, officials, unlike many users, generally did not see crowdsourcing as 'free data'. Accordingly, officials' support for crowdsourcing was dependent upon adequately mitigating the risks and costs of poor data and in managing the 'hidden' costs associated with developing new processes, systems or changing current systems. Support from survey qualified participants for cadastral crowdsourcing is low. Most survey qualified participants did not consider other supporting processes or data, and distrusted the capability of non-survey qualified users to provide measurement or positional information. Given that $94 \%$ of the survey qualified participants experienced issues with accuracy and $86 \%$ identified completeness issues, resistance to crowdsourcing as a means to improve the cadastre seems difficult to justify. The data quality issues encountered by participants point to an underlying need to improve the cadastre.

There is widespread recognition that some crowdsourced contributions would be of high value. The need to improve cadastral data, and the potential benefits identified by officials and users, may explain why most users and officials (and some surveyors) are open to using crowdsourcing to undertake cadastral improvement. Participants were slightly wary of relying on user trust mechanisms such as frequency of a contribution, the location of a contributor or even who the contributor is, due to the difficulties in identifying and holding accountable the actual contributors for any issues subsequently found. Support from participants only exists if a balance between risks and benefits is achieved. 
Mitigations of risks (such has those against poor quality data) focused on:

- avoiding unauthorised change and controlling quality in order to protect the cadastre through either user QA or a final verification step, (preferably undertaken by the dataset administrator) that would minimise the chance of any error entering the system

- data acceptance controls through the use of facilitating tools and processes, designed to manage users and the acquisition of specific data that is needed for the cadastre

- metadata that describes the contributions and identifies the contributor so that informed decisions can be made by LINZ as to whether to accept the data, manage the data and in turn for users in determining whether it is fit for their purposes

Users have a much higher expectation of data quality and of contributors when associated with authoritative datasets. Accordingly, participants were interested in how, and to what extent, data would be integrated into the existing cadastre. Contributors also want to understand the aims and objectives of geospatial crowdsourcing projects (see section 4.4.2). Surveyors and officials assumed that LINZ would accept crowdsourcing contributions for integration into the cadastre. Two distinct options for enabling crowdsourced data to be used with existing cadastral data were identified:

1. data is either managed in an unstructured way, and therefore not integrated (or very loosely integrated) with the existing cadastral data; or

2. contributors are managed by ensuring that only specific data or information could be submitted. This management would ensure data was correctly structured so that it could be integrated with the existing cadastral data

For most potential contributors, multiple drivers or reasons would be required to encourage contributions. The motivations to contribute ranged between those that were altruistic and those that were more self-serving (egotistical). Reasons to contribute also ranged between intrinsic and extrinsic motivations. Users and officials identified a wide range of benefits of contributed information, irrespective of the motivation such being able to extend the cadastre, obtain new data, reuse information that would otherwise be lost, use surveyor skills more widely and increase the efficiency of the system and use of the data. Accordingly participants thought that:

- a greater effort should be made to align 'future work' of users with the needs of the cadastre,

- there should be mechanisms for users to record information pertinent to boundaries without the need to engage a surveyor or a solicitor. These would include contributions which will aid future decision making, including measurements, photos or documents or advice. 


\section{DISCUSSION}

Opinion varies as to the best approaches for geospatial crowdsourcing within the cadastre in New Zealand, including even whether it should be permitted. This chapter discusses existing contributions and builds on the major issues, findings and opportunities identified in the results. This chapter focuses on understanding and possibly resolving barriers to applying crowdsourcing to the cadastre. The chapter explores what is authoritativeness, how data could be integrated, how the motivations of contributors can be safely acquired and applied, and the use of existing data providers and the implications of this research.

\subsection{AUTHORITATIVENESS}

The entire cadastre is generally viewed by participants as being authoritative. Participants rely on it for its intended purpose of defining the 'where' in relation to property rights (Grant et al., 2014 p6). However, many uses of cadastral information or derived components were never originally intended. The parcel fabric for example, was a 'spatial indexing system' and not designed for widespread geospatial analysis and overlay (LINZ, 2013a). Issues of authoritativeness were of prime importance to most users, surveyors and officials. Participants implied that to be authoritative, the data must be created or collected under some authority. For the NZ cadastre, the Cadastral Survey Act (2002) sets out the authority for cadastral data to be regulated, collected and managed.

A key finding of this research was that perceptions of VGI are almost as critical as the contribution itself. Irrespective of the quality of the contributions, or even whether no authoritative contributions are permitted (refer to section 4.7.2), participants identified that simply allowing crowdsourced data to be included in the cadastre has the potential to negatively impact the perception of authoritativeness. This is especially the case if issues were traced back to crowdsourced information. Were issues to occur, then the supporting role that the cadastre plays in society and the economy, and its suitability to service the public need to define the 'where' in property rights restrictions and responsibilities (Grant et al., 2014) could be undermined. Consequently, the fears of many participants who are strongly opposed to incorporating crowdsourcing in the cadastre may be fulfilled and accordingly regretted by administrators. The challenge, therefore, is to enable the use and integration of crowdsourced information so that it does not undermine confidence in cadastral 'authoritativeness'. Officials and administrators may need to expand their roles to include a significant focus on education and perception mitigation. This additional focus would be supplementary to the work required to enable the benefits of fundamental geospatial data to be obtained (see section 2.4.3). 
As identified in the results chapter, data providers and users do not have a single cohesive view or understanding of authoritativeness. Often data users and data providers have different perspectives of what is part of the cadastre, how it should be managed and whether it is authoritative. It then follows that their views differ as to what constitutes an authoritative database, dataset or individual data element. In addition, the views and perspectives of the role of the authority (officials) managing the databases and holding data, also vary. However, differences between surveyors/users and officials are better managed than because the regulatory and strategic views are usually derived from a single government agency.

To avoid confusion, the use of the terms and concepts relating to 'authoritative data' or 'authoritative databases' needs be undertaken carefully and in the light of specific definitions. Equally however, a proliferation of existing terms and definitions for different subsets of data within a wider system (such as the cadastre) is not helpful. Confusion as to whether a data set is authoritative may be exacerbated if crowdsourced data is accepted and integrated because not all elements or records in the dataset are 'authoritative'. Concepts of what authoritative actually means appears to be changing from the simple perspectives of whether a dataset is produced or backed by the Government. Accordingly, a dataset traditionally seen as 'authoritative' may now include 'non authoritative data'. This change 'begs the question' - is it still authoritative?

The characteristics of a fundamental dataset (see section 2.4.3) fully encompass the elements (and more) users implied for authoritativeness and helps address the apparent confusion as what is authoritative. The NZ cadastre fits within the 'cadastral and property' theme and the cadastre itself contributes digital parcels, cadastral and survey definition, land districts and sub parcels to the potential list of fundamental datasets. The remaining datasets in this theme are; the rights register, rating units, valuation and crown land/state areas. These datasets all fit within the wider definitions and uses of the cadastre as detailed in section 262.4.3. When combined with the requirements for fundamental datasets to be under formal custodianship and stewardship, it appears that the concept of fundamental datasets now provides the much needed basis for a more encompassing definition of 'authoritativeness'

\subsection{INTEGRATION OF VGI INTO THE CADASTRE.}

Most users recognised that significant benefits could be gained from crowdsourced cadastral data and identified a number of ways that VGI could add value to across the breath of the cadastre. These examples included improving responsiveness, reducing costs, identifying errors or maintenance issues, enabling reuse of existing data and extending the scope of the cadastre. Because of the risks and potential data quality issues, user suggestions were heavily tempered with the need by an appropriate authority such as LINZ or licensed surveyors to retain control of not only the data entering the system, but also the extent to which it is integrated. 
There was little consensus on the extent or level of integration that contributor information should have with the existing cadastral data. This may be because participant views on whether to support VGl, any perceived issues and mitigations usually focused on just one or two themes or applications of cadastral data. The impressions gained from interviewing the officials and administrators indicated that everyone was also heavily influenced by their understanding of what $\mathrm{VGl} / \mathrm{crowdsourcing}$ was, and of their own individual role and cadastral experience. Accordingly, it is unlikely that no single intervention may be appropriate for all contributions or user circumstances and that multiple interventions may be needed for some data to account for different user or data variables. VGI management using multiple interventions within a single environment requires additional research as most applied uses of crowdsourcing in the literature focusses only on individual applications (Basiouka and Potsiou, 2012) or reports that are an aggregation of various individual applications (Haklay et al., 2014, Kostanski, 2012 , McLaren, 201 1, Rice et al., 2012).

Although seven different approaches to avoiding or mitigating VGI related issues have been identified, these approaches reflect disparate points of reference between extremes of a restrictive data focus and a more 'hands off' user focus. To demonstrate the typology of the seven different approaches to avoiding or mitigating VGI related issues, identified in the literature, Arnstein's (1969) public participation model has been adapted to create the following diagram (Figure 28). This diagram summarises the role that each mitigation approach may play in protecting an authoritative database like the cadastre from negative aspects of crowdsourcing.

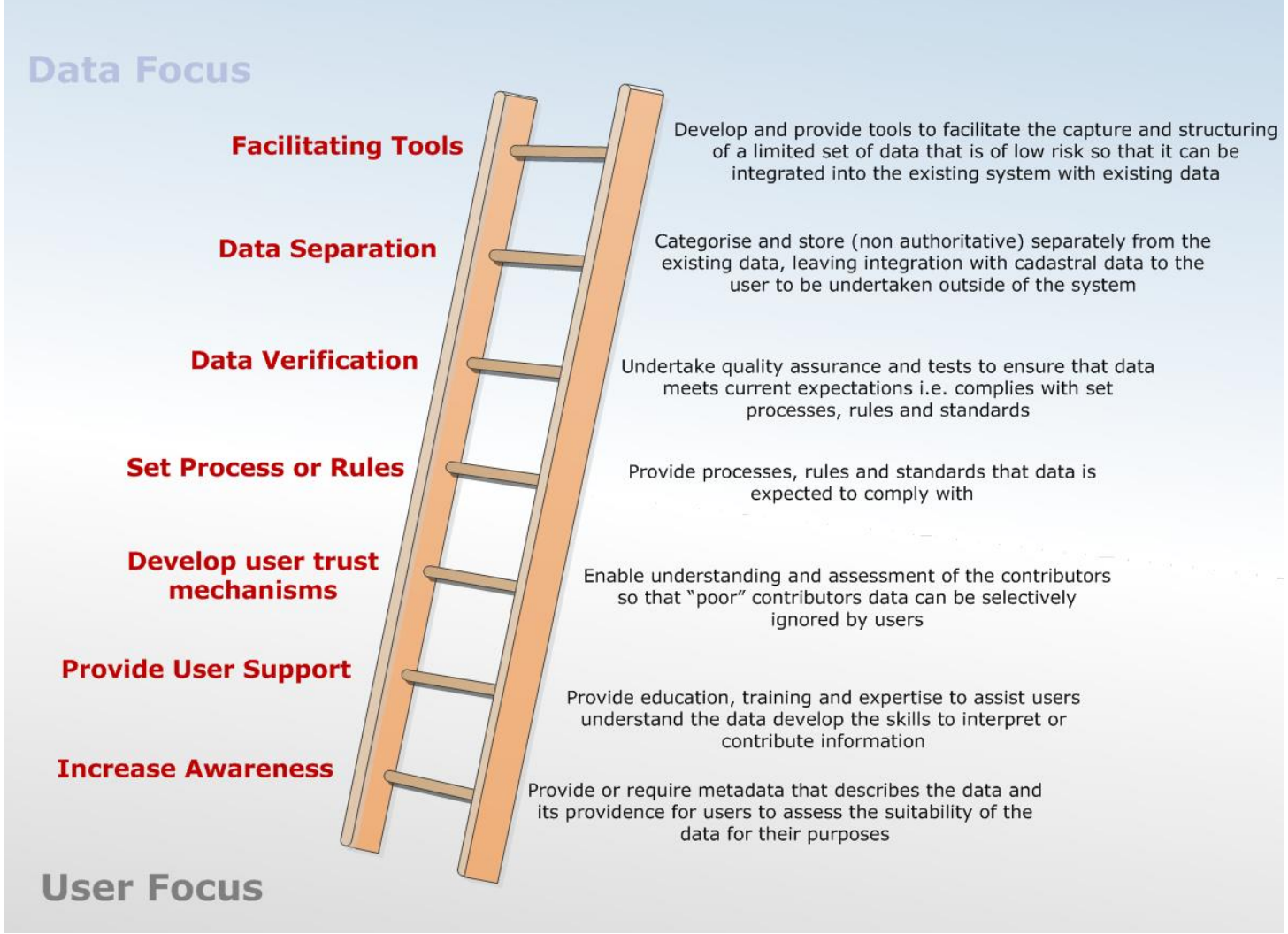

Figure 28: Approaches to mitigating issues associated with geospatial crowdsourcing

(Authors' own) 
To protect the cadastre, separating VGI contributions from the 'authoritative' record was preferred by many participants. Separation, as a more extreme form of data management, raises usability issues of how the separated crowdsourced data can be used in conjunction with the cadastral data. One option is to rely on the intrinsic spatial capabilities of VGI (where it exists, or can be derived) to perform overlays or spatial joins to link the two datasets. Another option is to use data links such shared identifiers or other attributes as primary/foreign keys (e.g. parcel number and appellations). The practical implementation of linking disparate datasets is by a key and is common in existing broader cadastral datasets (such as zoning and valuation datasets). This concept is explored in greater detail later in this section (see Figure 29).

Prior to accepting VGI contributions, the effort required to keep disparate datasets linked so that the information can be used in conjunction with the cadastral data also needs to be considered. Maintaining attribute linkages can take significant effort as changes to either dataset have to be continually assessed to create new links or to repair broken ones. However, not maintaining such linkages lower the effort required for maintenance, meaning that the usefulness of the contributions will gradually deteriorate over time. It is accordingly, usually only suitable for data that has a short period of usefulness. The alternative, to rely on spatial linkages requires both datasets to be spatially accurate with known datum/projection characteristics. The potential extent of formal integration of a contribution into the fundamental cadastre also depends upon how closely the structure the contributions are to the existing data held in the cadastre. Most digital cadastral data is stored and managed within a highly standardised data model (LINZ, 2012a). To integrate crowdsourced data, the data must be structured as per the existing cadastral data and with the appropriate links. However the extent to which other data elements then become reliant on the contribution is of concern to users and officials. Determining how important these contributed data elements are, can help set the appropriate level of integration. Less important contributions can then be integrated in such a way that their removal would not generate integrity issues, i.e. they should be loosely integrated. Loosely integrated contributions could also include information that does not have attribute linkages or where its use is for contextual purposes such as imagery.

In considering responses from all the research participants on whether geospatial crowdsourcing should be integrated into the cadastre, the main delineating factors for the level of integration were:

- the perceived risk of a negative impact or likelihood of significant benefit on the cadastre from the contribution

- the purpose of the information; whether this was intended add to the cadastral record, for contextual use or informational use

- how important the information/data is to the contributor, end users or officials 
The three integration factors are primarily subjective. Risk and importance are relative variables. In addition, the level of integration itself changes the perceptions of the quality of the data and its authoritativeness. So although data may be capable of being tightly integrated, it may be better to integrate it less. Integrating to a lesser extent indicates to users that the data may be of a lower quality or less authoritative. Conversely, the more authoritative the data, the greater the effort that should be expended to integrate it to the highest standard practicable.

The impression gained from the research participants was that the riskier the source of the information, such as data coming from untrained people, the less comfortable participants were with contributions being formally integrated into the cadastre. That is, there is a preference for keeping data separate, and linking contribution through attributes or relying on the contributions intrinsic spatial capability for any use in conjunction with authoritative cadastral data. If the data was simply for context (such as mapping of occupation) or for information (e.g. advice of possible mark disturbance) then loosely integration or linking would likely be more acceptable to those surveyed. Conversely, tight integration should be applied to very high value cadastral data that users of the cadastre could rely on (such as survey vectors and boundary dimensions from licensed cadastral surveyors).

The three categories of data (informational, contextual and cadastral) as identified in the previous paragraph relate to the value of the contribution. The factors of value, importance, risk and the level/extent of integration which participants identified that affect cadastral integration can be demonstrated in a matrix form (Table 9). This matrix enables the interrelationships between them to be more easily understood and for individual contributions to be easily understood.

\begin{tabular}{|c|c|c|c|c|c|c|c|c|c|}
\hline & \multicolumn{3}{|c|}{ Critical } & \multicolumn{3}{|c|}{ Important } & \multicolumn{3}{|c|}{ UnImportant } \\
\hline & $\begin{array}{l}\text { Low } \\
\text { Risk }\end{array}$ & $\begin{array}{c}\text { Med } \\
\text { Risk }\end{array}$ & $\begin{array}{l}\text { High } \\
\text { risk }\end{array}$ & $\begin{array}{l}\text { Low } \\
\text { Risk }\end{array}$ & $\begin{array}{c}\text { Med } \\
\text { Risk }\end{array}$ & $\begin{array}{l}\text { High } \\
\text { risk }\end{array}$ & $\begin{array}{l}\text { Low } \\
\text { Risk }\end{array}$ & $\begin{array}{c}\text { Med } \\
\text { Risk }\end{array}$ & $\begin{array}{c}\text { High } \\
\text { risk }\end{array}$ \\
\hline Cadastral & Tight & $\begin{array}{l}\text { Tight/ } \\
\text { Loose }\end{array}$ & Loose & $\begin{array}{l}\text { Tight/ } \\
\text { Loose }\end{array}$ & Loose & $\begin{array}{l}\text { Linked/ } \\
\text { Loose }\end{array}$ & Loose & $\begin{array}{l}\text { Linked/ } \\
\text { Loose }\end{array}$ & Linked \\
\hline Contextual & $\begin{array}{l}\text { Tight/ } \\
\text { Loose }\end{array}$ & Loose & $\begin{array}{l}\text { Linked/ } \\
\text { Loose }\end{array}$ & Loose & $\begin{array}{l}\text { Linked/ } \\
\text { Loose }\end{array}$ & Linked & $\begin{array}{l}\text { Linked/ } \\
\text { Loose }\end{array}$ & Linked & $\begin{array}{l}\text { No } \\
\text { Linkage }\end{array}$ \\
\hline Informational & Loose & $\begin{array}{l}\text { Linked/ } \\
\text { Loose }\end{array}$ & Linked & $\begin{array}{l}\text { Linked/ } \\
\text { Loose }\end{array}$ & Linked & $\begin{array}{l}\text { No } \\
\text { Linkage }\end{array}$ & Linked & $\begin{array}{l}\text { No } \\
\text { Linkage }\end{array}$ & $\begin{array}{l}\text { No } \\
\text { Linkage }\end{array}$ \\
\hline
\end{tabular}

Table 9: Demonstration level of cadastral integration based on dependent variables

(Authors own) 
Four options for integration of geographic crowdsourcing are proposed in Figure 29. This figure proposes a model where contributions are integrated to the varying levels as shown in Table 9). The integrations places contributions either into the fundamental cadastre (the existing cadastre managed by LINZ under the Cadastral Survey Act 2002), are linked to it by attributes (keys) or are unlinked. Linked data may have similar characteristics to the data that is integrated into the fundamental cadastre, but differentiated by just a decision as to whether a contribution is integrated into the fundamental cadastre or not. The contribution is kept separate from the formal
cadastre but the linkages to cadastral records are
developed and maintained. The contribution could
be integrated into the fundamental cadastre if
desired. This is similar to existing broader Cadastral
components. An example could be a photo (with
geo-tag and mark id) of engineering works affecting
survey marks, a valution rating unit, survey vectors
transcribed from survey plans (with associated plan
ids and line or node id's).
The contribution is accepted but kept separate from the formal cadastre. No additional effort to enable end-users to use the contribution in conjunction with cadastral records is made. The use with cadastral data is dependent upon the intrinsic capabilities contained within the contribution such as geo-referencing. An example could be a photo(with geo-tag) of engineering works affecting survey marks or a GPS/GNSS file showing a rivers edge.

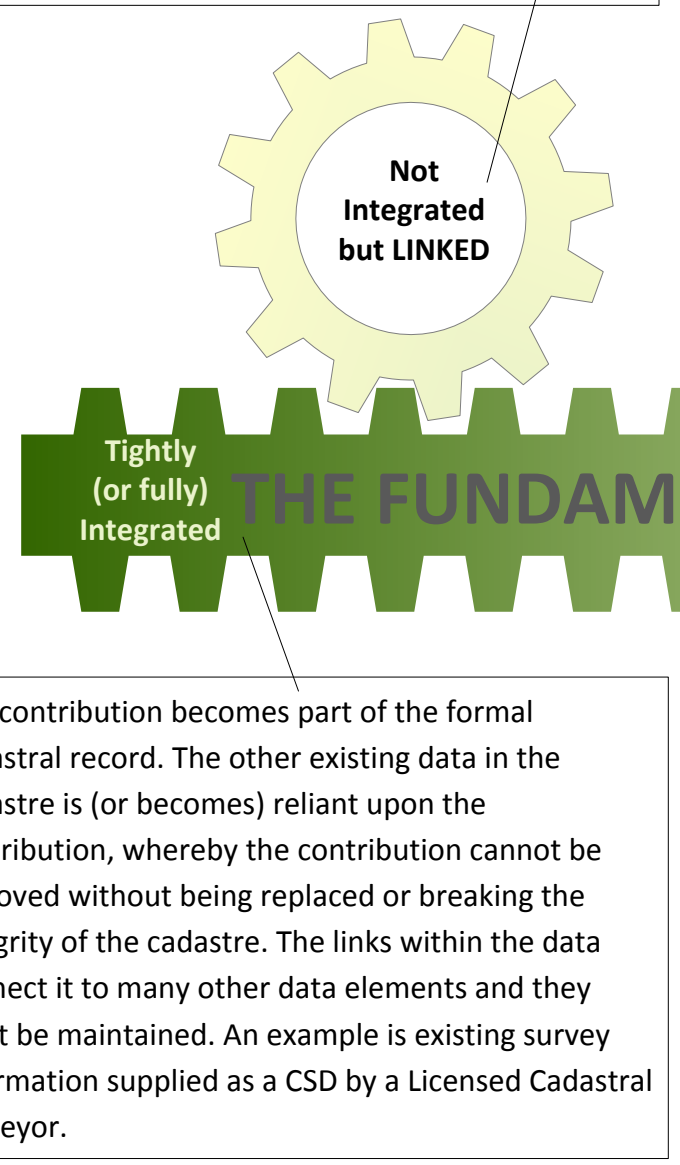

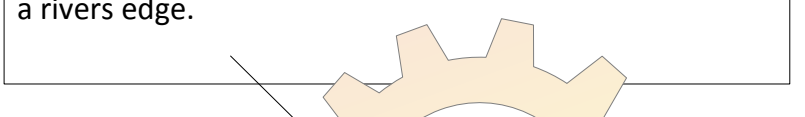

Not Integrated and unlinked
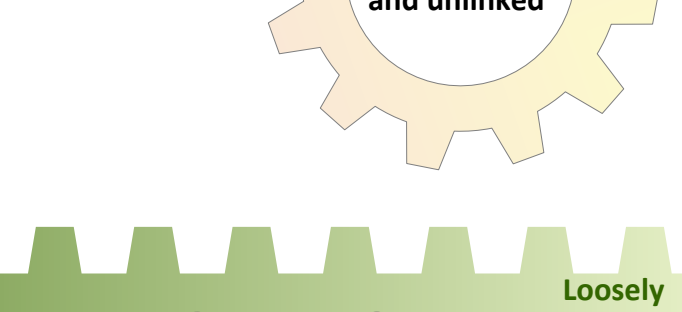
ENTAL CADASTRE (or partially) Integrated

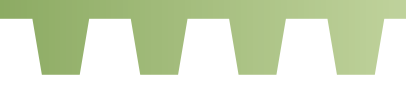

The contribution becomes part of the formal cadastral record, but its use is either not structured data (such as the existing images of survey plans), or its use is optional. Cadastral data is reliant only to the extent upon which links exist within the information, not having links is not critical to its use. An example could be survey vectors transcribed from survey plans (with associated plan ids and line or node id's, but with "non authoritative" metadata.) or documents supplied by owners that record informal agreements or affidavits. 
Figure 29 represents the integration types users identified and also aligns well with the new strategic view of the NZ cadastre where the linked data would likely be data associated with the broader cadastre (Grant et al., 2014).

The NZ cadastral strategy was released after the data collection stages of this research and despite identifying that crowdsourcing has a potential role to play in the maintenance of the cadastre, clearly considers that crowdsourced contribution should not be integrated into the fundamental cadastre. This strategy states within the crowdsourcing section that:

"For the fundamental cadastre, all information is required to be lodged and certified by a licensed cadastral surveyor" (Grant et al., 2014 pl2)

The research undertaken in this study, however, identified that there are aspects of the fundamental cadastre where crowdsourced information could provide benefit. Possible areas include data recapture of survey observations from CSD's prior to Landonline, and some high quality observations associated with engineering works, CORS stations and other data collected for precision surveys such as those associated with Geodetic surveys. Thus, the strategic view put forward by Grant et al. (2014) seems overly prescriptive, limiting and even contrary to current practice where LINZ staff (who are not licensed cadastral surveyors) make changes to the cadastre and enter information. Accordingly, this research proposes that the decision as to whether to integrate crowdsourced information into the fundamental cadastre should be driven first by whether the contribution is subject to the Cadastral Survey Act (2002) or not, and second by the level of risk or importance of the contribution.

\subsection{MOTIVATIONS AND CATEGORISING POTENTIAL CONTRIBUTORS}

The results in section 4.3, found that most participants require multiple drivers or reasons to consider contributing geospatial crowdsourcing. While question 2.7 of the phase 1 survey asked participants about what would encourage or influence them to contribute VGI, this research did not explicitly focus on contributor motivations. However, the reasons to contribute are influenced by a range of motivating factors. These factors ranged between altruistic and egotistical reasons (see section 4.3.1) and those which are internally or externally driven (see section 4.3.1). Finkelstien (2009) indicates that altruism/egoism is a continuum and HaskiLeventhal (2009) likewise proposes that intrinsic/extrinsic motivations are not necessarily polar opposites but lie on a continuum. 
Figure 30, shows a altruism/egoism continuum and a intrinsic/extrinsic continuum perpendicular to each other and centered on reasons of mutual benefit. This contributor motivation framework, is proposed as a conceptual framework to enable contributor reasons to contribute to categorised and grouped. Grouping contributor reasons together in this way may enable common mitigations and support to be applied to contributions so that the integrity of the cadastre is not compromised. Specific initiatives may also naturally align themselves to one of the classified groups shown in Figure 30. Because each initiative will comprise of individuals or organisations with similar motivation, this motivation framework may provide managers of authoritative databases (like the cadastre) with a means to target/assess specific groups of data producers or users (crowds). By developing initiatives in this way, through the classification of contributor motivations, administrators will also be able to ensure that appropriate support or incentives are provided, risks are better managed and that only appropriate aspects of the authoritative dataset are influenced or changed by geographic crowdsourcing.

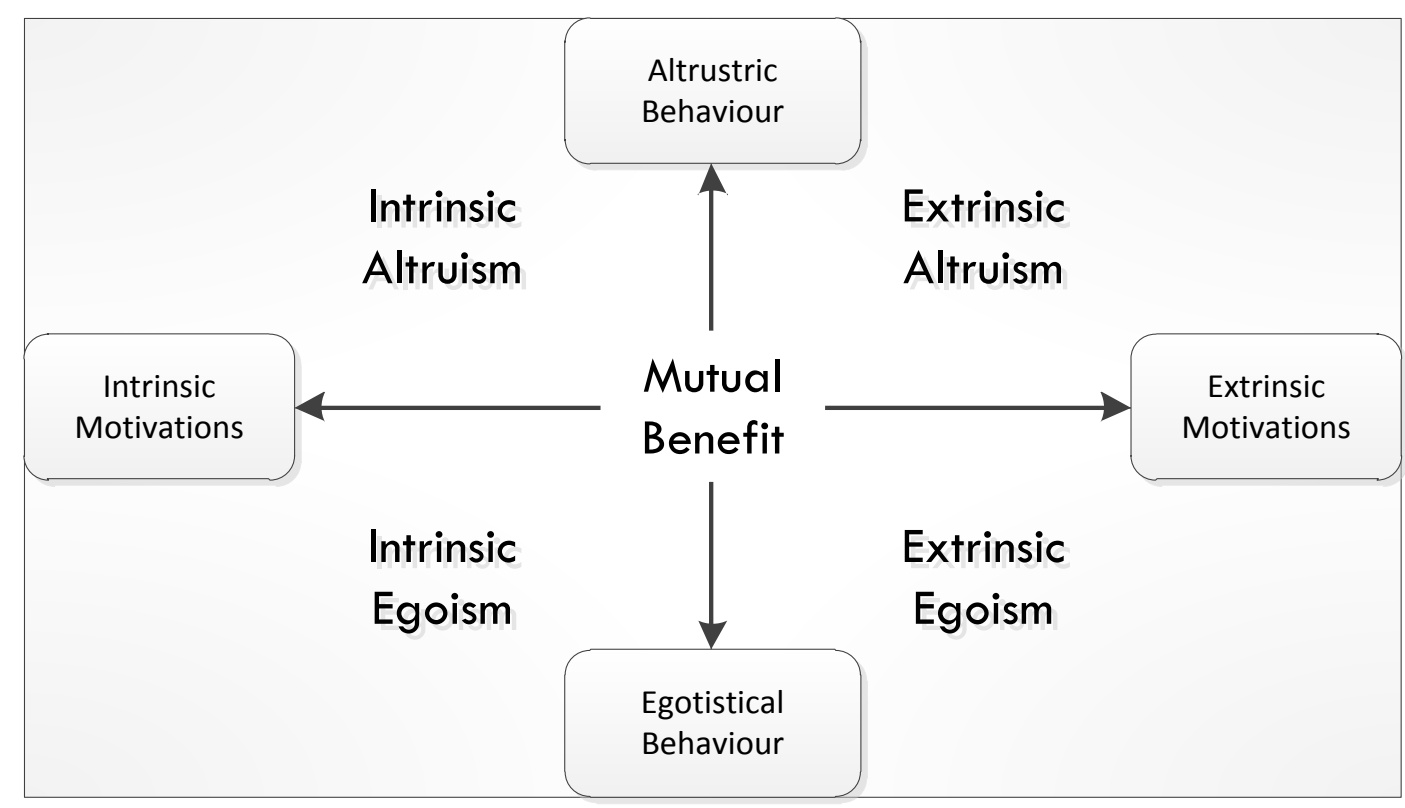

Figure 30: Contributor motivation framework.

(Authors' own)

Unfortunately few responses in this study that indicated a reason to contribute had enough information to assess both continua. Additional specific research is therefore required to test the proposed framework. This future research will need to assess the application of contributor motivation framework to the applicability of crowdsourcing to the cadastre or other authoritative databases. However, to demonstrate the potential, six examples known of by the author, or proposed by research participants are used to show the applicability of volunteered data to the cadastre. These are matched against the five proposed elements of the framework. 
Behaviour/Motivator Source/provider

\begin{tabular}{|c|c|c|}
\hline Mutual Benefit & $\begin{array}{l}\text { Licensed } \\
\text { Cadastral } \\
\text { Surveyors } \\
\text { LINZ/ Local } \\
\text { Council }\end{array}$ & $\begin{array}{l}\text { A surveyor wishes to retain additional adoptions on } \\
\text { my survey so that future surveyors (including } \\
\text { themselves) have the data available which will also } \\
\text { save LINZ doing it later (Nikkel, 2014) pers.com. } \\
\text { A local council needing to undertake a sewer scheme } \\
\text { upgrade and agrees to work with LINZ to upgrade } \\
\text { the parcel mapping. LINZ undertakes the historic } \\
\text { cadastral data capture. The council undertakes all } \\
\text { geodetic surveying work to enable the old surveys to } \\
\text { be integrate and adjusted (LINZ, } 2011 \text { a) }\end{array}$ \\
\hline Intrinsic Altruism & Local Council & $\begin{array}{l}\text { A government funded engineering project offer the } \\
\text { boundary capture and survey work associated with } \\
\text { as-built surveys that were not needed for easement } \\
\text { CSD's (Cooper, 2012) pers.com. }\end{array}$ \\
\hline Intrinsic Egoism & Local Council & $\begin{array}{l}\text { To enable boundaries align with aerial imagery, a } \\
\text { local council commissions survey work for the extent of } \\
\text { a small towns so that can provide better services and } \\
\text { submit the data via standard survey } \\
\text { channels(Andrews, } 2006 \text { a, Andrews, 2006b) }\end{array}$ \\
\hline $\begin{array}{l}\text { Extrinsic } \\
\text { Altruism }\end{array}$ & $\begin{array}{l}\text { Licensed } \\
\text { Cadastral } \\
\text { Surveyors }\end{array}$ & $\begin{array}{l}\text { LINZ wishes to assess the potential of re-using } \\
\text { archived surveyor data capture A surveyor responds } \\
\text { to a LINZ request and offers old SDRmap project files } \\
\text { (a legacy survey processing package) for this } \\
\text { purpose. }\end{array}$ \\
\hline Extrinsic Egoism & $\begin{array}{l}\text { Student / } \\
\text { Lecturer }\end{array}$ & $\begin{array}{l}\text { So as to better understand least squares surveying } \\
\text { students/lecturers respond to a LINZ request to } \\
\text { undertake cadastral adjustments to clear the backlog. } \\
\text { (example inspired by a participant suggestion) }\end{array}$ \\
\hline
\end{tabular}

Table 10: Potential examples cadastral geospatial crowdsourcing based on behaviour/motivation continua

\subsection{FACILITATING TOOLS AND DATA QUALITY}

A definition for an authoritative dataset as extensive as that indicated in section 5.1 means that there is a wide range of datasets that could be considered authoritative. Accordingly, a large range of authoritative data may also mean a wide range of potential contributors for administrators with stewardship or custodian responsibilities to consider and support. For these administrators (and especially those with legislative responsibilities, such as the Surveyor General), to look towards crowdsourced geographic information to aid in maintaining and developing fundamental data, an understanding of who the contributors are is important. Because of the variability in contributor knowledge, experience and data capture capability; 
an extensive range of data volumes and data quality is likely. Through understanding the characteristics of different crowds and their motivations (refer section 5.3), administrators will need to provide appropriate support, ensure appropriate 'crowds' are targeted for contributions and guarantee only appropriate aspects of the authoritative dataset are influenced or changed by geographic crowdsourcing. These measures will safeguard the cadastral datasets from material sourced from varying crowds by additionally ensuring that appropriate controls on the acceptance and integration of the contribution can be undertaken. These controls should aim to have minimal involvement from officials so that both tangible and intangible costs to accept data do not exceed their benefits, and contributors are not unnecessarily inconvenienced with over rigorous interventions.

With many research participants from across the data collections stages being quite concerned about the data quality that would come from VGI contributions, facilitating tools seem to be the only practical avenue if data is to be integrated into the cadastre. Accordingly, to protect the cadastral data, ease quality concerns and target specific contributors; adapting Facilitated-VGI (F-VGI) for cadastral purposes may be the solution to using geospatial crowdsourcing without significant negative effects. Whereas $\mathrm{VGl} /$ crowdsourcing encourages wide and varied contributions from an extensive range of participants, F-VGI (as introduced in section 2.1.6) encourages and supports specific types of contributions via a facilitator (Seeger, 2008). If this facilitation is extended to include customised tools (commonly referred to as being needed by the research participants) the control, management and structuring of data could be built in, thus creating facilitated geospatial crowdsourcing. F-VGl by encouraging specific contributions effectively ensures that only 'safe' and authorised contributions are accepted. A potential example could be the creation of a smartphone app that enables authorised users to transcribe survey information from existing survey plan for subsequent $Q A$ and integration. The rules of cadastral survey, LINZ help desk support and the submission process of CSD's to Landonline is effectively a very advanced from of F-VGI.

VGI contributors are rarely guided as to the specific information required and often work in isolation without knowing if the information they provide is of use to others or of an acceptable quality. This research (section 4.4.2) found that contributors want to understand the aims and objectives of geospatial crowdsourcing projects, and that the process of contributing information to the cadastre must be easy to understand, contribute and use. Because F-VGI projects have a specific purpose they could provide customised channels through which specific data can be targeted and accepted. 
Facilitated geospatial crowdsourcing (including the use of tools) will:

- encourage contributions from users that are commensurate with their skills and capability ( section 4.2 .1 )

- ensure that contributors know that the information supplied is useful and valued (section 4.3.2) through it having been requested and subsequently accepted

- Addresses quality concerns (section 4.5 .2 ) by structuring data for integration

Furthermore, this research proposes that a modified F-VGI approach will enable known and credible data producers (such as cadastral surveyors) to provide specific 'higher value', specialised or critical functions. These credible data producers are uniquely suited to providing these more challenging needs because they already have the ability to create, certify and submit cadastral datasets, or they have verifiable advanced skills, tools or knowledge. Other potential contributors can be used for less critical or sensitive tasks - provided suitable tools or processes are available. Which tasks can be directed to users may be better determined and targeted based upon the categorisation of 'produser' motivations.

Section 4.7.1 discussed the officials view on the need for specific tools and processes to help standardise geospatial crowdsourced contributions. With some officials recognising the potential of crowdsourcing and others concerned about costs of development, support and integration with existing systems mean that there is no clear view as whether facilitated geospatial crowdsourcing is, on balance, beneficial. In this matter additional research is required to assess costs versus benefits. These same conflicting issues have also been raised by Johnson and Sieber (2013 p70) in their discussion on the costs of VGI.

\subsection{USING EXISTING DATA PRODUCERS}

Throughout the research, the potential value offered by crowdsourced geographic information was continually being contrasted by participants to the risks of change and consequential error. Participants (not surprisingly) answered questions from their own perspective, based on their knowledge and experience; generating a large amount of potentially contradictory information. In some cases, long held beliefs and training about cadastre and cadastral surveying, came up against limited knowledge and understanding of other geospatial concepts and capabilities. A few participants (surveyors and officials) recognised that the cadastre already contains elements of crowdsourced information provided under the guise of "official data". Generally, this data was contributed by licensed cadastral surveyors or organisations. However some processes, such as the fees, survey rules and regulations, and how the system implements them, makes it challenging for surveyors to include additional data. 
The following example is an extract from a surveyor objecting to processes relating to the "free information" he provides and which require the charging of additional fees/or remove of the data from the CSD.

I have captured the additional survey information to provide LINZ with up to date measurements between the cadastral survey network marks and to provide additional detail of adopted boundary pegging ties not previously captured into LoL [Landonline] as part of the survey conversion process. In effect I am assisting LINZ and LoL by going out of my way to capture and show this additional information that will enrich LoL. There is no benefit to my client to show this information

(Nikkel, 2014)

Additional examples of crowdsourcing in the cadastre are included in section 5.3, Table 10.

Nikkel, (2014) in his correspondence with the author ${ }^{3}$, also highlights that a cultural change is required so that the benefits and impacts of voluntary surveyor contributions to the system can be realised.

"...we need to work on the culture of encouraging surveyors to capture additional data if it is missing from LoL and not much effort to do so. The argument is that if we want a better more accurate system, then the more surveyors who capture the odd additional vector as part of their datasets the better and more quickly a countrywide SDC [survey data capture] dataset will populate.

Lots of little efforts (pseudo crowdsourcing) will accumulate to a big collective result. As professionals we should be thinking of the greater community good, and in the LoL context this includes our greater community of kindred cadastral users.

(Nikkel, 2014)

Additionally, section 4.7.3 on resourcing challenges highlighted that some data necessary to support contributions, such as data capture from survey plans, is restricted because of fee structures (see section 2.4.2) and only being available through the Landonline system. Administrators need to review how fees, survey rules and other processes (such the inability to exclude some data from CSD certification) are subtly excluding crowdsourcing. Research into how barriers can be lowered or removed is also required. For example, adding metadata such as the source or certification against individual observations, may enable 'crowdsourced' and 'authoritative' data to be held together, yet processed and managed differently. This framework would ensure that non-authoritative observations are still appropriately managed

\footnotetext{
3 This correspondence was subsequent to the data collection phases of the research. The author was added into the conversation after the initial correspondence had concluded between the surveyor and LINZ.
} 
while enabling them to be more tightly integrated into the fundamental cadastre. Removing these barriers will impact on the funding stream of the entire cadastral system. But such a move may be the only way to remove additional costs, high levels of QA and proof of reliability for data that is not strictly necessary for a CSD or linked/loosely integrated data. Administrators need to consider other avenues for accepting data that targets the requirements on the Chief Executive "to determine the structure of, and to store and provide access to, cadastral survey data"

(Cadastral Survey Act 2002 s9(e)).

Nikkel (2014) suggests a cultural change is required for both surveyors and administrators. Changing who can provide geospatial information and what can comprise crowdsourced information requires a cultural change. Such a cultural change will reduce focus on negative impacts and perceptions of crowdsourcing (as persistently identified on by the research participants) and increase the understanding of the potential scope and applicability of geospatial crowdsourcing to the cadastre.

\subsection{IMPLICATIONS OF THE RESEARCH}

To realise the potential of acquiring geospatial data from the crowd, the authority receiving the data must be

"prepared to entertain some important procedural and cultural changes that build on the motivations and recognize the characteristics of the [produser] culture"

(Coleman et al., 2009)

Accordingly, the author advocates enabling crowdsourcing data for the cadastre via an adapted F-VGI model. In such a model, crowdsourcing initiatives are developed by administrators of authoritative geospatial datasets who provide enhanced support, tools and quality to protect the data (or system) from unauthorised change, while not unnecessarily limiting users' ability to contribute. Users are able to provide information in addition to traditional data sources and consequently the user base becomes as integral to the maintenance of the cadastre as the existing data producers and system providers/maintainers.

User, data producers and officials' perceptions of crowdsourcing must however move from a view of contributors being a large conglomeration, to one where contributors are seen as niche groups of individuals. These niche groups could provide distinct sets of information commensurate with their motivations, skills and capabilities; to meet a known need. Niche groups of contributors could be more easily encouraged and supported by the administrator of the dataset. Creating a management framework for crowdsourced data that encourages 
specific contributions and then actively manages them will enable the crowdsourced data to coexist with the authoritative data without compromising the integrity of the dataset. By taking a multiple crowdsourced approach based on contributor motivations, specific groups of people can be classified, targeted and collected together by administrators. The 'designer' crowds are then 'matched' to specific data or informational needs. Each 'crowd' would differ in capabilities, freedom to act, incentives provided or restrictions imposed to fulfill the specific requirements of the authoritative dataset. Active identification and management of "niche designer crowds' will assist in moving the view of crowdsourcing away from the perception of 'just being free data', provided by the masses and managed with a 'one size fit all' approach.

The research shows that crowdsourcing is applicable to the cadastre as discussed in sections 5.2 to 5.5 by:

- Integrating to varying degrees (as appropriate) crowdsourced data or informational contributions (section 5.2),

- applying a framework to target and categorise potential contributors into 'niche' crowds (section 5.3),

- adapting F-VGI concepts to manage and support 'niche' crowds and their data contributions (section 5.4),

- reconceptualising the role of existing data providers for low risk/high value contributions and using their known credibility and skills more extensively. (section 5.5).

However, the applicability of crowdsourcing to the NZ cadastre is tempered by the longstanding standards, conventions, existing processes and opinions of crowdsourcing that are well entrenched amongst users, data providers and administrators. These barriers are especially strong with regard to the acceptance and use of cadastral data in the fundamental cadastre (Grant et al., 2014). Additionally, because cadastral definition is the domain of licensed cadastral surveyors (Cadastral Survey Act 2002), there appears little appetite to introduce new providers for new official survey measurements. Crowdsourcing all aspects of the cadastre is therefore unlikely in the short-term without significant cultural, legislative or regulatory change. To use crowdsourcing, now or in the future, considerable care must be taken to protect and preserve existing uses. To consider using VGI within the cadastre, new methods, processes and controls will be necessary, but users still expect that LINZ will undertake final acceptance/verification checks (see 4.7.1). Controls must be applied in a manner that does not compromise the 'authoritative' data and can be incorporated into official processes, whilst not unnecessarily limiting or hindering the contributors. 
Three key changes are necessary to safely enable greater use of crowdsourced information.

- processes or data models that manage data will need to change to enable integration of crowdsourced data while protecting the existing authoritative data,

- fit for purpose tools, support and QA need to be developed to ensure that appropriate data is received and meets quality standards, and

- targeted application and segmentation of users groups for specific tasks or functions is important, i.e. the creation of 'mini crowds' where the characteristics of the crowd are known and where they are working within their capabilities and interests 


\section{CONCLUSIONS}

\subsection{THE RESEARCH QUESTION}

This research found that geospatial crowdsourcing is applicable to the NZ cadastre. There is real potential to create a significant change in the range of data, cadastral scope, and completeness of data.

Crowdsourcing concepts could enable users to contribute data or information, reconceptualise the role of the existing data providers (LCS's) and enable the reuse of cadastral related work that does not normally eventuate in a CSD. Crowdsourcing can provide a new paradigm to the data collection and maintenance processes of the NZ cadastre and will provide significant benefits if properly managed. To move beyond whether crowdsourcing is applicable to the cadastre and to realise the potential of cadastral crowdsourcing, opportunities for the acquisition of crowdsourced information needs to be encouraged and enabled. Although, the applicability of crowdsourcing to the cadastre has been shown throughout this research; users, data producers and administrators need to change their perception of what crowdsourcing is, and what it can provide. Cultural, legislative and procedural change as well as new tools are also required to enable the extensive, efficient and safe use of crowdsourcing in the cadastre.

\subsection{SUPPLEMENTARY RESEARCH QUESTIONS}

This research examined two supplementary questions:

1. Are surveyors willing to provide geospatial crowdsourced information beyond their professional capacity?

2. Should geospatial crowdsourced information be allowed into the NZ cadastre and if so to what extent?

Regarding the first supplementary question, some surveyors are willing to provide geospatial crowdsourced information mainly in conjunction with their professional capacity through adding additional data to their existing work (see section 5.5).

Regarding the second supplementary question, voluntary contributions to the cadastre may be a matter of perspective. Licensed cadastral surveyors can be a considered a 'crowd' in their own right and already provide information, including some in a voluntary capacity. To take the perspective more common amongst the research participants, where crowdsourced information is provided by the user base or the public, then the case is less clear cut when 
considering the fundamental cadastre. The research found that concerns about the use of crowdsourced data was high and that generally only the most important, low risk data should be considered for formal integration and held in the cadastre. Even then it must be able to be identified via appropriate metadata. Other crowdsourced information should not generally be formally integrated but only linked via attribution or intrinsic spatial capabilities. However, where appropriate data and tools are available to ensure quality, there is real potential in customised forms of crowdsourcing - especially in regard to the broader cadastre.

Similarly, Coleman (2010) found:

If volunteers are encouraged appropriately, if the processes [are] managed wisely, and if the potential and the limitations of their contributions are understood and used in the proper context - our research suggests the opportunity to produce and enjoy richer and more up-to-date databases than we have ever seen in the past.

(Coleman, 2010)

\subsection{APPLICATIONS OF THE RESEARCH}

Although the research did not set out to challenge the historical maintenance model for the cadastre, it shows that a crowdsourcing methodology could supplement existing data maintenance processes and contribute to cadastral enhancement methodologies. However, instead of purely focusing on new contributions, efforts should also be directed to reusing cadastral related work or aligning 'future work' that has a cadastral base. Therefore work that is undertaken outside the formal cadastral framework can improve the cadastre, and only need be undertaken once. Possible examples are the use of student assignments, data collected for large infrastructure projects work to improve cadastral mapping. (Table 10). Changes to the authoritative database may be required, such as the need for field level metadata to enable VGI to co-exist (i.e. be tightly integrated) with existing authoritative data.

A unique feature of the cadastre is that the existing user base includes authorised private sector contributors (existing licensed cadastral surveyors and approved geodetic surveyors) who provide data to the cadastre in professional or contractual capacities and may also choose to do so voluntarily (intrinsic or extrinsic altruism). These users have an existing established credibility and access to the authoritative system so consequently, their specialist skills and knowledge can be immediately leveraged. Additional gains could be made by examining existing rules and processes to identify and remove barriers for voluntary contributions to encourage additional data in CSD's where appropriate (Nikkel, 2014). In, addition, this specific 'crowd' (predominately cadastral surveyors) could be incentivised (e.g. paid) to take part in data improvement initiatives such as data back capture for cadastral mapping improvement(LINZ, 2013a). 


\subsection{FUTURE RESEARCH}

The conclusions of this research reiterate those of Basiouka and Potsiou (2014), in both the potential, applicability and the current state of play of crowdsourcing in the cadastre where:

It is clear that VGI is not the ultimate solution to all geospatial data updating and maintenance challenges. Faced by mapping organisations. However, there is a growing agreement that it potentially represents one important channel for such updates, and one that needs to be investigated, prototyped and introduced in a reasonable, informed manner.

(Basiouka and Potsiou, 2014 p354)

Several areas of future research were identified in the course of analysing the data obtained from users, data producers and officials.

\subsubsection{Motivation}

As discussed in section 5.3 a framework comprising of motivation and behaviour continua was proposed. The framework combines the altruism/egoism behaviours with the intrinsic/extrinsic motivations. Research into the motivations of users is required to be able verify whether reasons to contribute can be categorised according to this framework, and that in doing so crowdsourcing initiatives can be planned, or facilitated, around 'crowds' that have similar motivational drivers. The additional research to develop this work on contributor motivations may then also further develop the application of contributor motivations to the applicability of crowdsourcing to the cadastre or other authoritative databases. This research could potentially be facilitated by additional research into the user understanding of what CGD related concepts/terms are, and how it impacts on user motivations to contribute.

\subsubsection{INTEGRATION}

The range of potential information for crowd sourcing is extensive. Participants indicated that the extent of integration with the cadastre should vary based upon the risk of harm, the purpose, and the importance of the information. A graduated matrix was proposed (Table 9) to work in conjunction with proposed options for integration and alignment of data with the cadastre (Figure 29). Additional research is required to apply these models. This research could better define the levels of integration (tight, loose \& linked), the extent of their overlap and what types of data or data elements fit in each category.

The discussion on using existing data producers noted that administrative functions subtly exclude voluntary contributions through rigorous requirements applied to all data (see 
section 5.5). Whether this exclusion could be mitigated by field level metadata so that 'crowdsourced' and 'authoritative' data could be held together, yet processed and managed differently requires additional research. Changes to data structures solely to store nonauthoritative data would strike to the heart of how authoritative systems currently manage data. It may however also pose significant risk to the existing data or necessitate changes to its use. Additional research would evaluate this and if the risks are able to be managed, provide guidance to administrators on how to achieve tightly integrated of crowdsourced data in authoritative datasets.

\subsubsection{InTERVentions to Mitigate Data Issues}

In examining and categorising the suggested mitigations from participants to address potential issues with the use of geospatial crowdsourcing, the typology model based on the ladder of public participation (Arnstein 1969) was adapted. The seven typologies shown in Figure 28 are based on comments or inferences from participants. Accordingly more research is required to establish whether all mitigation typologies have been identified. 


\section{REFERENCES}

ACIL TASMAN, 2009. Spatial information in the New Zealand economy. Realizing Productivity Gains Available http://www.acilallen.com.au/cms files/ACIL spatial\%20information NewZealand.pdf

ACKERMAN, R. K. 2008. An Info-Centric Force Learns to Share. Signal, 62, 39-39-42.

ADITYA, T. 2010. Usability Issues in Applying Participatory Mapping for Neighborhood Infrastructure Planning. Transactions in GIS, 14, 119-147.

ALLINGHAM, C. 2014. A Review of Quality of Geo-Data from User's Perspective. Universal Journal of Geoscience, 2, 70-75.

ALVAREZ, M., DELGADO, T. \& IGLESIAS, R. 2010. Social SDI's: a Challenge for Land Surveyors. Proceedings of the XXIV FIG International Congress 2010. Sidney, Australia.

ANDREWS, P. J. 2006a. Survey report for SO 377749.

ANDREWS, P. J. 2006b. Survey report for SO 377752.

ARNSTEIN, S. R. 1969. A ladder of citizen participation. Journal of the American Institute of planners, $35,216-224$.

BASIOUKA, S. \& POTSIOU, C. 2012. VGI in Cadastre: a Greek experiment to investigate the potential of crowd sourcing techniques in Cadastral Mapping. Survey Review, 44, 153-161.

BASIOUKA, S. \& POTSIOU, C. 2014. The volunteered geographic information in cadastre: perspectives and citizens' motivations over potential participation in mapping. GeoJournal, 79, 343-355.

BENNETT, R., MOLEN, P. V. D. \& ZEVENBERGEN, J. 2012. Fitted, Green, and Volunteered: Legal and Survey Complexities of Future Boundary Systems. Geomatica, 66, 181-193.

BENNETT, R., RAJABIFARD, A., KALANTARI, M., WALLACE, J. \& WILLIAMSON, I. 2010. Cadastral futures: building a new vision for the nature and role of cadastres. FIG Congress, 2010.1116.

BENNETT, R., TAMBUWALA, N., RAJABIFARD, A., WALLACE, J. \& WILLIAMSON, I. 2013. On recognizing land administration as critical, public good infrastructure. Land Use Policy, 30, 8493.

BEVIN, A. 1999. Cadastre 2014 Reforms in New Zealand. Proceedings of FIG Commission VII AGM, Waitangi, p99.

BISHR, M. \& MANTELAS, L. 2008. A trust and reputation model for filtering and classifying knowledge about urban growth. GeoJournal, 72, 229-237.

BROWN, M. M. \& BRUDNEY, J. L. 1998. A "Smarter, Better, Faster, and Cheaper" Government: Contracting and Geographic Information Systems. Public Administration Review, 58, 335-345.

BRUNS, A. 2008. The Future Is User-Led: The Path towards Widespread Produsage. Fibreculture Journal. Fibreculture Publications.

BUDHATHOKI, N., NEDOVIC-BUDIC, Z. \& BRUCE, B. 2010. An interdisciplinary frame for understanding volunteered geographic information. Geomatica, 64, 11-26.

CADASTRAL SURVEY ACT. 2002 No 12. New Zealand: Parliamentary Counsel Office.

CADASTRAL SURVEYORS LICENSING BOARD 2013. Standards for Licensing Cadastral Surveyors.

CADASTRE LTD 2003. Business Case Framework for Improved Spatial Accuracy in Digital Cadastral Database (DCDB). http://www.icsm.gov.au/publications/: Intergovernmental Committee on Surveying and Mapping, .

CLOUSTON, A. 2010. Data Quality Improvement Strategy. Land Information New Zealand (LINZ). 
COLEMAN, D. J. 2010. Volunteered geographic information in spatial data infrastructure: An early look at opportunities and constraints. Spatially Enabling Society: Research, Emerging Trends and Critical Assessment, Leuven University Press, Leuven, Belgium, Leuven.

COLEMAN, D. J. 2013. Potential Contributions and Challenges of VGI for Conventional Topographic Base-Mapping Programs. Crowdsourcing geographic knowledge. Springer.

COLEMAN, D. J., GEORGIADOU, Y. \& LABONTE, J. 2009. Volunteered Geographic Information: the nature and motivation of produsers. International Journal of Spatial Data Infrastructures Research, 4, 332-358.

CONNOR, D. M. 1988. A new ladder of citizen participation. National Civic Review, 77, 249-257.

COOPER, P. 2012 2. RE: Asbuilt data. email to CLOUSTON, A.

CROWDSOURCING.ORG 2012. Crowdsourcing and Crowdfunding Explained.

DEPARTMENT OF SUSTAINABILITY AND ENVIRONMENT 2011. Business Case for a Spatially Accurate Map Base. In: SINCLAIR KNIGHT MERZ (ed.). http://www.dtpli.vic.gov.av/_data/assets/word_doc/0007/1 10977/Business-Case-for-aSpatially-Accurate-Map-Base-2011.doc.

DILLMAN, D., SMYTH, J. \& CHRISTIAN, L. 2009. Internet, mail, and mixed-mode surveys: the total design method. John Wiley \& Sons, New Jersey.

DONNELLY, N. 2009. Maintaining accurate coordinates for geospatial datasets after a geodetic datum update. Eilat 2009 - FIG working week. Dan Eilat Hotel, Eilat, Isreal.

DONNELLY, N. \& PALMER, J. 2006. Issues with maintaining spatial accuracy in a nationwide digital cadastral network. 5th Trans Tasman Survey Conference. Cairns.

DOWSON, E. M. 1956. Land registration /by Sir Ernest Dowson and V.L.O. Sheppard, London :, H.M.S.O.

EFFENBERG, W. \& WILLIAMSON, I. P. Digital cadastral databases: the Australian Experience. Proceedings of $A G I, 1997$.

ELWOOD, S. 2008. Volunteered geographic information: key questions, concepts and methods to guide emerging research and practice. GeoJournal, 72, 133-135.

ELWOOD, S. 2010. Geographic information science: emerging research on the societal implications of the geospatial web. Progress in human geography, 34, 349-357.

ELWOOD, S., GOODCHILD, M. F. \& SUI, D. Z. 2012. Researching volunteered geographic information: Spatial data, geographic research, and new social practice. Annals of the Association of American Geographers, 102, 571-590.

ENEMARK, S. 2008. Underpinning Land Management-A major challenge for the global surveying profession. Geodetski list, 62, 83-97.

ESTELLÉS-AROLAS, E. \& GONZÁLEZ-LADRÓN-DE-GUEVARA, F. 2012. Towards an integrated crowdsourcing definition. Journal of Information science, 38, 189-200.

FENTON, A. 2006. Weft QDA. 1.0.1 ed. http://www.pressure.to/qda/.

FINKELSTIEN, M. A. 2009. Intrinsic vs. extrinsic motivational orientations and the volunteer process. Personality and Individual Differences, 46, 653-658.FIG. 1995. FIG Statement on the Cadastre [Online]. Available: http://fig.net/pub/figpub/pub 11 /figpub 1 1.htm.

FLANAGIN, A. J. \& METZGER, M. J. 2008. The credibility of volunteered geographic information. GeoJournal, 72, 137-148.

GANAPATI, S. 2011 . Uses of Public Participation Geographic Information Systems Applications in EGovernment. Public administration review, 71, 425-434. 
GOODCHILD, M. F. 2007. Citizens as sensors: the world of volunteered geography. GeoJournal, 69, 211-221.

GOODCHILD, M. F. 2008. Commentary: whither VGI? GeoJournal, 72, 239-244.

GOODCHILD, M. F. 2009. NeoGeography and the nature of geographic expertise. J. Locat. Based Serv., 3, 82-96.

GOODWIN, D. \& MCKINNON, D. 2010. An alternative cadastral survey dataset for New Zealand. New Zealand Surveyor, 33.

GOUVEIA, C. \& FONSECA, A. 2008. New approaches to environmental monitoring: the use of ICT to explore volunteered geographic information. GeoJournal, 72, 185-197.

GRANT, D., HAANEN, A. \& DYER, M. 2014. Cadastre 2034 A 10-20 Year Strategy for developing the cadastral system: Knowing the 'where' of land-related rights. In: ZEALAND, L. I. N. (ed.).

GRANT, D., MANNERS, B. \& DEMPSEY, J. 2010. Towards Tomorrow's Cadastral Survey Industry. FIG Congress 2010. Sydney: FIG.

GRINNELL, C. K. 2009. From Consumer to Prosumer to Produser: Who Keeps Shifting My Paradigm? (We Do!). Public Culture, 21, 577-598.

GRIRA, J., BÉDARD, Y. \& ROCHE, S. 2010. Spatial data uncertainty in the VGI world: Going from consumer to producer. Geomatica, 64, 61-71.

HAANEN, A., BEVIN, T. \& SUTHERLAND, N. e-Cadastre-Automation of the New Zealand Survey System. Joint AURISA and Institution of Surveyors Conference, Adelaide, South Australia (93KB), 2002.

HAKLAY, M. 2010. How good is volunteered geographical information? A comparative study of OpenStreetMap and Ordnance Survey datasets. Environment and planning. B, Planning \& design, 37, 682.

HAKLAY, M., ANTONIOU, V., BASIOUKA, S., SODEN, R. \& MOONEY, P. 2014. Crowdsourced Geographic Information Use in Government.

HANSEN, H. \& REINAU, K. 2006. The Citizens in E-Participation. In: WIMMER, M., SCHOLL, H., GRÖNLUND, Å. \& ANDERSEN, K. (eds.) Electronic Government. Springer Berlin Heidelberg.

HASKI-LEVENTHAL, D. 2009. Altruism and volunteerism: The perceptions of altruism in four disciplines and their impact on the study of volunteerism. Journal for the Theory of Social Behaviour, 39, 271-299.HARVEY, F. 2013. To Volunteer or to Contribute Locational Information? Towards Truth in Labeling for Crowdsourced Geographic Information. In: SUI, D., GOODCHILD, M. F. \& ELWOOD, S. (eds.) Crowdsourcing Geographic Knowledge. Springer.

HEIPKE, C. 2010. Crowdsourcing geospatial data. ISPRS Journal of Photogrammetry and Remote Sensing, 65, 550-557.

HIRST, B. 2010. Cadastre 2014 - Australia and New Zealand; now and the future. FIG Congress 2010. Sydney: FIG.

HORISBERGER, J.-L. 2010. Land Administration as an effective and efficient public service. BiH training course for top managers at BEV, Vienna.

HOWE, J. 2006. The rise of crowdsourcing. Wired magazine, 14, 1-4.

HUDSON-SMITH, A., BATTY, M., CROOKS, A. \& MILTON, R. 2009. Mapping for the Masses. Social Science Computer Review, 27, 524-538.

HULL, S. \& WHITTAL, J. 2013. Good e-Governance and Cadastral Innovation: In Pursuit of a Definition of e-Cadastral Systems. South African Journal of Geomatics, 2, 342-357.

ISO, 2005. ISO 19115. Geographic information - metadata. Geneva: International Organization for Standardization 
ISO, 2013. ISO 19157. Geographic information - data quality. Geneva: International Organization for Standardization

JICK, T. D. 1979. Mixing qualitative and quantitative methods: Triangulation in action. Administrative science quarterly, 602-611.

JOHNSON, P. A. \& SIEBER, R. E. 2013. Situating the Adoption of VGI by Government. Crowdsourcing geographic knowledge. Springer.

KAUFMANN, J., GUBLER, E., GLATTHARD, T. \& STEUDLER, D. Swiss Cadastre: Cadastre 2014 for Sustainability. Proceedings FIG XXII International Congress, 2002. 19-26.

KAUFMANN, J. \& STEUDLER, D. 1998. Cadastre 2014. In: FIG, W. G. O. F. C. (ed.).

KEENJA, E., DE VRIES, W., BENNETT, R. \& LAARAKKER, P. 2012. Crowd Sourcing for Land Administration: Perceptions within the Netherlands Kadaster. FIF Working Week 2012. Rome, Italy 6-10 May 2012.

KING, S. 2011 . Improving the accuracy of New Zealands digital cadastre. Draft version, submitted to Surveying and Spatial Science conference, Wellington, NZ.

KINZETT, C. 2013. RE: Volunteered Geographic Information. CRM:0188307. Type to NIKKEL, T., CLARK, D., FERREL, A. \& CLOUSTON, A.

KOSTANSKI, L. 2012. Crowd-sourcing Geospatial Information for Government - Reports to Churchhill Fellowship Trust Australia and United Nations Group of Experts on Geographic names.

LANKES, R. D. 2008. Credibility on the internet: shifting from authority to reliability. Journal of documentation, 64, 667-667.

LINZ 1996. Survey and Titles Automation Strategy.

LINZ 2007. Structured Learning Programme - Part B.

LINZ 2009a. Introducing the New Rules for Cadastral Survey 2010. In: OFFICE OF THE SURVEYOR GENERAL (ed.). http://www.linz.govt.nz/sites/default/files/docs/surveysystem/introducingrules-for-cadastral-survey-2010.pdf.

LINZ 2009b. Standard for integration \& provision of cadastral survey data - LINZS10003.

LINZ 2011 a. Improving the Accuracy of the Cadastre Around the Rotorua Lakes.

LINZ. 2011b. Landonline Survey and Title Service Fees and Charges summary [Online]. http://www.landonline.govt.nz/. Available: http://www.landonline.govt.nz/sites/default/files/Fees\%20schedule\%202011\%20updated\% 20oct.pdf [Accessed 20/07/14.

LINZ. 2011 c. Spatial Data Infrastructure cookbook V1.1 [Online]. http://www.landonline.govt.nz/. Available http://www.linz.govt.nz/about-linz/our-location-strategy/strategy-and-workprogramme/sdi-cookbook-v1 1-home

LINZ 2012 a. Landonline Bulk Data Extract - Overveiw.

LINZ $2012 b$. Rules for Cadastral Survey 2010. In: OFFICE OF THE SURVEYOR GENERAL (ed.). http://www.linz.govt.nz/.

LINZ 2013a. Digitial Parcel Improvement - Indicative Business Case.

LINZ $2013 \mathrm{~b}$. Standard for lodgement of cadastral survey datasets - LINZS70000.

LINZ 2013c. The power of 'where' drives New Zealand's success - The 10 year view for Land Information New Zealand. Land Information New Zealand

LINZ 2014. Steward and custodian framework for New Zealand fundamental geospatial themes and datasets (V2.2).

MANU, C. 2012 . Business Case - Landonline Data Quality Improvement. 
MANZOOR, S., QURESHI, T. A., LIAQAT, M. D., FAROOQ, M. K. \& SHAMAIL, S. A comparison between Cadastre 2014 and cadastral systems of different countries. Proceedings of the 3rd international conference on Theory and practice of electronic governance, 2009. ACM, 293297.

MCLAREN, R. 2011 . Crowdsourcing support of land administration: a new, collaborative partnership between citizens and land professionals. Royal Institution of Chartered Surveyors (RICS) Report November.

MOONEY, P. \& CORCORAN, P. 2012. The Role of Communities in Volunteered Geographic Information Projects. Proceedings of the 9th Symposium on Location Based Services, Vol. 1 of Lecture Notes in Geoinformation and Cartography, 2012. Springer Berlin/Heidelberg, 35371.

MUGGENHUBER, G., NAVRATIL, G., TWAROCH, C. \& MANSBERGER, R. 2011. Development and Potential for Improvement of the Austrian Land Administration System. FIG Working Week 2011.

MUMMIDI, L. N. \& KRUMM, J. 2008. Discovering points of interest from users' map annotations. GeoJournal, 72, 215-227.

NCDCDS (US), \& Moellering, H. (1987). A draft proposed standard for digital cartographic data. National Committee for Digital Cartographic Data Standards. Available http://pubs.er.usgs.gov/publication/ofr87308

NAVRATIL, G. \& FRANK, A. 2013. VGI for land administration-a quality perspective. ISPRSInternational Archives of the Photogrammetry, Remote Sensing and Spatial Information Sciences, 1, 159-163.

NEDOVIC-BUDIC, Z., BRUCE, B. \& BUDHATHOKI, N. R. 2008. Reconceptualizing the role of the user of spatial data infrastructure. GeoJournal, 72, 149-160.

NIKKEL, T. 2014 . RE: LT 476257. Type to CLOUSTON, A.

NZIS 2014. 2014 NZIS Annual Member's Survey. NZIS.

OPUS 2013. Digital Parvel Boundary Information: Findings from Customer and Economic Research.

PICKLES, J. 2006. Ground Truth 1995-2005. Transactions in GIS, 10, 763-772.

RAMBALDI, G., CHAMBERS, R., MCCALL, M. \& FOX, J. 2006. Practical ethics for PGIS practitioners, facilitators, technology intermediaries and researchers. Participatory Learning and Action, 54, 106-113.

REES, T. 1999. PARTICIPATION AND VOLUNTEERING. Promoting Participation: Law Or Politics?, 193.

RICE, M. T., PAEZ, F. I., MULHOLLEN, A. P., SHORE, B. M. \& CALDWELL, D. R. 2012. Crowdsourced Geospatial Data: A Report on the Emerging Phenomena of Crowdsourced and UserGenerated Geospatial Data. DTIC Document.

ROWE, G. 2003. The survey conversion project - making a survey-accurate digital cadastre for New Zealand a reality. New Zealand Surveyor, 293, 31-38.

SALKIN, P. E. 2005. GIS in an age of homeland security: accessing public information to ensure a sustainable environment.(geographic information systems). William and Mary environmental law and policy review, 30, 55.

SCHADE, S., DÍAZ, L., OSTERMANN, F., SPINSANTI, L., LURASCHI, G., COX, S., NUÑEZ, M. \& DE LONGUEVILLE, B. 2010. Citizen-based sensing of crisis events: sensor web enablement for volunteered geographic information. Applied Geomatics, Online only, 16.

SEEGER, C. J. 2008. The role of facilitated volunteered geographic information in the landscape planning and site design process. GeoJournal, 72, 199-213. 
SEVERINSEN, J. \& REITSMA, F. 2013. Finding the Quality in Quantity: Establishing Trust For Volunteered Geographic Information. Proceedings of the SIRC NZ Conference.

STATE SERVICES COMMISSION 1997. Policy framework for New Zealand Government-held information.

STEUDLER, D. \& RAJABIFARD, A. 2012. Spatially Enabled Society. In: (FIG), I. F. O. S. (ed.) Joint publication of FIG-Task Force on Spatially Enabled Society in cooperation with GSDI Association and with the support of Working Group 3 of the PCGIAP. FIG Report 2012.: International Federation of Surveyors (FIG).

SUI, D., ELWOOD, S. \& GOODCHILD, M. 2013a. Crowdsourcing Geographic Knowledge: Volunteered Geographic Information (VGI) in Theory and Practice, Springer.

SUI, D., GOODCHILD, M. \& ELWOOD, S. 2013b. Volunteered geographic information, the exaflood, and the growing digital divide. Crowdsourcing Geographic Knowledge. Springer.

TERRANOVA, T. 2000. Free labor: Producing culture for the digital economy. Social text, 18, 33-58.

THATHER, J. 2013. From Volunteered Geographic Information to Volunteered Geographic Services. Crowdsourcing Geographic Knowledge. Springer.

TOUYA, G. \& GIRRES, J.-F. 2010. Quality Assessment of the French OpenStreetMap Dataset. Transactions in GIS, 14, 435.

TRIMI, S. \& SHENG, H. 2008. Emerging trends in M-government. Communications of the ACM, 51, 5358.

TRITTER, J. Q. \& MCCALLUM, A. 2006. The snakes and ladders of user involvement: moving beyond Arnstein. Health Policy, 76, 156-168.

TULLOCH, D. L. 2008. Is VGI participation? From vernal pools to video games. GeoJournal, 72, 161 171.

UN-FIG. 1996. THE BOGOR DECLARATION - United Nations Interregional Meeting of Experts on the Cadastre 1996 Bogor, Indonesia

UN-FIG. 1999. BATHURST DECLARATION- United Nations Declaration on Land Administration Systems for Sustainable Development. UN-FIG Workshop on Land Tenure and Cadastral Infrastructure for Sustainable Development, Bathurst, Australia, 1999. 12.

VAN DEN BROEK, D. 2010. From Terranova to terra firma: a critique of the role of free labour and the digital economy. The economic and labour relations review : ELRR, 20, 123.

VAN DER MOLEN, P. 2003. The Future Cadastres-Cadastres after 2014, FIG Working Week, 2003, 13-17 April, Paris France, 42 pp.

VAN EXEL, M., DIAS, E. \& FRUIJTIER, S. 2010. The impact of crowdsourcing on spatial data quality indicators. The 6th International Conference on GIS, September 2010. Zurich, Switzerland.

WIKIPEDIA. 2014. List of crowdsourcing projects [Online]. Wikipedia, The Free Encyclopedia. Available:

http://en.wikipedia.org/w/index.php?title=List_of_crowdsourcing_projects\&oldid=61537126 0 [Accessed July 2014.

WILLIAMSON, I. 1985. Cadastres and land information systems in common law jurisdictions. Survey Review, 28, 114-129.

WILLIAMSON, I. \& TING, L. 2001. Land administration and cadastral trends-a framework for reengineering. Computers, Environment and Urban Systems, 25, 339-366. 


\title{
8. APPENDICIES
}

\subsection{PHASE 1 SURVEY QUESTIONNAIRE}

\author{
Introduction
}

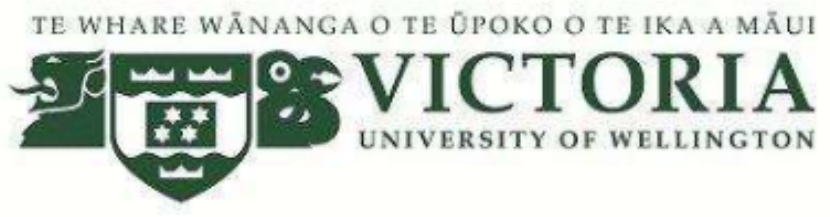

Volunteered Geographic Information (VGI) and the New Zealand Cadastre

Thank you for agreeing to participate in this survey.

The survey should take approximately 15 - 20 minutes to complete.

How to complete this survey

Please answer the questions from your own personal perspective.

The survey targets two specialist areas (Volunteered Geographic Information (VGI) and the cadastre). You are not expected to be an expert in either area.

\section{Confidentiality}

All responses to the survey are strictly anonymous and no identifying personal information is sought. Any identifiable information included in your commentary will be removed prior to publication.

\section{Disclosures}

This survey forms part of a thesis for a Masters in Geographic Information Science (MGIS). It may also be published in papers and/or used for presentations by the author.

The primary author, is employed by Land Information New Zealand (LINZ) and is supported by LINZ via a financial scholarship comprising of payment of University fees, associated expenses and study leave. The author is also is a full member of the New Zealand Institute of Surveyors (NZIS). LINZ and NZIS are not involved in the development of this research but have agreed to advertise the links to this questionnaire. The results of this survey will not be available in raw format to these or any other organisations.

\section{Future stages}

At the end of this survey, you will be asked if you are willing to take part in future stages of this research. These stages will explore in greater detail the motivations and issues around Volunteered Geographic Information (VGI). If you are willing, you will be asked for contact details. These details will not, and cannot, be associated in any way with your responses to this survey.

Any questions?

If you have any difficulties completing the survey, please contact the researcher -

Andrew Clouston +64 (27) 294-1854 or email andrew.clouston@vuw.ac.nz

Andrew is supervised by Dr Mairead de Roiste at Victoria University of Wellington who can be contacted at +64 (4) 463-6431 or mairead.deroiste@vuw.ac.nz

Q1.3.

\section{Consent Form}

Please read this section carefully as it includes information about the data privacy for this survey.

- I have been provided with adequate information relating to the nature and objectives of this research project, I have understood that information and have been given the opportunity to seek further clarification or explanations.

- I understand that I may withdraw from this study at any time before the final submission of data without 
providing reasons.

- I understand that if I withdraw from the project, any data I have provided will be destroyed.

- I understand that any information or opinions I provide will be anonymous and reported only in an aggregated/non-attributable form.

- I understand that when this research is completed the information obtained will be retained.

Yes, I wish to take part in this survey

No, I wish to ext

\section{Understanding Volunteered Geographical Information (VGI)}

Q2.1.

Do you know what Volunteered Geographic Information (VGI) is?

Please select only one option.

\begin{tabular}{l}
\hline I know I am reasonably certain I do not know \\
Q2.2. \\
Have you used or encountered any Volunteered Geographic Information (VGI)? \\
Please select only one option. \\
Yes \\
No \\
Don't know \\
Have you contributed Volunteered Geographic Information (VGI)? \\
Please select only one ogtion. \\
Yes \\
No Unsure
\end{tabular}

Q2.4.

You have indicated that you are unfamiliar with Volunteered Geographic Information (VGI).

Because this research is interested in the relationships between VGI and the the New Zealand Cadastre, the following information about VGI aims to provide you some additional context so that you can make informed selections in the following questions as they relate to VGI.

Volunteered Geographic Information (VGI) is generally about geospatial data (e.g. mapping data) that is created and shared for free.

Crowdsourcing is a similar concept (but not limited to geographic information) where people freely (and often anonymously) contribute information.

VGI contributions commonly form part of a larger collaborative effort or 'project' such as Open Streetmap, or are focused on broader community issues such as community mapping responses to natural disasters. 
To what extent do the following factors limit your contribution (or potential contribution) to VGI? Please select only one ootion for each attribute.

\begin{tabular}{|c|c|c|c|c|}
\hline & Not limiting & Somewhat limiting & Reasonably limiting & Extremely Limiting \\
\hline I don't know how I can be involved & $\odot$ & $\bigcirc$ & $\odot$ & $\odot$ \\
\hline I don't have the time to be contribute & $\bigcirc$ & $\bigcirc$ & $\bigcirc$ & $\bigcirc$ \\
\hline \multirow[t]{2}{*}{$\begin{array}{l}\text { I don't have the necessary skills to } \\
\text { capture data to enable me to contribute }\end{array}$} & $\odot$ & $\bigcirc$ & $\odot$ & $\odot$ \\
\hline & Not limiting & Somewhat limiting & Reasonably limiting & Extremely Limiting \\
\hline $\begin{array}{l}\text { I don't have the necessary equipment to } \\
\text { capture data to contribute }\end{array}$ & $\odot$ & $\odot$ & $\odot$ & $\odot$ \\
\hline I don't want to give away my data & $\odot$ & $\odot$ & $\odot$ & $\odot$ \\
\hline $\begin{array}{l}\text { I haven't found a project that I'm interested } \\
\text { in supporting }\end{array}$ & $\bigcirc$ & $\bigcirc$ & $\bigcirc$ & $\odot$ \\
\hline
\end{tabular}

Q2.6.

Please specify any other significant factors that limit your contribution (or potential contribution) to VGI.

Q2.7.

To what extent do the following factors encourage or influence you to contribute VGI?

Please select only one option for each attribute.

\begin{tabular}{|c|c|c|c|c|}
\hline & Not influential & Somewhat Influential & Quite Influential & Very influential \\
\hline $\begin{array}{l}\text { I can access support and } \\
\text { guidance. }\end{array}$ & O & O & 0 & ○ \\
\hline $\begin{array}{l}\text { I feel that I'm providing a } \\
\text { valuable social (or public) } \\
\text { service. }\end{array}$ & ○ & O & O & ○ \\
\hline $\begin{array}{l}\text { By giving it away, I am free of } \\
\text { the costs or responsibilities of } \\
\text { owning the data (e.g. storage, } \\
\text { maintenance). }\end{array}$ & O & O & 0 & O \\
\hline $\begin{array}{l}\text { I am passionate or interested } \\
\text { in a particular dataset and this } \\
\text { helps share that passion. }\end{array}$ & 0 & 0 & 0 & 0 \\
\hline
\end{tabular}

Q2.8.

Please specify any other influential factors that would encourage you to contribute VGI

\section{Understanding Cadastral Data}

Q3.1.

Do you know what the New Zealand cadastre is?

Please select only one option.

Yes, I know

0
I am reasonably certain

(
I am uncertain

○
I do not know 
Q3.2.

Have you used New Zealand Cadastral data?

Please select only one option.

Yes

No

Q3.3.

How well do you understand the scope of cadastral data (i.e. how and where cadastral data is used)?

Please select only ane option.

I understand very well C
I understand quite well

0
I somewhat understand

○

I do not understand

Q3.4.

Have you actively participated in the gathering or creation of cadastral data?

Please select only one option.

\section{Yes \\ No}

Q3.5.

How well do you understand how cadastral data is created?

Please select only one option.

I understand very well

0
I understand quite well

0
I somewhat understand

I do not understand

Q3.7.

How important are the following components of Cadastral data to your use of cadastral data? Please select only one option for each component.

\begin{tabular}{|c|c|c|c|c|c|}
\hline & Not Important & $\begin{array}{l}\text { Somewhat } \\
\text { Important }\end{array}$ & Quite Important & Very Important & $\begin{array}{l}\text { I do not } \\
\text { understand }\end{array}$ \\
\hline $\begin{array}{l}\text { Survey observations between } \\
\text { survey marks and connections } \\
\text { to the cadastral boundaries }\end{array}$ & $\bigcirc$ & $\bigcirc$ & 0 & 0 & 0 \\
\hline $\begin{array}{l}\text { Survey observations along } \\
\text { cadastral boundaries (such as } \\
\text { boundary dimensions) }\end{array}$ & $\odot$ & $\bigcirc$ & ○ & $\odot$ & ○ \\
\hline $\begin{array}{l}\text { Survey mark information (e.g. } \\
\text { names, coordinates) }\end{array}$ & $\bigcirc$ & $\odot$ & $\bigcirc$ & $\odot$ & ○ \\
\hline \multirow[t]{2}{*}{$\begin{array}{l}\text { Positions and/or shapes of } \\
\text { parcels (i.e. the mapping } \\
\text { representation of the parcel) }\end{array}$} & $\odot$ & $\odot$ & $\odot$ & $\odot$ & $\bigcirc$ \\
\hline & Not Important & $\begin{array}{l}\text { Somewhat } \\
\text { Important }\end{array}$ & Quite Important & Very Important & $\begin{array}{l}\text { I do not } \\
\text { understand }\end{array}$ \\
\hline $\begin{array}{l}\text { Parcel information (e.g. } \\
\text { appellation, area, purpose, etc.) }\end{array}$ & $\bigcirc$ & $\bigcirc$ & $\bigcirc$ & $\odot$ & ○ \\
\hline $\begin{array}{l}\text { The authoritativeness of the } \\
\text { cadas tral information (e.g. } \\
\text { trustworthiness and reliability) }\end{array}$ & $\odot$ & $\odot$ & $\bigcirc$ & $\odot$ & ○ \\
\hline $\begin{array}{l}\text { Historical cadastral information } \\
\text { that has not been digitised (e.g. } \\
\text { old plans, fieldbooks, traverse }\end{array}$ & $\odot$ & $\bigcirc$ & $\bigcirc$ & 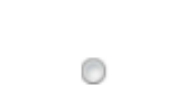 & ○ \\
\hline
\end{tabular}


sheets, etc.)

Q3.8.

Have you experienced issues in relation to the following attributes?

Please select only one option for each attribute. If you are unsure, please select don't know.

\begin{tabular}{|c|c|c|c|}
\hline & Yes & No & Don't know \\
\hline $\begin{array}{l}\text { Cadastral data that is } \\
\text { inaccurate }\end{array}$ & ○ & ○ & ○ \\
\hline $\begin{array}{l}\text { Cadastral data that is } \\
\text { incomplete }\end{array}$ & ○ & ○ & ○ \\
\hline $\begin{array}{l}\text { Cadastral data that is out-of- } \\
\text { date }\end{array}$ & 0 & O & ○ \\
\hline
\end{tabular}

Q3.9.

Do you have any other comments on the New Zealand Cadastre or wish to further explain some of your answers?

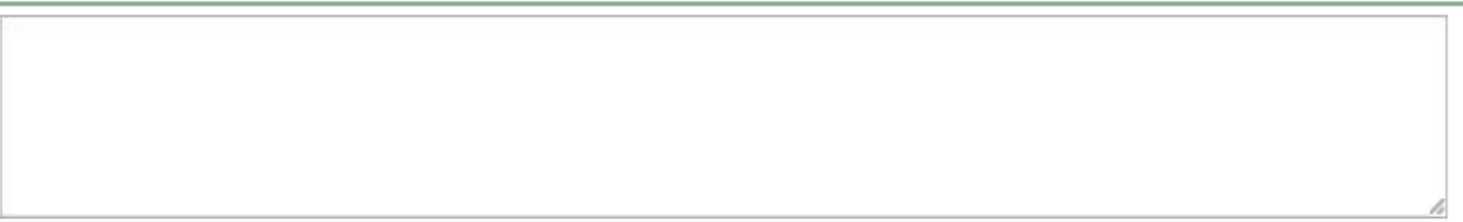

\section{Volunteered Cadastral Data}

Q4.1.

What is the like lihood of you providing Volunteered Cadastral Data, if the mechanisms to accept the data are available?

Please select only one option.

\begin{tabular}{ccccc}
\hline Verylikely & Likely & Unlikely & Very unlikely & Don't Know \\
$\bigcirc$ & 0 & 0 & 0 & 0
\end{tabular}

Q4.2.

How capable are you to provide the following data services?

Please consider the combination of your your skills and your access to suitable equipment.

Please select one option for each service/role

\begin{tabular}{|c|c|c|c|c|}
\hline & $\begin{array}{l}\text { I am highly } \\
\text { capable }\end{array}$ & $\begin{array}{l}\text { I am generally } \\
\text { capable }\end{array}$ & $\begin{array}{l}\text { I might be } \\
\text { capable }\end{array}$ & Not capable \\
\hline $\begin{array}{l}\text { Collecting and processing new survey information to Cadas tral } \\
\text { standards for (or between) existing survey marks }\end{array}$ & ○ & $\bigcirc$ & ○ & ○ \\
\hline $\begin{array}{l}\text { Collecting and processing new survey information to Geodetic } \\
\text { standards (e.g. High quality GPS observations) }\end{array}$ & O & ○ & ○ & ○ \\
\hline \multirow[t]{2}{*}{$\begin{array}{l}\text { Capture of historic/old survey observations (e.g. data entry off } \\
\text { old plans or traverse sheets) }\end{array}$} & O & ○ & ○ & ○ \\
\hline & $\begin{array}{l}\text { I am highly } \\
\text { capable }\end{array}$ & $\begin{array}{l}\text { I am generally } \\
\text { capable }\end{array}$ & $\begin{array}{l}\text { I might be } \\
\text { capable }\end{array}$ & Not capable \\
\hline Quality assurance services (where others capture data) & O & ○ & ○ & ○ \\
\hline Digitising services (e.g. capture of natural boundaries) & 0 & 0 & O & O \\
\hline
\end{tabular}


Q4.3.

Of the services in the previous question, how likely would you be to contribute to them. (i.e... how willing are you)?

Please assume that mechanisms to accept the data are available

Please select One option for each service/role

\begin{tabular}{|c|c|c|c|c|}
\hline & Very Likely & Likely & Unlikely & Very Unlikely \\
\hline $\begin{array}{l}\text { Collecting and processing new survey information to Cadastral } \\
\text { standards for (or between) existing survey marks }\end{array}$ & O & 0 & O & $\bigcirc$ \\
\hline $\begin{array}{l}\text { Collecting and processing new survey information to Geodetic } \\
\text { standards (e.g. High quality GPS observations) }\end{array}$ & ○ & 0 & ○ & ○ \\
\hline \multirow[t]{2}{*}{$\begin{array}{l}\text { Capture of historic/old survey observations (e.g. data entry off } \\
\text { old plans or traverse sheets) }\end{array}$} & O & O & O & O \\
\hline & Very Likely & Likely & Unlikely & Very Unlikely \\
\hline Quality assurance services (where others capture data) & O & 0 & O & ○ \\
\hline Digitising services (e.g. capture of natural boundaries) & ○ & 0 & O & ○ \\
\hline
\end{tabular}

Q4.4.

Please outline any other services or data that you think others may be able to contribute

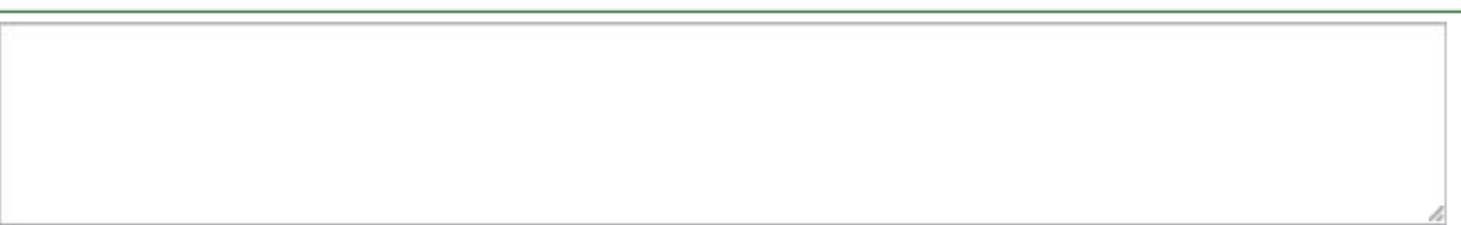

Q4.5.

New Zealand Cadastral Information is stored and managed in a digital system (Landonline) and generally only licensed cadastral surveyors are able to add to and change the cadastre.

When Landonline was created, the data was compiled from a variety of sources (e.g. fieldbooks, survey plans, DCDB, etc.) and not all of this was entered in to Landonline. As a result, many parcels in the cadastre are not based directly on the original surveyed measurements and are of variable quality. VGI may be a means to digitally capture the missing original measurements or provide other supporting accuracy information.

The following scenarios seek your opinion as to the impact on the cadastre if VGI is obtained and used. Please select only one option for each scenario

\begin{tabular}{|c|c|c|c|c|c|}
\hline & $\begin{array}{c}\text { vastly } \\
\text { improve the } \\
\text { cadastre }\end{array}$ & $\begin{array}{c}\text { generally } \\
\text { improve the } \\
\text { cadastre }\end{array}$ & $\begin{array}{l}\text { make no real } \\
\text { difference }\end{array}$ & $\begin{array}{l}\text { generally } \\
\text { harm the } \\
\text { cadastre }\end{array}$ & $\begin{array}{l}\text { severely } \\
\text { harm the } \\
\text { cadastre }\end{array}$ \\
\hline $\begin{array}{l}\text { New survey observations (e.g. GPS data) are provided } \\
\text { by qualified but un-licensed surveyors }\end{array}$ & 0 & 0 & 0 & $\odot$ & 0 \\
\hline $\begin{array}{l}\text { New survey observations (e.g. GPS data) are provided } \\
\text { by people with no survey training }\end{array}$ & 0 & 0 & 0 & $\odot$ & 0 \\
\hline \multirow[t]{2}{*}{$\begin{array}{l}\text { Original survey observations are digitally re-captured } \\
\text { and provided by qualified but un-licensed surveyors }\end{array}$} & 0 & 0 & $\bigcirc$ & $\odot$ & 0 \\
\hline & $\begin{array}{c}\text { vastly } \\
\text { improve the } \\
\text { cadastre }\end{array}$ & $\begin{array}{c}\text { generally } \\
\text { improve the } \\
\text { cadastre }\end{array}$ & $\begin{array}{l}\text { make no real } \\
\text { difference }\end{array}$ & $\begin{array}{l}\text { generally } \\
\text { harm the } \\
\text { cadastre }\end{array}$ & $\begin{array}{l}\text { severely } \\
\text { harm the } \\
\text { cadastre }\end{array}$ \\
\hline $\begin{array}{l}\text { Original survey observations are digitally re-captured } \\
\text { and provided by people with no survey training }\end{array}$ & $\odot$ & 0 & 0 & $\odot$ & 0 \\
\hline $\begin{array}{l}\text { Parcel boundaries are traced off old paper plans (the } \\
\text { original observations are not captured) }\end{array}$ & $\odot$ & 0 & 0 & 0 & 0 \\
\hline $\begin{array}{l}\text { Fences and other topographic data are traced off } \\
\text { aerial photography to estimate boundary positions }\end{array}$ & $\odot$ & 0 & 0 & $\odot$ & 0 \\
\hline
\end{tabular}


Q4.6.

Would you like to comment or further explain some of your answers?

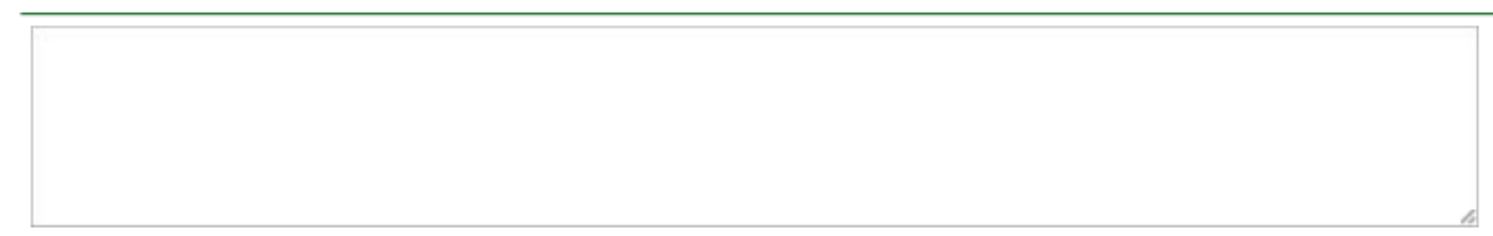

Q4.7.

If VGI is added to the cadastre, what do you think will happen to the overall accuracy of the cadastre? Please select only one option.

Significantly degrade

Slightly degrade

No effective difference

Slightly improve

Significantly improve

$\bigcirc$

○

Q4.8.

If VGI is added to the cadastre, how concerned are you regarding the reliability and trustworthiness of the cadastre?

Please select only one option.

not concemed

○

minorly concerned

○

Q4.9.

If VGI is added to the cadastre, what do you think will happen to the overall completeness of the cadastre? Please select only one option.

Significantly degrade Slightly degrade

O

○

C

Q4.10.

If you wish to comment or further explain some of your answers, please do so. very concerned

○

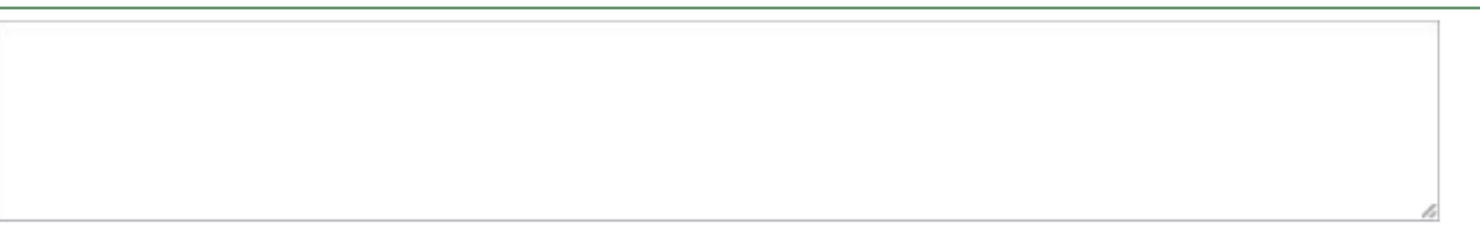

\section{Profile Information}

Q5.1.

What is your gender?

Please select only one option.
Male

Female 
What is your age?

Please select only one option
(1) Younger than 18 years
(1) Between 18 and 35 years
Between 35 and 50 years
(1) Between 50 and 65 years
Older than 65 years

Q5.3.

What is your highest qualification?

Please select oniy one ontion.
O NZCEA levels 1-3 (e.g. High school diplomas)
O NZCEA levels 4-6 (e.g. Trade certificates/polytechnic diplomas)
NZCEA levels 7-8 (e.g. Bachelors \& Honours degrees and post graduate diplomas)
O NZCEAlevels 9-10 (e.g. Masters degree and PhD)
I I have no formal qualifications

Q5.4.

Are you currently a New Zealand licensed cadastral surveyor?

Please select only one ontion.
Yes
No

Q5.5.

Have you ever been licensed/registered to undertake cadastral surveys?

Prease select onily one option.
(1) Yes
No

Q5.6.

Do you have cadastral surveying qualifications?

Please select only one option.
Y Yes
No

Q5.7.

Where do you live?

Please select only one ootion
New Zealand
- Australia
Other (Please specify) 
Q5.8.

In which Territorial Authority (or Unitary Authority) do you live?

Please select only one option. (Tip: type the first letter of the TA name to help find your TA in the list)

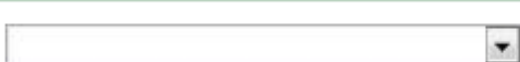

Q5.9.

What is your employment status?

Please select only one option.

Full time employment (including self employment)

Part time employment

Not employed (including unemployed, retired, students etc.)

Q5.10.

What is your job or role within the business or organisation where you work?

You may select more than one answer.

Senior or middle management

Technical professional

Data analyst/technician

Sales and marketing/client liaison

Researcher, Scientist, Academic or similar

Other (please specify)

-

Q5.11.

Which one of the following best describes your employment relationship with the business or organisation where you work?

Please select only one option.
I own the business either solely or with others
I I work for the business
I am employed by a public service organisation (e.g government agency, charity)
Other (please specify)

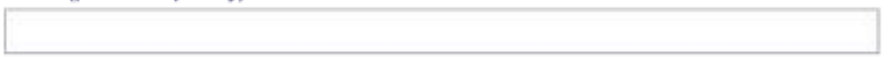

Q5.12.

How large is the business or organisation where you work?

Please select only one option.
less than 10 employees
10 - 29 employees
- 30 - 99 employees
O 100 - 499 employees
$\mathbf{5 0 0 + \text { employees }}$ 
Q8.1.

\section{CONSENT TO BE APPROACHED FOR THE NEXT PHASE}

Thank you for taking the time to participate in this survey. Your responses will be submitted as when you move to the next page and will subsequently be analysed and summarised in conjunction with information obtained from other participants.

The next phase of the research will obtain further information from users of the cadastre to best identify where VGI is best suited. If you are willing to participate, please select "Yes, I am willing to be contacted for the next research phase".

The submit button saves your responses to the survey regardless of whether or not you choose to be available for future stages.

Yes, I am willing to be contacted for the next research phase and would like to submit my responses

No, submit my responses

\section{Cadastral Individual Profile Information}

Q6.1.

Overall, what percentage of your work relies on cadastral data?

Please move the slider, or click on the bar to indicate your estimation

Not reliant Extremely reliant

\begin{tabular}{r|l|l|l|l|}
\multicolumn{2}{c|}{0} & & & \\
\hline $\begin{array}{r}\text { Estimated percentage } \\
\text { (\%) of business } \\
\text { reliance on cadastral } \\
\text { data }\end{array}$ & & & & \\
\end{tabular}

Q6.2.

How do you see your usage of cadastral data changing in the next three (3) years?

Please select only one option.

\begin{tabular}{cccc}
\hline Increasing usage & Similar usage & Decreasing usage & Don't know
\end{tabular}

Q6.3.

Do you generate cadastral data?

Please select only one option.
Yes
No
Don't know

Q6.4.

How will your generation (capture or collation) of cadastral data changing in the next three (3) years?

Please select only one option. 
Significantly increase

○
Remain broadly similar

O
Significantly decrease

○

\section{Cadastral Work Profile Information}

Q7.1.

This section is intended for either an owner of the business or a senior/middle manager.

If you cannot answer on behalf of the business please feel free to skip this section.

I can respond on behalf of the business

I I wish to skip this section

Q7.2.

What percentage of the organisations' work relies on cadastral data?

Please move the slider, or click on the bar to indicate your estimation

Not reliant

Extremely reliant

\begin{tabular}{r|r|l|l|l|}
\multicolumn{2}{c|}{0} & & & \\
\\
$\begin{array}{r}\text { Estimated percentage } \\
(\%) \text { of business } \\
\text { reliance on cadastral } \\
\text { data }\end{array}$ & & & & \\
\end{tabular}

Q7.3.

How will the organisations' usage of cadastral data change in the next three (3) years?

Please select only one option.

Significant increase

Remain similar

Significant decrease

Don't know

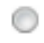

○

Q7.4.

Does the organisation generate cadastral data?

Please select only one option.
Yes
(1) No
Don't know

Q7.5.

How will the organisations' generation (capture or collation) of cadastral data change in the next three (3) years?

Please select only one option. 
Q7.6.

Does your business have cadastral information that is not already in the cadastre?

Please select only ane option
Yes
No

Q7.7.

How willing is your business to volunteer existing cadastral that is not already in the cadastre? Please select only one option

Our business is willing to go to significant effort to make most of this data available (e.g. prepare a survey information onlyCSD)

Our business is willing to go to moderate efforts to make most of this data available (e.g. data reprocessing, format conversion,extract from archives etc.)

Our business is willing to go to minimal efforts to release most of this data (e.g. provide in its raw/existing form)

Our business is not willing to volunteer most of this data

Q7.8.

What percentage of this cadastral resource is already in a digital form? Please move the slider, or click on the bar to indicate your estimation

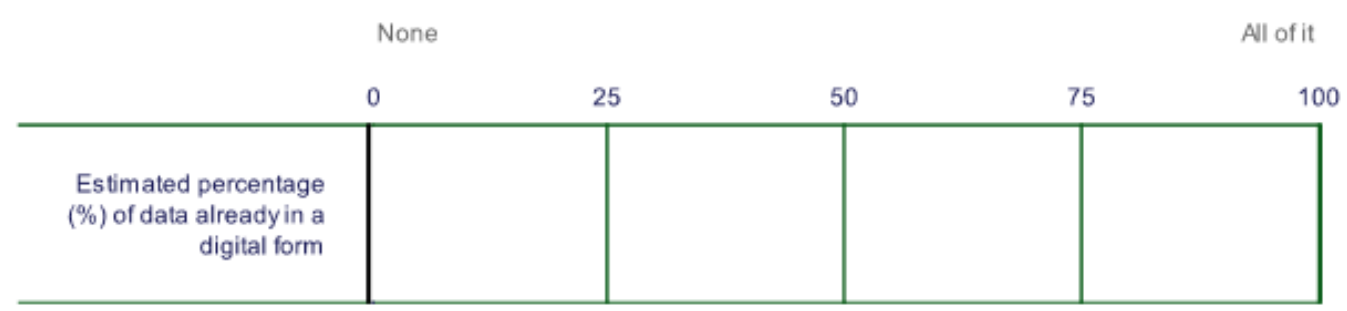

Q7.9.

Please briefly describe what these cadastral data resources are? (e.g. GPS observations, boundary calculations etc.)

Please list the most significant resources 


\subsection{PHASE 2 INTERVIEW STRUCTURE - OPENING QUESTIONS AND DISCUSSION PROMPTS}

\section{Introduction}

$\mathrm{Hi}$ I'm Andrew

Thank you for agreeing to participate in this research.

\section{Question 1}

Before we begin, I need to ensure that you understand the information that l've already provided and that I have your written consent to proceed.

Do you have any questions that you'd like me to answer?

\begin{tabular}{|l|l|}
\hline Prompt & Notes \\
\hline Research Aims & \\
\hline Confidentiality & \\
\hline Interview Transcript & \\
\hline Right to withdraw & \\
\hline Other questions & \\
\hline $\begin{array}{l}\text { Consent. } \\
\text { (and check the form } \\
\text { is signed) }\end{array}$ & \\
\hline
\end{tabular}

\section{Question 2}

Firstly, l'd like to discuss what your role and responsibilities in LINZ are, and how that relates to the NZ Cadastre. Please tell me what you do at LINZ.

\begin{tabular}{|l|l|}
\hline Prompt & Notes \\
\hline Role & \\
\hline Responsibilities & \\
\hline Links to the cadastre & \\
\hline $\begin{array}{l}\text { Relationship to other } \\
\text { roles or functions }\end{array}$ & \\
\hline Other points made & \\
\hline
\end{tabular}

\section{Question 3}

This research is about Volunteered Geographic Information (VGI). So I'd like to hear in your own words what you understand VGI to be.

\begin{tabular}{|l|l|}
\hline Prompt & Notes \\
\hline What is VGI & \\
\hline To what extent do & \\
you support the & \\
concept of the use of & \\
VGl in the Cadastral & \\
context & \\
\hline Discuss any changes & \\
\hline
\end{tabular}




\begin{tabular}{|l|l|}
\hline in understanding \\
over time
\end{tabular}

\section{Question 4}

How do you think VGI could be used in the cadastral context?

\begin{tabular}{|l|l|}
\hline Prompt & Notes \\
\hline How could VGI be & \\
used (Maintenance, & \\
QA, Data Capture, & \\
project & \\
improvements) & \\
\hline $\begin{array}{l}\text { What would be the } \\
\text { best use of VGI }\end{array}$ & \\
\hline $\begin{array}{l}\text { Short term, long term } \\
\text { differences }\end{array}$ & \\
\hline $\begin{array}{l}\text { What value will VGI } \\
\text { provide }\end{array}$ & \\
\hline $\begin{array}{l}\text { Are there options } \\
\text { that should be } \\
\text { prioritised or } \\
\text { excluded }\end{array}$ & \\
\hline Other discussion & \\
\hline
\end{tabular}

\section{Question 5}

What concerns do you have about using VGI in the cadastral context?

\begin{tabular}{|l|l|}
\hline Prompt concerns & Notes \\
\hline $\begin{array}{l}\text { Discuss accuracy, } \\
\text { (e.g. }\end{array}$ & \\
authoritativeness, \\
trustworthiness)
\end{tabular}




\section{Question 6}

There is a wide variety of people with an interest in the cadastre. How do you see this changing or being managed if $\mathrm{VGl}$ is used in the cadastre?

\begin{tabular}{|l|l|}
\hline Prompt & Notes \\
\hline $\begin{array}{l}\text { Changes that will } \\
\text { eventuate with } \mathrm{VGI}\end{array}$ & \\
\hline $\begin{array}{l}\text { What skills are } \\
\text { required to contribute } \\
\text { or manage VGI }\end{array}$ & \\
\hline $\begin{array}{l}\text { What is the role of } \\
\text { Government/officials }\end{array}$ & \\
\hline $\begin{array}{l}\text { What other roles will } \\
\text { develop or be } \\
\text { required }\end{array}$ & \\
\hline Other discussion & \\
\hline
\end{tabular}

\section{Question 7}

The final aspect of this interview that l'd like to cover relates to managing the cadastre and VGI, including the role that your official position has.

What part (or potential part) does your position have in allowing, enabling or managing VGI in the New Zealand Cadastre?

\begin{tabular}{|l|l|}
\hline Prompt & Notes \\
\hline $\begin{array}{l}\text { Personal role in } \\
\text { allowing, enabling or } \\
\text { managing VGI }\end{array}$ & \\
\hline $\begin{array}{l}\text { Impact on workloads. } \\
\text { (increase/decrease) }\end{array}$ & \\
\hline $\begin{array}{l}\text { Use of 'non cadastral' } \\
\text { information }\end{array}$ & \\
\hline $\begin{array}{l}\text { VGl integration with } \\
\text { existing information. } \\
\text { e.g. tightly or loosely } \\
\text { controlled/managed } \\
\text { (if allowed at all) }\end{array}$ & \\
\hline Financial ramifications & \\
\hline Other discussion & \\
\hline
\end{tabular}




\subsection{QUALITATIVE ANALYSIS WITH SURVEY TRAINING SEPARATION}

\begin{tabular}{|c|c|c|c|c|c|c|}
\hline $\begin{array}{l}\text { Do you know what Volunteered } \\
\text { Geographic Information (VGI) is? }\end{array}$ & $\begin{array}{l}\text { Survey } \\
\text { Qualified }\end{array}$ & $\begin{array}{c}\text { Not } \\
\text { Survey } \\
\text { Qualified }\end{array}$ & Combined & $\begin{array}{l}\text { Survey } \\
\text { Qualified } \\
(n=76)\end{array}$ & $\begin{array}{c}\text { Not } \\
\text { Survey } \\
\text { Qualified } \\
(n=35)\end{array}$ & $\begin{array}{c}\text { Combined } \\
(\mathrm{n}=111)\end{array}$ \\
\hline $\begin{array}{l}\text { I know + } \\
\text { I am reasonably certain }\end{array}$ & 41 & 30 & 71 & $36.9 \%$ & $27.0 \%$ & $64.0 \%$ \\
\hline $\begin{array}{l}\text { I am uncertain }+ \\
\text { I do not know }\end{array}$ & 35 & 5 & 40 & $31.5 \%$ & $4.5 \%$ & $36.0 \%$ \\
\hline Total & 76 & 35 & 111 & $68.5 \%$ & $31.5 \%$ & $100.0 \%$ \\
\hline
\end{tabular}

\begin{tabular}{|c|c|c|c|c|c|c|}
\hline $\begin{array}{c}\text { Have you used or encountered any } \\
\text { Volunteered Geographic Information } \\
\text { (VGI)? }\end{array}$ & $\begin{array}{c}\text { Survey } \\
\text { Qualified }\end{array}$ & $\begin{array}{l}\text { Not } \\
\text { Survey } \\
\text { Qualified }\end{array}$ & Combined & $\begin{array}{l}\text { Survey } \\
\text { Qualified } \\
(n=75)\end{array}$ & $\begin{array}{l}\text { Not } \\
\text { Survey } \\
\text { Qualified } \\
(n=35)\end{array}$ & $\begin{array}{c}\text { Combined } \\
(n=110)\end{array}$ \\
\hline Yes & 28 & 22 & 50 & $25.5 \%$ & $20.0 \%$ & $45.5 \%$ \\
\hline No & 27 & 10 & 37 & $24.5 \%$ & $9.1 \%$ & $33.6 \%$ \\
\hline Don't know & 20 & 3 & 23 & $18.2 \%$ & $2.7 \%$ & $20.9 \%$ \\
\hline Total & 75 & 35 & 110 & $68.2 \%$ & $31.8 \%$ & $100.0 \%$ \\
\hline
\end{tabular}

\begin{tabular}{|c|c|c|c|c|c|c|}
\hline $\begin{array}{l}\text { Have you contributed Volunteered } \\
\text { Geographic Information (VGI)? }\end{array}$ & $\begin{array}{l}\text { Survey } \\
\text { Qualified }\end{array}$ & $\begin{array}{c}\text { Not } \\
\text { Survey } \\
\text { Qualified }\end{array}$ & Combined & $\begin{array}{l}\text { Survey } \\
\text { Qualified } \\
(n=75)\end{array}$ & $\begin{array}{c}\text { Not } \\
\text { Survey } \\
\text { Qualified } \\
(n=35)\end{array}$ & $\begin{array}{c}\text { Combined } \\
(n=110)\end{array}$ \\
\hline Yes & 13 & 11 & 24 & $11.8 \%$ & $10.0 \%$ & $21.8 \%$ \\
\hline No & 52 & 22 & 74 & $47.3 \%$ & $20.0 \%$ & $67.3 \%$ \\
\hline Unsure & 10 & 2 & 12 & $9.1 \%$ & $1.8 \%$ & $10.9 \%$ \\
\hline Total & 75 & 35 & 110 & $68.2 \%$ & $31.8 \%$ & $100.0 \%$ \\
\hline
\end{tabular}

\begin{tabular}{|c|c|c|c|c|c|c|c|}
\hline \multicolumn{2}{|c|}{$\begin{array}{l}\text { To what extent do the following } \\
\text { factors limit your contribution (or } \\
\text { potential contribution) to VGI? }\end{array}$} & \multirow{2}{*}{$\begin{array}{c}\begin{array}{c}\text { Survey } \\
\text { Qualified }\end{array} \\
39\end{array}$} & \multirow{2}{*}{$\begin{array}{c}\text { Not } \\
\text { Survey } \\
\text { Qualified }\end{array}$} & \multirow{2}{*}{$\begin{array}{c}\text { Combined } \\
62\end{array}$} & \multirow{2}{*}{$\begin{array}{c}\begin{array}{c}\text { Survey } \\
\text { Qualified } \\
(n=75)\end{array} \\
35.5 \%\end{array}$} & \multirow{2}{*}{$\begin{array}{c}\text { Not } \\
\text { Survey } \\
\begin{array}{c}\text { Qualified } \\
(n=35)\end{array} \\
20.9 \%\end{array}$} & \multirow{2}{*}{$\begin{array}{c}\begin{array}{c}\text { Combined } \\
(\mathrm{n}=110)\end{array} \\
56.4 \%\end{array}$} \\
\hline Part Question: I & $\begin{array}{l}\text { Not limiting }+ \\
\text { Somewhat limiting }\end{array}$ & & & & & & \\
\hline can be involved & $\begin{array}{l}\text { Reasonably limiting + } \\
\text { Extremely Limiting }\end{array}$ & 36 & 12 & 48 & $32.7 \%$ & $10.9 \%$ & $43.6 \%$ \\
\hline & Total & 75 & 35 & 110 & $68.2 \%$ & $31.8 \%$ & $100.0 \%$ \\
\hline \multirow{3}{*}{$\begin{array}{l}\text { Part Question: I } \\
\text { don't have the time } \\
\text { to be contribute }\end{array}$} & $\begin{array}{l}\text { Not limiting + } \\
\text { Somewhat limiting }\end{array}$ & 35 & 19 & 54 & $31.8 \%$ & $17.3 \%$ & $49.1 \%$ \\
\hline & $\begin{array}{l}\text { Reasonably limiting + } \\
\text { Extremely Limiting }\end{array}$ & 40 & 16 & 56 & $36.4 \%$ & $14.5 \%$ & $50.9 \%$ \\
\hline & Total & 75 & 35 & 110 & $68.2 \%$ & $31.8 \%$ & $100.0 \%$ \\
\hline
\end{tabular}




\begin{tabular}{|c|c|c|c|c|c|c|c|}
\hline \multicolumn{2}{|c|}{$\begin{array}{l}\text { To what extent do the following } \\
\text { factors limit your contribution (or } \\
\text { potential contribution) to VGI? } \\
\text { (CONTINUED) }\end{array}$} & $\begin{array}{l}\text { Survey } \\
\text { Qualified }\end{array}$ & $\begin{array}{c}\text { Not } \\
\text { Survey } \\
\text { Qualified }\end{array}$ & Combined & $\begin{array}{l}\text { Survey } \\
\text { Qualified } \\
(n=75)\end{array}$ & $\begin{array}{l}\text { Not } \\
\text { Survey } \\
\text { Qualified } \\
(n=35)\end{array}$ & $\begin{array}{c}\text { Combined } \\
(n=110)\end{array}$ \\
\hline \multirow{3}{*}{$\begin{array}{l}\text { Part Question: I } \\
\text { don't have the } \\
\text { necessary skills to } \\
\text { capture data to } \\
\text { enable me to } \\
\text { contribute }\end{array}$} & $\begin{array}{l}\text { Not limiting }+ \\
\text { Somewhat limiting }\end{array}$ & 68 & 28 & 96 & $61.8 \%$ & $25.5 \%$ & $87.3 \%$ \\
\hline & $\begin{array}{l}\text { Reasonably limiting + } \\
\text { Extremely Limiting }\end{array}$ & 7 & 7 & 14 & $6.4 \%$ & $6.4 \%$ & $12.7 \%$ \\
\hline & Total & 75 & 35 & 110 & $68.2 \%$ & $31.8 \%$ & $100.0 \%$ \\
\hline \multirow{3}{*}{$\begin{array}{l}\text { Part Question: I } \\
\text { don't want to give } \\
\text { away my data }\end{array}$} & $\begin{array}{l}\text { Not limiting }+ \\
\text { Somewhat limiting }\end{array}$ & 53 & 28 & 81 & $48.2 \%$ & $25.5 \%$ & $73.6 \%$ \\
\hline & $\begin{array}{l}\text { Reasonably limiting + } \\
\text { Extremely Limiting }\end{array}$ & 22 & 7 & 29 & $20.0 \%$ & $6.4 \%$ & $26.4 \%$ \\
\hline & Total & 75 & 35 & 110 & $68.2 \%$ & $31.8 \%$ & $100.0 \%$ \\
\hline
\end{tabular}

\begin{tabular}{|c|c|c|c|c|c|c|c|}
\hline \multicolumn{2}{|c|}{$\begin{array}{l}\text { To what extent do the following } \\
\text { factors encourage or influence you to } \\
\text { contribute VGI? }\end{array}$} & \multirow{2}{*}{$\begin{array}{c}\text { Survey } \\
\text { Qualified }\end{array}$} & \multirow{2}{*}{$\begin{array}{c}\text { Not } \\
\text { Survey } \\
\text { Qualified } \\
23\end{array}$} & \multirow{2}{*}{$\begin{array}{c}\text { Combined } \\
58\end{array}$} & \multirow{2}{*}{ 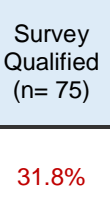 } & \multirow{2}{*}{$\begin{array}{c}\begin{array}{c}\text { Not } \\
\text { Survey } \\
\text { Qualified } \\
(n=35)\end{array} \\
20.9 \%\end{array}$} & \multirow{2}{*}{$\begin{array}{c}\begin{array}{c}\text { Combined } \\
(n=110)\end{array} \\
52.7 \%\end{array}$} \\
\hline Part Question: I can & $\begin{array}{l}\text { Not influential + } \\
\text { Somewhat Influential }\end{array}$ & & & & & & \\
\hline guidance. & $\begin{array}{l}\text { Quite Influential + } \\
\text { Very influential }\end{array}$ & 40 & 12 & 52 & $36.4 \%$ & $10.9 \%$ & $47.3 \%$ \\
\hline & Total & 75 & 35 & 110 & $68.2 \%$ & $31.8 \%$ & $100.0 \%$ \\
\hline \multirow{3}{*}{$\begin{array}{l}\text { Part Question: I feel } \\
\text { that I'm providing a } \\
\text { valuable social (or } \\
\text { public) service. }\end{array}$} & $\begin{array}{l}\text { Not influential + } \\
\text { Somewhat Influential }\end{array}$ & 24 & 12 & 36 & $21.8 \%$ & $10.9 \%$ & $32.7 \%$ \\
\hline & $\begin{array}{l}\text { Quite Influential + } \\
\text { Very influential }\end{array}$ & 51 & 23 & 74 & $46.4 \%$ & $20.9 \%$ & $67.3 \%$ \\
\hline & Total & 75 & 35 & 110 & $68.2 \%$ & $31.8 \%$ & $100.0 \%$ \\
\hline \multirow{3}{*}{$\begin{array}{l}\text { Part Question: By } \\
\text { giving it away, I am } \\
\text { free of the costs or } \\
\text { responsibilities of } \\
\text { owning the data } \\
\text { (e.g. storage, } \\
\text { maintenance). }\end{array}$} & $\begin{array}{l}\text { Not influential + } \\
\text { Somewhat Influential }\end{array}$ & 51 & 28 & 79 & $46.4 \%$ & $25.5 \%$ & $71.8 \%$ \\
\hline & $\begin{array}{l}\text { Quite Influential + } \\
\text { Very influential }\end{array}$ & 24 & 7 & 31 & $21.8 \%$ & $6.4 \%$ & $28.2 \%$ \\
\hline & Total & 75 & 35 & 110 & $68.2 \%$ & $31.8 \%$ & $100.0 \%$ \\
\hline \multirow{3}{*}{$\begin{array}{l}\text { Part Question: I am } \\
\text { passionate or } \\
\text { interested in a } \\
\text { particular dataset } \\
\text { and this helps share } \\
\text { that passion. }\end{array}$} & $\begin{array}{l}\text { Not influential, Somewhat } \\
\text { Influential }\end{array}$ & 43 & 17 & 60 & $39.1 \%$ & $15.5 \%$ & $54.5 \%$ \\
\hline & $\begin{array}{l}\text { Quite Influential, Very } \\
\text { influential }\end{array}$ & 32 & 18 & 50 & $29.1 \%$ & $16.4 \%$ & $45.5 \%$ \\
\hline & Total & 75 & 35 & 110 & $68.2 \%$ & $31.8 \%$ & $100.0 \%$ \\
\hline
\end{tabular}

\begin{tabular}{|c|c|c|c|c|c|c|}
\hline $\begin{array}{c}\text { Do you know what the New Zealand } \\
\text { cadastre is? }\end{array}$ & $\begin{array}{l}\text { Survey } \\
\text { Qualified }\end{array}$ & $\begin{array}{l}\text { Not } \\
\text { Survey } \\
\text { Qualified }\end{array}$ & Combined & $\begin{array}{l}\text { Survey } \\
\text { Qualified } \\
(n=75)\end{array}$ & $\begin{array}{c}\text { Not } \\
\text { Survey } \\
\text { Qualified } \\
(n=35)\end{array}$ & $\begin{array}{c}\text { Combined } \\
(n=110)\end{array}$ \\
\hline $\begin{array}{l}\text { Yes }+ \text { I know }+ \\
\text { I am reasonably certain }\end{array}$ & 69 & 30 & 99 & $62.7 \%$ & $27.3 \%$ & $90.0 \%$ \\
\hline $\begin{array}{l}\text { I am uncertain + } \\
\text { I do not know }\end{array}$ & 6 & 5 & 11 & $5.5 \%$ & $4.5 \%$ & $10.0 \%$ \\
\hline Total & 75 & 35 & 110 & $68.2 \%$ & $31.8 \%$ & $100.0 \%$ \\
\hline
\end{tabular}




\begin{tabular}{|c|c|c|c|c|c|c|}
\hline $\begin{array}{l}\text { How well do you understand the } \\
\text { scope of cadastral data (i.e. how and } \\
\text { where cadastral data is used)? }\end{array}$ & $\begin{array}{l}\text { Survey } \\
\text { Qualified }\end{array}$ & $\begin{array}{c}\text { Not } \\
\text { Survey } \\
\text { Qualified }\end{array}$ & Combined & $\begin{array}{l}\text { Survey } \\
\text { Qualified } \\
(n=75)\end{array}$ & $\begin{array}{l}\text { Not } \\
\text { Survey } \\
\text { Qualified } \\
(n=35)\end{array}$ & $\begin{array}{c}\text { Combined } \\
(n=110)\end{array}$ \\
\hline $\begin{array}{l}\text { I understand very well + } \\
\text { I understand quite well }\end{array}$ & 72 & 22 & 94 & $65.5 \%$ & $20.0 \%$ & $85.5 \%$ \\
\hline $\begin{array}{l}\text { I somewhat understand + } \\
\text { I do not understand }\end{array}$ & 3 & 13 & 16 & $2.7 \%$ & $11.8 \%$ & $14.5 \%$ \\
\hline Total & 75 & 35 & 110 & $68.2 \%$ & $31.8 \%$ & $100.0 \%$ \\
\hline
\end{tabular}

\begin{tabular}{|c|c|c|c|c|c|c|c|}
\hline $\begin{array}{c}\text { Have you actively participated in the } \\
\text { gathering or creation of cadastral } \\
\text { data? }\end{array}$ & $\begin{array}{c}\text { Survey } \\
\text { Qualified }\end{array}$ & $\begin{array}{c}\text { Not } \\
\text { Survey } \\
\text { Qualified }\end{array}$ & Combined & $\begin{array}{c}\text { Survey } \\
\text { Qualified } \\
(\mathrm{n}=75)\end{array}$ & $\begin{array}{c}\text { Not } \\
\text { Survey } \\
\text { Qualified } \\
(\mathrm{n}=35)\end{array}$ & $\begin{array}{c}\text { Combined } \\
(\mathrm{n}=110)\end{array}$ \\
\hline & Yes & 68 & 7 & 75 & $61.8 \%$ & $6.4 \%$ & $68.2 \%$ \\
\hline & No & 7 & 28 & 35 & $6.4 \%$ & $25.5 \%$ & $31.8 \%$ \\
\hline & Total & 75 & 35 & $\mathbf{1 1 0}$ & $68.2 \%$ & $31.8 \%$ & $100.0 \%$ \\
\hline
\end{tabular}

\begin{tabular}{|c|c|c|c|c|c|c|}
\hline $\begin{array}{l}\text { How well do you understand how } \\
\text { cadastral data is created? }\end{array}$ & $\begin{array}{l}\text { Survey } \\
\text { Qualified }\end{array}$ & $\begin{array}{l}\text { Not } \\
\text { Survey } \\
\text { Qualified }\end{array}$ & Combined & $\begin{array}{l}\text { Survey } \\
\text { Qualified } \\
(n=75)\end{array}$ & $\begin{array}{c}\text { Not } \\
\text { Survey } \\
\text { Qualified } \\
(n=35)\end{array}$ & $\begin{array}{c}\text { Combined } \\
(n=110)\end{array}$ \\
\hline $\begin{array}{l}\text { I understand very well + } \\
\text { I understand quite well }\end{array}$ & 72 & 18 & 90 & $65.5 \%$ & $16.4 \%$ & $81.8 \%$ \\
\hline $\begin{array}{l}\text { I somewhat understand + } \\
\text { I do not understand }\end{array}$ & 3 & 17 & 20 & $2.7 \%$ & $15.5 \%$ & $18.2 \%$ \\
\hline Total & 75 & 35 & 110 & $68.2 \%$ & $31.8 \%$ & $100.0 \%$ \\
\hline
\end{tabular}

\begin{tabular}{|c|c|c|c|c|c|c|c|}
\hline \multicolumn{2}{|c|}{$\begin{array}{c}\text { How important are the following } \\
\text { components of Cadastral data to your } \\
\text { use of cadastral data? }\end{array}$} & \multirow{2}{*}{$\begin{array}{c}\text { Survey } \\
\text { Qualified } \\
9\end{array}$} & \multirow{2}{*}{$\begin{array}{c}\text { Not } \\
\text { Survey } \\
\text { Qualified }\end{array}$} & \multirow{2}{*}{$\begin{array}{c}\text { Combined } \\
27\end{array}$} & \multirow{2}{*}{$\begin{array}{c}\begin{array}{c}\text { Survey } \\
\text { Qualified } \\
(n=73)\end{array} \\
8.7 \%\end{array}$} & \multirow{2}{*}{$\begin{array}{c}\begin{array}{c}\text { Not } \\
\text { Survey } \\
\text { Qualified } \\
(n=31)\end{array} \\
17.3 \%\end{array}$} & \multirow{2}{*}{$\begin{array}{c}\begin{array}{c}\text { Combined } \\
(n=104)\end{array} \\
26.0 \%\end{array}$} \\
\hline $\begin{array}{l}\text { Part Question: Survey } \\
\text { observations between }\end{array}$ & $\begin{array}{l}\text { Not Important }+ \\
\text { Somewhat Important }\end{array}$ & & & & & & \\
\hline $\begin{array}{l}\text { connections to the } \\
\text { cadastral boundaries }\end{array}$ & $\begin{array}{l}\text { Quite Important + Very } \\
\text { Important }\end{array}$ & 64 & 13 & 77 & $61.5 \%$ & $12.5 \%$ & $74.0 \%$ \\
\hline & Total & 73 & 31 & 104 & $70.2 \%$ & $29.8 \%$ & $100.0 \%$ \\
\hline \multirow{3}{*}{$\begin{array}{l}\text { Part Question: Survey } \\
\text { observations along } \\
\text { cadastral boundaries } \\
\text { (such as boundary } \\
\text { dimensions) }\end{array}$} & $\begin{array}{l}\text { Not Important }+ \\
\text { Somewhat Important }\end{array}$ & 7 & 18 & 25 & $6.7 \%$ & $17.1 \%$ & $23.8 \%$ \\
\hline & $\begin{array}{l}\text { Quite Important + } \\
\text { Very Important }\end{array}$ & 66 & 14 & 80 & $62.9 \%$ & $13.3 \%$ & $76.2 \%$ \\
\hline & Total & 73 & 32 & 105 & $69.5 \%$ & $30.5 \%$ & $100.0 \%$ \\
\hline \multirow{3}{*}{$\begin{array}{l}\text { Part Question: Survey } \\
\text { mark information (e.g. } \\
\text { names, coordinates) }\end{array}$} & $\begin{array}{l}\text { Not Important }+ \\
\text { Somewhat Important }\end{array}$ & 8 & 16 & 24 & $7.7 \%$ & $15.4 \%$ & $23.1 \%$ \\
\hline & $\begin{array}{l}\text { Quite Important + Very } \\
\text { Important }\end{array}$ & 64 & 16 & 80 & $61.5 \%$ & $15.4 \%$ & $76.9 \%$ \\
\hline & Total & 72 & 32 & 104 & $69.2 \%$ & $30.8 \%$ & $100.0 \%$ \\
\hline \multirow{3}{*}{$\begin{array}{l}\text { Part Question: Positions } \\
\text { and/or shapes of parcels } \\
\text { (i.e. the mapping } \\
\text { representation of the } \\
\text { parcel) }\end{array}$} & $\begin{array}{l}\text { Not Important + } \\
\text { Somewhat Important }\end{array}$ & 6 & 5 & 11 & $5.7 \%$ & $4.8 \%$ & $10.5 \%$ \\
\hline & $\begin{array}{l}\text { Quite Important + } \\
\text { Very Important }\end{array}$ & 67 & 27 & 94 & $63.8 \%$ & $25.7 \%$ & $89.5 \%$ \\
\hline & Total & 73 & 32 & 105 & $69.5 \%$ & $30.5 \%$ & $100.0 \%$ \\
\hline
\end{tabular}




\begin{tabular}{|c|c|c|c|c|c|c|c|}
\hline \multicolumn{2}{|c|}{$\begin{array}{c}\text { How important are the following } \\
\text { components of Cadastral data to your } \\
\text { use of cadastral data? } \\
\text { (CONTINUED) }\end{array}$} & \multirow{2}{*}{$\begin{array}{c}\text { Survey } \\
\text { Qualified }\end{array}$} & \multirow{2}{*}{$\begin{array}{c}\text { Not } \\
\text { Survey } \\
\text { Qualified }\end{array}$} & \multirow{2}{*}{$\begin{array}{c}\text { Combined } \\
10\end{array}$} & \multirow{2}{*}{$\begin{array}{c}\begin{array}{c}\text { Survey } \\
\text { Qualified } \\
(n=73)\end{array} \\
3.8 \%\end{array}$} & \multirow{2}{*}{$\begin{array}{c}\begin{array}{c}\text { Not } \\
\text { Survey } \\
\text { Qualified } \\
(n=31)\end{array} \\
5.7 \%\end{array}$} & \multirow{2}{*}{$\begin{array}{c}\begin{array}{c}\text { Combined } \\
(n=104)\end{array} \\
9.5 \%\end{array}$} \\
\hline Part Question: Parcel & $\begin{array}{l}\text { Not Important + } \\
\text { Somewhat Important }\end{array}$ & & & & & & \\
\hline $\begin{array}{l}\text { appellation, area, } \\
\text { purpose, etc.) }\end{array}$ & $\begin{array}{l}\text { Quite Important + } \\
\text { Very Important }\end{array}$ & 69 & 26 & 95 & $65.7 \%$ & $24.8 \%$ & $90.5 \%$ \\
\hline & Total & 73 & 32 & 105 & $69.5 \%$ & $30.5 \%$ & $100.0 \%$ \\
\hline \multirow{3}{*}{$\begin{array}{l}\text { Part Question: The } \\
\text { authoritativeness of the } \\
\text { cadastral information } \\
\text { (e.g. trustworthiness and } \\
\text { reliability) }\end{array}$} & $\begin{array}{l}\text { Not Important + } \\
\text { Somewhat Important }\end{array}$ & 0 & 7 & 7 & $0.0 \%$ & $6.7 \%$ & $6.7 \%$ \\
\hline & $\begin{array}{l}\text { Quite Important + } \\
\text { Very Important }\end{array}$ & 72 & 25 & 97 & $69.2 \%$ & $24.0 \%$ & $93.3 \%$ \\
\hline & Total & 72 & 32 & 104 & $69.2 \%$ & $30.8 \%$ & $100.0 \%$ \\
\hline \multirow{3}{*}{$\begin{array}{l}\text { Part Question: } \\
\text { Historical cadastral } \\
\text { information that has not } \\
\text { been digitised (e.g. old } \\
\text { plans, fieldbooks, } \\
\text { traverse sheets, etc.) }\end{array}$} & $\begin{array}{l}\text { Not Important + } \\
\text { Somewhat Important }\end{array}$ & 10 & 17 & 27 & $9.7 \%$ & $16.5 \%$ & $26.2 \%$ \\
\hline & $\begin{array}{l}\text { Quite Important + } \\
\text { Very Important }\end{array}$ & 62 & 14 & 76 & $60.2 \%$ & $13.6 \%$ & $73.8 \%$ \\
\hline & Total & 72 & 31 & 103 & $69.9 \%$ & $30.1 \%$ & $100.0 \%$ \\
\hline
\end{tabular}

\begin{tabular}{|c|c|c|c|c|c|c|c|}
\hline \multicolumn{2}{|c|}{$\begin{array}{l}\text { Have you experienced issues in } \\
\text { relation to the following attributes? }\end{array}$} & \multirow{2}{*}{$\begin{array}{c}\begin{array}{c}\text { Survey } \\
\text { Qualified }\end{array} \\
69\end{array}$} & \multirow{2}{*}{$\begin{array}{c}\begin{array}{c}\text { Not } \\
\text { Survey } \\
\text { Qualified }\end{array} \\
16\end{array}$} & \multirow{2}{*}{$\begin{array}{c}\text { Combined } \\
85\end{array}$} & \multirow{2}{*}{$\begin{array}{c}\begin{array}{c}\text { Survey } \\
\text { Qualified } \\
(n=73)\end{array} \\
69.0 \%\end{array}$} & \multirow{2}{*}{$\begin{array}{c}\begin{array}{c}\text { Not } \\
\text { Survey } \\
\text { Qualified } \\
(n=27)\end{array} \\
16.0 \%\end{array}$} & \multirow{2}{*}{$\begin{array}{c}\begin{array}{c}\text { Combined } \\
(n=100)\end{array} \\
85.0 \%\end{array}$} \\
\hline Part Question: & Yes & & & & & & \\
\hline inaccurate & No & 4 & 11 & 15 & $4.0 \%$ & $11.0 \%$ & $15.0 \%$ \\
\hline & Total & 73 & 27 & 100 & $73.0 \%$ & $27.0 \%$ & $100.0 \%$ \\
\hline \multirow{3}{*}{$\begin{array}{l}\text { Part Question: Cadastral } \\
\text { data that is incomplete }\end{array}$} & Yes & 63 & 15 & 78 & $63.6 \%$ & $15.2 \%$ & $78.8 \%$ \\
\hline & No & 10 & 11 & 21 & $10.1 \%$ & $11.1 \%$ & $21.2 \%$ \\
\hline & Total & 73 & 26 & 99 & $73.7 \%$ & $26.3 \%$ & $100.0 \%$ \\
\hline \multirow{3}{*}{$\begin{array}{l}\text { Part Question: Cadastral } \\
\text { data that is out-of-date }\end{array}$} & Yes & 45 & 13 & 58 & $47.4 \%$ & $13.7 \%$ & $61.1 \%$ \\
\hline & No & 28 & 9 & 37 & $29.5 \%$ & $9.5 \%$ & $38.9 \%$ \\
\hline & Total & 73 & 22 & 95 & $76.8 \%$ & $23.2 \%$ & $100.0 \%$ \\
\hline
\end{tabular}

\begin{tabular}{|c|c|c|c|c|c|c|}
\hline $\begin{array}{l}\text { What is the likelihood of you providing } \\
\text { Volunteered Cadastral Data, if the } \\
\text { mechanisms to do so are available? }\end{array}$ & $\begin{array}{l}\text { Survey } \\
\text { Qualified }\end{array}$ & $\begin{array}{c}\text { Not } \\
\text { Survey } \\
\text { Qualified }\end{array}$ & Combined & $\begin{array}{c}\text { Survey } \\
\text { Qualified } \\
(n=74)\end{array}$ & $\begin{array}{l}\text { Not } \\
\text { Survey } \\
\text { Qualified } \\
(n=35)\end{array}$ & $\begin{array}{c}\text { Combined } \\
(n=109)\end{array}$ \\
\hline \begin{tabular}{l|l|} 
Very likely + \\
Likely
\end{tabular} & 39 & 16 & 55 & $35.8 \%$ & $14.7 \%$ & $50.5 \%$ \\
\hline $\begin{array}{l}\text { Don't Know + Unlikely + } \\
\text { Very unlikely }\end{array}$ & 35 & 19 & 54 & $32.1 \%$ & $17.4 \%$ & $49.5 \%$ \\
\hline Total & 74 & 35 & 109 & $67.9 \%$ & $32.1 \%$ & $100.0 \%$ \\
\hline
\end{tabular}




\begin{tabular}{|c|c|c|c|c|c|c|c|}
\hline \multicolumn{2}{|c|}{$\begin{array}{l}\text { How capable are you to provide the } \\
\text { following data services? }\end{array}$} & \multirow{2}{*}{$\begin{array}{c}\text { Survey } \\
\text { Qualified }\end{array}$} & \multirow{2}{*}{$\begin{array}{c}\text { Not } \\
\text { Survey } \\
\text { Qualified } \\
8\end{array}$} & \multirow{2}{*}{$\begin{array}{c}\text { Combined } \\
71\end{array}$} & \multirow{2}{*}{$\begin{array}{c}\begin{array}{c}\text { Survey } \\
\text { Qualified } \\
(n=75)\end{array} \\
57.3 \%\end{array}$} & \multirow{2}{*}{$\begin{array}{c}\begin{array}{c}\text { Not } \\
\text { Survey } \\
\text { Qualified } \\
(\mathrm{n}=35)\end{array} \\
7.3 \%\end{array}$} & \multirow{2}{*}{$\begin{array}{c}\begin{array}{c}\text { Combined } \\
(\mathrm{n}=110)\end{array} \\
64.5 \%\end{array}$} \\
\hline $\begin{array}{l}\text { Collecting \& processing } \\
\text { new survey information }\end{array}$ & $\begin{array}{l}\text { I am highly capable }+ \\
\text { I am generally capable }\end{array}$ & & & & & & \\
\hline $\begin{array}{l}\text { for (or between) existing } \\
\text { survey marks }\end{array}$ & $\begin{array}{l}\text { I might be capable + } \\
\text { Not capable }\end{array}$ & 12 & 27 & 39 & $10.9 \%$ & $24.5 \%$ & $35.5 \%$ \\
\hline & Total & 75 & 35 & 110 & $68.2 \%$ & $31.8 \%$ & $100.0 \%$ \\
\hline \multirow{3}{*}{$\begin{array}{l}\text { Collecting and } \\
\text { processing new survey } \\
\text { information to Geodetic } \\
\text { standards (e.g. High } \\
\text { quality GPS } \\
\text { observations) }\end{array}$} & $\begin{array}{l}\text { I am highly capable }+ \\
\text { I am generally capable }\end{array}$ & 55 & 8 & 63 & $50.0 \%$ & $7.3 \%$ & $57.3 \%$ \\
\hline & $\begin{array}{l}\text { I might be capable + } \\
\text { Not capable }\end{array}$ & 20 & 27 & 47 & $18.2 \%$ & $24.5 \%$ & $42.7 \%$ \\
\hline & Total & 75 & 35 & 110 & $68.2 \%$ & $31.8 \%$ & $100.0 \%$ \\
\hline \multirow{3}{*}{$\begin{array}{l}\text { Capture of historic/old } \\
\text { survey observations } \\
\text { (e.g. data entry off old } \\
\text { plans or traverse sheets) }\end{array}$} & $\begin{array}{l}\text { I am highly capable }+ \\
\text { I am generally capable }\end{array}$ & 65 & 14 & 79 & $59.6 \%$ & $12.8 \%$ & $72.5 \%$ \\
\hline & $\begin{array}{l}\text { I might be capable + } \\
\text { Not capable }\end{array}$ & 9 & 21 & 30 & $8.3 \%$ & $19.3 \%$ & $27.5 \%$ \\
\hline & Total & 74 & 35 & 109 & $67.9 \%$ & $32.1 \%$ & $100.0 \%$ \\
\hline \multirow{3}{*}{$\begin{array}{l}\text { Quality assurance } \\
\text { services (where others } \\
\text { capture data) }\end{array}$} & $\begin{array}{l}\text { I am highly capable }+ \\
\text { I am generally capable }\end{array}$ & 61 & 15 & 76 & $55.5 \%$ & $13.6 \%$ & $69.1 \%$ \\
\hline & $\begin{array}{l}\text { I might be capable + } \\
\text { Not capable }\end{array}$ & 14 & 20 & 34 & $12.7 \%$ & $18.2 \%$ & $30.9 \%$ \\
\hline & Total & 75 & 35 & 110 & $68.2 \%$ & $31.8 \%$ & $100.0 \%$ \\
\hline \multirow{3}{*}{$\begin{array}{l}\text { Digitising services (e.g. } \\
\text { capture of natural } \\
\text { boundaries) }\end{array}$} & $\begin{array}{l}\text { I am highly capable }+ \\
\text { I am generally capable }\end{array}$ & 61 & 18 & 79 & $55.5 \%$ & $16.4 \%$ & $71.8 \%$ \\
\hline & $\begin{array}{l}\text { I might be capable + } \\
\text { Not capable }\end{array}$ & 14 & 17 & 31 & $12.7 \%$ & $15.5 \%$ & $28.2 \%$ \\
\hline & Total & 75 & 35 & 110 & $68.2 \%$ & $31.8 \%$ & $100.0 \%$ \\
\hline
\end{tabular}

\begin{tabular}{|c|c|c|c|c|c|c|c|}
\hline \multicolumn{2}{|c|}{$\begin{array}{l}\text { Of the services in the previous } \\
\text { question, how likely would you be to } \\
\text { contribute to them }\end{array}$} & \multirow{2}{*}{$\begin{array}{c}\text { Survey } \\
\text { Qualified }\end{array}$} & \multirow{2}{*}{$\begin{array}{c}\text { Not } \\
\text { Survey } \\
\text { Qualified }\end{array}$} & \multirow{2}{*}{$\begin{array}{c}\text { Combined } \\
49\end{array}$} & \multirow{2}{*}{$\begin{array}{c}\begin{array}{c}\text { Survey } \\
\text { Qualified } \\
(n=72)\end{array} \\
37.4 \%\end{array}$} & \multirow{2}{*}{$\begin{array}{c}\begin{array}{c}\text { Not } \\
\text { Survey } \\
\text { Qualified } \\
(\mathrm{n}=35)\end{array} \\
8.4 \%\end{array}$} & \multirow{2}{*}{$\begin{array}{r}\begin{array}{r}\text { Combinec } \\
(n=106)\end{array} \\
45.8 \%\end{array}$} \\
\hline Collecting and & $\begin{array}{l}\text { Very Likely + } \\
\text { Likely }\end{array}$ & & & & & & \\
\hline $\begin{array}{l}\text { standards for (or } \\
\text { between) existing survey } \\
\text { marks }\end{array}$ & $\begin{array}{l}\text { Unlikely + } \\
\text { Very Unlikely }\end{array}$ & 32 & 26 & 58 & $29.9 \%$ & $24.3 \%$ & $54.2 \%$ \\
\hline & Total & 72 & 35 & 107 & $67.3 \%$ & $32.7 \%$ & $100.0 \%$ \\
\hline \multirow{3}{*}{$\begin{array}{l}\text { Collecting and } \\
\text { processing new survey } \\
\text { information to Geodetic } \\
\text { standards (e.g. High } \\
\text { quality GPS } \\
\text { observations) }\end{array}$} & $\begin{array}{l}\text { Very Likely + } \\
\text { Likely }\end{array}$ & 37 & 12 & 49 & $34.3 \%$ & $11.1 \%$ & $45.4 \%$ \\
\hline & $\begin{array}{l}\text { Unlikely + } \\
\text { Very Unlikely }\end{array}$ & 36 & 23 & 59 & $33.3 \%$ & $21.3 \%$ & $54.6 \%$ \\
\hline & Total & 73 & 35 & 108 & $67.6 \%$ & $32.4 \%$ & $100.0 \%$ \\
\hline \multirow{3}{*}{$\begin{array}{l}\text { Capture of historic/old } \\
\text { survey observations } \\
\text { (e.g. data entry off old } \\
\text { plans or traverse sheets) }\end{array}$} & $\begin{array}{l}\text { Very Likely + } \\
\text { Likely }\end{array}$ & 39 & 12 & 51 & $36.1 \%$ & $11.1 \%$ & $47.2 \%$ \\
\hline & $\begin{array}{l}\text { Unlikely + } \\
\text { Very Unlikely }\end{array}$ & 34 & 23 & 57 & $31.5 \%$ & $21.3 \%$ & $52.8 \%$ \\
\hline & Total & 73 & 35 & 108 & $67.6 \%$ & $32.4 \%$ & $100.0 \%$ \\
\hline
\end{tabular}




\begin{tabular}{|c|c|c|c|c|c|c|c|}
\hline \multicolumn{2}{|c|}{$\begin{array}{l}\text { Of the services in the previous } \\
\text { question, how likely would you be to } \\
\text { contribute to them } \\
\text { (CONTINUED) }\end{array}$} & \multirow{2}{*}{$\begin{array}{c}\begin{array}{c}\text { Survey } \\
\text { Qualified }\end{array} \\
37\end{array}$} & \multirow{2}{*}{$\begin{array}{c}\text { Not } \\
\text { Survey } \\
\text { Qualified }\end{array}$} & \multirow{2}{*}{$\begin{array}{c}\text { Combined } \\
50\end{array}$} & \multirow{2}{*}{$\begin{array}{c}\begin{array}{c}\text { Survey } \\
\text { Qualified } \\
(n=72)\end{array} \\
34.3 \%\end{array}$} & \multirow{2}{*}{$\begin{array}{c}\begin{array}{c}\text { Not } \\
\text { Survey } \\
\text { Qualified } \\
(n=35)\end{array} \\
12.0 \%\end{array}$} & \multirow{2}{*}{$\begin{array}{c}\begin{array}{c}\text { Combined } \\
(n=106)\end{array} \\
46.3 \%\end{array}$} \\
\hline Quality assurance & $\begin{array}{l}\text { Very Likely + } \\
\text { Likely }\end{array}$ & & & & & & \\
\hline $\begin{array}{l}\text { services (where others } \\
\text { capture data) }\end{array}$ & $\begin{array}{l}\text { Unlikely + } \\
\text { Very Unlikely }\end{array}$ & 36 & 22 & 58 & $33.3 \%$ & $20.4 \%$ & $53.7 \%$ \\
\hline & Total & 73 & 35 & 108 & $67.6 \%$ & $32.4 \%$ & $100.0 \%$ \\
\hline \multirow{3}{*}{$\begin{array}{l}\text { Digitising services (e.g. } \\
\text { capture of natural } \\
\text { boundaries) }\end{array}$} & $\begin{array}{l}\text { Very Likely + } \\
\text { Likely }\end{array}$ & 34 & 14 & 48 & $31.5 \%$ & $13.0 \%$ & $44.4 \%$ \\
\hline & $\begin{array}{l}\text { Unlikely + } \\
\text { Very Unlikely }\end{array}$ & 39 & 21 & 60 & $36.1 \%$ & $19.4 \%$ & $55.6 \%$ \\
\hline & Total & 73 & 35 & 108 & $67.6 \%$ & $32.4 \%$ & $100.0 \%$ \\
\hline
\end{tabular}

\begin{tabular}{|c|c|c|c|c|c|c|c|}
\hline \multicolumn{2}{|c|}{$\begin{array}{l}\text { What is the impact on the cadastre if } \\
\text { the following types of VGI is obtained } \\
\text { and used: }\end{array}$} & \multirow{2}{*}{$\begin{array}{c}\text { Survey } \\
\text { Qualified } \\
41\end{array}$} & \multirow{2}{*}{$\begin{array}{c}\text { Not } \\
\text { Survey } \\
\text { Qualified } \\
22\end{array}$} & \multirow{2}{*}{$\begin{array}{c}\text { Combined } \\
63\end{array}$} & \multirow{2}{*}{$\begin{array}{c}\begin{array}{c}\text { Survey } \\
\text { Qualified } \\
(n=75)\end{array} \\
38.0 \%\end{array}$} & \multirow{2}{*}{$\begin{array}{c}\begin{array}{c}\text { Not } \\
\text { Survey } \\
\text { Qualified } \\
(n=33)\end{array} \\
20.4 \%\end{array}$} & \multirow{2}{*}{$\begin{array}{c}\begin{array}{c}\text { Combined } \\
(n=108)\end{array} \\
58.3 \%\end{array}$} \\
\hline \multirow{4}{*}{$\begin{array}{l}\text { New survey } \\
\text { observations (e.g. GPS } \\
\text { data) are provided by } \\
\text { qualified but un-licensed } \\
\text { surveyors }\end{array}$} & $\begin{array}{l}\text { vastly improve the } \\
\text { cadastre + generally } \\
\text { improve the cadastre }\end{array}$ & & & & & & \\
\hline & make no real difference & 8 & 6 & 14 & $7.4 \%$ & $5.6 \%$ & $13.0 \%$ \\
\hline & $\begin{array}{l}\text { generally harm the } \\
\text { cadastre }+ \\
\text { severely harm the } \\
\text { cadastre }\end{array}$ & 26 & 5 & 31 & $24.1 \%$ & $4.6 \%$ & $28.7 \%$ \\
\hline & Total & 75 & 33 & 108 & $69.4 \%$ & $30.6 \%$ & $100.0 \%$ \\
\hline \multirow{4}{*}{$\begin{array}{l}\text { New survey } \\
\text { observations (e.g. GPS } \\
\text { data) are provided by } \\
\text { people with no survey } \\
\text { training }\end{array}$} & $\begin{array}{l}\text { vastly improve the } \\
\text { cadastre }+ \text { generally } \\
\text { improve the cadastre }\end{array}$ & 12 & 11 & 23 & $11.1 \%$ & $10.2 \%$ & $21.3 \%$ \\
\hline & make no real difference & 1 & 3 & 4 & $0.9 \%$ & $2.8 \%$ & $3.7 \%$ \\
\hline & $\begin{array}{l}\text { generally harm the } \\
\text { cadastre }+ \\
\text { severely harm the } \\
\text { cadastre }\end{array}$ & 62 & 19 & 81 & $57.4 \%$ & $17.6 \%$ & $75.0 \%$ \\
\hline & Total & 75 & 33 & 108 & $69.4 \%$ & $30.6 \%$ & $100.0 \%$ \\
\hline \multirow{4}{*}{$\begin{array}{l}\text { Original survey } \\
\text { observations are digitally } \\
\text { re-captured and } \\
\text { provided by qualified but } \\
\text { un-licensed surveyors }\end{array}$} & $\begin{array}{l}\text { vastly improve the } \\
\text { cadastre + generally } \\
\text { improve the cadastre }\end{array}$ & 56 & 24 & 80 & $51.9 \%$ & $22.2 \%$ & $74.1 \%$ \\
\hline & make no real difference & 11 & 6 & 17 & $10.2 \%$ & $5.6 \%$ & $15.7 \%$ \\
\hline & $\begin{array}{l}\text { generally harm the } \\
\text { cadastre }+ \\
\text { severely harm the } \\
\text { cadastre }\end{array}$ & 8 & 3 & 11 & $7.4 \%$ & $2.8 \%$ & $10.2 \%$ \\
\hline & Total & 75 & 33 & 108 & $69.4 \%$ & $30.6 \%$ & $100.0 \%$ \\
\hline \multirow{3}{*}{$\begin{array}{l}\text { Original survey } \\
\text { observations are digitally } \\
\text { re-captured and } \\
\text { provided by people with } \\
\text { no survey training }\end{array}$} & $\begin{array}{l}\text { vastly improve the } \\
\text { cadastre + generally } \\
\text { improve the cadastre }\end{array}$ & 16 & 10 & 26 & $15.0 \%$ & $9.3 \%$ & $24.3 \%$ \\
\hline & make no real difference & 6 & 5 & 11 & $5.6 \%$ & $4.7 \%$ & $10.3 \%$ \\
\hline & $\begin{array}{l}\text { generally harm the } \\
\text { cadastre }+ \\
\text { severely harm the } \\
\text { cadastre }\end{array}$ & 52 & 18 & 70 & $48.6 \%$ & $16.8 \%$ & $65.4 \%$ \\
\hline & Total & 74 & 33 & 107 & $69.2 \%$ & $30.8 \%$ & $100.0 \%$ \\
\hline
\end{tabular}




\begin{tabular}{|c|c|c|c|c|c|c|c|}
\hline \multicolumn{2}{|c|}{$\begin{array}{l}\text { What is the impact on the cadastre if } \\
\text { the following types of VGI is obtained } \\
\text { and used: (CONTINUED) }\end{array}$} & \multirow{2}{*}{$\begin{array}{c}\begin{array}{c}\text { Survey } \\
\text { Qualified }\end{array} \\
13\end{array}$} & \multirow{2}{*}{$\begin{array}{c}\text { Not } \\
\text { Survey } \\
\text { Qualified }\end{array}$} & \multirow{2}{*}{$\begin{array}{c}\text { Combined } \\
21\end{array}$} & \multirow{2}{*}{$\begin{array}{c}\begin{array}{c}\text { Survey } \\
\text { Qualified } \\
(n=75)\end{array} \\
12.1 \%\end{array}$} & \multirow{2}{*}{$\begin{array}{c}\begin{array}{c}\text { Not } \\
\text { Survey } \\
\text { Qualified } \\
(\mathrm{n}=33)\end{array} \\
7.5 \%\end{array}$} & \multirow{2}{*}{$\begin{array}{c}\begin{array}{c}\text { Combined } \\
(n=108)\end{array} \\
19.6 \%\end{array}$} \\
\hline \multirow{4}{*}{$\begin{array}{l}\text { Parcel boundaries are } \\
\text { traced off old paper } \\
\text { plans (the original } \\
\text { observations are not } \\
\text { captured) }\end{array}$} & $\begin{array}{l}\text { vastly improve the } \\
\text { cadastre + generally } \\
\text { improve the cadastre }\end{array}$ & & & & & & \\
\hline & make no real difference & 20 & 13 & 33 & $18.7 \%$ & $12.1 \%$ & $30.8 \%$ \\
\hline & $\begin{array}{l}\text { generally harm the } \\
\text { cadastre }+ \\
\text { severely harm the } \\
\text { cadastre }\end{array}$ & 42 & 11 & 53 & $39.3 \%$ & $10.3 \%$ & $49.5 \%$ \\
\hline & Total & 75 & 32 & 107 & $70.1 \%$ & $29.9 \%$ & $100.0 \%$ \\
\hline \multirow{4}{*}{$\begin{array}{l}\text { Fences and other } \\
\text { topographic data are } \\
\text { traced off aerial } \\
\text { photography to estimate } \\
\text { boundary positions }\end{array}$} & $\begin{array}{l}\text { vastly improve the } \\
\text { cadastre }+ \text { generally } \\
\text { improve the cadastre }\end{array}$ & 12 & 11 & 23 & $11.1 \%$ & $10.2 \%$ & $21.3 \%$ \\
\hline & make no real difference & 14 & 8 & 22 & $13.0 \%$ & $7.4 \%$ & $20.4 \%$ \\
\hline & $\begin{array}{l}\text { generally harm the } \\
\text { cadastre }+ \\
\text { severely harm the } \\
\text { cadastre }\end{array}$ & 49 & 14 & 63 & $45.4 \%$ & $13.0 \%$ & $58.3 \%$ \\
\hline & Total & 75 & 33 & 108 & $69.4 \%$ & $30.6 \%$ & $100.0 \%$ \\
\hline
\end{tabular}

\begin{tabular}{|c|c|c|c|c|c|c|c|}
\hline \multicolumn{2}{|c|}{$\begin{array}{l}\text { If VGI is added to the cadastre what is } \\
\text { the impact on: }\end{array}$} & \multirow{2}{*}{$\begin{array}{c}\begin{array}{c}\text { Survey } \\
\text { Qualified }\end{array} \\
26\end{array}$} & \multirow{2}{*}{$\begin{array}{c}\text { Not } \\
\text { Survey } \\
\text { Qualified }\end{array}$} & \multirow{2}{*}{$\begin{array}{c}\text { Combined } \\
36\end{array}$} & \multirow{2}{*}{$\begin{array}{c}\begin{array}{c}\text { Survey } \\
\text { Qualified } \\
(n=75)\end{array} \\
24.1 \%\end{array}$} & \multirow{2}{*}{$\begin{array}{c}\begin{array}{c}\text { Not } \\
\text { Survey } \\
\text { Qualified } \\
(n=33)\end{array} \\
9.3 \%\end{array}$} & \multirow{2}{*}{$\begin{array}{c}\begin{array}{r}\text { Combined } \\
(n=108)\end{array} \\
33.3 \%\end{array}$} \\
\hline \multirow{4}{*}{$\begin{array}{l}\text { The overall accuracy of } \\
\text { the cadastre? }\end{array}$} & $\begin{array}{l}\text { Significantly degrade + } \\
\text { Slightly degrade }\end{array}$ & & & & & & \\
\hline & No effective difference & 6 & 4 & 10 & $5.6 \%$ & $3.7 \%$ & $9.3 \%$ \\
\hline & $\begin{array}{l}\text { Slightly improve }+ \\
\text { Significantly improve }\end{array}$ & 43 & 19 & 62 & $39.8 \%$ & $17.6 \%$ & $57.4 \%$ \\
\hline & Total & 75 & 33 & 108 & $69.4 \%$ & $30.6 \%$ & $100.0 \%$ \\
\hline \multirow{4}{*}{$\begin{array}{l}\text { The overall } \\
\text { completeness of the } \\
\text { cadastre? }\end{array}$} & $\begin{array}{l}\text { Significantly degrade + } \\
\text { Slightly degrade }\end{array}$ & 10 & 1 & 11 & $9.3 \%$ & $0.9 \%$ & $10.2 \%$ \\
\hline & No effective difference & 12 & 3 & 15 & $11.1 \%$ & $2.8 \%$ & $13.9 \%$ \\
\hline & $\begin{array}{l}\text { Slightly improve + } \\
\text { Significantly improve }\end{array}$ & 53 & 29 & 82 & $49.1 \%$ & $26.9 \%$ & $75.9 \%$ \\
\hline & Total & 75 & 33 & 108 & $69.4 \%$ & $30.6 \%$ & $100.0 \%$ \\
\hline
\end{tabular}

\begin{tabular}{|c|c|c|c|c|c|c|}
\hline $\begin{array}{l}\text { If } \mathrm{VGI} \text { is added to the cadastre, how } \\
\text { concerned are you regarding the } \\
\text { reliability and trustworthiness? }\end{array}$ & $\begin{array}{l}\text { Survey } \\
\text { Qualified }\end{array}$ & $\begin{array}{l}\text { Not } \\
\text { Survey } \\
\text { Qualified }\end{array}$ & Combined & $\begin{array}{l}\text { Survey } \\
\text { Qualified } \\
(n=75)\end{array}$ & $\begin{array}{l}\text { Not } \\
\text { Survey } \\
\text { Qualified } \\
(n=33)\end{array}$ & $\begin{array}{c}\text { Combined } \\
(n=108)\end{array}$ \\
\hline \begin{tabular}{|l|l|}
$\begin{array}{l}\text { not concerned }+ \\
\text { minorly concerned }\end{array}$ \\
\end{tabular} & 23 & 14 & 37 & $21.3 \%$ & $13.0 \%$ & $34.3 \%$ \\
\hline $\begin{array}{l}\text { moderately concerned }+ \\
\text { very concerned }\end{array}$ & 52 & 19 & 71 & $48.1 \%$ & $17.6 \%$ & $65.7 \%$ \\
\hline Total & 75 & 33 & 108 & $69.4 \%$ & $30.6 \%$ & $100.0 \%$ \\
\hline
\end{tabular}




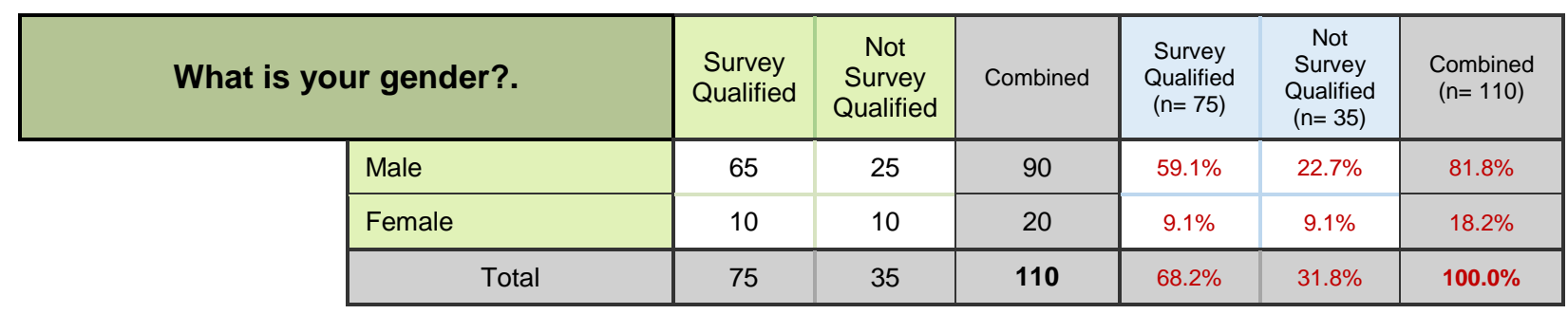

\begin{tabular}{|c|c|c|c|c|c|c|}
\hline $\begin{array}{c}\text { What is your age? Please select only } \\
\text { one option. }\end{array}$ & $\begin{array}{l}\text { Survey } \\
\text { Qualified }\end{array}$ & $\begin{array}{l}\text { Not } \\
\text { Survey } \\
\text { Qualified }\end{array}$ & Combined & $\begin{array}{l}\text { Survey } \\
\text { Qualified } \\
(n=75)\end{array}$ & $\begin{array}{c}\text { Not } \\
\text { Survey } \\
\text { Qualified } \\
(n=35)\end{array}$ & $\begin{array}{c}\text { Combined } \\
(n=110)\end{array}$ \\
\hline Younger than 18 years & 0 & 0 & 0 & $0.0 \%$ & $0.0 \%$ & $0.0 \%$ \\
\hline $\begin{array}{l}\text { Between } 18 \text { and } 35 \\
\text { years }\end{array}$ & 21 & 18 & 39 & $19.1 \%$ & $16.4 \%$ & $35.5 \%$ \\
\hline $\begin{array}{l}\text { Between } 35 \text { and } 50 \\
\text { years }\end{array}$ & 27 & 10 & 37 & $24.5 \%$ & $9.1 \%$ & $33.6 \%$ \\
\hline $\begin{array}{l}\text { Between } 50 \text { and } 65 \\
\text { years }\end{array}$ & 24 & 7 & 31 & $21.8 \%$ & $6.4 \%$ & $28.2 \%$ \\
\hline Older than 65 years & 3 & 0 & 3 & $2.7 \%$ & $0.0 \%$ & $2.7 \%$ \\
\hline Total & 75 & 35 & 110 & $68.2 \%$ & $31.8 \%$ & $100.0 \%$ \\
\hline
\end{tabular}

\begin{tabular}{|c|c|c|c|c|c|c|}
\hline $\begin{array}{l}\text { What is your employment status? } \\
\text { Please select only one option. }\end{array}$ & $\begin{array}{c}\text { Survey } \\
\text { Qualified }\end{array}$ & $\begin{array}{l}\text { Not } \\
\text { Survey } \\
\text { Qualified }\end{array}$ & Combined & $\begin{array}{l}\text { Survey } \\
\text { Qualified } \\
(\mathrm{n}=76)\end{array}$ & $\begin{array}{c}\text { Not } \\
\text { Survey } \\
\text { Qualified } \\
(n=35)\end{array}$ & $\begin{array}{c}\text { Combined } \\
(n=111)\end{array}$ \\
\hline $\begin{array}{l}\text { Full time employment } \\
\text { (including self } \\
\text { employment) }\end{array}$ & 63 & 26 & 89 & $56.8 \%$ & $23.4 \%$ & $80.2 \%$ \\
\hline Part time employment & 8 & 2 & 10 & $7.2 \%$ & $1.8 \%$ & $9.0 \%$ \\
\hline $\begin{array}{l}\text { Not employed } \\
\text { (including unemployed, } \\
\text { retired, students etc.) }\end{array}$ & 5 & 7 & 12 & $4.5 \%$ & $6.3 \%$ & $10.8 \%$ \\
\hline Total & 76 & 35 & 111 & $68.5 \%$ & $31.5 \%$ & $100.0 \%$ \\
\hline
\end{tabular}

